\title{
UTILIZING SOCIAL MEDIA TO INFORM INCLUSIVE APPAREL DESIGN FOR BABY BOOMER WOMEN
}

A Dissertation
presented to
the Faculty of the Graduate School
at the University of Missouri-Columbia
In Partial Fulfillment
of the Requirements for the Degree
Doctor of Philosophy
SANDRA STARKEY
Dr. Jean Parsons, Major Professor
December 2016


(C) Copyright by Sandra Starkey 2016 All Rights Reserved 
The undersigned, appointed by the dean of the Graduate School, have examined the dissertation entitled

\section{UTILIZING SOCIAL MEDIA TO INFORM INCLUSIVE}

\section{APPAREL DESIGN FOR BABY BOOMER WOMEN}

presented by Sandra Starkey,

a candidate for the degree of doctor of philosophy,

and hereby certify that, in their opinion, it is worthy of acceptance.

Professor Jean Parsons, Committee Chair

Professor Jana Hawley

Professor Myunghee Sohn

Professor Amanda Hinnant 


\section{ACKNOWLEDGEMENTS}

I would like to express my deep appreciation and gratitude to my advisor, committee members, family and friends for their never-ending assistance and support throughout my doctoral program.

I would like to thank my advisor Dr. Jean Parsons who has provided continual guidance and mentorship and has not only helped me to complete my program but has better prepared me for a career in our field of apparel design scholarship. Her wisdom combined with her engaging sense of humor made the journey less daunting and I enjoyed our time together working on this research.

My committee members, Dr. Hawley, Dr. Sohn and Dr. Hinnant all provided friendly guidance and valuable suggestions that strengthened my research in numerous ways and I am thankful for their willingness to help me with my program. I am particularly grateful for their flexibility and patience during the latter part of the dissertation writing process.

My family and friends have provided the needed encouragement and continual support to help me get through the long hours and constant demands of a doctoral program. I want to thank my parents, Dale and Eleanor Novotny and my sister Sherri Valentine who always had confidence in my ability. Finally, I would like to thank my husband Bob Meier and my daughter Isabella for their continual patience and understanding during the last few years to help me reach my educational goals. 
Table of Contents

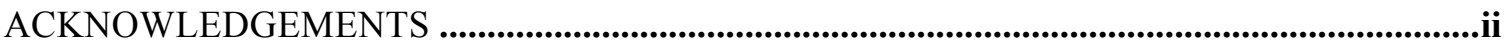

LIST OF FIGURES .................................................................................................................................v

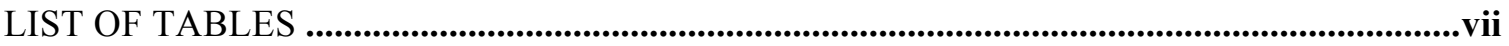

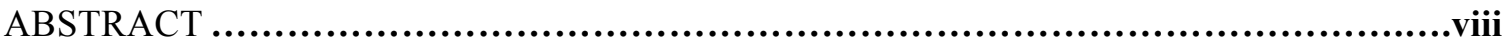

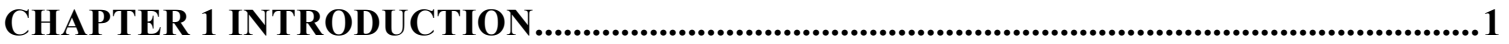

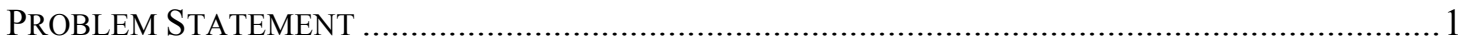

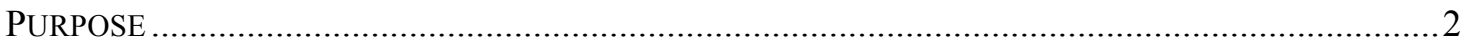

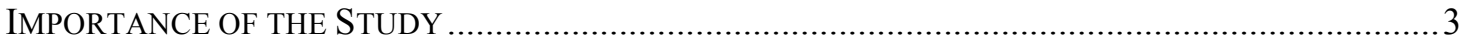

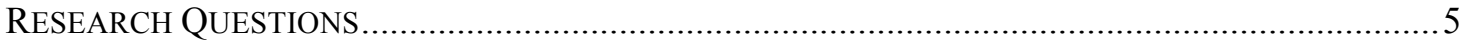

SCOPE OF THE STUDY

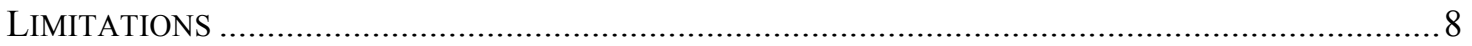

CHAPTER 2 REVIEW OF THE LITERATURE ..................................................................9

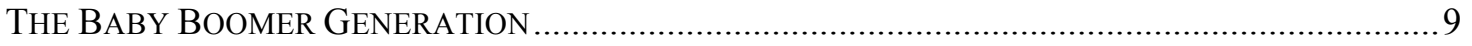

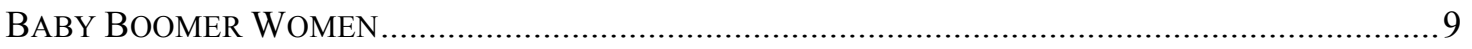

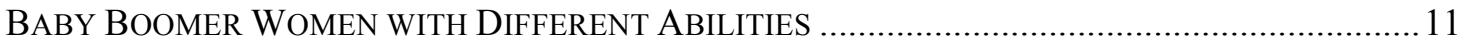

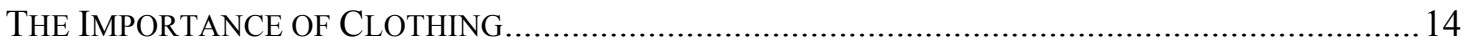

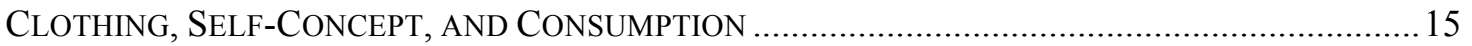

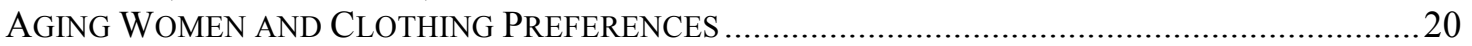

THE LifE COURSE PERSPECTIVE AND CONTINUITY THEORY ON AGING..................................21

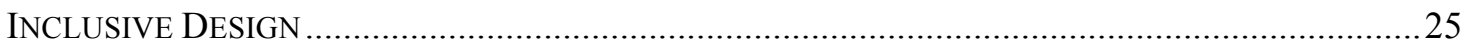

INCLUSIVE DESIGN IN THE FIELD OF TEXTILE AND APPAREL DESIGN .................................... 31

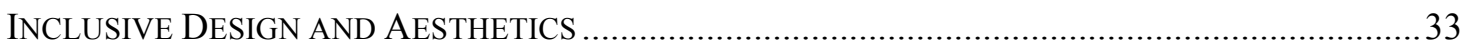

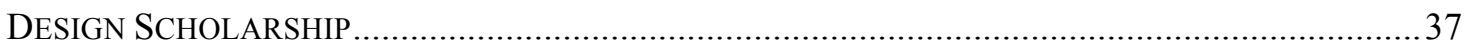

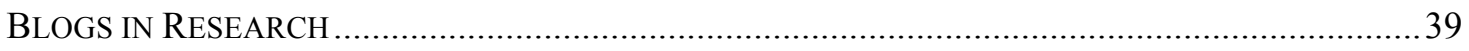

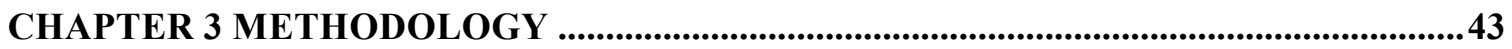

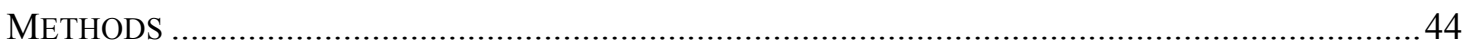

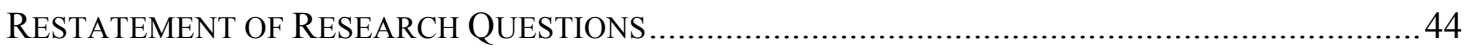

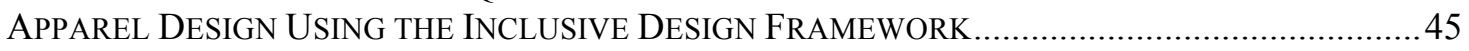

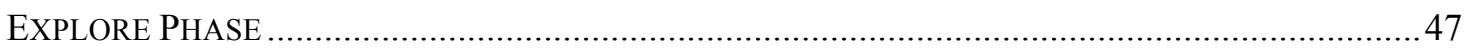

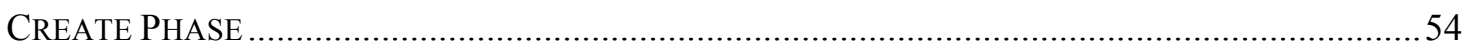

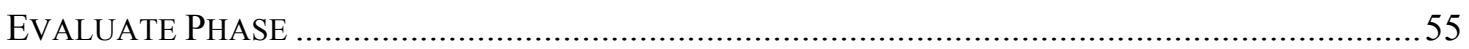

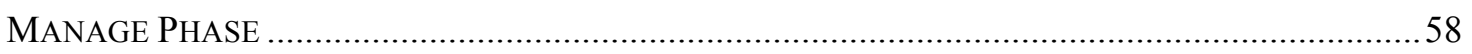

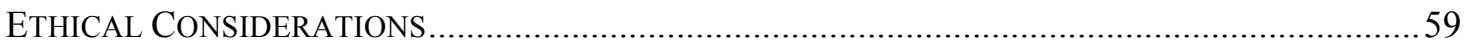

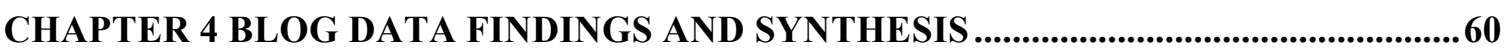

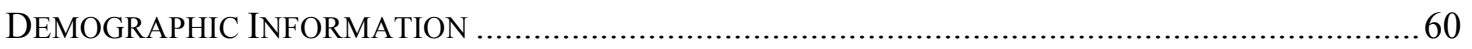

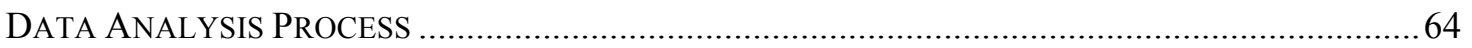

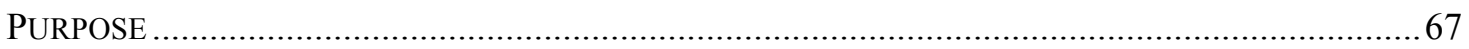

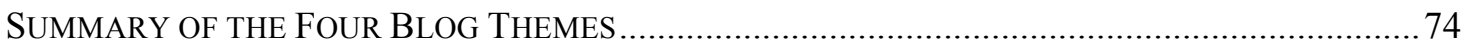

Personal Style............................................................. 74

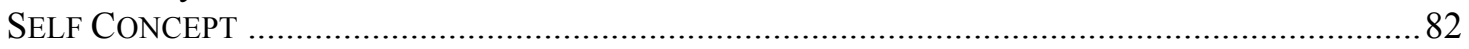

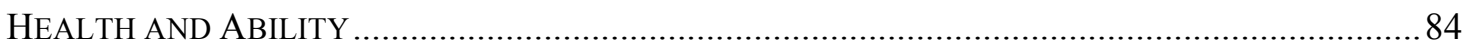

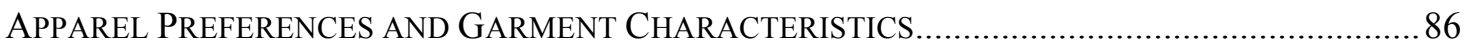

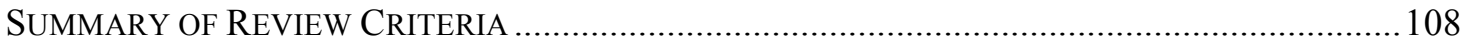

CHAPTER 5 THE APPAREL DESIGN PROCESS .............................................................112

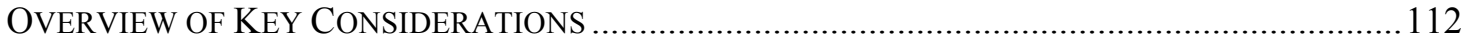

APPAREL DESIGN PROCESS USING THE INCLUSIVE DESIGN FRAMEWORK ............................132 


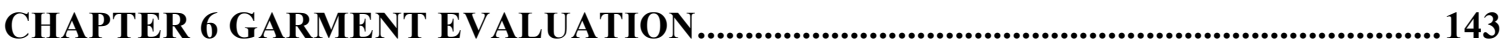

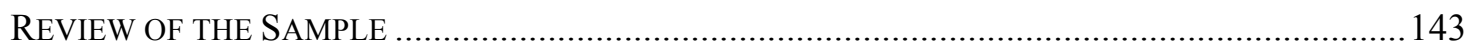

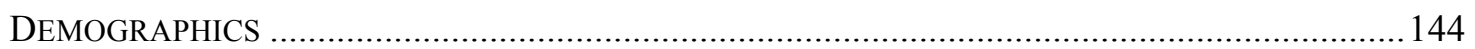

PROCEDURES FOR GARMENT VIEWING BY RESEARCH PARTICIPANTS ................................... 145

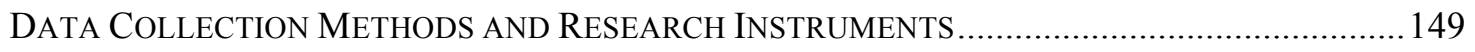

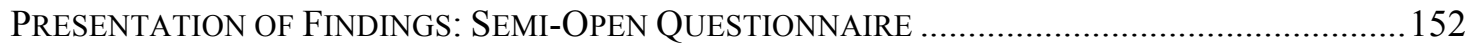

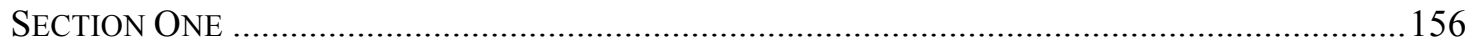

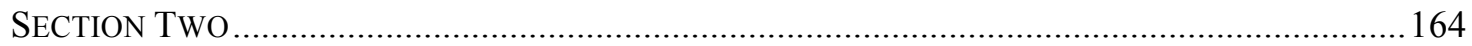

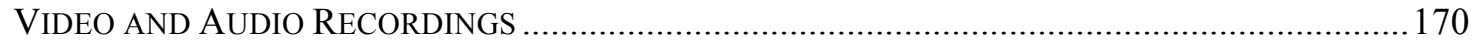

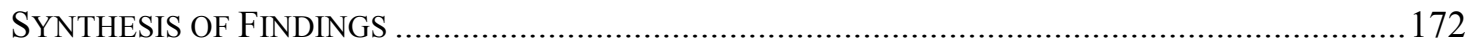

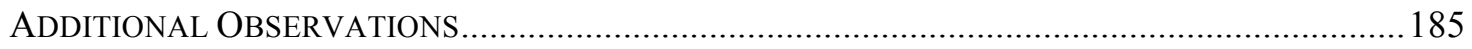

CHAPTER 7 CONCLUSIONS AND RECOMMENDATIONS..........................................186

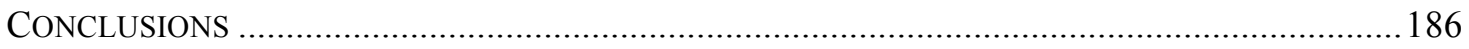

EVALUATION OF THE INCLUSIVE DESIGN FRAMEWORK FOR APPAREL DESIGN ..................... 192

THE USE OF BLOGS IN RESEARCH TO INFORM APPAREL DESIGN FOR BABY BOOMER WOMEN

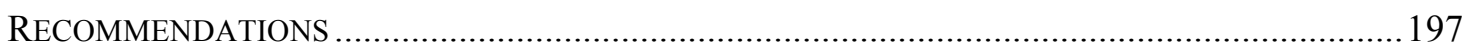

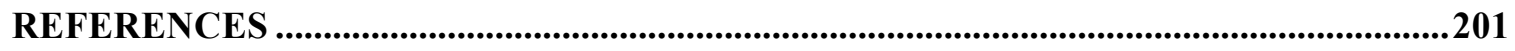

APPENDIX 1: INCLUSIVE DESIGN FOR BABY BOOMER WOMEN POSTER........215

APPENDIX 2: BLOGGER PERSONAE CHART ...................................216

APPENDIX 3: ID EXCLUSION CALCULATOR WITH DATA GENERATED ABOUT

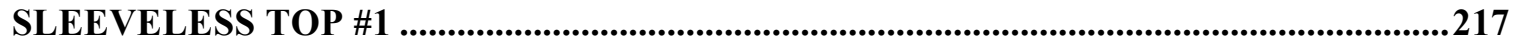

APPENDIX 4: FLYER ADVERTISEMENT FOR STUDY PARTICIPANTS.............213

APPENDIX 5: STATIC IMAGES FROM GARMENT MODELING VIDEO ....................219

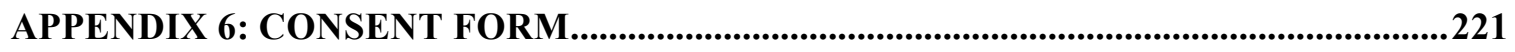

APPENDIX 7: GARMENT DESCRIPTION SHEETS .........................................................223

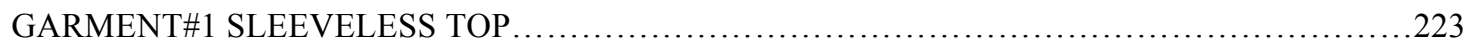

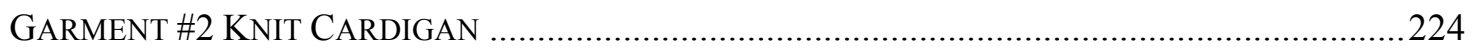

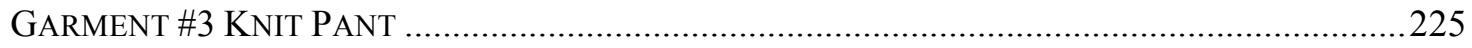

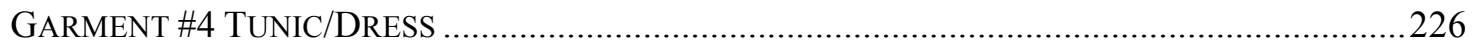

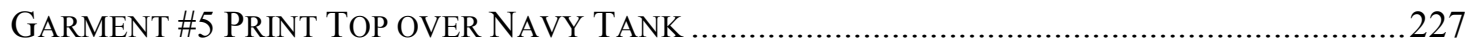

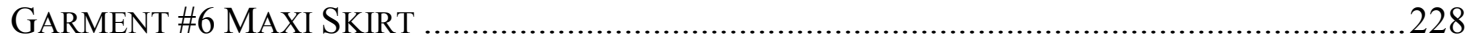

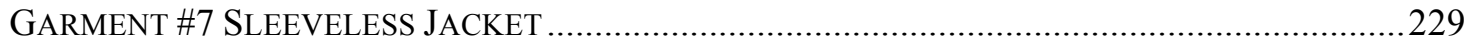

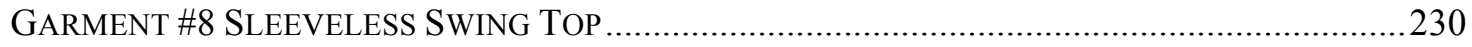

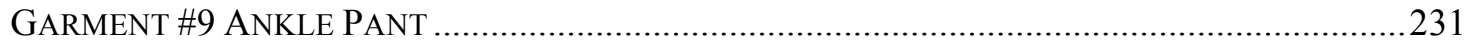

APPENDIX 8: STUDY QUESTIONNAIRE .........................................................................232

VITA.............................................................................237 


\section{LIST OF FIGURES}

Figure 1-1. The woman on the left gazes at a stylishly dressed mannequin appears to have abandoned fashion for comfort....................................................................... 1

Figure 2-1. Diagram of the four Inclusive Design Stages showing how they interrelate... 31

Figure 3-1. Phases and key activities of inclusive design. ............................................ 46

Figure 4-1. Bloggers presenting a dramatic approach to dress.................................... 70

Figure 4-2. Example of blogs that serve a dual purpose ............................................ 73

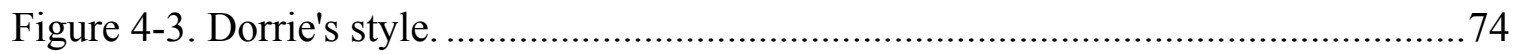

Figure 4-4. Jennifer adds drama to her wardrobe with a long maxi-coat........................78

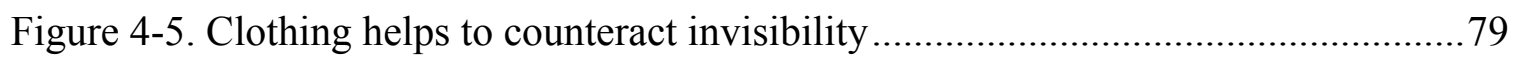

Figure 4-6. Valerie is constantly on the lookout for unique vintage apparel to suit her

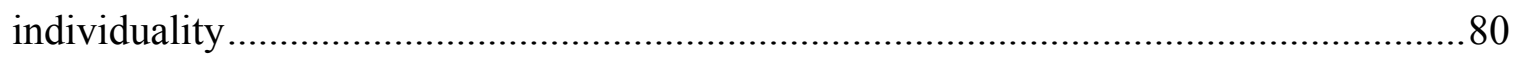

Figure 4-7. Stephanae wearing a knit top layered over a striped dress (left) and a stylish

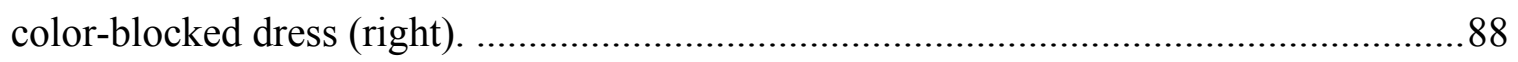

Figure 4-8. Judith poses in front of a vibrant backdrop that matches her ensemble. ........89

Figure 4-9. Susan A modeling a favorite maxi dress. ............................................... 91

Figure 4-10. Une Femme is shown wearing a flowing cardigan over slim jeans. ............94

Figure 4-11. Eugenia in a fitted blouse, skirt, and cape. ..........................................97

Figure 4-12. Layering garments of different lengths with fitted denim. .......................98

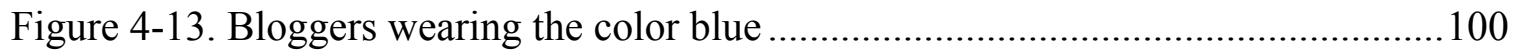

Figure 4-14. (Left to right) Jess layers shades of pink in an outfit inspired by the color palette in her scarf, Une Femme incorporates a printed blouse into her outfit, Judith wears a printed maxi-dress. 
Figure 4-15. Dorrie wears one of her favorite jackets with three-quarter-length sleeves.

Figure 5-1. The four outfits in the mini-collection.

Figure 5-2. The idea log is a place to jot down general design ideas so they are not

forgotten.

Figure 5-3. Three examples of entries in the design process journal

Figure 5-4. The images of the final draped outcome of Maxi Skirt \#6 on the dressmaker form that was stored in a digital file. .118

Figure 5-5. Silk organza print edge finish and tie and cotton print edge finish with jewelry embellishment attached to the magnetic closure.

Figure 5-6. Sleeveless Jacket \#7 features a unique digital print, shown in detail and expanded view. A motif in this print also served as a model for Reversible Print Top \#5.

Figure 5-7. Bloggers were interested in apparel options that offered coverage to the arms.

Figure 5-8. Three examples of garments whose appearance modified by tying.

Figure 5-9. The length in the front of Sleeveless Swing Top \#9 was modified/shortened to be appealing to both wheelchair users and non-wheelchair users.

Figure 5-10. Garments that include features that allow adjustment in fits.

Figure 5-11. Coordinating pieces in the mini-collection creates what one blogger identifies as a capsule wardrobe.

Figure 6-1. Two separate angles of the room setup facing away from the door. 146 


\section{LIST OF TABLES}

Table 2-1. The Top Five Evaluative Criteria for Purchase Decisions ...............................36

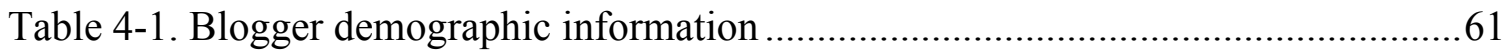

Table 4-2. Summary of the review criteria for inclusive apparel design with definitions.

Table 6-1. Demographic information for study participants in Phase Three. .................145

Table 6-2. Example of the first section of the questionnaire, including prompts. ..........150 


\title{
UTILIZING SOCIAL MEDIA TO INFORM INCLUSIVE APPAREL DESIGNS FOR BABY BOOMER WOMEN
}

\author{
Sandra Starkey \\ Dr. Jean Parsons, Dissertation Supervisor
}

\begin{abstract}
Apparel design solutions for an aging population with unique needs are lacking in the retail industry and specifically for baby boomer women. The fashion industry does not acknowledge that older women value fashion and are interested in maintaining a sense of style into old age. This study focused on expanding inclusive apparel design strategies and specifically to evaluate baby boomer women's clothing preferences through their fashion blogs. Vital to this research was the design and construction of a mini-collection of clothing that served two purposes. First, as a starting point in the development of apparel prototypes designed specifically to satisfy multiple needs without calling attention to special requirements. Second, to provide physical garments that users interacted with and provided feedback about to inform recommendations for inclusive apparel prototypes designed for baby boomer women.

The results from this study found that the study participants were interested in a variety of clothing styles and silhouettes and specifically in fashion trends that could be modified to accommodate an aging body. Design solutions addressed a range of needs without calling attention to disabilities. Simple designs with easy to manage closures and special details to enhance personal style were favored by the study participants. This research contributed to apparel design scholarship, fully documented and evaluated the inclusive design process and added to the body of qualitative research that utilizes social media and specifically blogs as a rich data source.
\end{abstract}




\section{Chapter 1 Introduction}

\section{Problem Statement}

Growing older and dressing stylishly is often a problem, especially for women over the age of fifty who are interested in fashion. According to author and Sixty \& $\mathrm{Me}$ blogger Margaret Manning, society perpetuates the myth that older women's fashion is a choice between appearing youthful by wearing designer clothing, and abandoning fashion altogether to focus on comfort. Although she notes "[c]lothes are, of course, only a small reflection of who we are as older women," the fact remains that "we have every right to be seen (and to want to be seen) after 60" (Manning, 2014). And this opinion is shared by many aging women, not just women in their sixties. Still, a disparity exists between how some older women would like to dress, what they feel is appropriate for their age, and the perceived options available in the U.S. market (Borland \& Akram, 2007; Thomas \& Peters, 2009). Figure 1-1 illustrates what Manning is talking about when she says that society perpetuates the myth that older women's fashion is a choice between two extremes.

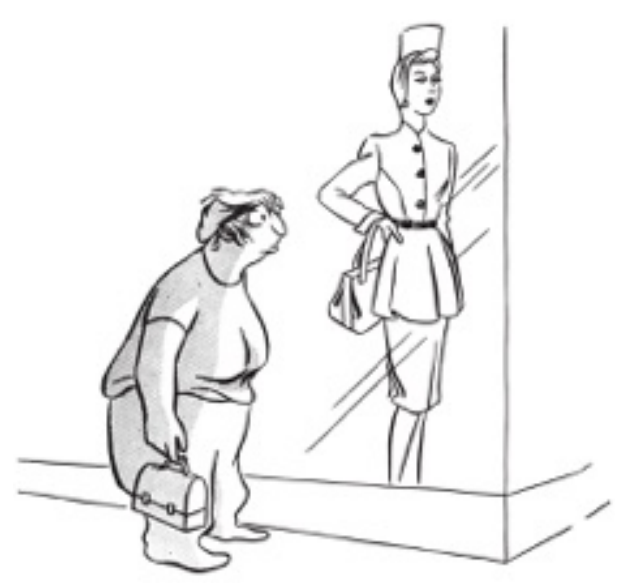

Figure 1-1. The woman on the left gazes at a stylishly dressed mannequin. The woman appears to have abandoned fashion for comfort. Copyright 2016 by Clipart of LLC. Reprinted with permission. 
This is partly because older women, despite representing a growing and viable market category, are often overlooked by designers and manufacturers in the apparel industry (Szmigin \& Carrigan, 2001; Thomas \& Peters, 2009). Unfortunately, it appears that the fashion industry does not wish to acknowledge that older women value fashion and remain interested in maintaining a sense of style into old age (Lewis, Medvedev, \& Seponski, 2009).

\section{Purpose}

The focus of this dissertation was to expand apparel design strategies using an inclusive design framework to accommodate broader markets, particularly aging women and specifically to evaluate baby boomer women's clothing preferences through their fashion blogs. In addition, it was important to design and construct a mini-collection of clothing for the study that served two purposes. First, as a starting point in the development of apparel prototypes designed specifically to satisfy multiple needs without calling attention to special requirements. Second, to provide physical garments that potential users interacted with and provided feedback about that would ultimately inform additional recommendations for apparel designed for boomer women.

Women that fall into the baby boomer category — that is, those born between 1946 and 1964-want to have as many clothing choices as their younger counterparts. The vast size of this population brings to the forefront a host of issues related to aging that are hard to ignore. They comprised nearly a fourth of the U.S. population in 2012 and, as a group, have demanded much attention through the course of their lives (Moody \& Sasser, 2012). Further, the 23 million older women in the United States outnumbered the men by nearly 6 million in 2011 (Administration on Aging, 2011). Because they are the largest segment 
of the boomer population, this study recognized that it is important to understand how women view and experience the unique changes that the aging process brings.

The life course perspective and the continuity theory on aging are two multidisciplinary approaches used to view old age that were tools applied to develop a better understanding of aging women in relation to their clothing choices. The life course perspective approach was used to view old age in the context of a lifetime of significant experiences that interrelate and shape subsequent phases of life. The continuity theory on aging was a tool to help understand how women adjust to the aging process through clothing choices, specifically in order to maintain a consistent self-concept over the course of their life.

As we age, a decline in physical ability is to some extent inevitable; therefore, it was important to include insight from women with a range of physical abilities. The aging U.S. population has resulted in a larger percentage of individuals with disabilities and special apparel needs (Administration on Aging, 2011). In 2010, 56.7 million people in the U.S. were disabled and represented $\$ 200$ billion dollars in discretionary income (Brault, 2012). Women represent a significant portion of the population that falls into an aging and disabled category so their opinions are an important part of the study. This demographic shift necessitates a more holistic approach to apparel design because it is a market that is often neglected by both the apparel products industry and design educators (Howe, 2011). Thus, this research included women with a range of physical capabilities.

\section{Importance of the Study}

The importance of the study is three-fold. First, it was critical to look at boomer women with a range of capabilities because the findings will inform apparel design 
inclusive of a broad range of needs, not solely those related to disability or aging. This inclusive design framework is based on the principles of universal design that promote developing environments and products for people with diverse individual needs and ability levels (NC State University Center For Universal Design). Significantly, an inclusive design framework will inform design in a way that can address those needs without calling attention to individual differences (Wingate, Kaiser \& Freeman, 1986). And while the inclusive design framework has not been widely adopted in textiles and apparel, research indicates that it is a viable option that may satisfy the needs of broader target markets (Carroll \& Kincade, 2007; Howe, 2011; Radvan, 2013). This study will specifically evaluate the benefits of the inclusive design framework for apparel design. Utilizing this framework to include the clothing preferences of an aging and possibly disabled consumer may also help expand apparel design strategies into other untraditional markets with needs that have yet to be met. Ultimately, research that addresses inclusive design strategies will provide tools for future designers to better meet the desires of an increasingly diverse population.

Secondly, aesthetics was included as an important part of the research. Inclusive design frameworks for non-apparel products often fall short because, while the frameworks mention aesthetics, the resulting designs are predominantly functional, with little consideration given to how users respond to the visual design of the product. This has been shown to contribute to a lack of product acceptance (Macdonald, 2004). The same holds true for fashion, as two separate apparel design studies that utilized an inclusive design framework also concluded that attention should be given to aesthetics (Carroll \& Kincaid, 2007; Howe, 2011). 
Finally, the internet—and specifically social media—was a rich source of data. Although it is still in early stages of use, it is increasingly recognized in the social sciences as a valuable research tool to uncover deeper knowledge (Hookway, 2008). Thus, this research utilized social media in qualitative research, particularly as a research tool in the field of textiles and apparel scholarship. Analyzing blogs by boomer women offered another perspective on aging women's clothing preferences and inclusively designed apparel. More generally, blogs are often valuable sources of information for designers because they frequently feature fashion trends and new product innovations (Fiore, 2008). For this project, blogs were exceptionally valuable because they included natural, unprompted texts and personal narratives similar to those contained in diaries but written with a specific audience in mind and viewable by the public (Hookway, 2008; Lee and $\operatorname{Im}, 2008)$.

By exploring the intersection of multiple important, relevant topics, this research adds to the literature related to women's studies, aging studies, disability studies, inclusive design, and the field of textiles and apparel design. Scholars and designers interested in apparel design, consumer behavior, and marketing to these segments of the population should find this information beneficial. This research has the potential to advance qualitative research related to the use of social media and internet use.

\section{Research Questions}

With the interrelated goals of ascertaining the clothing preferences of female baby boomers, informing inclusive apparel design for boomer women with a range of abilities, and determining the usefulness of blogs as a source of data to inform apparel design for boomer women, the following questions guided the research process: 
1. What specific clothing characteristics do baby boomer women identify as important and how can their preferences be incorporated into inclusive apparel designs?

2. How can the inclusive design framework be adapted to apparel design strategies aimed at boomer women with a range of physical abilities?

3. How can blogs as a form of social media be used to inform apparel design for specific segments of the female boomer cohort?

\section{Scope of the Study}

Presenting the feelings and opinions of aging women that are approaching or fall within the baby boomer age range was vital to this research, so the study included women approximately 48 to 70 years of age. The age range was dictated by the ages of the women that were writing the blogs. A preliminary review of blogs" "about" pages and mission statements indicated that women falling into the general baby boomer age bracket wrote fashion blogs for similar reasons, notably as a way to cope with aging. Blogs by women approaching or within the targeted age range were chosen because their authors are representative of the women that the garments were intended for.

Moreover, from within this age group, female bloggers with a range of capabilities were included in the study to inform inclusively designed garments. A key component of the research was the design and actual construction of garments. The design and construction of a mini-collection of clothing is vital to the evaluation and development of inclusive apparel design strategies for the study. The clothing construction process helped to refine the ideas beyond aesthetics so garments were actually wearable. In addition, the clothing provided the physical objects needed to elicit 
feedback about the designs. A limited number of garments were produced, however a range of styles and fabrications were represented in the mini-collection.

The garment development process is important because it aids in hands-on problem solving related to clothing design for boomer women. It was a goal of the study to develop apparel design strategies that satisfy the broadest range of needs possible. However, through development of a line of apparel, this study acknowledges that it is unrealistic to assume a single group of garment designs could satisfy all the needs and wants of all boomer women and at the same time cater to the full spectrum of disabilities.

A goal of the study was to obtain genuine information from blogs that reflected the blogger's personal feelings and opinions, so the study does not include blogs that are motivated solely for financial gain or predominantly as a means of advertising or for marketing purposes. As a general rule, bloggers include a disclosure statement that outlines policies related to product endorsement, sponsored posts, text, and side bar advertisements. These disclaimers enabled the researcher to evaluate (to the extent possible) whether the blogger is self-motivated. It is common for bloggers to recommend products that will benefit their readers, and this was not considered a conflict of interest unless the blogger specifically stated that sponsors determine blog content. Current and active blogs are included in the study and, because this is the way that blogs appear, bloggers' posts will be evaluated in reverse chronological order. Specifically blogs were reviewed starting from the most current post and ended with the oldest post. The study only included blogs that provide a purpose statement — whether in the form of a biography page, "about" pages, or mission statement—which helped to determine the purpose and integrity of the blogs. 


\section{Limitations}

Researcher bias in terms of data collection and analysis is a possible limitation of the study. The researcher determined the search criteria for the blogs, and it is possible that relevant blogs may have unintentionally been left out of the process. Nonetheless, a concerted effort was made to be as thorough as possible, and new blogs were added as they were found. Recommendations listed on individual blog sites provided a significant source for determining additional sites to investigate and, as a component of minimizing researcher bias, reviewing those sites was a regular part of the research process. The researcher also utilized peer review as well as the help of her committee to reduce the risk of leaving out important sources.

Despite the fact that blogs and, more broadly, social media have the potential to provide valuable information for research, due to the limited knowledge about the motivations for older women that present and/or participate in blogs (especially since this segment of the population has historically been slower to embrace new technology), this data source is potentially skewed. Moreover, it is possible that, on average, female bloggers are more vocal or active than other female baby boomers or that bloggers could have misrepresented themselves as female baby boomers.

Another limitation of the study was the number of garments that were produced for the mini-collection. A line of garments is generally developed with a cohesive theme or style that is evident in each of the individual pieces that make up the collection. Due to the wide range of opinions within the baby boomer age range it was not possible to address all of the blogger's needs when designing a limited yet unified number of garments for the mini-collection. 


\section{Chapter 2 Review of the Literature}

\section{The Baby Boomer Generation}

As the boomer generation continues to age, it will become increasingly important to find solutions to assist the largest segment of the U.S. population (76 million strong in 2014) into the next stage of life. As a group, they are living longer than prior generations, and are both better educated and healthier. They have also proven to be sophisticated and more demanding consumers than were previous generations at the same age (O'Rourke, 2015). Baby boomers control approximately half of all discretionary income in the United States and three-fourths of the total net worth and financial assets of the country (Moody \& Sasser, 2012; U. S. Census Bureau Data and Statistics, 2010). Lifestyles of typical boomers are distinctly different from that of their parents, and boomers view aging differently. Younger baby boomers in their fifties and early sixties characteristically don't identify with their chronological age, so it is not surprising that they often do not look or act according to the expectations for their age (Furlong, 2012; Moody \& Sasser, 2012). Because of these changes in attitudes and lifestyles, it is no wonder that their needs for products and services are unique.

\section{Baby Boomer Women}

The aging baby boomer population has changed the dynamic of the economy and represents a substantial segment of consumers. It is, however, unrealistic to view boomers as one homogenous group (Furlong, 2007). The term cohort is used to identify individuals that were born in a particular time period, and within the baby boomer cohort there is a tremendous amount of diversity. The boomer cohort is often divided into two 
groups: the "leading-edge boomers" born between 1946 and 1954 and the "late boomers" born between 1955 and 1964 (Moody \& Sasser, 2012, p. 444). Due to the range of ages within the baby boomer cohort, it is understandable that differences would exist because of their varying relationships to historical events as well as due to their varying social class, ethnicity, and gender (Moody \& Sasser, 2012).

Further differentiation of the baby boomer demographic is also necessary given that the diverse range of their wants and needs as consumers is not informed solely by age (Moody and Sasser, 2012; Szmigin and Carrigan, 2001). Women are an increasingly larger segment of the boomer population and their numbers are projected to steadily increase (Population Projections, 2014). Women in the United States are responsible for eighty percent of all household expenditures and shop more than men in all retail categories except convenience store shopping (Hale, 2011). Boomer women in particular exhibit considerable purchasing power, accounting for a significant amount of all clothing expenditures (Consumer Expenditure Survey, 2013; Lockwood, 2014). Yet, despite the consensus that boomer women are willing to spend more money on clothing than their younger counterparts, they are often overlooked by the apparel industry (Nam et al., 2007) and are frustrated about their clothing choices (LaBat \& DeLong, 1990; Lee et al., 2012; Nam et al., 2007; Salusso, Reich, \& Goldsberry, 2006).

While the female boomer market has captured the attention of several well-known companies, the overall numbers remain quite low. Chico's, J. Jill, Talbots, Lands' End, Eileen Fisher, and Ann Taylor have successfully catered to a female boomer market, and a study by Howarton and Lee (2010) attributes their successes to an emphasis on fit and style (Howarton \& Lee, 2010). In looking at apparel options and buying behaviors of 
boomer women ages 50-69, their study found that female boomers wanted well-fitting, quality garments that were age-appropriate yet fashionable (Howarton \& Lee, 2010). This study is significant because it clearly identifies specific garment qualities that boomer women found appealing, and these qualities will be listed later in the chapter.

\section{Baby Boomer Women with Different Abilities}

Expanding apparel design strategies to accommodate markets such as boomer women makes sense and was the basis for this study; however, it is important to recognize additional characteristics of the demographic that may influence their opinions about clothing. Baby boomers are an aging segment of the population that includes women with a range of abilities, a significant part of which exhibits capabilities somewhere between the categories of "fully abled" and "disabled" (Inclusive design toolkit, 2013).

To successfully design garments for a range of abilities, it is important to recognize that, in addition to overall growth in the disabled population, people aging with impairment is a fairly recent phenomenon in the United States (Putnam, 2002). Due to medical advancements, new rehabilitative technologies, and increased health and consumer education, many individuals that have developed physical impairments at a relatively young age have a longer life expectancy. (Putnam, 2002). This, as well as the growing number of older adults who acquired physical impairment later in life, will change the overall needs of the aging population worldwide (Clarkson, 2007). Designers will increasingly face challenges to provide options that help an aging and impaired population maintain a high quality of life in a society that promotes independent living. 
This study incorporates key principles from the social model of disability because it views disability in the context of society rather than at the individual level. There are two models that provide the basic foundations for distinctly different streams of research in disability studies: the medical model and the social model of disability. The social model of disability was the result of a movement by disability activists and educators to redefine disability in society. The medical model of disability presents disability from a "personal tragedy" framework and associates the disabled individual with the "functional limitations or psychological losses" that arise as a result of an unpleasant chance event experienced by ill-fated members of society (Oliver, 1990). This model has been criticized because the disabled individual is identified with the specific impairment that he or she possesses as well as with the clinical diagnosis and prescribed treatment necessary to achieve supposed normalcy. Defining an individual solely based on impairment was viewed by many people as a form of discrimination (Hunt, 1998), as it contradicted the belief that disabled people are unique individuals with rights to make decisions about their personal welfare.

The foundation for the social model of disability emerged in Paul Hunt's 1966 essay titled "A Critical Condition.” Hunt was a disability activist and a founding member of The Union of the Physically Impaired Against Segregation (UPIAS) in Britain in 1976. Writing from personal experience, he helped inform the UPIAS definition of disability as "people who have physical impairments," a definition that clearly separated the individual from the impairment. In 1983, Mike Oliver, a scholar in the UK with disabilities himself, further developed Hunt's ideas that were eventually solidified into the social model of disability. Oliver and his contemporaries presented disability as a 
"social state and not a medical condition" (Oliver, 1990), and based the model on the idea that illness and disability are not one and the same. The social model of disability acknowledges medical treatment as an important option for all individuals if deemed necessary and/or desirable specifically by the individual with the disability.

The social model of disability clearly separates the individual from the impairment. This includes the right to make personal choices that may not be specifically related to the impairment. In an article advocating personal choices related to disability and independent living, Brisenden strongly argued for the freedom of choice in all areas of life despite impairment: "If society was organized on a more equitable basis, many of the problems associated with not being physically 'perfect' (as if such a concept had any logical basis), would disappear" (Brisenden, 1986). The term equitable is often linked to the social model of disability and is also the number one principle of universal design and fundamental to inclusive design. A more equitable society needs alternative solutions in apparel design for the female boomer population that includes women with a range of abilities. In the past, functional apparel designed specifically for disabled consumers has not worked because it was perceived as stigmatizing (Wingate, Kaiser, \& Freeman, 1983). Disabled consumers prefer stylish, well-fitting apparel that does not call attention to their disabilities (De Klerk \& Ampousah, 2003). Designing apparel for such a broad range of needs, however, presents a tremendous challenge for designers. The inclusive design framework offers one approach to designing for a diverse range of needs, and the social model of disability offers a solid platform from which to implement the inclusive design framework that will be discussed later in the chapter. 
In order to develop successful apparel design strategies to include a range of consumers, it will be necessary to gain a deeper understanding of the types of clothing that boomer women find desirable, in terms of function, fashion, and the ways in which clothing is used for personal expression. The importance of clothing for aging women is established in the next section, and the relationships between clothing and self-concept and the aging female consumer follows. Because few studies consider boomer women exclusively, it was necessary to review studies that covered aging women and larger segments of the population that also included boomer women.

\section{The Importance of Clothing}

The importance of clothing as meaningful objects that go beyond serving as merely functional and protective coverings for the body has been repeatedly established in research (Csikszentmihalyi \& Rochberg-Halton, 1981; Kaiser, 1998). In their study on personal belongings, Csikzentmihalyi and Rochberg-Halton found that people were emotionally tied to objects, that those objects were closely related to self-concept, and that clothing in particular was an object used to express identity (1981). In another study

on favorite objects, Wallendorf and Arnould found that objects fulfilled special functions in terms of "security and self-concept" (1988, p. 532). Objects were viewed from a multicultural perspective and, while they suggested that the definition of self might vary, the importance of objects related to self-concept appeared to be universal. These findings are particularly relevant to this study because one goal was to establish that clothing is an important object for older women.

Consumer research also identifies possessions as playing a self-defining role for the individual in identity management (Belk, 1988a). Goffman contends that a part of the 
self is removed when personal possessions like clothing are taken away, resulting in a loss of control (1961). Further, the extended self as it relates to the care and ownership of possessions aids in the maintenance of healthy personalities (Belk, 1988b). In general, this literature reflects the importance of maintaining control over one's possessions, including apparel. Thus, the lack of suitable apparel options on the market for aging women becomes problematic because clothing is a personal object that fulfills more than functional needs. Clothing is a tool to manage appearance both individually and in social contexts, and it has significant effects on the wearer. Because most studies cluster aging women together as one group that spans a fairly broad age range and does not specifically differentiate boomer women, there is a gap in the research on the importance and meaning of clothing for these women. However, information on women, aging, and older women's fashion was still useful to help gain a stronger understanding of aging women as a whole.

\section{Clothing, Self-Concept, and Consumption}

As the body undergoes changes due to the aging process, it is no surprise that feelings related to self-concept change over time (Moody \& Sasser, 2012). In a study designed to gain a deeper understanding of body image perceptions of both aging women and men, Halliwell and Dittmar found that body image was related to self-concept and self-esteem and was important to both women and men throughout adulthood. However, maintaining a good appearance was a more common concern for female respondents (Halliwell \& Dittmar, 2003, p. 679). A “double standard of aging” emerged as men expressed concern about lessened physical ability related to the aging body, while women focused on the perceived decline of attractiveness (Halliwell \& Dittmar, 2003). 
Generally, the physical effects of aging on men are perceived more favorably than for women. This concept of a double standard of aging is nothing new and has been a topic of research for many years (Saucier, 2004; Sontag, 1972).

As a result of these differences in perceptions, women found the aging process to be more problematic than men and, in turn, this had an increased effect on self-concept (Halliwell \& Dittmar, 2003; Twigg, 2007). In addition, physical changes affected body image and prompted aging women to adopt adaptive strategies to deal with these changes through clothing (Holmlund, Hagman, \& Polsa, 2011; Jackson \& O'Neal, 1994; Lee, 2011; Lee \& Sontag, 2010). Lee's research identified clothing as a tool to aid in successful aging and specifically as a way to camouflage physical changes in the body to enhance overall self-esteem (Lee, 2011). Moreover, Lee and Sontag's research affirms clothing's importance as an expression of self and links a psychological closeness with clothing with perceived quality of life (Lee \& Sontag, 2010). It is unsurprising, then, that the lack of clothing options due to fit was a recurring theme in literature on aging and was found to negatively affect how older women felt about themselves. Proper fit is fundamental to self-concept and to an individual's psychological and social well-being (Lee \& Sontag, 2010; Twigg, 2007). Lee and Sontag (2010) stated:

Clothing is a resource that older persons can use to help satisfy needs for physical safety, belonging, social acceptance, self-regard and self-actualization. The more psychologically close clothing is to the self, the more one may expect the older person to rely on the usefulness of the resource for need satisfaction. (p. 446) 
Though Lee and Sontag's study also focused on older men along with women, it remains important here because it represents the importance of clothing as an aid in aging well regardless of gender.

Additional research suggests that older women in particular manipulated appearance as a way to deal with their self-perceptions of aging. Jackson and O'Neal's analysis of twenty-nine studies found that women consciously managed appearance through clothing perceived to lessen the appearance of aging by choosing flattering, comfortable styles and/or by altering garments to enhance appearance and improve fit (1994). A relationship between aging perceptions and appearance-related behavior was also evident. From their analysis, three distinct types of older female consumers emerged. Type one was specifically concerned with the number of clothing options available on the market to compensate for a change in perceived body type. Type two preferred altering clothing as a strategy to adapt available clothing to a changing body type. Type three expressed an interest in comfortable clothing that included special features that could accommodate decline in ability (Jackson \& O'Neal, 1994). Covering a forty-year period, this research was significant because it demonstrated aging women to be a complex demographic with a diverse range of needs.

Thomas and Peters examined the self-concept, lifestyles, and apparel consumption of older women and found that older women strive to attain individuality regardless of their age (2009). In general, Thomas and Peters suggest that older women define themselves by "their individual self (unique attributes), the relational self (interpersonal bonds of attachment), and the collective self (symbolic generational membership)." Further, over three-fourths of the participants in their study, which 
included one terminally ill woman, maintained the importance of "always trying to look their best" (Thomas \& Peters, 2009). Older women generally felt better about themselves if they were happy with their clothing choices, but admitted they were not always satisfied with the choices available to them on the market (Thomas \& Peter, 2009). Additional findings from their interviews suggest that fashion affects self-concept, and that fashion isn't limited to apparel but also includes accessories, hair, and make-up. Taken together, these findings suggest that senior women use apparel to symbolize, communicate, and reinforce their different definitions of the self.

Research also shows that fashion carries social importance for both non-disabled and disabled women and that dress has the power to affect the self-esteem of the wearer regardless of ability (Kaiser 1997; Lamb, 2001). As part of a larger study examining disabled adult consumers, Chang et al.'s research about self-concept and clothing selection identified self-esteem as a major force motivating clothing choices (2013). Disabled consumers in particular use apparel as a vehicle to enhance self-concept, especially if they are uncomfortable about their appearance. This supports the idea that it is beneficial to include women with a range of physical abilities in research to gain a deeper understanding of women and aging as a whole. Moreoever, using apparel as a means for personal expression can be an effective way to break down barriers between individuals with and without disabilities (Kaiser, 1997). As Kaiser (1997) stated:

Through the manipulation of clothing and accessories, persons with disabilities may emphasize other aspects of the self, even if total concealment of the disability is not possible. Appearance management is regarded by some persons with physical disabilities as a potential means for improving on the social impact of a 
physical disability, but it is realistically expected to serve a secondary role in appearance perception on the part of others. (p. 191)

In other words, clothing can be used as a tool to help disabled individuals feel more comfortable in social contexts, even if it proves to be more important to the wearer than the observer. This is important because social interaction plays an important role in helping individuals define both their own identity and the identity of others. It is therefore unsurprising that individual appearance management cannot exist independently of social contexts (Kaiser, 1997). Thus, for older women, clothing and fashion are part of a holistic approach to define oneself that includes self-concept as well as personal and impersonal social relationships.

Two studies about The Red Hat Society provide a glimpse of the importance of dress in the context of social membership (Stalp et al., 2009; Yarnal \& Liechty, 2010). The Red Hat Society is a unique organization for women ages fifty and up. It encourages dressing in red and purple as a reminder to enjoy life and to "grow older in a playful manner" (The Red Hat Revolution, 2015), the personal pleasure of which results in a new sense of self and an increased sense of camaraderie among members. Moreover, their dress code promotes a sense of identity, particularly for women in later life who question their visibility. Membership in the society is unique for these women because the activities and their satisfaction are not tied to family, community, or paid work obligations (Stalp et al., 2009). Yarnal and Liechty found that women in the Red Hat Society used dress to shape the self and that group participation liberated members. The increased public interaction that followed also provided positive exposure and often resulted in favorable public reevaluation of the aging female body (2010). The Red Hat Society provides a prime example of the importance of the older female consumer 
(Yarnal \& Liechty, 2010). Members devise unique and playful ensembles that embody how they wish to project themselves within the context of the organization.

\section{Aging Women and Clothing Preferences}

The consumption patterns of female consumers 50 years of age and older have been the subject of multiple studies (Homlund, Hagman, \& Polsa, 2011; Howarton \& Lee, 2010; Lee et al.., 2012; Thomas \& Peters, 2009). Several studies discovered that women ages 50-63 valued fit, fashion, aesthetics, and the opportunity to express individual style when making clothing choices (Holmlund, Hagman, \& Polsa, 2011; Lee et al., 2012). In their study of women over the age of 65, Thomas and Peters found that participants had a strong sense of style, viewed fashion as a part of their lifestyle, and admitted peer influence in their purchasing behavior (2009). Studies also found older women's shopping trips to be less frequent than when they were younger, but the time spent shopping proved to be more efficient and productive. Moreover, studies suggest that older female consumers understand their personal needs and preferences better than when they were younger, so when suitable choices are found, expenditures are higher (Lee et al., 2012).

In a qualitative market analysis of 229 boomer women, Howarton and Lee identified the following clothing preferences and behaviors. Boomer women reported using color and layering techniques to alter the appearance of their bodies and used black in particular to minimize certain areas, such as the mid-section of the torso. Study participants liked full and short sleeves and rounded necklines. Slightly over half indicated a preference for solid colors but were interested in prints or patterned tops and colorful accessories to accent solid-colored ensembles. Depending on the setting, slacks 
with blouses and jeans with t-shirts were at the top of the list for clothing choices. Skirts with blouses, and dresses were low on the list of favorites. Comfort, fit, and flattering styles were listed as priorities, while only half of boomer women listed versatility as a requirement. Ease of care and natural fiber contents were identified as desirable (2010). An overwhelming majority of the women in their study also expressed difficulty finding age-appropriate styles and believed that the apparel industry overlooked their specific apparel needs (Howarton \& Lee, 2010). The term age-appropriate is difficult to define because, in addition to other factors like cultural context and geographic location, it is highly subjective and based on individual preferences. Nonetheless, Howarton and Lee suggest that designers could benefit from the survey findings to create "boomer apparel that is better fitting and more stylish" (2010, p. 227).

\section{The Life Course Perspective and Continuity Theory on Aging}

The life course perspective, which will be presented along with the continuity theory on aging, helps to better understand the importance of clothing for women throughout life. Described by Moody and Sasser (2012) as a concept that "refers to the meaningful pattern seen in the passing of time," the life course perspective is a multidisciplinary approach used to view old age in the context of a lifetime of significant experiences or stages that interrelate and shape subsequent phases of life. It is useful because it acknowledges old age as interrelated with and equally important to other phases in life both at an individual level and as experienced by a particular group of individuals that falls into a specific age range. Unsurprisingly, it suggests, for example, that women who value clothing at a younger age also appreciate apparel in other stages of life. Age and gender also play important roles within this perspective because it 
recognizes that men and women experience and interpret life differently, especially in what constitutes appropriate behavior at different ages (Settersten \& Mayer, 1997).

The following two inclusive design studies provide solid examples of the benefits of using a life course perspective. The Royal College of Arts (RCA) in London utilized an inclusive design framework from a life course perspective in the design of a variety of non-apparel products for an aging and disabled population. Because RCA recognized that many segments of the population are not included in mainstream design-which results in a disconnect between people and their environments - an ongoing goal in their research was to better understand and eliminate design exclusion in product development. Aging is a natural part of the future and integral to the life course (Coleman \& Myerson, 2001), so young designers were challenged to approach design problems for products and services from a life course perspective and develop solutions that could accommodate the aging process. The project theme, titled "design for our future selves," was successful for two reasons. First, young designers developed solutions to meet the needs of people other than themselves; in other words, the project was "other" motivated. Secondly, students worked closely with actual product users who provided firsthand information about their specific needs over a period of time. Accordingly, design solutions were significantly more successful at meeting the user needs (Coleman \& Myerson, 2001).

A second study about older women and the importance of clothing provided valuable information about the role of style, experience, and the importance of clothing over time (Dankl, 2013). For this, Dankl created style biographies from information she received from home visits and in-depth conversations with participants. Clothing retained over the course of participants' lives both provided information about the participants 
and, in a broader sense, represented the symbolic and social meaning of material culture in the form of dress. The retention of certain pieces of clothing that are kept over the life course offers insight into what is most important to individuals and how those priorities change with age.

Understanding clothing preferences in the past and the modifications one makes over time could inform better design solutions for the future. This directly relates to the main tenets of the life course perspective and the continuity theory on aging. The continuity theory on aging works well within the life course perspective because it suggests that adaptive responses to aging are approached by using familiar solutions (Atchley, 1989). Atchley (1989) stated:

To the extent that change builds upon, and has links to, the person's past, change is a part of continuity. As a result of both their own perceptions and pressures from the social environment, individuals who are adapting to normal aging are both predisposed and motivated toward inner psychological continuity as well as outward continuity of social behavior and circumstances. (p.183)

In other words, the continuity theory on aging posits that older individuals strive for continuity in their lives based on what has been important in the past. However, they must make modifications to their lives to accommodate limitations brought on by the aging process. Their adaptive decisions may be influenced by physical or mental limitations, and the extent of the modifications is influenced by the degree to which those limitations are experienced.

Moreover, continuity theory can be used as a tool for understanding how women adjust to the aging process through clothing choices and, more specifically, how they 
maintain a consistent self-concept over the course of their lives. Otieno and Shweta's study supports the continuity theory on aging and found that women's ideals related to self-concept and clothing appeared to be similar regardless of age. The research evaluated the clothing preferences of two groups of women ages eighteen to thirty and thirty-one to fifty-five. They found that both cohorts directly related their clothing preferences to body image and took actions to present the best outward appearances possible. Both groups were inclined to use noninvasive means like exercise and clothing to present a positive body image related to self-concept (Otieno \& Shweta, 2007). In addition, both groups of women used clothing as an adaptive strategy, but the older group modified the way they used clothing for self-concept based on their perceptions about appropriateness for their particular life stage. Otiena and Shweta's study suggests that while women's feelings about self-concept may have changed throughout the course of their lives, their use of clothing as a tool to help maintain a positive self-concept remained constant.

The continuity theory on aging provides a way to view how boomer women may adapt to the aging process using clothing. Freund and Baltes refer to successful aging (aging well) as "satisfaction with one's own aging, positive emotions and the absence of loneliness" (1998, p. 531), which means that aging well is highly subjective and personally defined. Moody and Sasser expand on these concepts and state that aging well is contingent on developing individual strengths to help make up for the inevitable declines in other areas (2012). Older women often use apparel as a tool to increase satisfaction with aging and enhance positive emotions related to self-concept. In a social sense, The Red Hat Society again serves as an example of organized social interaction based on appearance and dress that promotes the well-being of older women. Social 
involvement has been found to counteract feelings of loneliness for members and in turn promotes aging well.

In summary, part of being human involves the continuous process of change and adaptation, and this directly affects design practice. Clothing preferences may need to be modified to suit the current wants and needs of boomer women, consistent with the continuity theory on aging and the life course perspective. The past, present, and future are all interrelated, and viewing design from a life course perspective aids designers in anticipating future needs. This could specifically help solve apparel design problems related to aging and impairment from the standpoints of both function and aesthetics. The awareness of common physical changes that are likely to occur over time as a result of aging could inform apparel design solutions that are built into garments to accommodate future needs. For example, if decreased dexterity is recognized as a common result of aging, then one solution is garments designed with larger, easier-to-grasp zipper pulls for ease in donning and doffing. Further, identifying the aesthetic qualities boomer women have valued in both the past and present could both enhance the desirability of and increase the acceptance of new designs.

\section{Inclusive Design}

The inclusive design framework provides a guide for designers when developing products for a range of consumer needs and offers the potential to do so without calling attention to individual differences. An explanation of the inclusive design (ID) framework is important for this research because it guided the apparel design process to create garment prototypes for boomer women with a range of needs. Boomer women can benefit from this approach because this segment of the population does not want to be 
singled out or, more specifically, labeled as aging. A section on aesthetics will be included because they are an important component in successful product design but are often missing in ID.

Inclusive design is one of three approaches - the other two being universal design and design for all — that promote developing environments and products to satisfy a diverse range of needs and abilities. The philosophies behind all three are similar, the fundamental differences being related to the size and scope of the intended markets. Universal design and design for all target the population as a whole; in contrast, the ID framework guides the development of products for a specific set of users within the population and stresses usability for as many people as possible within the identified group. All three design frameworks are positive approaches to design that emerged based on the need to design for a wider range of users. Universal design provided the foundation by developing a set of guidelines, and the ID framework is based on the general principles set forth by universal design.

Towards the end of the twentieth century, the need for research focused on developing products, services, programs, systems and environments for an increasingly older and disabled U.S. population became increasingly evident. As Follette et al. explain, "The limitations imposed by products and environments designed and built without regard to the needs and rights of all American citizens are significant but often unrecognized" (1998). In response, the United States Department of Education's National Institute on Disability and Rehabilitation Research funded a body of research in 1998, the outcome of which was universal design. The research resulted in a set of guidelines to inform a design process focused on accommodating diverse needs regardless of age, 
ability, sex, and economic status.

Universal design is based on seven principles developed to inform new design, to aid in evaluating existing design, and to assist in educating both designers and consumers. Designs based on the seven principles should be "useful and marketable to people with diverse abilities" (Follette et al., 1998; Etchell \& Yelding, 2004). Thus, within the universal design framework, special consideration is given to cognition, vision, hearing, speech, body function, and mobility. Developed by Ron Mace in collaboration with a group of architects, product and environmental designers, and engineers, the seven principles of universal design are as follows:

1. Equitable Use: The design is useful and marketable to people with diverse abilities.

2. Flexibility in Use: The design accommodates a wide range of preferences and abilities.

3. Simple and Intuitive Use: Use of the design is easy to understand, regardless of the user's experience, knowledge, language skills, or current concentration level.

4. Perceptible Information: The design communicates necessary information effectively to the user, regardless of ambient conditions or the user's sensory abilities.

5. Tolerance for Error: The design minimizes hazards and adverse consequences of accidental or unintended actions.

6. Low Physical Effort: The design can be used efficiently and comfortably and with minimum of fatigue. 
7. Size and Space for Approach and Use: Appropriate size and space is provided for approach, reach, manipulation, and use regardless of user's body size, posture or mobility. (The Principles of Universal Design, Version 2.0, 1997)

The successful implementation of these principles requires understanding the wide range of human aptitude (Follette et al., 1998). While universal design methods may be all encompassing (they have even been described as a "one size fits all" approach [Etchell \& Yelding, 2004]), the responsibility to actually satisfy all consumers' needs falls on the shoulders of the product developers and environmental designers to be successful. It has been questioned whether any design can truly be universal depending on a particular place and time (Salemen, 2012). Presently, few apparel design studies have incorporated the principles of universal design to guide clothing solutions that were both inclusive to a range of needs while accommodating the personal style of the wearer. One notable exception is Park et al.'s research that utilized universal design to aid in the apparel design process. Their study considered aesthetics as part of the universal design process and created a garment that accommodated body changes related to pregnancy in addition to maintaining aesthetic appeal (2014). In addition, a second garment was designed as part of the study to accommodate a variety of changing body types that may be a result of the aging process (Park et al., 2014).

The inclusive design framework is also based on those seven principles but modifies the universal design approach by acknowledging that while one design may not work for all people, one design may satisfy multiple needs (Carroll \& Kincade, 2007; Inclusive Design Toolkit, 2013). An inclusive approach to design lessens the possibility 
that an older or disabled person may feel stigmatized by products that specifically cater to age-related decline or impairment. Individuals often reject purely functional products that call attention to impairments because the perceived negative outward appearances outweigh the benefit of functional attributes. Some examples are ramps, canes, walkers, shower bars, and orthopedic shoes (Bichard, Coleman, \& Langdon, 2007; Candy \& Williams, 2011). An aging baby boomer population will undoubtedly be in a position to demand products that enhance functionality but do not appear different than similar products or call attention to the impairments of the user. Hidden benefits may be a way to avoid the "aesthetic stigma" as an important way to add value through inclusive design (Bichard, Coleman, \& Langdon, 2001).

The Inclusive Design Toolkit, based on twelve years of research at the Engineering Design Centre (EDC) at the University of Cambridge, was used as a guide to inform the development of inclusively designed garments for this dissertation (Inclusive design toolkit, 2013). Presented on a website designed and updated by the $\mathrm{EDC}_{2}$ the toolkit provides a detailed definition and explanation of inclusive design and offers information and tools to directly assist inclusively designed projects. The ID toolkit presents the following definition for inclusive design as adapted from The British Standards Institute: it is "the design of mainstream products and/or services that are accessible to, and usable by, as many people as reasonably possible ... without the need for special adaptation or specialized design" (2013). The ID framework incorporates a user-centered approach that aims to guide design for a wide range of abilities and does not focus on loss of capability. Research suggests that including the user in the product design process may increase user satisfaction and aid in the overall success of the design 
process. While this may not satisfy all users, it may satisfy a broader range of users (Martins \& Martins, 2012). Several studies identify disabled individuals as extreme users or users that have needs that require the most assistance (Coleman \& Myerson, 2001; Dankl, 2013). Including the extreme user into the design process may broaden the range of user acceptance.

The Inclusive Design Toolkit identifies four measures as necessary for inclusively designed products to be successful: the product must be functional, usable, desirable and viable (Inclusive Design Toolkit, 2013). Functionality is determined by how suitable the product features are in satisfying the user's needs, though it is necessary to note that additional product features do not necessarily translate into a more functional product. Usability addresses the level of ease with which a product can be managed; products that are not usable can cause frustration and affect the user's ability to act independently. Desirability refers to favorable product characteristics, which may include visual or tactile appeal, social status signifiers, and product impact on the quality of life. Lastly, from a business sense, the viability of inclusively designed products is measured by "profitability" as well as "feasibility," that is, the ability to offer timely production at an affordable price. For the present research, profitability and feasibility were not addressed because the garments were not developed beyond the prototype stage.

The following diagram illustrates the steps involved in creating an ID product. Project management guides the cycles, here identified as exploration, creation, and evaluation. They aid the designer in answering the following four key questions: What are the needs? How can the needs be met? How well are the needs met? What should we do next (Inclusive Design Toolkit, 2013). 


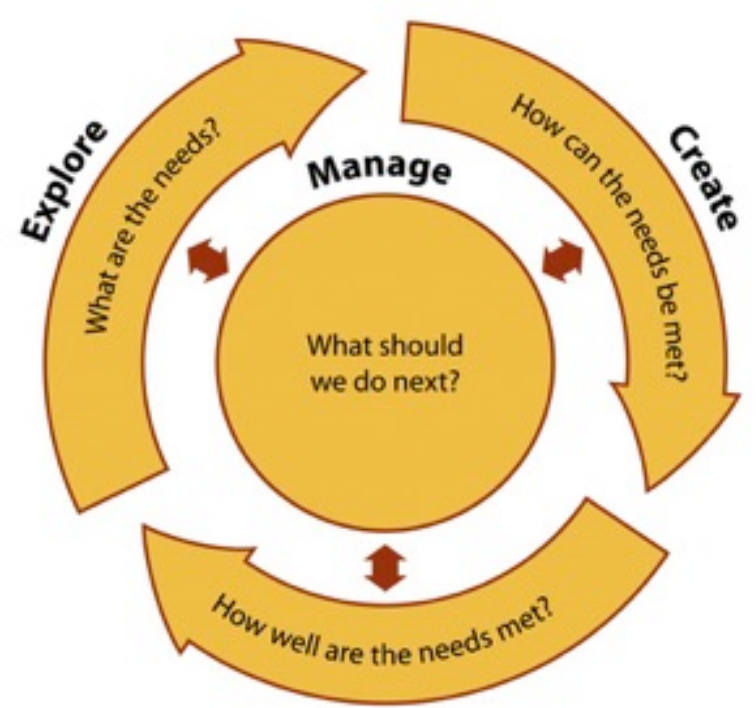

Evaluate

Figure 2-1. Diagram of the four Inclusive Design Stages showing how they interrelate. Copyright 2015 by EDC. Reprinted with permission.

Three of the four stages above — the explore, create, and evaluate stages —include activities to help refine the design process. The remaining stage, the manage stage, takes place throughout the entire project and emphasizes reviewing and planning the next action in product development. All of this information from the EDC Inclusive Design Toolkit website (of which this is only a brief overview) directly informed the apparel designed for this project. This information will be provided in detail in the following methods section.

\section{Inclusive Design in the Field of Textile and Apparel Design}

The ID framework has already been used to guide research and design related to ergonomics, fashion, and unique populations (Carroll \& Kincade, 2007; Martins \& Martins, 2012). ID is a realistic approach to apparel design because it seems unlikely that, for example, one garment could be designed to satisfy all users' needs. However, designing apparel and products for multiple users is potentially cost effective and may be 
a valuable way to broaden target market size (Vanderheiden \& Vanderheiden, 1992). Thus, perhaps one garment could satisfy a range of women within the female boomer cohort or, alternatively, a garment designed for boomer women could appeal to women in other demographics. This is reasonable because features designed to accommodate special needs may also benefit nondisabled individuals in terms of clothing comfort or mobility (Kaiser, 1997).

Inclusive Design provides a guide for designers to use when developing apparel and accessories for a range of consumer needs, including needs related to disability (Carroll \& Kincade, 2007; Howe, 2011; Radvan, 2013). The goal is to provide options that will accommodate unique needs without isolating problems related to physical impairment. ID offers the potential to address needs without calling attention to individual differences, and this is important because it was found to be a concern for those with disabilities (Wingate, Kaiser, \& Freeman, 1983-1986).

A meta-study investigating the actual use of ID theory in ID practice found a difference between the actual number of inclusive design steps recorded in the studies and the number recommended by the EDC model (Herriott, 2013). The specific products were not identified in the reports and the study acknowledged that not all designed products would be commercially produced. In the sixty-six published studies using inclusive design frameworks that were reviewed, on average only forty-three percent of the ID steps were completed. This suggested that, in general, designers were either not completing all of the steps or not clearly documenting their ID process (Herriott, 2013). This study is significant because it documents inconsistent application and/or documentation of design processes related to ID theory in product development. This was 
also true for two other apparel design studies that used an ID framework (Carroll \& Kincade, 2007; Radvan, 2013), though it is not apparent whether these studies employed a systematic approach to ID because the specific steps were not included. It will be beneficial to apply and document the apparel design process based on an established framework (like the EDC version) to evaluate the framework's effectiveness in solving apparel design problems for boomer women.

\section{Inclusive Design and Aesthetics}

An inclusive approach to design has many advantages related to satisfying a wide range of user needs, but a focus on functionality often overrides the incorporation of aesthetic qualities. While it is often hard to differentiate what separates successful products from those that fall short of consumer expectations, a recurring theme in literature about products designed for untraditional markets (such as aging and disabled populations) highlights the need for designers to build in features that make them more aesthetically appealing (Bichard, Coleman, \& Langdon, 2007; Howe 2011). The desire for better aesthetics has been documented in a number of studies and specifically includes assistive and adaptive products (Newell, 2003), clothing (Carroll \& Kincade, 2007; Radvan, 2013), and shoes (Candy \& Williams, 2011), to name a few. Unfortunately, users would rather go without certain products than use products that do not fulfill their aesthetic needs, even if other sacrifices come as a result (Newell, 2003).

To expand on the earlier discussion about the importance of objects, it makes sense to explore the relationship between aesthetics and objects. As part of a comprehensive multi-disciplinary evaluation of aesthetics in general, the "aesthetic object" emerged as one of five key categories of aesthetics (Fiore, Kimle, \& Moreno, 
1996b). The aesthetic object was further divided into three defining qualities: the "formal qualities, expressive qualities, and referential meaning of the object" (Fiore, Kimle, \& Moreno, 1996b). An object's formal qualities are the compositional elements of design such as color and proportion. Expressive qualities can be explained as the capacity an object has to convey emotions and feelings, and referential aspects are summarized as the "symbolic nature" of an object (Fiore, Kimle, \& Moreno, 1996b).

Defining aesthetics presents a challenge because "aesthetic refers to both a quality of an object and a state of being" (Fiore, Kimle, \& Moreno, 1996a). Aesthetics is defined here as something that is perceived through the senses (Woolf, 1979). Knowledge about oneself and others is gained through the senses and meaning is found through sensory responses that include but are not limited to pleasure (Csikszentmihalyi \& RochbergHalton, 1981; Postrel, 2007). The importance of the emotional experience related to interacting with an object can be quite powerful and is easily understood when we consider the range of possible responses when interacting with artwork (Goldman, 1990). Through the senses, the aesthetic experience can facilitate meaning specifically through contact with the fundamental qualities of the object, and this experience extends beyond art and applies to all objects (Csikszentmihalyi \& Rochberg-Halton, 1981).

The aesthetic and sensory qualities of products adds to their overall desirability beyond functionality, and they can be a way to express individuality through personalization of style choices (Postrel, 2007). They represent an important component of what Hekkert calls the product experience:

the entire set of effects that is elicited by the interaction between a user and a product, including the degree to which all our senses are gratified (aesthetic 
experience), the meaning we attach to the product (experience of meaning), and the feelings and emotions that are elicited (emotional experience). (2006, p. 160) The product experience described here also overlaps with the aesthetic experience outlined by Fiore, Kimle, and Moreno earlier (1996b). When considered in tandem, they help to organize and explain the aesthetic product experience - the degree to which the senses are gratified by the formal qualities of the object, the expressive or emotional responses elicited by the object, and the referential aspects or symbolic nature of the object. While aesthetics in design are often misunderstood as having solely to do with beauty, aesthetics as a complex component of design stimulates the senses as well as provides greater meaning through possession and interaction with objects.

Aesthetic qualities and specifically the formal qualities as described above (composition, color, and proportion, for example) can set a product apart and add to product acceptance in the marketplace, so it is no wonder that aesthetic attributes were found to be the most important in a study evaluating the criteria female consumers used when selecting apparel (Eckman, Damhorst, \& Kadolph, 1990). Eighty-eight women ages 18-60 were interviewed using free-response methods that encouraged purchase criteria to naturally emerge during the study (1990). Aesthetic criteria were found to be the most important to the respondents, with visual characteristics rated the highest. The most important criteria were style, color \& pattern, fabric, appearance, and fit. The following table identifies and defines the top five criteria for purchase decisions (Eckman, Damhorst, \& Kadolph, 1990, p. 17). 
Category

\section{Aesthetic criteria}

Color/Pattern

Styling

Appearance

Fabric

\section{Performance and quality}

Fit

Judgments of how the garments conformed to the shape of the body. Aside from overall evaluations of fit, specific concerns about waist, bust, and armhole were mentioned.

Table 2-1. The Top Five Evaluative Criteria for Purchase Decisions

The same aesthetic criteria consistently emerged when participants were asked both general and specific questions about purchase criteria, and this pertained to both purchased and non-purchased items. In addition to the aesthetic criteria, fit was also found to consistently affect purchase decisions related to performance and quality. This data ultimately helped to develop a model about the apparel purchase decision process, though the criteria has tremendous merit on its own and is valuable for studies such as 
this one that are aimed at identifying product characteristics that women find desirable.

\section{Design Scholarship}

An essential portion of this study was to design actual garments for boomer women using the inclusive design framework to elicit feedback from potential wearers. A cohesive mini-collection resulted from a series of actions that first included a solid research foundation identifying what boomer women might want by considering each blogger's wants and needs. This led to the actual design process (i.e., making the garments) that incorporated garment styles and qualities that the women reported as desirable. The actual creation of the clothing designs was necessary and provided another way to determine what types of clothing boomer women wanted by including feedback from potential wearers later in the study. This was a valuable activity in the design process because new understanding can develop through "varying aspects of existing artifacts" (in this case, clothing) and "reflecting upon the use of those artifacts" (Cross, 2001, p. 54). Reflection and decision-making were ongoing during design development and a beneficial part of the overall design process.

To clarify design practice in research, Pedgley developed three models that describe three different types of design activities in the context of design scholarship. Model-1 is summarized as an inquiry into the design process itself, while Model-2 focuses on the improvement of design procedures or tools, and Model-3 develops improvements to existing designs (Pedgley, 2007). This research specifically falls in line with Model-3 because many of the garments were similar to existing ones but were improved by incorporating features to make them more desirable in terms related to wearability and aesthetics. The design artifact (and in this case the clothing) was also 
used to gain a better idea about baby boomers apparel needs. In addition, design activity that seeks solutions (Model-3) works well within the ID steps of exploring and creating because the goal is to develop inclusive solutions for clothing (University of Cambridge, 2013).

While defining design research has historically been a challenge, design process can be a helpful research tool if properly documented (Frayling, 1993; Nimkulrat, 2009; Pedgley \& Wormald, 2007), and documentation is a critical part of design scholarship (Frayling, 1993; Nimkulrat, 2009; Pedgley \& Wormald, 2007). Accurately identifying what the designer knows can be a challenge because much of that knowledge is intrinsic to the specific designer (Cross, 1982), a phenomenon understood as tacit knowledge (Friedman, 2008). Because designing is often a personal endeavor and to some extent a subconscious exercise, designers must be cognizant of the design process and determine ways to effectively identify and textualize the steps (Pedgley, 2007). It is often difficult to document design activity in an identical manner for different designs, in part because the act of design varies in intensity depending on the amount of concentration demanded by the task at hand (Pedgley \& Wormald, 2007); this means that different design activities may require different types and levels of documentation, and in turn, documentation will vary in the amount of detail and attention given to specific tasks. Diaries, sketchbooks, and photographs have all been used as effective ways to document design activities to create a better understanding of the actual processes of making (Nimkulat, 2007, Pedgley \& Wormald, 2007). Journals, sketchbooks, and photographs were the tools used in this research to document and reflect on the garment design as well as the development process, and their use will be explained more fully in chapter five. 


\section{Blogs in Research}

Because the fashion and style opinions of boomer women are essential to this research, and because blogs will be an integral source of information, it is necessary to define and review blogs as an important data source in qualitative research and to discuss the benefits of using blogs in this study. Sometimes referred to as weblogs, blogs are personal sites on the internet that feature individual pages that include comments (posts) and images arranged in reverse chronological order (Bausch, Haughey, \& Hourihan, 2002). Information posted in this manner provides a retrievable data source representing a particular timespan that could be valuable when performing longitudinal research (Hookway, 2008). Blogs are often compared to online versions of personal diaries where bloggers (blog writers) present their intimate thoughts, feelings, and experiences (Chenail, 2011; Hookway, 2008). While handwritten diaries are generally considered private, blogs are used for private disclosure in the public domain (Lee, Im, \& Taylor, 2008). Bloggers' posts are often quite candid because, even though they are publicly accessible, bloggers maintain a sense of anonymity (Murthy, 2008). Blogs are frequently updated and generally intended for public viewing, unless the blogger wishes to keep content private by using personal settings that limit viewership to designated individuals (Hookway, 2008).

It is difficult to fully evaluate the use of blogs specifically by an older population. The Pew Research Center reported that in 2014, 87\% of American adults used the internet. Seventy-five percent of all adults and half of all adults over age 50 took advantage of social media sites including blogs (Internet User Demographics, 2014), and for the past eight years, women have maintained a modest increase over men in their use 
of social media (Perrin, 2015). In 2010, Pew reported that approximately 12 million adults or $8 \%$ of internet users kept a blog. Bloggers in the study reported personal creativity and motivation as their primary reasons for doing so, with financial gain as the least common reason listed for maintaining a blog (Lenhart \& Fox, 2006; Rainie, 2010).

Despite bloggers making up a fairly small percentage of the U.S. population, it is still valuable to use blogger information in qualitative research because it provides a perspective that allows a glimpse of the "individual's point of view" within the "constraints of everyday life," both of which are deemed important in qualitative research (Denzin \& Lincoln, 2003, p. 5). Older women use blogs for personal expression and their blog posts represent an interesting case of collective opinions worthy of research, thus their inclusion here.

Several points related to the use of blogs in research should be considered. The first is that it may be difficult to evaluate the sincerity or truthfulness of bloggers. Hookway suggests that even if bloggers aren't entirely truthful, they "still tell us something about the manner in which specific social and cultural ideas such as morality are constructed" (2008, p. 97). It is also worth noting that not everyone has equal access to the internet. This is commonly referred to as the digital divide (Murthy, 2008). Although older individuals are embracing computer technology at a steady rate it is still acknowledged that there is an "age-based digital divide" (Czaja, 2005, Czaja et al., 2006), and access issues are critical for the population of the study. Differences exist in both the availability of access and in the amount of internet use depending on the age cohort. Late boomers ages 60 and younger have more in-home access than older boomers and in turn use the internet more frequently (Selwyn, 2003). Overall, internet use continues to 
increase even for those 65 and older (UCLA, 2003; File \& Ryan, 2014). The concept of digital divide is complex and while the gap has narrowed considerably as more people gain access, it is acknowledged that other factors that may limit the benefits of internet use are equally important (The UCLA Internet Report Year Three, 2003).

Despite an aging population being at present healthier than past generations, changes in ability are often inevitable and may have an effect on how the individual interacts with internet technology (Czaja, 2005). In addition, adults with disabilities were approximately twenty percent less likely to use the internet than nondisabled users (File \& Ryan, 2014). In contrast, it is important to note that internet technology offers access to people that may not otherwise be included, such as marginalized groups or individuals with impairments (Murthy, 2008). For "home bound older adults" the internet can be a way to stay in touch with support systems that include social networking sites and specifically blogs (Choi, Dinitto, \& Eysenbach; 2013).

Though the use of blogs in research has not been fully explored, Clarke and Van Amerom successfully used blogs as a research tool to evaluate self-identification of depression from both male and female perspectives as written in their blogs. In another study, blog posts were evaluated from a marketing standpoint to better understand participants' opinions about travel destinations, and the researchers determined that travel blogs were a "means to gather rich, authentic, and unsolicited customer feedback" (Pan, McLaurin, \& Crotts, 2007). These two cases provide solid examples of blogs used as data in research. In a study aimed at identifying innovative research in qualitative methodology, blogs as a part of the larger category of online research methods were identified as having substantial promise (Wiles, Crow, \& Pain, 2011). 
The internet increasingly offers new avenues for social research, and blogs in particular can provide a data source that offers large volumes of naturalistic data readily available in textual form (Hookway, 2008). Moreover, blogs often provide personal information that is different than information elicited from standard interview procedures (Murthy, 2008), since it is naturally occurring and readily available for interpretation. Blogs were a rich source of information that helped to better understand the fashion and style preferences of baby boomer women for this study.

This chapter provided the needed background information to help better understand the baby boomer generation and specifically women that fall in the boomer age range to include women with a range of abilities. This is in addition to the changes related to the aging process that may affect self-esteem. An overview of the inclusive design framework and design scholarship provided the foundation for the design activity for the research, and the chapter ended with a discussion of the usefulness of blogs as a rich data source in qualitative research. The following chapter builds on this body of information and explains in detail the methods used for the study. 


\section{Chapter 3 Methodology}

A constructivist point of view guided this research with the understanding that meaning is created through human interaction with people and objects. Further, it highlights the significance of the individual point of view within a cultural context (Crotty, 1998; Schwandt, 1994). The researcher served as observer and interpreter and is an integral and valuable part of the research process focused on uncovering deeper meaning. It is an expectation within applied research practices that the researcher will provide insight as a result of personal experiences in the formulation of solutions aimed at solving problems identified through the course of the study (Patton, 1990), and here, the researcher identified with the women in the study because she falls within the included demographic and has an interest in fashion. Moreover, the researcher's industry experience and background in apparel design provide a knowledge base that aided in designing and developing the garment prototypes. The research was exploratory in nature, so qualitative methods will aid in achieving the desired outcomes. The study objectives are as follows:

1. Identify the clothing preferences and perceived problems from the point of view of boomer women with a range of physical abilities through their fashion and style blogs

2. Design and develop a line of inclusively designed prototype garments based on information gained from boomer women

3. Evaluate the garment prototypes by obtaining feedback about functionality, desirability, and inclusivity from boomer women with a range of abilities 


\section{Methods}

Narrative inquiry was used as a qualitative avenue for sense-making and provided rich insight about older women, clothing, and style within the parameters of a particular culture at a particular time (Crotty, 1998). The study was organized according to the phases of concept design that are outlined in the EDC inclusive design (ID) toolkit: Explore, Create, Evaluate and Manage. The blog data obtained from the Explore phase directly informed the design of the garment prototypes in the Create phase, and after completion of the prototypes, feedback through participant interaction with the garments formed a part of the Evaluate phase. The Manage phase is ongoing throughout concept design and will also be explained later in this chapter.

The methods outlined here are organized first by restating the research questions for immediate reference. An overview of apparel design and the inclusive design framework is presented first, followed by an explanation of each of the individual phases and how they were utilized for the study.

\section{Restatement of Research Questions}

Research Questions:

1. What specific clothing characteristics do baby boomer women identify as important and how can their preferences be incorporated into inclusive apparel designs?

2. How can the inclusive design framework be adapted to apparel design strategies aimed at boomer women with a range of physical abilities?

3. How can blogs as a form of social media be used to inform apparel design for specific segments of the female boomer cohort? 


\section{Apparel Design Using the Inclusive Design Framework}

An inclusive design framework was used to guide the overall design process for this study because it had the potential to aid apparel designers in designing for a broader range of boomer women. The guidelines presented by the Engineering Design Centre (EDC) at Cambridge were chosen to assist in implementation of the ID framework for this study and are included as a part of the EDC toolkit that outlines a general design process incorporating resources to aid in designing inclusively. The purpose of the ID toolkit is to guide and simplify the design process, and it was chosen because it has a solid foundation of research supporting its development and success (Herriott, 2013; University of Cambridge, 2013).

In addition, the inclusive design framework provided a comprehensive set of tools to aid designers in inclusive design. Multiple activities were presented within each of the four phases, though not all of the activities were equally beneficial for the study objectives, so only those activities that directly applied will be included in this section. Other less essential activities will be reviewed and evaluated later in the paper. It is important to clarify that the ID phases guided the study and the apparel design process specifically, and that apparel design and inclusive design co-existed to develop the best possible outcomes. This section will specifically explain the four phases and how they applied to this study. 


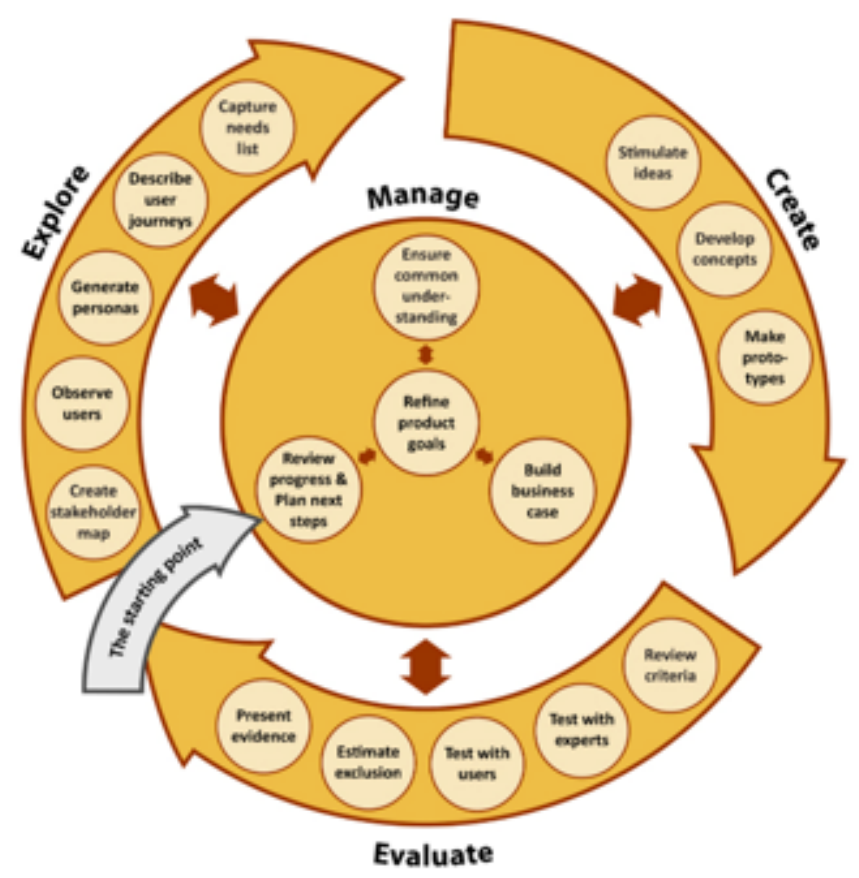

Figure 3-1. Phases and key activities of inclusive design. This diagram indicates key activities within the phases of inclusive design. Copyright 2015 by EDC. Reprinted with permission.

Overview of the four phases. The four phases that the EDC outlines for concept development include exploring user needs (Explore), creating solutions to satisfy the needs (Create), evaluating whether the needs have been met (Evaluate), and ongoing management of the project (Manage). As stated earlier, within each phase of ID, key activities and resources were available to help designers to design more inclusively. Figure 3-1 shows the phases of ID as well as the activities that are identified in the circles with the corresponding phase. Guiding principles are offered to encourage creative and inclusive thinking in the design process. This study used the blog data to better understand user diversity among women who fall in the baby boomer age range with a spectrum of abilities and needs. The framework guided the development of inclusive solutions that do not include special adaptations or specialized designs for extreme users. 
Wearers may have a range of needs that span a broad spectrum of difficulties in putting on, taking off, and wearing a particular garment. Inclusive design acknowledges that in some cases it is not feasible to provide solutions to satisfy individuals with the severest of difficulties when the only solution may be specialized garments.

\section{Explore Phase}

Gathering opinions about fashion, style, aging, and garment preferences through the blog data was the primary means to acquire a deeper understanding of boomer women's needs. Two guiding principles outlined in the Explore stage were applicable to apparel design in this study: (1) differences in needs are normal, and (2) detail is essential. In apparel design it is important to note that needs are as unique as the individual wearing the garment and that attention to detail will aid the designer in better satisfying those needs.

The EDC recommends user observation (Observe Users) to aid in identifying needs during the Explore stage. This study accomplished those observations through both the blog images and texts, all of which provided valuable information about what the bloggers liked and disliked, as well as what motivated their apparel choices. A second activity (Capture Needs List) was intended to identify the apparel needs of the bloggers, and was implemented in the data analysis stage through observation, notetaking, coding, and categorizing the blog data.

Research Design to Capture the Needs List. Narrative inquiry is a method that recognizes that people communicate their experiences in narrative or story form. Because personal narratives are a way to understand individual experiences as expressed and interpreted by the individual to uncover meaning (Clandinin, 2006), narrative inquiry will 
aid in this study's investigation of the feelings and opinions that aging women express about their relationship with clothing and their perceived clothing options. Further, the stories people tell, explains Josselson, "are played out in the context of other stories that may include societies, cultures, families and other intersecting plotlines in a person's life" (2011, p. 224). From this, Clandinin and Connelly (2000) identify three constant qualities in narrative inquiry:

1. Temporality: Recognizes the transitional nature of interaction related to time

2. Sociality: Acknowledges "feelings, hopes, desires, aesthetic reaction and moral dispositions" related to external influences (2006, p.480)

3. Place: Considers the physical locations where experiences are situated Narrative inquiry works well when viewing experiences from the life course perspective and continuity theory on aging, as these three qualities facilitate understanding related to temporality, sociality, and place. The life course perspective presents life as a series of interrelated, transitional stages over time related to temporality. In addition, the continuity theory on aging recognizes that modifications are made based on the inevitable changes that aging brings, and narrative research is based on continuity as the nature of experience (Clandinin \& Connelly, 2000). All of these dimensions of boomer women's narratives are relevant to the present research.

The narrative research employed here is consistent with the hermeneutic tradition historically used to uncover hidden meaning in texts (Crotty, 1998; Denzin \& Lincoln, 2003). Crotty describes hermeneutics as "understanding the whole through grasping its parts, and comprehending the meaning of parts through divining the whole" (1998, pg. 92). Written texts provide the foundation for narrative inquiry but images have proven to 
be a rich and valuable data source as well (Harrison, 2002). Narrative analysis incorporates a hermeneutic approach and is a combination of "categorization and contextualization" with an awareness of patterned relationships (Josselson, 2011). Significantly, a modern approach to hermeneutics allows for the development of multimeaning making as opposed to the belief that words carry a single meaning.

Blogs as a rich data source. Fashion and style blogs written by women who fall in the baby boomer cohort were reviewed for this study. The researcher analyzed a combination of written texts and photographed images to gain a better understanding of how a specific group of women feel about their clothing options. Narrative inquiry provided insight into how female fashion bloggers make sense of their world within the specific context of their blog posts and within a particular time and place.

Further, the opinions of a sub-group of the fashion bloggers that included women with a range of abilities were of particular interest to this study. One purpose of the analysis was to interpret relevant portions of the data to seek answers to specific research (McKee, 2003). This subgroup of women offered information that informed design inclusive of a range of abilities (McKee, 2003).

Data collection. Blogs were the primary source of data for this part of the study. Appropriate blogs were identified using key words in Google searches to find blogs written by women who approached or fell around the baby boomer age category. The following search terms, which resulted in thirty-eight possible blogs for the study, were used in a preliminary search: older, aging, baby boomer, women, female, bloggers, disability, fashion, and style. Blogger recommendations and blog directories also provided sources for additional blogs. A preliminary review of several of the blogs 
revealed a substantially smaller number of blogs written by women with self-proclaimed disabilities, and that some of the blog writers had a range of impairments that were not evident upon initial inspection.

Blogs that appeared to be used solely for financial gain were eliminated from the data set. It is common, though, for bloggers to promote businesses by recommending products; this was not viewed as a problem for this study because women bloggers often recommended fashion suitable for older women as a way to help them solve problems. Some bloggers are compensated for the number of forwarded clicks or purchases that result from traffic from their sites, but this type of activity is nearly impossible to track or is imperceptible to the viewer. A number of prominent blogs about older women and fashion were eliminated because they either lacked the voice of the women in the actual blogs or they did not pertain specifically to aging, fashion, and style. It was up to the discretion of the researcher to identify blogs appropriate for the study, and this was typically accomplished by reviewing sections that described the purpose or mission of each blog (often titled the "About" page) as well as several of the actual blog posts.

Blog texts as data. Blog texts written by older female fashion bloggers were chosen for the study because they provided a rich source of data about the personal feelings and preferences of older women. The blogs were desirable because the information presented is self-motivated and came directly from the women themselves, similar to personal diaries. Moreover, blogs lend themselves to narrative research because narrative inquiry looks specifically at content and meaning that may be in the form of texts (Josselson, 2011). 
Blog images as data. The images that bloggers posted in conjunction with the blog texts were also used as data for the study, though it is important to note that images are a viable data source on their own (Harper, 1998; Harrison, 2002). As Harper observed, "Images evoke deeper elements of human consciousness" (2002, p. 13); they have the power to express what is not easily articulated in words. Harrison defines this function related to narrative research as a counter-narrative (2002), which was important within the 1990s disability movement in the UK when photographers presented a unique perspective of what it meant to be disabled through the use of photographic images for the fundraising campaign (Hevey as cited in Harrison, 2002). The images presented a different view of disability that could not be captured in the campaign posters' copy.

Because images often provide an alternative perspective, they can connect an individual to a particular experience. Visual data can be used in a number of ways, but existing images - that is, images that are naturally occurring or taken for personal reasons rather than created specifically for research - have been used quite extensively to better understand belief systems and cultural patterns (Emmison, Smith, \& Mayall, 2013). The images incorporated into the blogs used for this study fell into this category. Collier also stressed the importance of the contextual setting of the images as data and suggested that comparing images to related images is important in meaning construction (Collier, 2004). Photographic images were equally as important as texts in meaning construction for this research.

Data analysis. As discussed earlier, narrative research approached analysis by considering the relationship of the specific parts to the whole. This is evident in Josselson's four operations, outlined below, that guide narrative data analysis and which 
were adapted for use in this study (2011). Collier's four-stage model for image analysis was also reviewed and found to be comparable to Josselson's four operations (2004, p. 39). When identifying steps for data analysis, it was essential to consider both texts and images, so both of these approaches were combined for this research. The resulting four operations that guided the data analysis process are summarized below. The process began with step one, but movement back and forth between the steps was necessary until meaningful data and themes emerged. The duration of blog posts (per blogger) that were viewed varied depending on how many times a month a blogger posted as well as the amount of new data that was forthcoming in the posts. Blogs posts were reviewed until no new data or themes emerged. The following is an outline of Josselson's four operations:

1. Step One: Individual blogs are analyzed, questions that arise are noted

a. Structure and codes are identified

i. Within individual images

ii. Within individual texts

b. Specific parts are reviewed again for meaning

i. Within individual images

ii. Within individual texts

c. Overarching meanings and themes among images and texts are considered in relation to the parts of the blogs

2. Step Two: Individual blogs are analyzed, with multiple readings performed to identify different interpretations.

3. Step Three: Individual blogs are analyzed, and individual readings continue until 
a. No new interpretations are revealed

b. Themes make sensible patterns and become unified

c. Detailed descriptions are produced

4. Step Four: Blogs are evaluated and compared to other blogs as a whole as the researcher evaluates the data related to the larger body of data to increase sensitivity to meaning

Coding strategy. The research objectives informed the coding strategies outlined here. In general, the analysis was flexible and adaptable, based on the needs of the study. Within the context of narrative analysis, a primary goal is "thematic analysis" and “patterned relationships," both of which are indicative of a categorical approach (Josselson, 2011, p. 227). Images as data required a slightly different, more detailed approach to coding as well because additional reflection and documentation were required during the analysis process as a form of record keeping (Collier 2004, Saldana, 2009).

Initially, data analysis was approached using Saldana's coding filters to help organize the data and provide the needed information based on the objectives of the study (2009). The three chosen filters were descriptive, process, and narrative coding. Descriptive coding aids in identifying the general topics being presented (2009, p. 70). Process coding is often performed alongside other forms of coding and highlights actions and emotional responses (2009, p.78). In keeping with narrative inquiry, narrative coding is "exploratory," "speculative," and focused on the human condition, identity, and “presentation of self” (2009, p. 109). 
NVivo for Mac qualitative software was used during the data collection and analysis stage of the study. NVivo software has the ability to import and manage a wide range of qualitative data, including images, web pages, audio and video files, and text. When dealing with a large volume of data in narrative research, computer applications are a solution to help manage the data (Clandinin \& Connelly, 2000).

Once the data was coded and categorized, analytical memos were written as a way to review the data and evaluate the coding/categorization process. The analytical memos took a variety of forms and at times resembled journaling or note taking, and were further coded and categorized as needed and themes emerged (Clandinin \& Connelly, 2000; Saldana, 2009). In narrative inquiry, a second set of personal reflections is often created that aid in the analytical process. The reflections can take a variety of creative forms to include journaling, letter writing, and poetry (Clandinin \& Connelly, 2000). The reflection for this research took the form of journaling and note taking.

Based on the information obtained in this phase, the review criteria was developed to determine whether the needs were met. As outlined by the EDC, the review criteria is a summary of the predominant needs and for this study was developed from the themes that emerged during data analysis and then used later to evaluate the garment prototypes.

\section{Create Phase}

In direct response to the Explore phase, the Create phase involved developing solutions to meet the needs identified. Reflection was a key part of the process in all stages of design activity and took place before, during, and after garment construction. Activities in the Create stage aided in design development and included brainstorming, 
exploring different combinations of ideas, and developing prototypes. According to the EDC, prototypes are visual communication of basic ideas, which could take the form of rough sketches, models, or computer presentations. Actual garments were created as prototypes during the Create stage for this study. The guiding principles are to (1) strive for simplicity, (2) challenge assumptions, and (3) let ideas breathe (University of Cambridge (2013).

Data collected from the Explore phase of the study informed the design and development of inclusively designed apparel prototypes. The design process was documented using both journaling and photography techniques. The process of designing and constructing the garments was another way for the researcher to make sense of the data and a detailed description of the design process will be reviewed in chapter five.

\section{Evaluate Phase}

The Evaluate stage assessed how successfully the garment prototypes satisfied the needs of boomer women at two different times during the research, once during the pretest and then a second time with another group of baby boomer women. This is a critical stage in the development of most ID products (especially apparel) to ensure that the needs are actually met. First, a key principle was to test the prototypes and make changes (if needed) prior to the final evaluation by actual baby boomer women and this was identified by the EDC as the test with experts activity. To pre-test the apparel prototypes both the designer and a boomer-age model tried on the garments to evaluate them during and after garment construction. A boomer woman, the designer, and the advising faculty member then met as a group to review the garment designs prior to testing with boomer women. 
The next step was to test with users and for this study the users were the baby boomer women who could potentially wear the garments. The research design to test with baby boomer women is presented next.

Research design to test with users. Evaluating the final garment outcomes was accomplished by recruiting participants to view the completed garments on display forms through images in posters as well as a videotape of live models wearing the garments. A semi-open questionnaire was developed to elicit specific types of data that were categorized according to participant information, responses, and opinions (Gillham, 2005). A semi-open questionnaire consisted of open-ended questions that study participants reviewed and then answered in written form. This approach modified Gillham's open questionnaire format because some of the questions were slightly more structured and prompted answers that specifically pertained to the completed garments. Question development was guided by both the top five criteria for purchase decisions described in chapter two and the ID review criteria that was mentioned earlier. Still, question development followed Gillham's outline, and the questionnaire was tested (piloted) with a boomer woman interested in style and fashion as well as with two of the researcher's committee members prior to use to determine effectiveness (2005).

The questionnaires were completed after participants had the opportunity to interact with the garment prototypes and review additional garment information. The researcher and a colleague were available to answer any questions that participants had while interacting with the garments. This approach differed from Gillham's open questionnaire format, a distance method that does not involve human contact (2005). Participant reactions were videotaped as they entered the room and while they evaluated 
the garments. The audio recordings were later transcribed as a part of the video data as a way to triangulate the data and obtain an accurate account of participant's reaction to the garments.

Data from both the semi-open questionnaires and the video transcriptions were analyzed with the same categorical approach to analysis as in phase one and used Josselson's four operations that included identifying themes and patterned relationships (2011, p.227).

The modified process used by this study is not unprecedented. Radvan successfully implemented this strategy to obtain user feedback in a study that evaluated the inclusive design of seamless knitwear for women, including women with disabilities (Radvan, 2013). She modified the open questionnaire process by presenting the garments to the study participants and allowing them to try on the clothing prior to administering the questionnaire. Radvan found that the questionnaires helped focus the responses through standardized questions and minimized research bias because questions were consistently presented to the participants (2013). Her study serves as a suitable model to inform the methods for this portion of the present research. This study differed from Radvan's study because the participants in this study did not actually try on the garments however they had the opportunity to interact with the garments and view the garments being worn in the videotape.

Sample. Women who are interested in fashion and who fall within the designated age range were recruited as a part of purposeful sampling contingent on selecting “information-rich" cases for in-depth studies (Patton, 1990). Women living in and around Columbia, Missouri were considered as participants because they would have greater 
access to the garment prototypes. The researcher looked for participants at the University of Missouri and in the Columbia community as starting points in the search for participant referrals. Additional women were recruited as a result of snowball sampling from word of mouth recommendations from the initial study participants. Women with a range of abilities were included as they were necessary to help determine whether the garments were inclusive to a variety of needs. Contacts made in a prior pilot study that included women with disabilities were recruited to request participation and referrals (Starkey \& Parsons, 2013). While the sample did not provide information that is generalizable to the entire population, it nonetheless enabled the research to approach the topic on a deeper level to obtain the research objectives (Patton, 1990).

The Explore phase and the Evaluate phase of the study complement one another and triangulate the data by approaching the subject matter from different angles. The Explore phase used blogger data from boomer women to inform apparel design, while the Evaluate phase utilized feedback from boomer women about the garments that were created for the study. This helped to create a broader, deeper perspective (Denzin \& Lincoln, 2003). Specifically, in the Explore phase of the study, data was obtained by analyzing both images and texts, and user feedback obtained in the Evaluate phase added another layer of data for older women's clothing concerns.

\section{Manage Phase}

Project management is an important component of the inclusive design process and helps guide designers from phase to phase. Before moving to the next phase a series of questions are answered that relate directly to the four fundamental questions: What are the needs? How can the needs be met? How well are the needs met? What should we do 
next? (Cambridge, 2013). If these questions could not be answered sufficiently, additional attention was given to that particular phase before product development continued on to the next phase and set of activities. An underlying principle throughout the Manage phase of the study was to remain flexible and to change the course of the plan when necessary to better meet the needs.

Verification. Experienced faculty with extensive research backgrounds guided the overall research process to increase the accuracy of the study. Reflexivity accompanied interpretation of the data and the researcher disclosed any relevant bias that affected the data analysis process.

\section{Ethical Considerations}

The lack of human subjects in the first part of the study eliminated the need for IRB approval. However, because study participants were required to evaluate the garment prototypes in phase three, it was necessary to obtain IRB approval from the University of Missouri. Sandra Starkey was the principal investigator and the IRB project number was 2002967. In addition, every effort was made to give credit to authors, photographers, editors, and designers cited in the research. Any copyrighted images or materials used as a part of the research had prior approval. Finally, there were no known conflicts of interest in conducting the research. 


\section{Chapter 4 Blog Data Findings and Synthesis}

This phase of the study, the Explore phase, addresses the first research question and was designed to gain a deeper understanding of the apparel needs of baby boomer women as well as to identify the clothing characteristics that they specify as important, In addition, fashion and style blogs written by baby boomer women were reviewed to address the second research question, how can blogs as a form of social media be used to inform apparel design for specific segments of the female boomer cohort? This part of the study was instrumental in identifying the clothing preferences and perceived problems from the point of view of boomer women with a range of physical abilities, the first study objective.

Eighteen style blogs written by twenty women ranging in age from their late forties to early seventies fit the sample criteria for the study. They were examined to gather information about their clothing preferences and apparel needs, as well as their opinions about aging, ability, fashion, and style. The total of twenty bloggers included in the study, is due to the fact that two of the blogs were joint collaborations between two bloggers. This chapter begins with the bloggers' demographic information, followed by a description of the data analysis process using Josselsen's four operations outlined in the methods section. The chapter concludes with a summary of the four main themes that emerged during data analysis.

\section{Demographic Information}

Table 4-1 summarizes the demographic information that will be presented in this section. 
Table 4-1. Blogger demographic information

\begin{tabular}{|c|c|c|c|c|c|}
\hline Website Name and Address & $\begin{array}{l}\text { Blogger } \\
\text { Name }\end{array}$ & Age & Location & $\begin{array}{l}\text { Ethnicity/ } \\
\text { Race }\end{array}$ & $\begin{array}{l}\text { Ability/ } \\
\text { Health } \\
\end{array}$ \\
\hline $\begin{array}{l}\text { Fort Smith Stylista } \\
\text { http://fortsmithstylista.blogspot.com }\end{array}$ & Jan & 60 's & $\begin{array}{l}\text { Fort } \\
\text { Smith, } \\
\text { AR }\end{array}$ & $\begin{array}{l}\text { White } \\
\text { Caucasian }\end{array}$ & Not listed \\
\hline $\begin{array}{l}\text { Silver Girl } \\
\text { http://www.silverpooloflightgirl.blogspot.com }\end{array}$ & Brett & 52 & $\begin{array}{l}\text { Charlotte, } \\
\text { NC }\end{array}$ & $\begin{array}{l}\text { White } \\
\text { Caucasian }\end{array}$ & Caregiver \\
\hline $\begin{array}{l}\text { Pumps \& Studz } \\
\text { http://pumpsandstudz.blogspot.com }\end{array}$ & Delilah & $40 \mathrm{~s}$ & $\begin{array}{l}\text { Denver, } \\
\text { CO }\end{array}$ & $\begin{array}{l}\text { African } \\
\text { American }\end{array}$ & Not listed \\
\hline $\begin{array}{l}\text { Senior Style Bible } \\
\text { http://www.seniorstylebible.com/ }\end{array}$ & $\begin{array}{l}\text { Dorrie \& } \\
\text { Jodi }\end{array}$ & $60-80$ & $\begin{array}{l}\text { Las } \\
\text { Angeles, } \\
\mathrm{CA}\end{array}$ & $\begin{array}{l}\text { White } \\
\text { Caucasian }\end{array}$ & Not listed \\
\hline $\begin{array}{l}\text { Age of Grace } \\
\text { http://theageofgrace.com/ }\end{array}$ & Eugenia & $50 \mathrm{~s}$ & $\begin{array}{l}\text { Hershey, } \\
\text { PA }\end{array}$ & $\begin{array}{l}\text { African } \\
\text { American }\end{array}$ & Not listed \\
\hline $\begin{array}{l}\text { Elegantly Dressed and Stylish } \\
\text { http://www.elegantlydressedandstylish.com }\end{array}$ & Jess & $40 \mathrm{~s}$ & $\begin{array}{l}\text { Lake } \\
\text { Norman } \\
\text { area, NC }\end{array}$ & $\begin{array}{l}\text { White } \\
\text { Caucasian }\end{array}$ & $\begin{array}{l}\text { EDS: } \\
\text { Ehlers - } \\
\text { Danlos } \\
\text { Syndrome }\end{array}$ \\
\hline $\begin{array}{l}\text { High Latitude Style } \\
\text { http://highlatitudestyle.com }\end{array}$ & Nicole & $40 \mathrm{~s}$ & $\begin{array}{l}\text { Fairbanks, } \\
\text { AK }\end{array}$ & $\begin{array}{l}\text { White } \\
\text { Caucasian }\end{array}$ & Not listed \\
\hline $\begin{array}{l}\text { Not Dead Yet Style } \\
\text { http://notdeadyetstyle.blogspot.com }\end{array}$ & Patti & Mid 60s & $\begin{array}{l}\text { Small } \\
\text { coastal } \\
\text { town, FL }\end{array}$ & $\begin{array}{l}\text { White } \\
\text { Caucasian }\end{array}$ & Not listed \\
\hline $\begin{array}{l}\text { Fifty Not Frumpy } \\
\text { http://fiftynotfrumpy.blogspot.com }\end{array}$ & Susan A & $50 \mathrm{~s}$ & $\begin{array}{l}\text { Johnson } \\
\text { City, TN }\end{array}$ & $\begin{array}{l}\text { White } \\
\text { Caucasian }\end{array}$ & $\begin{array}{l}\text { Joint Pain } \\
\text { Migraines }\end{array}$ \\
\hline $\begin{array}{l}\text { Une Femme } \\
\text { http://unefemme.net }\end{array}$ & Not known & 57 & $\begin{array}{l}\text { Southern } \\
\text { CA }\end{array}$ & $\begin{array}{l}\text { White } \\
\text { Caucasian }\end{array}$ & Caregiver \\
\hline $\begin{array}{l}\text { Idiosyncratic Fashionistas } \\
\text { http://idiosyncraticfashionistas.blogspot.com }\end{array}$ & $\begin{array}{l}\text { Valerie \& } \\
\text { Jean }\end{array}$ & Mid 60s & NYC & $\begin{array}{l}\text { White } \\
\text { Caucasian }\end{array}$ & Neuroma \\
\hline $\begin{array}{l}\text { Spashionista } \\
\text { http://spashionista.com/index }\end{array}$ & Alicia & Mid 50s & $\begin{array}{l}\text { Nashville, } \\
\text { TN }\end{array}$ & Hispanic & $\begin{array}{l}\text { Cerebral } \\
\text { Palsy } \\
\text { wheelchair }\end{array}$ \\
\hline $\begin{array}{l}\text { Sublime Mercies } \\
\text { http://www.sublimemercies.com }\end{array}$ & Charlotte & $40 \mathrm{~s}$ & $\begin{array}{l}\text { Northeast } \\
\text { US, } \\
\text { Canada }\end{array}$ & $\begin{array}{l}\text { White } \\
\text { Caucasian }\end{array}$ & $\begin{array}{l}\text { Chronic } \\
\text { Back Pain- } \\
\text { wheelchair }\end{array}$ \\
\hline $\begin{array}{l}\text { A Well Styled Life } \\
\text { http://www.awellstyledlife.com }\end{array}$ & Jennifer & Mid $60 \mathrm{~s}$ & $\begin{array}{l}\text { Northern } \\
\text { CA }\end{array}$ & $\begin{array}{l}\text { White } \\
\text { Caucasian }\end{array}$ & Not listed \\
\hline $\begin{array}{l}\text { Style Crone } \\
\text { http://stylecrone.com }\end{array}$ & Judith & 71 & $\begin{array}{l}\text { Denver, } \\
\text { CO }\end{array}$ & $\begin{array}{l}\text { White } \\
\text { Caucasian }\end{array}$ & Not listed \\
\hline $\begin{array}{l}\text { Flattering Fifty } \\
\text { http://www.flattering } 50 . c o m\end{array}$ & Susan B & $50 \mathrm{~s}$ & $\begin{array}{l}\text { Northeast } \\
\text { US }\end{array}$ & $\begin{array}{l}\text { White } \\
\text { Caucasian }\end{array}$ & Not listed \\
\hline $\begin{array}{l}\text { Bold Blind Beautiful } \\
\text { http://boldblindbeauty.com }\end{array}$ & Stephanae & $52+$ & $\begin{array}{l}\text { Pittsburgh, } \\
\text { PA }\end{array}$ & $\begin{array}{l}\text { African } \\
\text { American }\end{array}$ & $\begin{array}{l}\text { Macular } \\
\text { Holes } \\
\text { cane }\end{array}$ \\
\hline $\begin{array}{l}\text { Elle Plus Black Blog } \\
\text { http://blog.plusblack.co.uk/category/accessible-style }\end{array}$ & Elle & $\begin{array}{l}\text { Baby } \\
\text { Boomer }\end{array}$ & UK & Unknown & $\begin{array}{l}\text { Auto } \\
\text { Immune } \\
\text { Disease- } \\
\text { wheelchair }\end{array}$ \\
\hline
\end{tabular}


Blog identification. Table 4-1 organizes the demographic information by blog name and website address followed by each blogger's first name. Une Femme did not identify herself by name in her blog and is therefore identified as Une Femme during this part of the study, while Susan A and Susan B were identified as such to keep their information clearly separated during coding.

Age. Baby-boomer women were included in the study as well as women who were both somewhat younger and somewhat older than baby-boomer age, as these women were found to have similar perspectives to the boomer bloggers and could provide valuable information when designing for baby-boomer women. Four bloggers were younger than baby-boomer age and listed their ages as their 40s. The largest category of bloggers (nine) fell into the late-boomer cohort, ranging in age from 52 to 61 . Four bloggers fell into the leading-edge age group (aged 62-70), and two bloggers were older than boomer age. Judith listed her age as 71 , meaning that her age was borderline boomer, while Dorie indicated her age as 80 . One blogger did not specifically list her age but referred to herself as a baby boomer. In particular, the four younger bloggers chosen for this study presented their style blogs as ways of coping with the aging process. Two bloggers in their forties were chosen because, in addition to presenting style information for aging women, they also offered unique style perspectives that included managing obstacles due to health problems. Jess experienced intermittent chronic pain as a result of Ehlers-Danlos Syndrome (EDS), a connective tissue disease, while Charlotte battled chronic back pain, which resulted in her daily use of either a cane or a wheelchair. Their perspectives are relevant to inclusive design for an older market because their experiences are not exclusive to their ages and may also be experienced by women older 
than their 40s. The two older bloggers were chosen because, while they were chronologically older, they presented a positive and youthful attitude about aging, style, and fashion that was not solely defined by their age.

Location. With two exceptions, all of the bloggers resided in locations across the United States. Blogs from a range of countries were initially reviewed but the sample was narrowed down to primarily US residents because those were blogs that were the closest match for the needed sample for the study. The two exceptions included one blogger that had resided in both the US and Canada and another blogger that lived in the UK.

Ethnicity and race. Ethnicity and race were not a central focus in the blog content and were rarely mentioned. Fifteen bloggers were White/Caucasian, three were Black/African American, one was Hispanic, and the race or ethnicity of one blogger was unknown.

\footnotetext{
Ability and health. Because one focus of this study was to design apparel inclusive to a broader range of women, ability and health concerns were noted in cases where bloggers wrote about their personal situations in their blogs. Eight bloggers openly discussed ability or health issues that created physical challenges for dressing or presenting their personal styles, and their opinions often suggested ways of adapting to these challenges. Table 4-1 includes demographic information and also notes a range of concerns related to vision, reach, dexterity, mobility, and sensitivity. Specific health conditions in the blogs include blindness due to macular holes, Ehlers-Danlos Syndrome (a chronic connective tissue disease), Neuroma, Cerebral Palsy, autoimmune disorder, chronic back pain, arthritis, and migraines. Additionally, two bloggers were directly
} 
involved in caregiving duties that may have affected some of their clothing decisions, though to what extent this was the case was not entirely clear.

It is important to note that the research incorporated key principles from the social model of disability, and in doing so evaluated bloggers' comments within the context of their blogs as a whole. This is in keeping with the social model of disability that views disability within the social context. It is important to acknowledge that comments from bloggers with unique needs do not necessarily refer to the disability, so comments that related specifically to ability were noted as such in the passage. General comments that provided a deeper understanding about disability and style were included in the data analysis because the bloggers deemed these comments important enough to write about in their posts. Consideration of these comments was useful when developing garments to be more inclusive to a range of needs.

Other demographic information. Demographic information such as marital status, education, and employment were not included in the table because they were not a significant part of the blog entries. Several bloggers disclosed their marital status as married, one blogger identified as bisexual but in a committed heterosexual relationship, one blogger mentioned being in a partnership, and the rest didn't mention relationships or marital status in the information reviewed for the study. Education and employment were seldom discussed, and were not discussed in detail when mentioned.

\section{Data Analysis Process}

As stated in the methods section, individual blogs were reviewed and then evaluated using Josselson's four operations. A description of the data analysis process follows. 
Individual blog analysis: Josselson's operations 1-3. Initially the blogs were reviewed one by one. The blog data was organized by copying and pasting both text and images into individual Microsoft Word documents that were identified by the blogger's name, blog title, and web address. Within each blog, individual posts were clearly identified and separated by date in keeping with how these posts appear in the blogs. After reviewing the individual posts, the researcher added observations that pertained to the image content. This consisted primarily of a description of what the bloggers were wearing in addition to garment characteristics. A document was created for each blogger and both texts and images were organized by date in reverse chronological order and added to the document until no new information emerged. As stated previously, individual blogs were reviewed until the concepts became saturated, so the actual time period for which the blogs were viewed varied. Analysis always began with the most current post, and overall blog analysis began around March 2015 and continued anywhere between nine months and approximately two years. The specific amount of time the blogs were reviewed varied because the frequency in which the bloggers posted varied. In addition, the blog content differed at times so if a post did not pertain to the study then it was skipped over. As stated earlier, the individual blogs were reviewed until no new information emerged and this is what determined the duration that the individual blogs were reviewed.

After the Word documents had been completed for each blog, the information was reviewed again and imported into NVivo qualitative software. The content of each of the documents were sorted and coded into NVivo. A node in the NVivo software represents an important topic or category, and these nodes were created as new categories emerged. 
Multiple nodes were created during the coding process: ability and concerns, aging and style, companies and products, garments and garment characteristics, inclusiveness, personal style, purpose, self-concept, sexuality, size, and value and price. In addition, subcategories were added under some of the nodes as needed to further organize the data. Information from each blogger's "About" page was coded and added to the nodes. Several bloggers mentioned in their blogs that they had been interviewed by other bloggers, so the content of the interviews was also included in the analysis. The bloggers that participated in interviews were Alicia, Delilah, Dorrie, Nicole, Patti, Susan A, and Valerie and Jean. Their interviews built on the information provided in their About pages and were deemed valuable because they helped the researcher to better understand the purpose behind the blogs.

Blog analysis: Josselsen's operation 4. After the blogs were analyzed one by one, blog content was then analyzed as a whole as part of the fourth operation. The Nvivo software groups information by categories, thus enabling the researcher to both review all of the data related to one category at a time and make comparisons between different categories. Comments from bloggers were commonly coded in more than one node with categories overlapping. After reviewing the nodes, four main themes emerged. One node, entitled purpose, was specifically created to organize information related to the purpose of the blogs and a discussion of the purpose will precede a discussion of the four main themes: personal style, self-concept, health \& ability, and apparel preferences \& garment characteristics. Comments about the aging process in general will be discussed with each of the themes. 


\section{Purpose}

The overarching purpose for writing the blogs was to promote style and fashion for aging women, with many bloggers using clothing as a tool to help women cope with the aging process. This section explains the purpose of the blogs and aids in creating a better understanding of the bloggers' personal perspectives.

To promote style and fashion. The importance of clothing to the boomer women's personal styles was apparent from the beginning of the study. This was the main context in which the blogs were written, and-as established earlier in the paperwas the main reason these blogs were specifically chosen. Bloggers had multiple reasons for writing their blogs, but the unifying reasons were to promote style and fashion as ways for women to adapt to the aging process in a positive way. Several of the bloggers and specifically Jess, Alicia and Stephanae were also setting examples to support other aging women with a range of abilities. Many of their supplementary reasons also related to the overarching themes of aging, style, and fashion. The Information and About sections on the blogs were particularly helpful in obtaining an overview of the bloggers' emphasis on style and fashion, a driving force for the initial creation of the blogs as the bloggers felt a desire to help themselves and other women continue to incorporate these values into their lives. The bloggers felt strongly about the positive effects of fashion and style and wished to encourage other women to embrace personal style despite the challenges that aging and health changes can present to maintaining one's appearance. This supports Thomas and Peters' findings that women are continually interested in individuality as they age (2009). 
Coping with the aging process. Blogs were often used as platforms to promote healthy or successful aging by using fashion to maintain a positive self-concept despite the physical changes that aging involves. The blogs titled Fifty Not Frumpy, Flattering Fifty, and Not Dead Yet Style, for example, are three of the many blogs that promote the concept of aging with style, and each one features personal interpretations of fashion at specific ages, times, and places. These are constant qualities in narrative inquiry and were used to facilitate a deeper understanding of the bloggers' opinions related to temporality, sociality, and place. The blogs aided the researcher to better understand the bloggers' perceptions of their personal experiences as expressed firsthand at the particular time they were written and within the specific social and physical contexts presented.

Life course perspective and continuity theory on aging. Based on the blog data, it appeared that most of the bloggers maintained an ongoing interest in fashion and style throughout their lives that was consistent with the continuity theory on aging within a life course perspective. Patti shares this sentiment within the context of her style blog: “It's an open secret that as we age, we don't really feel different inside than we did when we were young. We still have our hopes, dreams, and fears, modified by time but still present" (Not Dead Yet Style, 2015a). Charlotte also states that, "More and more, I realized that beauty and style have helped me survive all my life (Sublime Mercies, 2013)."

As the bloggers experienced the effects of aging, it was necessary to react and adapt to these changes. This information was shared by the bloggers. Susan B stated that, “As with so many post-50 things, I'm redefining how I think about dressing (Flattering 50, 2015a)." Une Femme shared her thoughts about her style and felt that her style will 
continue to evolve. She does not necessarily want to look younger but she does want to look current (not to be confused with trendy or 'in fashion'). In general, the bloggers in this study were concerned with maintaining their appearance as they aged and were not afraid to try new and different clothing options if they felt they were more suitable to their current situations.

It's also important to note an exception in the case of Alicia, who had lived with a disability all of her life and only later adapted appearance-management strategies as a way of counteracting what she perceived as undesirable reactions to her appearance in social settings. This is consistent with adaptive strategies that individuals with disabilities may use to deal with self-concept and appearance to better connect with others in social settings (Kaiser, 1997). In this particular case, the blogger did not adopt these strategies until she became considerably older, and therefore her behavior does not directly support the continuity theory on aging, which is often the case for individuals facing illness or disability (Atchley, 1989). Alicia discusses the turning point for her change by saying, It used to frustrate me to no end when I left my house that the majority of people glanced at me quickly, dismissed any notion that I might be able to engage in any kind of meaningful interaction with them, and spoke to me through my ablebodied companions. I just wanted to be taken seriously and not be dismissed at first glance. So I cleaned up, dressed up, and started paying attention to how other people reacted. The difference was undeniable. They looked at me and not through me, spoke to me directly, and treated me like any other person. Sure, there's always a jerk that will be predictably narrow-minded but they've become the exception and not the rule. (Spashionista, 2015) 
Clothing as a tool. It was apparent in the blog data that boomer women used clothing as a tool to manage their appearance, especially within the social context of their blogs at the particular times posted. Significantly, both younger and older bloggers in this study used clothing differently to adapt to aging. Bloggers that fell into the leading-edge boomer cohort (age 61 and older) were more adventurous with their personal styles than the younger bloggers and experimented more with untraditional shapes, exaggerated garment components, and dramatic color combinations and accents. Valerie and Jean (Figure 4-1) are prime examples of this tendency, perhaps because they live in New York City and socialize in an environment more conducive to individuality.

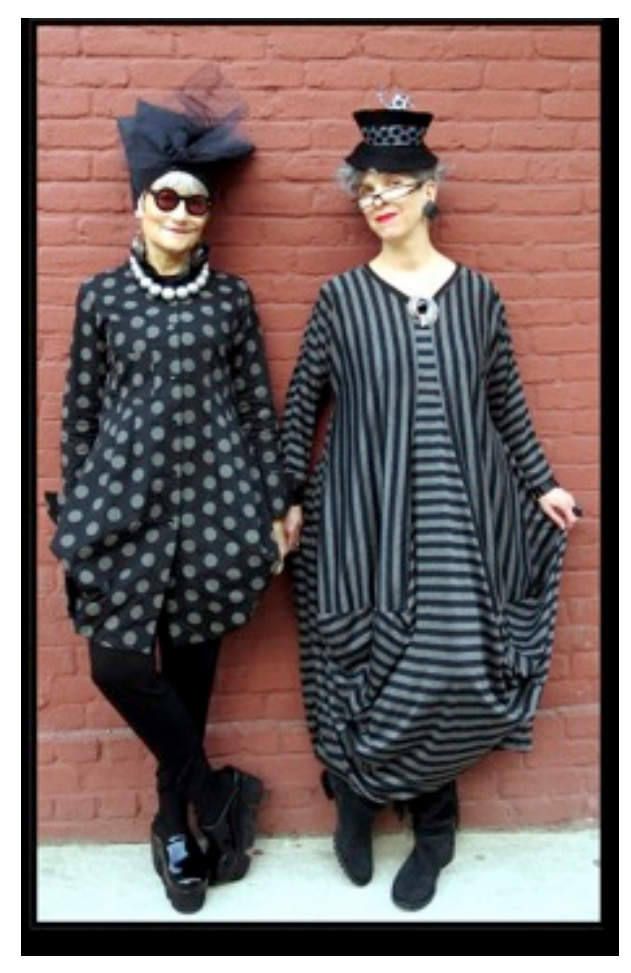

Figure 4-1. Bloggers presenting a dramatic approach to dress. Valerie and Jean, Leading Edge Boomers, Copyright 2015 by Idiosyncratic Fashionistas. Reprinted with permission.

The late boomers (women younger than age 61) generally modified their styles of dress to adapt to current clothing trends, though they still maintained their senses of 
individuality by adding their own signature styles or unique touches to what they identified as current fashion - in other words, older bloggers were not as concerned as younger bloggers about mainstream fashion influences. Jennifer, one of the older bloggers, exhibited characteristics from both groups and changed how she adapted her dress depending on the social situation and how she felt at that particular time. While Jennifer's style varied and she dressed dramatically at times, she also used clothing in a more subdued manner to adapt to current fashion trends. She was particularly concerned with retaining visibility as she aged, and in her fashion choices she may have been experimenting with ways to personally deal with the aging process and counteract invisibility. Jennifer devoted several long blog posts to this subject, including ways to combat invisibility, which will be discussed again later in this chapter.

For the most part, the bloggers presented positive posts about ways of accepting or overcoming the adverse effects of aging through their clothing choices. Even though bloggers were often disgruntled with the apparel choices available on the market, they rarely dwelled on their dissatisfaction to the point of negativity. Elle, a blogger who often wrote about her dissatisfaction with the lack of apparel options for older women with a range of health problems, injected humor into an otherwise downbeat blog post by ranting, "The whole process is so dispiriting. All I want is everyday wear-a few reasonably good looking, well-made, feel-good, oversized, long, black cotton tops... at a reasonable price. Do you feel me? I am currently in retail hell. Where is my retail nirvana? Please let me know if you've found one (Plus Black Blog, 2013b).

Bloggers also frequently used their blogs to call attention to other topics they deemed important, implying that bloggers may be set apart from the general population 
as vocal advocates of their causes. For example, Eugenia featured a monthly health concern such as breast cancer awareness and women's heart health in conjunction with her personal style posts (Figure 4-2), while Delilah promoted mature fashion for the plussize woman. Alicia's goal was twofold as both a style blogger and an advocate for women with disabilities. Charlotte's blog, however, openly discussed the broadest range of personal issues alongside the role that style plays in her life, as the following quote demonstrates:

Sublime Mercies is a blog about style, disability, feminism, and child sexual exploitation, also known as sex trafficking. Does that sound like an odd combination? Let me explain. When I started writing Sublime Mercies a few years ago, I honestly thought it would just be about style, just a foolish little diversion from important ideas, real life and, especially, chronic pain. I had not yet learned to really honour the positive, healing role that style and beauty have always played in my life. (Sublime Mercies, 2013)

Meanwhile, Elle used her blog to share information and resources with women who strive to maintain a sense of dignity and style regardless of lifestyle changes related to health problems, and Valerie and Jean challenged the concept of growing old gracefully in favor of "growing old with verve" (Idiosyncratic Fashionistas, 2009). Their enthusiasm was evident in both their writing and in the images they presented. It was clear that they had fun with fashion and this was apparent in the way that they dressed. Together, these examples represent the rich diversity in content represented in the blogs. 


\section{Fall Into Good Health}

BY: EUGENIA PUBUSHED ON: TUESDAY, OCTOBER 21, 2014 IN: CIVE ME GRACE

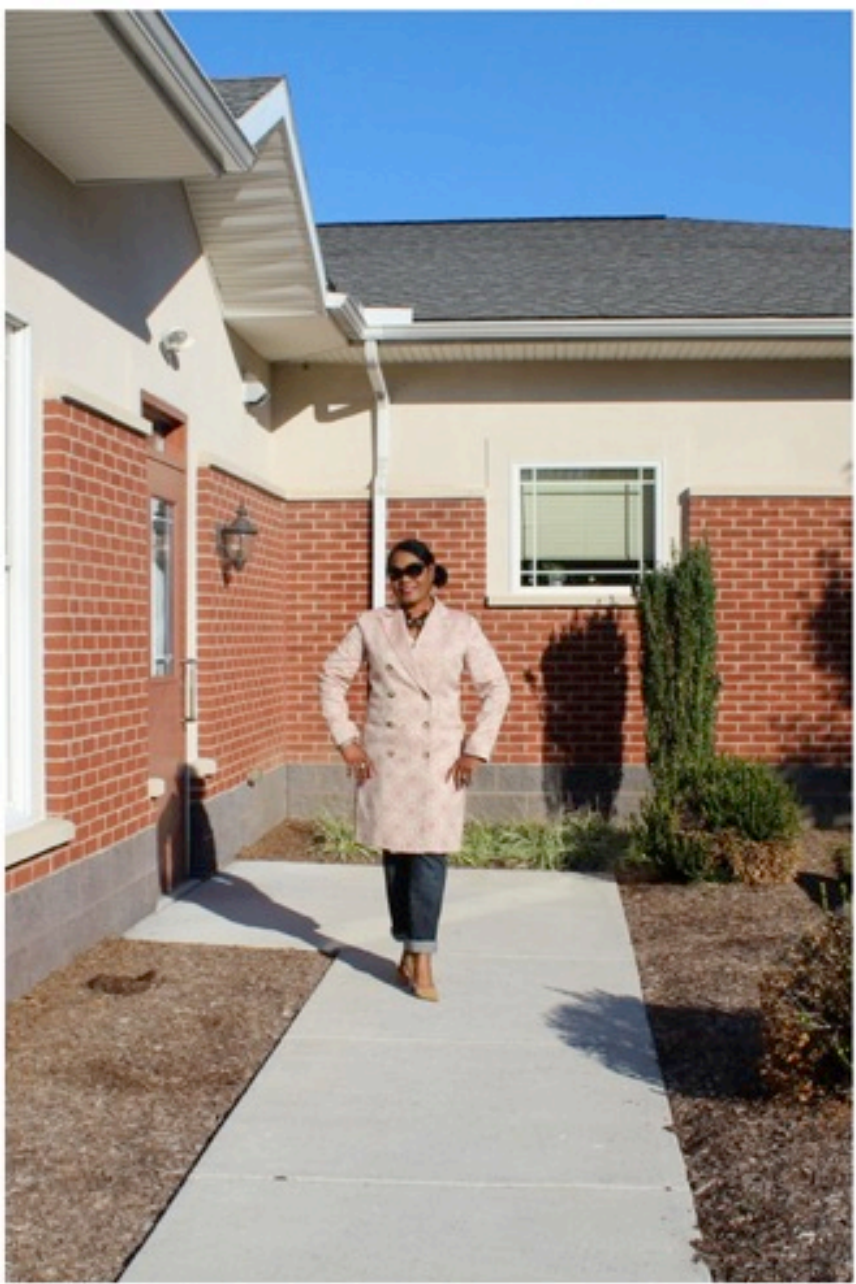

Fall into good health this season. During the summer warmer months, it's easy to stay metivated to walk, nun of exercise outside. As the days grow sherter and the grey months arrive-perhaps it's the lack of surlight:-one may lose the motivation to stay focused on fitness and weight management.

Earlier this year, I invested in a fiteit wrist band to help me stay on track not just during the summer months but all year long. I use the FitBas to rrask steas taken, distance covered, and calcries burned during the day - plus track my sleep cycle at night. We all tend to hibernate during the colder months, but we must set up ourselves up for success by planning ahead to exercise and eat healthy.

Figure 4-2. Example of blogs that serve a dual purpose; Eugenia promoting good health. Copyright 2015 by Age of Grace. Reprinted with permission. 


\section{Summary of the Four Blog Themes}

Personal Style. The bloggers unanimously used apparel to express themselves and felt that specially chosen articles of clothing helped them to develop their personal styles or distinct manner of dressing as a way to adapt to the aging process. Personal styleThis is not surprising since — as noted earlier — this was one of the primary reasons that bloggers gave for creating their blogs in the first place. Dorrie, for example, discussed the importance of fashion as she ages:

I've always been of the belief that as we get older, it's important to have a signature style that is modern, fashionable, and most importantly, still turns heads. My heart still skips a beat when I spy something I adore. If fashion has the power to do that, I'm happy to grow old, as long as I can do it looking great. (Senior Style Bible, 2015)

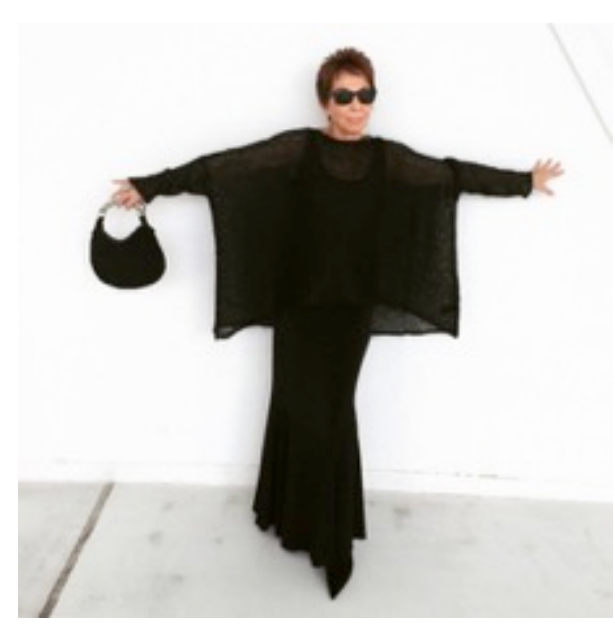

Figure 4-3. Dorrie's style. Copyright 2014 by Senior Style Bible. Reprinted with permission.

Similarly, Charlotte, a blogger in her 40s who manages daily chronic back pain with either a cane or wheelchair, commented on her style sense as she has aged: "I'm 
classier too, if truth be told. With age, even crippled age, comes self-awareness, sophistication, and poise that youngsters just simply cannot pull off (Sublime Mercies, 2013)." Susan A also adapts fashion to communicate her personal style and feels that the right clothing choices help her feel more comfortable in her lifestyle and within her social circle.

Fashion trends were relevant but secondary to creating a personal style for many of the bloggers; however, the bloggers were still aware of current trends and used them to inform their clothing choices to some extent. Jan supports this statement with the following two comments from one of her posts:

From where I sit, it seems that the consideration of trends is just another tool to evaluate new ideas, new combinations, and strengthen a new "eye" based on the ideas presented by designers that please me and excite my imagination. Really, there's nothing new under the sun. EVERY season there are retrospectives and reintroduction and re-imagining of old (often truly ancient!) ideas about how the body can be clothed.

Later in the same post she comments:

So I've come to the conclusion that trends and new ideas are:

1) the same thing, and only good or bad depending on use. And...

2) useful information for the evolution and education of my own taste.

I won't admit to the ignominy of being a "trend chaser" but plead guilty to using the ones I like to my advantage. Don't mind if I do, thank you. Trend aware, don't care! That's me. (Fort Smith Stylista, 2014a) 
Patti also states, "I have read dozens of fashion and style books, and have two shelves of them. There's a couple of provocative ideas in each book, nothing life-changing, but a few tidbits to store away. Other people's ideas (and blogs) do inspire me (Not Dead Yet Style, 2015a)." Valerie and Jean, however, have ideas about fashion and trends that are vastly different from most of the other bloggers. They have a diverse range of followers that include non-fashion week establishment types, older women, younger women and men. They believe that getting older is something to have fun and believe they don't have to follow fashion. They openly break fashion rules and claim that older women do not have to be invisible.

Many of the bloggers were interested in modifying current fashion trends to suit an aging body in ways that appeared more age appropriate. Age appropriateness was another recurring topic in the posts, and the bloggers often pondered what actually constituted age-appropriate clothing based on what they saw in stores, in magazines, and on the street. Age appropriateness meant different things to different bloggers, but for many bloggers it was based on their personal comfort levels. Alicia broaches the subject to readers in her post on the subject:

Do you believe in dressing "age appropriately" and what does it mean to you? I think that phrase means different things to different people. Some would argue that my Music City Hipster tank top isn’t age appropriate, but If I pair it with indigo skinny jeans, a crisp cotton jacket and some cork wedges I think it's perfect. I'm also Petite and I think Petite proportions lend themselves to dressing a little younger and getting away with it. (Van de Logt, 2014) 
Patti, meanwhile, preferred to be guided by what she deemed occasion-appropriate rather than age-appropriate clothing, using the specific occasion, event, or activity to guide her clothing choices: "Personally, I've never subscribed to the adage of age-appropriate clothing but rather, occasion-appropriate clothing that's comfortable and fits well, all of which have absolutely nothing to do with how many times we've watched the sun come up and go down.” (Not Dead Yet Style, 2015b)

Invisibility among women of a certain age was another common concern related to aging and style. Multiple bloggers felt that women of a certain age were less likely to be noticed, so they turned to styles of dress that were said to garner more compliments. Some of these clothing tactics included dressing "sexy" (Alicia, Figure 4-5) or "cutesy" (Brett). Jennifer devoted several blog posts to the subject of invisibility, "There's no doubt, some older women feel like they're wearing a cloak of invisibility. The reasons vary and while some women enjoy the freedom that it gives them, many do not (A Well Styled Life, 2015a)". Jennifer offered tips to help bloggers combat invisibility that included both clothing options and non-apparel solutions. Adding dramatic pieces of clothing to the wardrobe was one clothing strategy used to avoid invisibility such as the maxi-coat featured in Figure 4-4. She also felt that, in order to remain visible, attention should be given to grooming and fitness. 


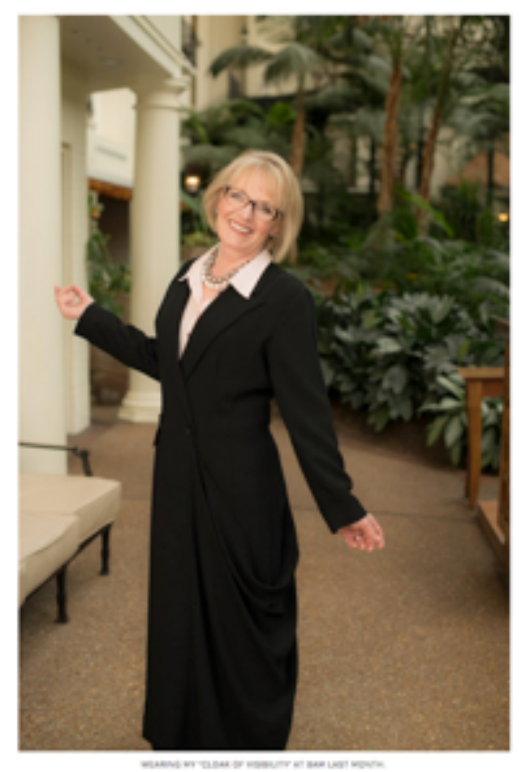

Figure 4-4. Jennifer adds drama to her wardrobe with a long maxi-coat. Copyright 2015 by A Well Styled Life. Reprinted with permission.

In addition to counteracting invisibility, Alicia felt that her clothing choices drew attention away from her disability as is shown in Figure 4-5. She shares the following thoughts: "This is the package I have to wrap in such a way that it distracts from the distraction that is my disability. Not an easy trick. But I am so lucky that I can put my best foot forward......er, best face forward.......best cleavage forward? (Spashionista, 2012).” As explained earlier in the chapter, Alicia adapted her appearance and clothing as a way of counteracting what she perceived as undesirable reactions to her appearance in social settings. 


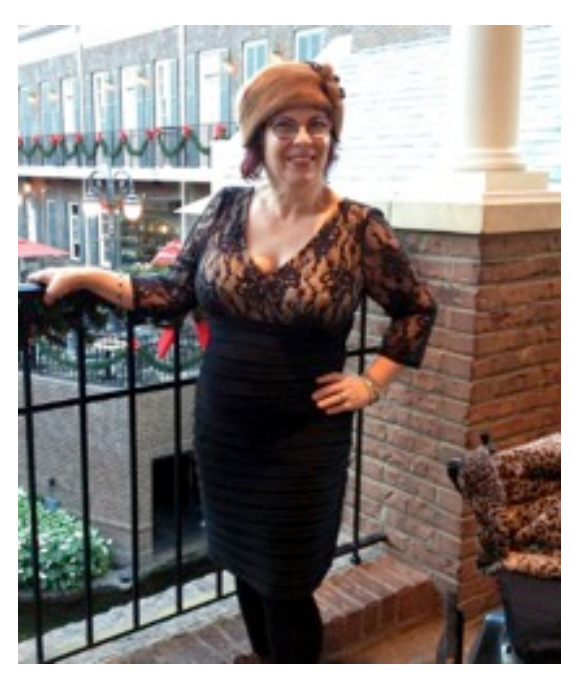

Figure 4-5. Clothing helps to counteract invisibility, as Alicia shows in this holiday photo, Dec. 2013. Copyright 2013 by Spashionista. Reprinted with permission.

Other bloggers added statement pieces to their wardrobe (including vintage clothing such as Valerie's dress in Figure 4-6.) as a way of expressing their individuality and standing out in a crowd. In contrast, Jennifer acknowledged that many women do not necessarily want to be visible all of the time and used clothing as a way to moderate her visibility depending on how she felt during the course of a particular day. 


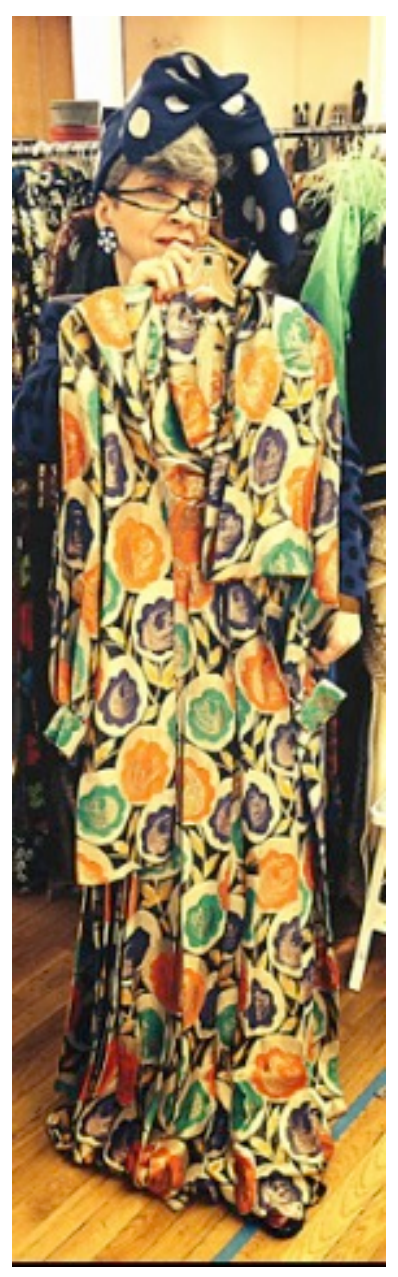

Figure 4-6. Valerie is constantly on the lookout for unique vintage apparel to suit her individuality. Copyright 2014 by Idiosyncratic Fashionistas. Reprinted with permission.

For Valerie and Jean, the notion of invisibility wasn't a concern; dressing in an eccentric manner was appropriate — even expected — in their social setting among an artsy and eclectic crowd in New York City. Clothing was a vehicle that Valerie and Jean openly used to remain visible, and their styles are unique to their personalities and generally oblivious to current trends (Figure 4-1). While Valerie and Jean's attentiongetting styles worked well for them personally, their styles aren't likely to be adopted by the majority of the bloggers in the study because they embraced a highly individualized 
approach to dress that may be perceived as too outrageous for most of this age group. Not all boomer women are interested in this type of personal style.

In general, bloggers often expressed the importance of taking ownership of personal style, even if it required more effort compared to when they were younger. Jennifer had a lot to say about dress and drama. She believes that if a woman is comfortable with drama, then she should be able to dress in an expressive manner: I have dramatic, head-turning garments in my wardrobe that I wear when I want to make a statement. I love capes, scarves, and drama. I adore hats, and wear them often. They're attention-getting simply because most women don't have the confidence to wear them. I don't think I wear goofy ones... but goofy is in the eye of the beholder....We are all a combination of style components that make up our personal style recipe. No one woman has the right or wrong formula for personal style. (A Well Styled Life, 2015a)

A recurring message throughout the blogs was that women wanted multiple options that aren't limited by age to help them present themselves. The following four passages illustrate the range of personal styles the bloggers discussed:

Delilah: I wouldn't say that I have a particular style because I can be boho, bold, glam, urban, or even preppy at times, it depends on my mood. The consistent adjective about my style is "chic." I believe that I am fashionable without being a slave to fashion and yet not afraid to take risks. (Van de Logt, 2015)

Jennifer: My personal style is a mix of classic, elegant, sporty, creative, and dramatic with a little feminine thrown into the mix. (A Well Styled Life, 2015b) 
Patti: I like a clean preppy style some days. It's simple and timeless. I do have to rough it up a little bit so as not to fit into any one style slot. (Not Dead Yet Style, 2015e)

Stephanae: The point of this post is to not be afraid to stretch your style. Even though distressed jeans may not necessarily be my thing I will try a pair and see if I feel differently. I've always dressed for how I feel. (Bold, Blind, Beauty, 2015b) The bloggers clearly liked to have clothing options that could help them express a variety of styles. They generally did not want to be identified with one particular style or specifically to be identified with the type casting or stereotyping that certain styles evoke. In addition the variations in how they dressed was often influenced by changing moods or feelings.

\section{Self Concept}

Clothing used as a tool to reflect personal style (distinct manner of dressing) as they aged often directly related to how the women felt about themselves. A constant message in Jennifer's blog was that confidence is linked to looking good, and if a woman feels confident, then she will not only look good, but also feel good about herself. In addition to Jennifer, the majority of the bloggers indicated that their clothing choices played an important role in how they felt about themselves. This is a reflection of the literature on clothing and self-esteem in chapter two (Lee, 2011; Thomas \& Peters, 2009). Along the same lines, as an advocate for women with disabilities, Alicia used her blog to present a positive self-image for aging women, especially those in wheelchairs. In an interview, she explained, "It's no secret that the disabled are the largest minority in the entire world. Not only do they have to overcome physical challenges on a daily basis, 
they also have self-esteem issues and economic barriers to contend with" (Van de Logt, 2014).

Coping with life changes is often problematic, and the inability to find acceptable clothing can be particularly troubling, especially for bloggers like Elle whose life was suddenly altered due to serious health problems. Unexpected physical changes dramatically affected her personal style, and in turn, negatively affected her selfconfidence. She confides in her blog that, "I cannot find my style in the product offerings I see around me. I am forced to represent myself visually to others with a look that simply doesn't feel like me" (Plus Black, 2013a). An inability to dress in her desired manner has dramatically affected her sense of self and consequently how she interacts with others. She specifically used stylish clothing to counteract the negative effects of her health problems and was on a constant mission to find apparel that would help boost her selfconfidence. She placed importance on simple designs made of natural fibers that fit well. Finding these types of garments as a plus sized wheel chair user was problematic.

Both Jennifer and Stephanae also advocate fashion as a way to enhance selfconfidence. Jennifer has a dramatic long black coat that she wears when her confidence needs a lift. "I pull this look out when I need a boost of confidence and it never fails me. I mix it with other styles to produce my personal style recipe (A Well Styled Life, 2015b).” Stephanae, meanwhile, suggests that confidence is a key component in conveying a fashionable appearance: "Even with all the pointers the most important ingredient to being fashionable is the way you carry yourself. If you walk with confidence and feel good about yourself you will look good and feel good! And you will convey that to others you meet (Bold, Blind, Beauty, 2015a).” 


\section{Health and Ability}

Comments in this section include remarks related primarily to disability or chronic problems that the bloggers experienced and shared in their blogs, though some bloggers shared other health information as well. This information was essential in gaining a deeper understanding of how the bloggers felt specifically about health and ability concerns. Bloggers discussed their concerns on several different levels, and statements like Stephanae's summarize some general feelings about disability: "Blind and vision-impaired women care about how they present themselves to the world, and like many women who are fully sighted, they want to be stylish (Bold, Blind, Beauty, 2015b)." Other bloggers re-emphasized in their posts their purpose for writing their blogs, and as Jess shares, "I try to take advantage of the good days. With this blog, I did not want to focus on the disease, but also show that if you do have this or others that you can try to dress up to make yourself feel good. I deal with chronic pain; however, I am in pain when I see some of the outfits people put together (Elegantly Dressed and Stylish, 2015)." Stephanae comments that "One of the reasons I started this blog was I learned firsthand how people oftentimes jump to the wrong conclusions simply because I use a white cane. The other reason was I felt an overwhelming desire to demonstrate that even in blindness/vision loss there is beauty and it's my hope to erase the negative connotations associated with it (Bold, Blind, Beauty, 2014a).”

Blogs were often used as vehicles to vent frustrations about disability and/or the limited number of options on the clothing market. Charlotte is particularly frustrated with her current situation, stating that, "I hate that I need a scooter. I hate why I need a scooter. I hate how I look in the scooter. I hate the particular scooter I'm using right now. But I do 
like my regained freedom. I can dress up and go out all by myself, like a real grown-up and everything! I can have little adventures. I can steal flowers to complete my outfit. These days, I would be housebound without that scooter (Sublime, Mercies, 2014)." Elle comments further about the combined problems related to size and ability, stating that, "For plus sizes, those of us with illnesses and/or disabilities, a huge problem with off-theshelf retail is poor fit and styling (Plus, 2013c).”

Bloggers with disabilities were more likely to discuss concerns directly related to their personal challenges however, as stated previously, some of the other bloggers also discussed health concerns. After years of health problems, Susan A underwent a major transformation when she adjusted her diet toward healthier eating habits, resulting in a significant loss of weight. Her weight loss directly impacted the clothes she could wear and brought about a positive change in how she presented her personal style. In general, the majority of the bloggers discussed concerns related to changes brought about by aging as part of categories such as comfort that will be discussed in the next section. Stephanae also shares her general view of the aging process in one of her blog posts: It's true with age, memory or rather the lack of memory is one of the many experiences we endure. Our bodies begin to make strange noises at the most inopportune times; like when getting up from a seated position, rolling out of bed, or walking and tooting. We have aches and pains in places we didn't even know we had, then there's the sagging, bagging, and dragging as our ever-evolving body parts give new meaning to shake, rattle and roll as they shift, shimmy, and jiggle. (Bold, Blind, Beautiful, 2015d) 
The above post was written by Stephanae however it is a good summary of how many of the bloggers felt about the aging process in general. Bloggers with disabilities were dealing with issue related to dress and ability and this was in addition to the concerns that these women had with aging. Health and ability concerns often go hand in hand with aging concerns however for some of the bloggers with disabilities it was another set of issues to deal along with aging.

\section{Apparel Preferences and Garment Characteristics}

Though each blogger's preferences were as unique as her personality, certain frequently mentioned clothing preferences are worth noting because they provided special insight or appeared to be of greater importance to many of the bloggers as they aged and therefore had the potential to inform design to satisfy a range of needs for boomer women. As mentioned earlier, specific apparel preferences as well as desirable garment qualities were separated during the coding process and organized to obtain a sense of importance. In addition, several underlying sub-themes emerged during data analysis to include the importance of aesthetics. This section begins with a discussion about aesthetics and will then summarize specific apparel preferences and garment characteristics that the bloggers listed as desirable. This information also came from the many images that bloggers presented in the blogs that featured their personal approach to aging and fashion. Due to the fact that the blogs were reviewed starting in March, it is a possible limitation of the study that some comments and apparel preferences may be geared towards warmer weather dressing.

Aesthetics. The aesthetic importance of clothing was an underlying theme throughout the blog posts. Bloggers were primarily interested in garments that could be 
worn to express their personal styles and this was particularly important as they aged. Color, pattern, and silhouette took precedence in their writing over functional qualities. Occasionally, garment features and components were mentioned that could make a garment easier to put on or could aid in garment comfort, but these suggestions were few and not intended to affect the aesthetic appeal of the garment in any way. Two such examples pertaining to closures included suggestions to incorporate large buttons to help with dexterity issues, with one blogger suggesting magnets as a viable solution to replace difficult-to-close fasteners. More often, however, bloggers made statements about what they liked or thought worked well in an outfit they had put together. Stephanae discussed some desirable qualities about a top that she'd layered over a dress for versatility(Figure 4-7): "Since the dress and the top are made of lightweight materials I could even comfortably wear this or a similar outfit in the summer without feeling the need to rip off my clothes due to an unexpected hot flash" (Bold, Blind, Beautiful, 2015b).” Another of Stephanae's comments involves a fitted dress: “The features I like most about the dress (aside from the fact I got it on sale) is the comfiness of the knit material, the color blocking is slimming, and it will nicely transition into spring (Bold, Blind, Beautiful, 2015b)." 

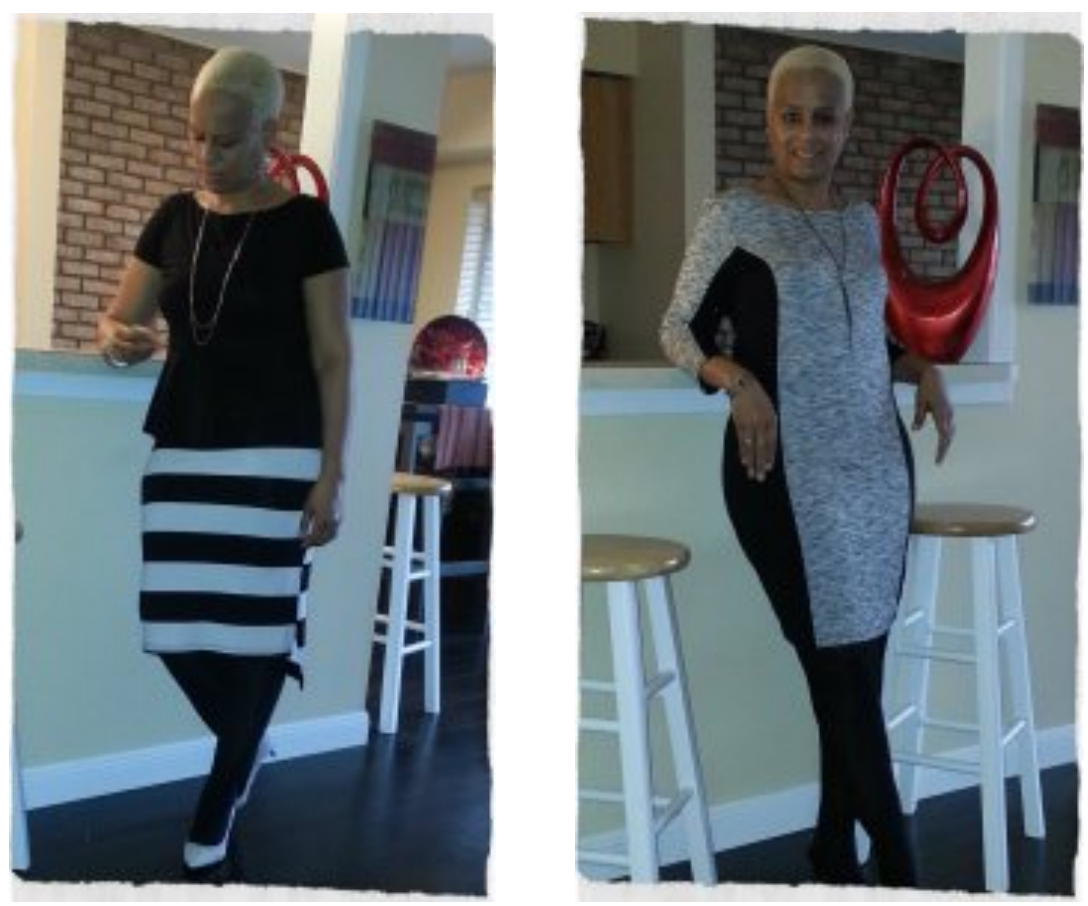

Figure 4-7. Stephanae wearing a knit top layered over a striped dress (left) and a stylish color-blocked dress (right). The left photo represents a comfortable and versatile outfit, while the right photo represents a comfortable yet slimming dress. Copyright 2015 by Bold, Blind, Beautiful. Reprinted with permission.

The formal aesthetic qualities outlined by Fiore, Kimle, and Moreno (1996b), discussed earlier in the paper, can be applied to the bloggers' clothing in this study. Formal or compositional qualities such as color and proportion were important to bloggers when creating the outfits presented in their blogs, with color carrying equal importance to visually impaired blogger Stephanae. Both Judith and Dorrie took the use of color a step further in their surroundings so that their outfits attained cohesion with the backgrounds presented in their photographs. Figure 4-8 shows how Judith was able to coordinate her outfit with a colorful backdrop. 


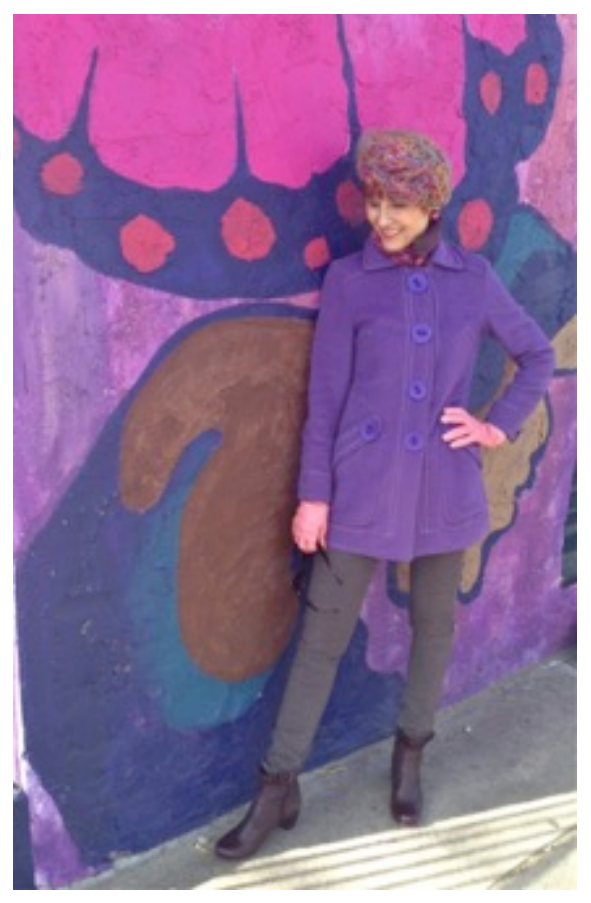

Figure 4-8. Judith poses in front of a vibrant backdrop that matches her ensemble. Copyright 2015 by Style Crone. Reprinted by permission.

Garments were often chosen for expressive qualities that conveyed the wearer's emotions and feelings. This most often pertained to special garments worn more than once that connected the bloggers to a memorable time and place. For several bloggers, Patti, Valerie and Jean, and Judith, vintage clothing items were not only expressive, but also conveyed a sense of individuality since they were generally one-of-a-kind items. The referential or symbolic nature of the garments worn in the photos can be interpreted as signifying individuality and self-confidence because these were ideals that bloggers wished to present. This is consistent with past research suggesting that individuality can be achieved through "personalization of style choices" (Postrel, 2007).

Aesthetics as an important component of apparel design includes sensory qualities that go beyond what is visually appealing. The most obvious example of this phenomenon from the blog data was the insistence on comfort combined with style, 
where bloggers were not willing to exchange garment comfort for style. This became increasingly important as they aged. Though several exceptions were noted in the case of the shoes worn by several of the bloggers, shoes and accessories were not a focus of this study, and this information is worth mentioning only as a side note. The following section will provide an overview of the bloggers' apparel preferences as well as several key garment characteristics deemed important. The remainder of this chapter will be a synthesis of both the blog data and images.

Specific apparel preferences and garment characteristics. Many types of garments and apparel preferences were presented in the blog images and texts, and the data revealed standouts and similarities in what the bloggers favored as components of their personal styles. The particular type of garment preferred at a particular point in time appears related to general fashion trends for many of the bloggers: for example, the greater interest in wearing dresses, specifically maxi dresses and similar ensembles that incorporated tops and long skirts ("How to find,"2015). This is consistent with many of the bloggers' interests in adapting current trends to their personal styles as they age, and could explain why the bloggers in the study disagree with past research finding dresses to be less desirable (Howarton and Lee, 2010). All but two bloggers featured at least one image of themselves wearing a dress in their blogs during the time period reviewed.

Comfortable, casual, "pulled-together" outfits proved to be the most popular for aging boomer women. Pulled-together outfits are defined here as carefully chosen combinations of garment pieces, accessories, and shoes that create a cohesive and polished appearance in the mind of the blogger. As mentioned earlier, maxi dresses, sundresses, and shift dresses were often worn by bloggers of all ages and abilities. Susan 
A has been a fan of maxi dresses for several seasons and states that, "Light and airy maxi dresses continue to be a great choice for warm weather dressing. I wore this black one a few summers ago but it was still a comfortable option for the garden tour Mr. Mickey and I were going on (Fifty Not Frumpy, 2015b)." Susan A is shown wearing her maxi dress in Figure 4-9. Charlotte equates the comfort of the maxi dress with that of a nightgown, and finds the maxi dress to be a stylish and comfortable alternative for hot summer weather.

The women in this study were far more interested in dresses than the women in previous studies, but this could be due to dresses having experienced a resurgence in popularity unseen in prior studies. It is possible that this is due to an increased availability and variety in product offering on the market for a broader range of sizes that includes more options for older women. The bloggers' interest also included looks that incorporated tops and skirts; both fitted tops and swing tops were preferred, depending on the overall look desired. Skinny pants, leggings, and fitted or skinny blue jeans were often worn as pant options. Jan comments, "Skinnies...this cut is new for me; Old Navy

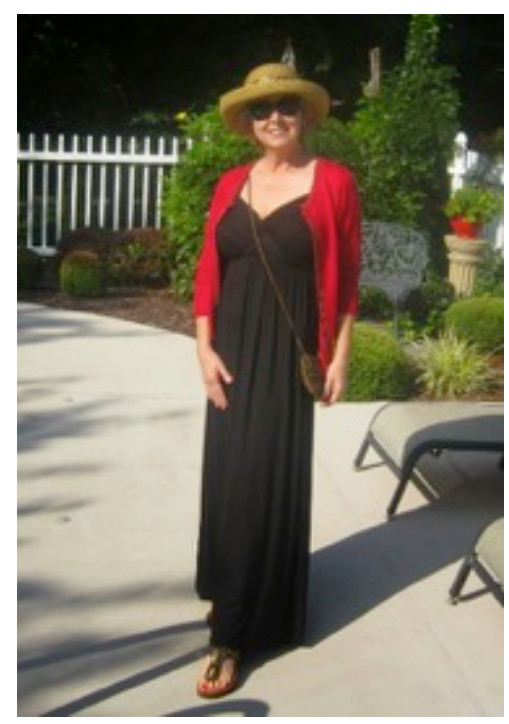

Figure 4-9. Susan A modeling a favorite maxi dress. Copyright 2015 by Fifty Not Frumpy, reprinted by permission. 
'Rock Star' with a side zip. Great skinnies to go under long tunics with flat front. Not quite leggings, not traditional jeans, but with back pockets. I love the fit (Fort Smith Stylista, 2014b)." The fitted pant that was chosen by the bloggers incorporated stretch fibers or knit fabrics so that they were comfortable. In addition, they were paired with longer tops, jackets or cardigans. This was essential to camouflage areas that the bloggers felt had changed as a result of aging like the stomach and hips.

Fitted jackets, longer lightweight jackets, and cardigans were presented as ideal layering options. Layering options were particularly important to some of the bloggers as a way to modify the look of certain garments such as a sleeveless dress or top. Layering cardigans over sleeveless tops was a way to maintain a sense of style while still providing the needed coverage that many older bloggers desired. Multiple bloggers (including three wheelchair users) also favored capes. Blog images suggested that bloggers preferred layering options like blazers or cardigans that could be worn over sleeveless tops or maxi dresses, such as Susan A's in Figure 4-9. Minimal, simple, classic, chic, and dramatic were adjectives that some bloggers used to describe their garments, and they often favored showing restraint when putting outfits together. This preference varied because these descriptions contradict some of the more elaborate styles intended to set them apart as discussed earlier.

Bloggers were not entirely happy with the options on the market in regards to fit because they felt that designers were generally focused on a younger market. Susan B states that, "Since turning 50, I find dressing well isn’t always easy. First off, designers aren't creating with the 50+ woman in mind. And things that looked great on me just 10 years ago no longer do (Flattering 50, 2015a).” 
Body-skimming garments and fitted garments were overwhelmingly given preference over tight as well as excessively full garments. It was evident that several bloggers had differing opinions about what constituted tight fit: for the most part, bloggers did not like garments that were so fitted that they hugged the body to the point of revealing body imperfections such as excess weight and (more specifically) fat folds. Susan B discusses fit, style, and fabric in the following post: "Personally, I look for dresses that will hide my little lumps and bumps. Consequently, dress fabric is important. My taste in fabrics, however, varies depending on the dress style. For example, I don't mind lightweight fabrics, especially lightweight jerseys or silk blend, for a wrap or draped dress. A wrap or draped dress's overlapping fabric hides the lumps and the lightweight material keeps the dress from becoming too bulky (Flattering 50, 2015b)."

In contrast, several bloggers were fine with garments that accentuated the bustline, such as the case of Alicia's equating a tighter fit with a sexy appearance that she found desirable (Figure 4-5). Several bloggers talked about the importance of balance in fit and preferred a combination of looser garments paired with fitted pieces, such as a loose top paired with a skinny pant or a fitted top paired with a full maxi skirt. For tops, a fitted appearance was generally preferred in the shoulders, bust, and midriff areas of the body, with more fullness favored in the waist and hip areas. Une Femme describes her preference for pieces that are body skimming yet not too tailored and with flowing silhouettes that are neither too tight nor too full. She explains in the following passage: I love clothing that has drape and movement, that flows. It's my version of feminine. An outfit composed entirely of woven tailored pieces (even if they fit me well) feels too stodgy...I need to watch the volume to avoid looking like I'm 
wearing a tent. The best pieces for me are those with a fit-and-flare silhouette which aren't too voluminous but allow enough fabric at the hem to provide that movement. Simplicity. (Une Femme, 2014)

She later adds that "a 'swing cut' top or jacket should still fit in the shoulders.

Conversely, too-tight clothing can either read as 'trying too hard' or again 'doesn't care." Figure 4-10 illustrates her style and shows Une Femme in a flowing cardigan over

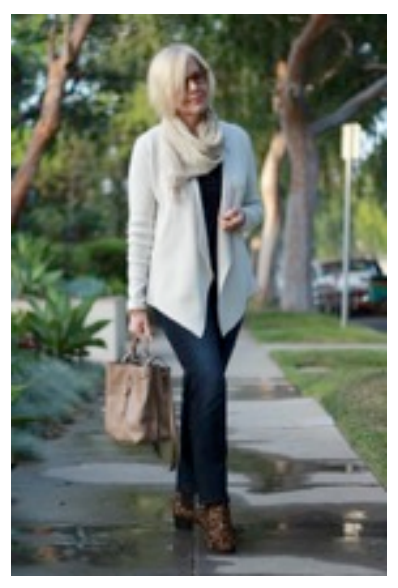

Figure 4-10. Une Femme is shown wearing a flowing cardigan over slim jeans. Copyright 2014 by Une Femme. Reprinted with permission.

slim jeans. Une Femme admits that her style has changed over time and that she has moved away from suits and tailored garments because they make her feel old.

Similar to other studies that list proper fit as a priority, this study identifies some specific fit preferences such as body-skimming garments that fit in the upper torso section and that are fuller in the lower torso regions. Slim, fitted pants, for example, were preferred by the bloggers, which could be in keeping with current fashion trends and is also consistent with today's preferred silhouettes Comfort was a key factor in fit, which is in turn central to the style and silhouette. 
It is also essential to note that the level of comfort sometimes referred to both physical comfort and emotional comfort. Jennifer shared an experience about a shopping excursion during which she tried on a short knit dress that she felt fit well and was flattering to her body type; however, despite the dress being one she liked, she was not comfortable with its overall short length, and so did not end up purchasing the garment because she didn't think it was age appropriate.

Softly structured garment silhouettes and easy shapes were apparent in draped styles that incorporated movement. Swing cut, trapeze-shaped, or fit and flare tops, tunics, and dresses (fitted at the bust and fuller towards the waist and hips) were presented as ideal by multiple bloggers because they were considered stylish yet comfortable.

It was not uncommon for bloggers to recommend ways to style garments to camouflage certain areas of the body that had changed as a result of the aging process. Susan B presented the concept of pairing several garments of varying lengths as a strategy to pull the eye away from problem areas. Susan B shares one of her fashion rules:

If you wear layers, try wearing ones that are different lengths. I'm starting to see tops with exaggerated tails around New York City. The long tails are hanging below short jackets. It's a look I think is going to gain momentum next fall. So...I've been inspired to wear my long sweater under my jean jacket. Varying lengths is also a great strategy for drawing attention away from problem areas, such as the stomach or hips or thighs. (Flattering 50, 2013) 
Several bloggers, such as Eugenia, preferred fitted tailored garments. Figure 14-11 shows an example of Eugenia in a button-down shirt with straight skirt. She is also wearing a cape, a favorite garment mentioned by other bloggers as well. Overall, blogger preferences varied tremendously depending on a range of factors that weren't always extensively explained in the blog posts. One blogger who opted for more casual flowing clothing silhouettes suggested a less structured work environment as motivation for her choice in garments but didn't elaborate on the nature of her work. In contrast, Eugenia's images indicated that she wore primarily shaped and structured styles as well as multiple formal gowns, suggesting the need for more traditionally structured silhouettes for daytime wear and fitted formalwear for other events. In general, many bloggers neglected to mention the specific purpose for the garments, though their preferences for these garments were quite clear. Three bloggers who used wheelchairs also modified their look to accommodate certain trends; for example, Alicia paired shorter shirts that appear longer while seated with narrow-cut pants all layered with structured jackets made from knit fabric for comfort. 


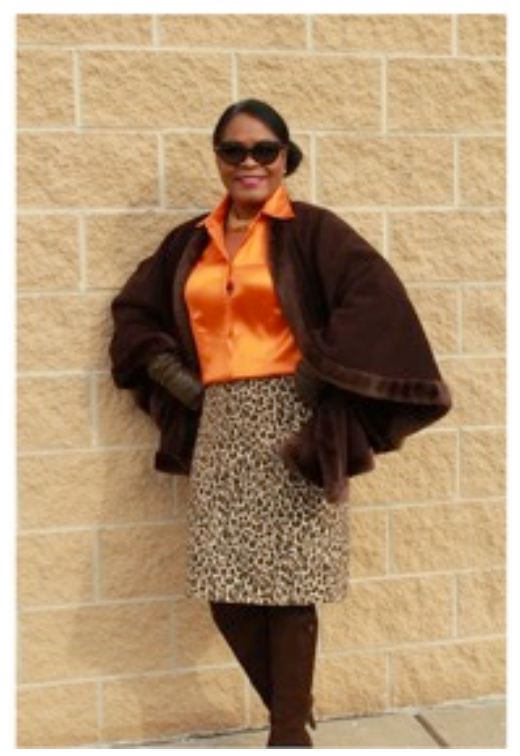

Figure 4-11. Eugenia in a fitted blouse, skirt, and cape. Eugenia is a blogger who preferred structured garments. Copyright 2015 by Age of Grace. Reprinted with permission.

Although specific fabrications and fibers were not discussed extensively in the blogs and were especially difficult to identify in the photos, some general observations were noted and some of the blogger comments are worth mentioning. Bloggers preferred soft, lightweight fabrics that incorporated stretch or garments made from knit fabrics. Dorrie, who wears a variety of knit garments, exemplifies this preference by saying, "I'm addicted to light weight knits. They're the perfect transitional pieces for Spring when the weather is often so fickle (Senior Style Bible, 2014)." Fabrics that skimmed the body without accentuating body bulges were also a priority, as Susan B made clear in her discussions of fit. Sheer tops and cardigans were layered over tank tops, camisoles, and dresses to add coverage without a heavy appearance for some of the bloggers. Susan A says that, "When the weather gets warm I often wear a nice tank top with jeans and a cardigan or jacket in a lightweight fabric (Fifty Not Frumpy, 2015a).” Bloggers liked sheer and lightweight fabrics but carefully incorporated into garments that were primarily 
used as layering pieces. A sheer cardigan over a sleeveless top was a way that bloggers could wear a sleeveless top without feeling as if they were exposing their arms, a concern for some bloggers. It was also a way to modify a look to suit their needs, to maintain a stylish appearance and in a way that was emotionally comfort because they had the needed coverage.

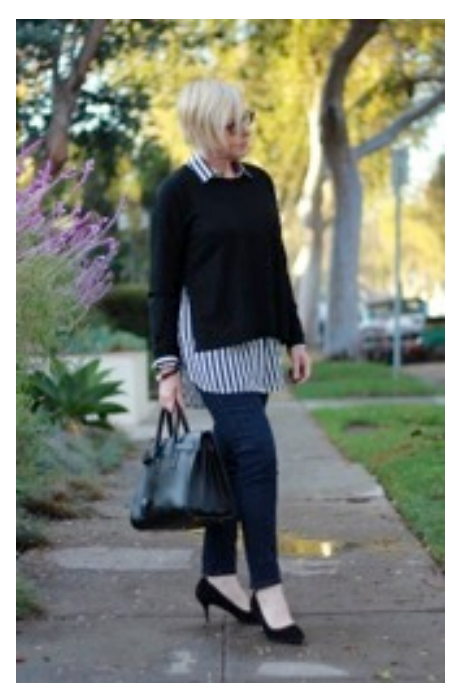

Figure 4-12. Layering garments of different lengths with fitted denim; Une Femme adds stripes to accent a layered look with jeans. Copyright 2015 by Une Femme. Reprinted with permission.

Jeans were overwhelmingly a wardrobe staple, with many bloggers listing their preference for denim with stretch. Dorrie shares in her post, I tend to favor jeans with some stretch, otherwise they tend to sag across my bum. I have a few brands that I know fit me well and I generally stick with them, although quite often they need to be shortened (Senior Style Bible, 2015).” Une femme often posted images of herself in slim, ankle-length denim pants, as shown in Figure 4-12.

While cotton and linen were often mentioned in the blog posts, their prevalence could be related to regional climate or to the blogs being reviewed in late spring or summer, when temperatures would warrant lighter weight, breathable fibers and fabrics. 
As Patti comments, "I like wearing cotton or linen skirts all Florida summer (Not Dead Yet Style, 2015d)." For wheelchair users, comfort was of the utmost importance, and Elle listed natural fibers (specifically cotton) as preferable, writing in one of her posts that, "[Wall London has] really good quality fabrics, the majority of which adhere to my natural fibre demands (permanent wheelchair use is like sitting on an electric blanket, all the time (Plus Black Blog, 2014)," and expressing her seasonal preference when she writes, "I absolutely hate Spring and Summer. Oh, not actual Spring/Summer of course, just the annual need to replenish my everyday wardrobe with basic $100 \%$ cotton tops, in black, in my (plus) size (Plus Black Blog, 2013b).” Elle also expresses her frustrations in finding her preferred fabric weight in the passage, "I am finding it harder and harder to obtain $100 \%$ cotton jersey for the warm seasons, even at retailers where it has been the norm in previous years. And no, for everyday wheel-life use, cotton mix, modal, viscose, polyester or rayon will not do. Precious fabrics, non-jersey fabrics-hopeless (Plus Black Blog, 2013b).”

It was apparent that fabric and fiber choices were often related to comfort, and the bloggers' overwhelming interest in comfort suggests the importance of aesthetics related to the sense of touch. It is no surprise that older women want to be stylish as well as comfortable, priorities that are often reflected in their fabric and fiber choices.

To the bloggers, color and print were important garment components and were managed differently depending on personal preferences. The importance of color cannot be overstated because, while some bloggers controlled and often minimized the amount of color worn, it was admittedly the design element that interested them the most about the garments. Several bloggers identified current color trends as essential for putting 
outfits together, and three women specifically mentioned Pantone's color forecasting as a valuable resource to guide their color choices.

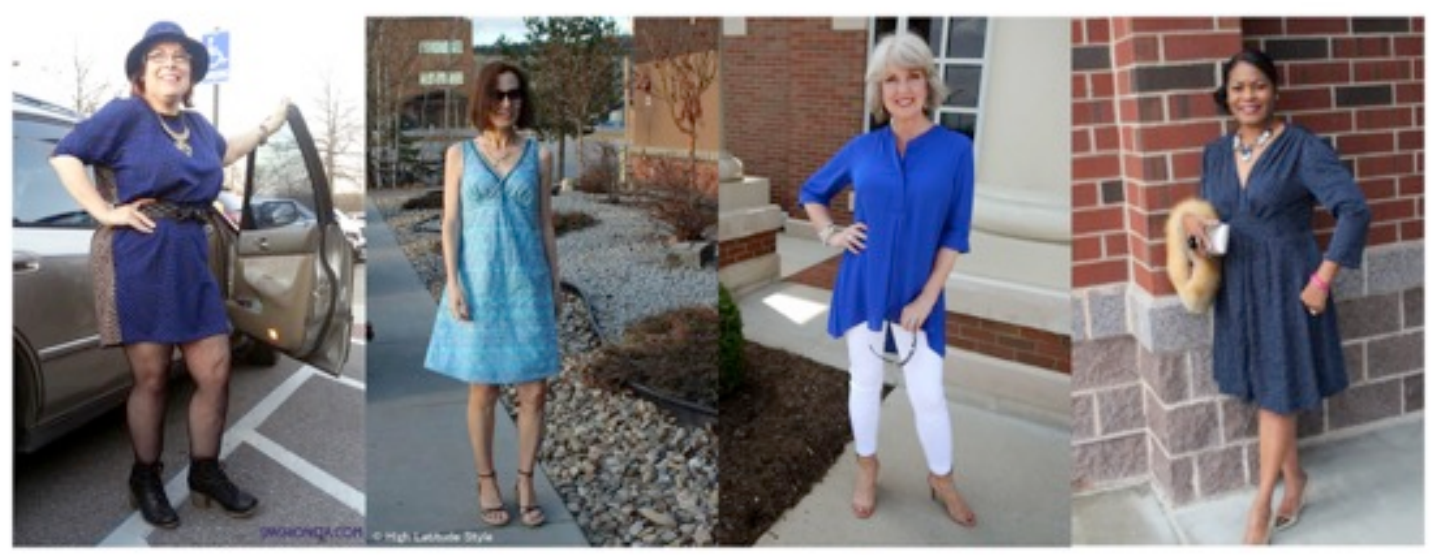

Figure 4-13. Bloggers wearing the color blue, from left to right: Alicia, Nicole, Susan A, Eugenia. Copyright 2015 by Spashionista, High Latitude Style, Fifty not Frumpy and Age of Grace. Reprinted with permission.

Bloggers presented a wide range of outfits and, as a general rule for half of the bloggers, neutral colors formed their foundations and were complimented with either a splash of color or a printed component (Figure 16). Several times bloggers mentioned the importance of color in the posts but presented images of clothing in the blogs that were predominantly solid colors and neutrals. Many of these bloggers specifically mentioned blue as a preferred color however a wide range of colors was presented in the blogs.

Black and white garments were often presented in blog images and described as classic and comfortable. While many bloggers stated their preference for black, one went so far as to apologize for the consistent use of black in her wardrobe. In terms of other colors, while the bloggers experimented with color, most incorporated color into their wardrobe in a carefully controlled manner. Even bloggers who preferred a more subdued 
color palette advocated the use of color for other women, and in one blog post representative of many of the other bloggers' opinions, Jennifer writes that

Color is personal. I'm a fan of neutrals and not pattern. Some women love bright colors because it makes them happy. They don't call it the Red Hat Society for nothing. These women are making a statement about their visibility. They will not be ignored and it's their privilege to do so. There is a fine line between colorful and clownish. If we cross that line intentionally, and are confident enough to wear it, that's our choice. (A Well Styled Life, 2015a)

In contrast to the bloggers who preferred a more subtle color palette, Brett often presented herself in ensembles that pushed the boundaries for both color and pattern. She was not afraid to wear bright color combinations and often incorporated oversized prints and/or stripes to mix together offbeat colors and patterns. Brett shared the following post while wearing a bright orange sweater with an oversized cobalt blue, orange, and white tulip-print pant:

I pulled out my Pixie Pants hoping for a great spring day. I know there is controversy over women of "a certain age" wearing printed pants. Well, in my opinion...just because you are a certain age doesn't mean you have to start wearing all black, beige or cream. Clothing should be fun and reflect your personality. Look for good fit and cut and don't worry so much about the print. Unless of course, it's unicorns, hello kitty or care bear related! (Silver Girl, 2015)

For other bloggers, printed garments were incorporated into the outfits as accent pieces and then in the form of a tank or shell worn with other solid-colored garments. If 
garments lacked the necessary visual interest, the bloggers incorporated a wide array of scarves, necklaces, belts, and shoes into their ensembles to add the needed color to make the garments more aesthetically appealing. In one post (Figure 4-14), Jess comments that, "I have just been in love with all of the pretty pinks and pastels lately, I wanted to create a look around this watercolor scarf and Impressionistic style (Elegantly Dressed and Stylish, 2015 )”. Print was incorporated into outfits in a variety of ways as shown in Figure 4-14: Jess accents her outfit with a printed scarf, Une Femme wears a pale yellow and gray print blouse with slim jeans, and Judith wears a boldly printed maxi dress.

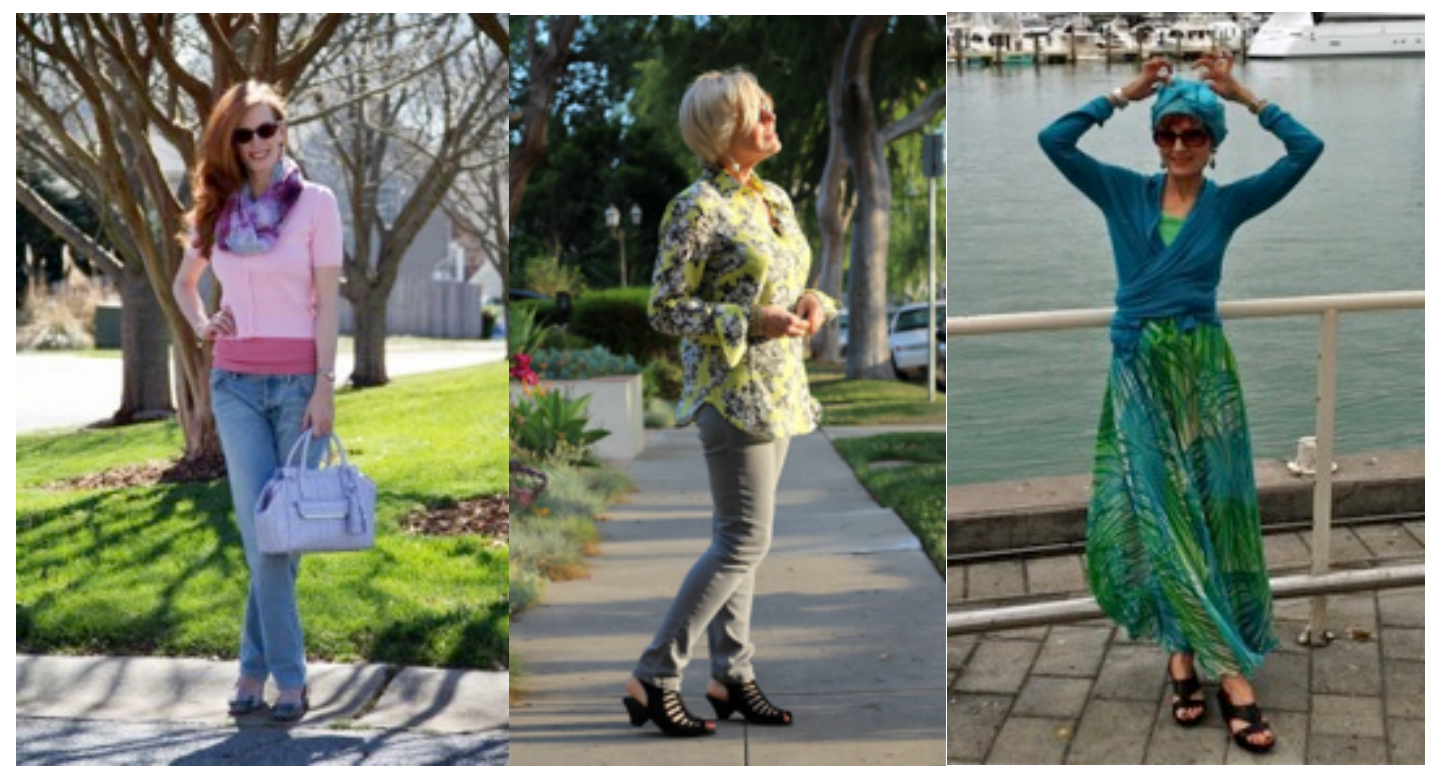

Figure 4-14. (Left to right) Jess layers shades of pink in an outfit inspired by the color palette in her scarf, Une Femme incorporates a printed blouse into her outfit, Judith wears a printed maxi-dress. Copyright 2015 by Elegantly Dressed and Stylish, Une Femme and Style Crone. Reprinted with permission.

Polka dots and stripes were the standout patterns, and prints took the form of either florals, bold geometrics, or animal prints, all of which are consistent with current fashion trends (Figure 4-11). Even bloggers like Valerie and Jean, who weren't particularly concerned with trends, wore garments that featured polka dots and stripes (Figure 4-1). 
Stephanae provided a unique perspective in her posts, as she experienced challenges related to blindness. The following post illustrates how important color can be to some visually impaired women:

Blind and vision impaired women care about how they present themselves to the world and like many women who are fully sighted they want to be stylish. Having an awareness of colors and which ones allow us to shine is very helpful when buying trending apparel, cosmetics, jewelry, accessories and even décor in the home. A color analysis can help in determining the colors that work best for you. (Bold, Blind, Beauty, 2014b)

Stephanae used her blog to educate her followers about the scientific process and psychology of color. Of particularly interest was her discussion about the experience of color as more than simply a visual perception, but as a feeling that varies depending on the specific color. These colors can evoke both positive and negative feelings when worn on the body, a sentiment shared by sighted bloggers as well. Stephanae writes that Describing color to someone who has never seen it is something I've been thinking on for a considerable amount of time. Take the color blue for example, it's been said by some that blue can be experienced as a feeling but what does that mean if I have never seen blue? Depending on whom you talk to and their perception of what blue means to them answers can vary from positive qualities like tranquility, and relaxation to the negative such as sadness and depression. Colors for many people (including those of us with blindness/vision loss) are just words. As I've said before and I will say many more times, confidence is the most 
important thing a person can wear. With confidence you can wear just about whatever you please and carry it off. (Bold, Blind, Beautiful, 2014b)

Overall, the importance of color and print were clear in both the blog texts and images. Bloggers used color and print to express their individuality and add interest to their ensembles, though what they deemed appropriate varied dramatically from blogger to blogger.

Though bloggers presented a wide range of garment components in the blog images reviewed, it was apparent that their preferences for particular garment components and details were dictated primarily by how favorable the bloggers felt about a particular body part, what features they felt needed concealing, and what fashion choices they thought appropriate for their age. These choices were highly subjective and personal to each of the bloggers.

Garment sleeves were a topic of conversation for some of the bloggers, with younger bloggers often wearing sleeveless tops and dresses as long as they had layering options for coverage, if they so desired. With the exception of one older blogger, all of the bloggers over age sixty always included a layering piece to be worn over sleeveless garments. Bat-wing sleeves, loose sleeves, and three-quarter-length sleeves (such as Dorrie's in Figure 4-15) were shown in blog photos, while cap sleeves were specifically mentioned as undesirable. Susan B discusses sleeves in a post:

I'm less inclined to wear sleeveless dresses. While I didn't see much change in my arms in my early 50 s, in the last year or so, my arms are clearly showing their age. I'm not about to wear long sleeves 24-7 or retire all my favorite sleeveless dresses 
and tops. Not yet, anyway. However, I am always on the lookout for stylish ways to wear 3/4 and long sleeves. (Flattering 50, 2014)

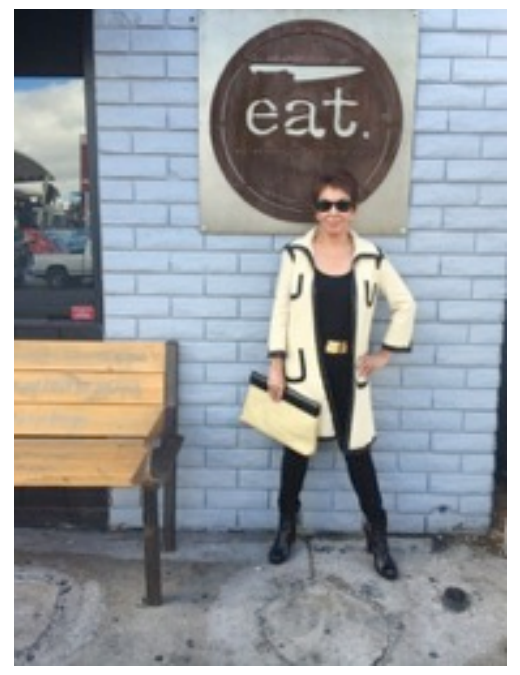

Figure 4-15. Dorrie wears one of her favorite jackets with three-quarter-length sleeves. Copyright 2015 by Senior Style Bible. Reprinted with permission.

Tops that were shorter or longer than average and looser, reversible tops, and tops with slits at the sides and back were favored. Crew- or scooped-neck tops were shown in the images, and button-up tops and shirt-dresses were worn in some blog entries. Several bloggers listed pockets as an added garment bonus. A couple of bloggers were quite verbal about their dislike of low-rise jeans and many of bloggers desired simple, slim pants. Bloggers in wheelchairs preferred garments without additional features that could cause bulk and discomfort, and those bloggers with dexterity limitations also preferred oversized buttons, hidden side zippers, and magnetic clasps for garment closure, with simplicity being the key to getting garments on and off the body.

In contrast to the studies reviewed earlier, garment versatility was a key feature for the majority of bloggers in this study. Versatility adds value to garments designed for 
boomer women by offering solutions to suit a variety of real-life situations in ways that reflect the wearer's individuality and personal style. Many of the bloggers were interested in owning fewer pieces as they aged, but choosing instead high quality and versatile garments that simplified the process of dressing.

Bloggers often discussed the importance of garment versatility, especially as it related to budget and lifestyle and to wardrobe management. Several disabled bloggers mentioned versatility as an important factor related specifically to cutting down on overall apparel costs. Nicole calculated the cost per anticipated wearing when deciding whether to purchase garments with trendy components, and several bloggers, including Delilah, were interested in garments with multiple wearing options as a way to purchase fewer garments in the long run or downsize their wardrobes. Other bloggers such as Une Femme desired garment components that worked together in multiple ways to accommodate the problem of limited packing space for travel. Stephanae in particular opted for a capsule wardrobe that consisted of a limited number of versatile clothing items that could be worn in multiple ways. Her capsule wardrobe was coordinated to suit multiple occasions because the garments were interchangeable or had layering options to change their overall appearance. As a vision-impaired blogger, this was also a way for Stephanae to manage her wardrobe. Additionally, she often used a talking color identifier to coordinate outfits without additional outside assistance, a helpful tool for organizing her capsule wardrobe. In summary, the majority of the bloggers felt that if garments were versatile and could be worn in multiple ways, then those garments formed an important addition to their wardrobes. 
The bloggers did not specifically mention well-known brands as favorably designing for an aging market, though some bloggers presented outfits and listed stores, brands, and designers that they liked related to what they were wearing in the blog photos. Bloggers had different formats for mentioning this information, with some occasionally acknowledging a store, brand, or designer. The stores that some of the bloggers listed were Artful Home, H \& M, HSN, JC Penney, J. Crew, Lane Bryant, Macy's, Mod Cloth, Nordstrom, Old Navy, Saks Fifth Avenue, Target, Thrift Stores, TJ Maxx, Wall London, and Zara. The brands that the bloggers listed were American Rag, Ashley Stewart, Dsquared, Eileen Fisher, Fabrizio Gianni, Guess, Jones New York, Land's End, Planet, and Zac \& Rachel. The designers that the bloggers listed were Amanda Valentine, Calvin Klein, Donna Karan, Helmut Lang, Heydari, James Pierce, Michael Kors, Ralph Lauren, Sigrid Olsen, Tory Burch, Trina Turk, and Tsumori Chisato.

Some of the bloggers recommended companies that catered to their readers' age group. Several internet-based companies such as Covered Perfectly, Eshakti, Karina Dresses, PIOL and Janska were mentioned in the blogs as providing products for a more diverse market with an emphasis on fit and comfort for a range of body types and sizes. Covered Perfectly designs tops specifically for women over age 40 , and as the name states, emphasizes designs that provide additional coverage by offering wider shoulder straps, longer sleeves, fullness in the midriff, and extra length. Eshakti provides custom clothing for sizes 0-36 and offers consumer options to choose from a range of neckline designs, sleeve choices, and garment lengths. This allows their clientele to customize garments to suit their specific needs. Karina Dresses and PIOL offers dresses for a range 
of sizes and body types and is focused on comfort and adjustable fit. Janska is another company that offers comfortable apparel and was started to provide products for individuals with unique needs related to health and aging. Several bloggers strongly endorsed these companies, and though it was apparent that the companies sometimes provided bloggers with incentives to review their garments, the bloggers expressed a desire to wear the garments regardless of company incentives. In addition to targeting older women and using the blogger endorsements to gain a web presence, the companies were also providing products such as those noted above that specifically catered to the needs of an older market, which was valuable to the bloggers.

\section{Summary of Review Criteria}

This portion of the study was a valuable part of the Explore phase of inclusive design because in addition to directly informing apparel design decision-making, the review criteria was developed to help evaluate whether or not the baby boomer women's needs had been met. The review criteria was intended to evaluate inclusive and aesthetic garment qualities because both were deemed important to the overall success of inclusively designed apparel.

This chapter identified the purpose for writing the blogs as well as the four main themes that emerged during data analysis: personal style, self-concept, health and ability, and apparel preferences and garment characteristics. Based on the four themes, the following list of review criteria were developed to aid in evaluating the apparel designs: garment types, style, color/pattern, fit, comfort, fabric, versatility, and ease of wear. The remainder of this chapter will provide a summary of the four themes, including the review criteria that were associated with the themes. 
Overall, the blogs provided a wealth of information about the reasons the bloggers had for writing the blogs, in addition to providing a glimpse of the importance of the blogs to the bloggers as they aged. Understanding the significance and motivation behind the blog posts aided in designing apparel for baby boomer women because it helped explain why the bloggers made some of their clothing choices. Each of the individual themes informed the apparel design process in slightly different ways. A list of the themes and the associated review criteria follows and is also represented in Table 4-2.

\begin{tabular}{|l|l|}
\hline $\begin{array}{l}\text { ID Review } \\
\text { Criteria }\end{array}$ & Definitions of the Review Criteria for Inclusive Apparel Design \\
\hline Garment Types & Preferred styles and silhouettes \\
\hline Style & Current fashionability, personal style, may include modified trends \\
\hline Color/Pattern & Color, print or texture \\
\hline Fit & $\begin{array}{l}\text { Desired amount of ease related to how the garment follows the shape } \\
\text { of the body }\end{array}$ \\
\hline Comfort & $\begin{array}{l}\text { Physical or emotional sense of well-being, pleasing to the senses, often } \\
\text { to the sense of touch }\end{array}$ \\
\hline Fabric & \begin{tabular}{l} 
Specific textile and or fiber content, appearance and perceived quality \\
\hline Versatility
\end{tabular} \\
$\begin{array}{l}\text { Options for multiple use, changeability and flexibility of garments or } \\
\text { garment features }\end{array}$ \\
\hline Ease of Wear & $\begin{array}{l}\text { Uncomplicated process related to putting on and taking off, special } \\
\text { consideration to closures }\end{array}$ \\
\hline Appearance & $\begin{array}{l}\text { How the garment looks on the body or on display, wearer's perception } \\
\text { of how the garment would appear on one's self, flattering vs. } \\
\text { unflattering }\end{array}$ \\
\hline
\end{tabular}

Table 4-2. Summary of the review criteria for inclusive apparel design with definitions.

The theme personal style emerged because maintaining a personal style was a way for the bloggers to positively adapt to the aging process. The bloggers indicated that they wanted a variety of stylish apparel options to help them express themselves so it was necessary to provide a range of clothing choices in the mini-collection. Versatile garments can be adapted to suit personal needs and style, which can appeal to baby boomer women and should be taken into consideration by designers when targeting this 
group. This theme directly informed the review criteria, Style and Versatility. Style pertains to the current fashionability of a garment that may include fashion trends or special features to enhance one's personal style. Versatility in a mini-collection will provide multiple options for use or features that allow changes or modifications in a garment's appearance.

The two themes self concept and health and ability identified how the bloggers felt about issues such as self-esteem, the aging process and challenges related to health and disability. This provided a deeper understanding about why the bloggers felt the way they did and in turn this helped to prioritize ways to address the concerns without abandoning fashion altogether. Specifically, designers should be aware of fashion trends when designing for an older market but should also be aware of what modifications can be made to garments to both appear stylish and also maintain a level of wearability that includes individuals with a range of abilities. The review criteria that were a result of these two themes were Comfort and Ease of Wear. Comfort is defined as the physical or emotional sense of well-being and/or something that is pleasing to the senses and often refers to the sense of touch. Ease of wear refers to the level of difficulty to don and doff a garment. In ID, the less complicated the better, and special consideration to garment closures is key.

The theme apparel preferences and garment characteristics provided specific information about garment types and features that were a starting point for new design solutions; in other words, it made sense to build on what the bloggers liked and what worked well in the past. This theme informed the review criteria Garment types, Color/Pattern, Fit and Fabric. Garment types are the preferred garment styles and 
silhouettes; color/pattern consists of color, print, or texture; fit is the amount of desirable ease related to how the garment follows the shape of the body; and fabric refers to the specific textile and/or fiber content. The appearance of the fabric and the perceived quality are also factors when evaluating a garment.

Because aesthetics were important to the success of inclusively designed apparel for this study, Eckman, Damhorst and Kadolph's top five criteria for purchase decisions were reviewed and compared to the review criteria presented here to evaluate whether aesthetics were sufficiently represented. Their top five criteria were color/pattern, styling, appearance, fabric, and fit (1990). With the exception of appearance, all of the criteria were represented in the review criteria for the study. Appearance was added to the list of review criteria and refers to how the apparel designs are perceived to look on the body, which will be important during evaluation of the apparel designs. 


\section{Chapter 5 The Apparel Design Process}

The apparel design process will be outline here, which included both inclusive and aesthetic aspects of apparel design. The chapter will be divided into three sections: first, an overview of key considerations for the design process that includes an explanation about inspiration, experimentation, and exploration for garment development; second, a review of the design objectives and examples of the apparel design outcomes and third, an overview of the inclusive design process as it related to apparel designed for this study.

This chapter will address the second part of research question number one that asks, How can their [bloggers] preferences be incorporated into inclusive apparel designs? In addition, this chapter will focus on the second research question: How can the inclusive design framework be adapted to apparel design aimed at boomer women with a range of physical abilities?

\section{Overview of Key Considerations}

The blog data from the Explore phase was the foundation for the development of design ideas that helped determine the needs of boomer women. The goal was to build on the information obtained in the blog data to add value through inclusive design. Through exploration and reflection, ideas were developed that could fulfill a range of needs without compromising aesthetics, an important aspect of clothing selection for boomer women. The challenge was to design inclusively without losing sight of the needs and wants of the boomer women, which made it necessary to balance both the aesthetic and functional properties of the garments while being mindful of simplicity and comfort. 


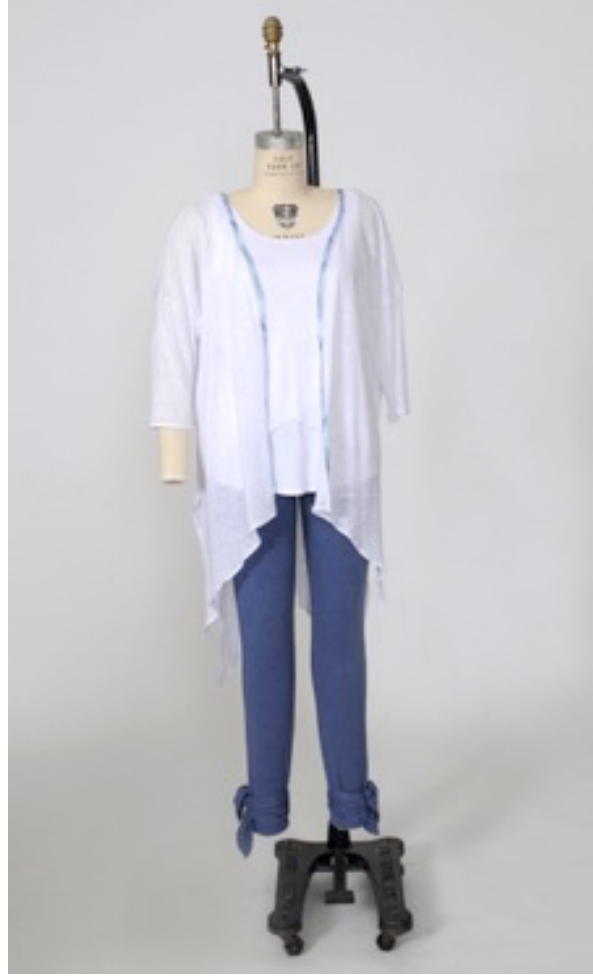

Outfit A

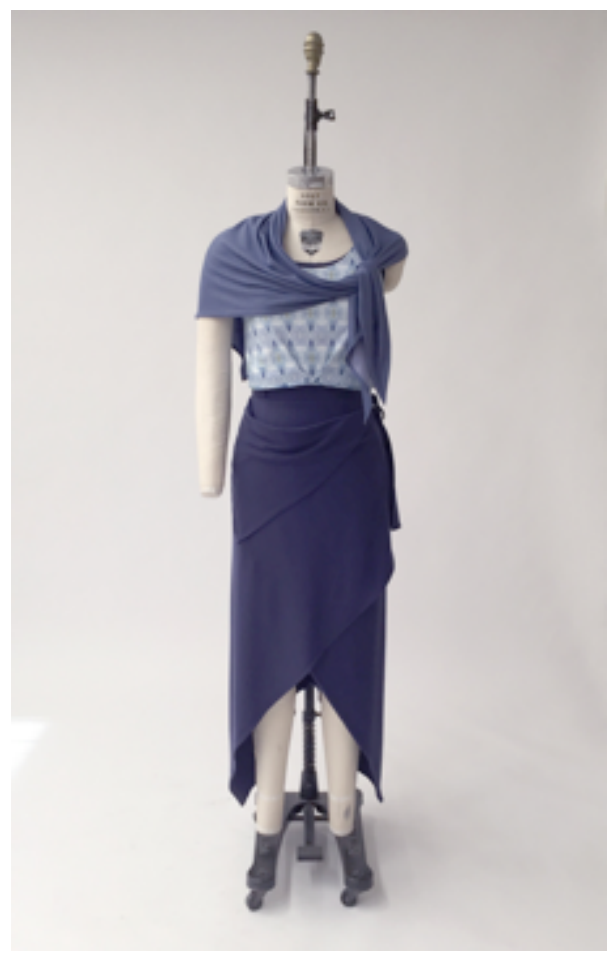

Outfit C

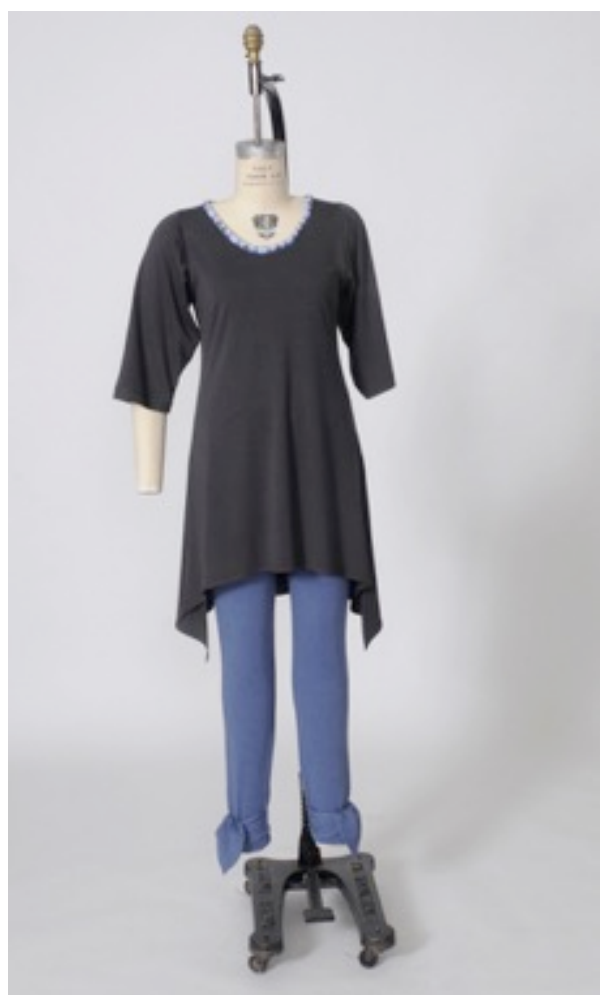

Outfit B

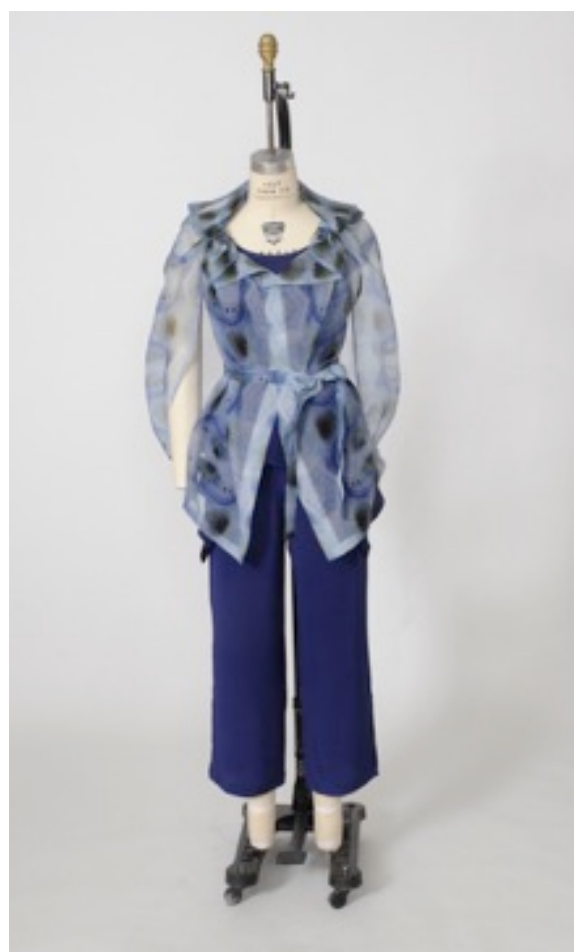

Outfit D

Figure 5-1. The four outfits in the mini-collection. 
Mini-Collection. It was initially decided that a minimum of three outfits would be created to provide an adequate body of work for the participants to evaluate later in the study; however, a total of four outfits was actually designed and constructed to add more variety (Figure 5-1).

The individual garments that comprised the outfits were interchangeable, creating approximately twenty different wearing options for each garment depending on the wearer's preferences (Appendix 1). This was a deliberate design decision because versatility was found to be an important garment characteristic based on the blog data. In addition, bloggers were interested in garments that could be worn together for a number of reasons, including for travel (Une Femme), to form part of a capsule wardrobe (Stephanae), or to downsize a wardrobe (Delilah). This made it essential for the garments that were designed for the a mini-collection to be worn together, in contrast to garments that suited some needs but weren't intended to be worn as a complete ensemble. It was also necessary to develop improvements and/or build in qualities to make garments more inclusive to a range of needs - an objective of the study.

Design scholarship. The apparel designs created for this study, with the exception of one design, all built on current styles and market trends and none of them departed entirely from existing clothing styles. This is not uncommon in the fashion industry: after a style has been accepted by the mainstream, designers will often make modifications to the original designs to create newness and, in turn, prolong the acceptance of a particular style (Ellinwood, 2011). This type of design activity was 
consistent with Pedgley's Model-3 (2007) and was a design decision that was made because it seemed necessary to stay true to styles that boomer women could relate to and then add some element that was new related to inclusive design or aesthetics. The minicollection was developed by the researcher and this included the entire design process beginning from ideation, design development, pattern drafting and/or draping, prototyping, and finally garment construction. The actual construction of the garments was vital to the research and it was also necessary to complete the garments to such an extent that participants in the Evaluate phase felt like they were interacting with a viable product (the clothing), thus providing a more authentic personal evaluation.

Apparel design process. The apparel design process for this study followed the general guidelines presented by the Cambridge Engineering Design Center (EDC) for inclusive design. These guidelines are outlined in the methods section, but are also explained more fully later in this chapter as they specifically pertained to the design process for this study. The garments created for this project were the result of incorporating the inclusive design framework with apparel design practice.

Documentation of the process. Because reflection is acknowledged as a key component in scholarly research that aids the designer in articulating the discoveries made through the creative process (Cross, 2001), reflective analysis was used for sense making throughout this project. Reflective analysis can take many forms, but journaling and digital photography were the methods used in this study to document and reflect on the design process.

Journals. The two types of journals that helped move the design process forward were the idea $\log$ and the process journal. An idea log (Figure 5-2) is a small notebook 
used to jot down random thoughts or ideas as they came to mind, especially during the project's initial phase. It included references, sources of inspiration, notes about future projects, and quick sketches. The notes in the idea log are often partial and unsystematic, and do not always pertain to a specific design project—rather, the idea log is a place for the writer to record and reflect on ideas that come to mind so they will not be lost. It is also an ongoing resource that can potentially generate ideas for future design projects.

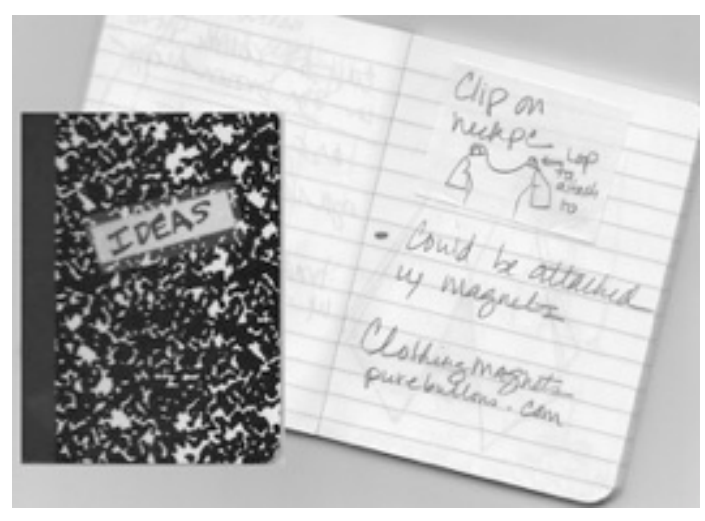

Figure 5-2. The idea log is a place to jot down general design ideas so they are not forgotten.

The design process journal was an additional journal that served multiple purposes and was separate from the idea log. It was a portable sketchbook where projectspecific ideas were stored, including reflections, inspirational photos, research notes and design resources. The design process journal also served as a sketchpad and a place to quickly record spontaneous ideas before they were lost from memory (Figure 5-3, bottom). This was a valuable tool to record serendipitous activity that could potentially to be developed further into viable garments for the mini-collection. The researcher also used the design process journal to work out design problems on paper during prototyping and specifically as a way to brainstorm about possible solutions that combined both sketching and questioning in the form of notetaking (Figure 5-3, top right). In addition, it was helpful for the researcher to map out and create visual connections on paper about 
possible combinations of garments for the mini-collection (Figure 5-3, top left). Because the design process varied by garment, the documentation also varied by garment, as is common in design practice (Pedgley, 2007).
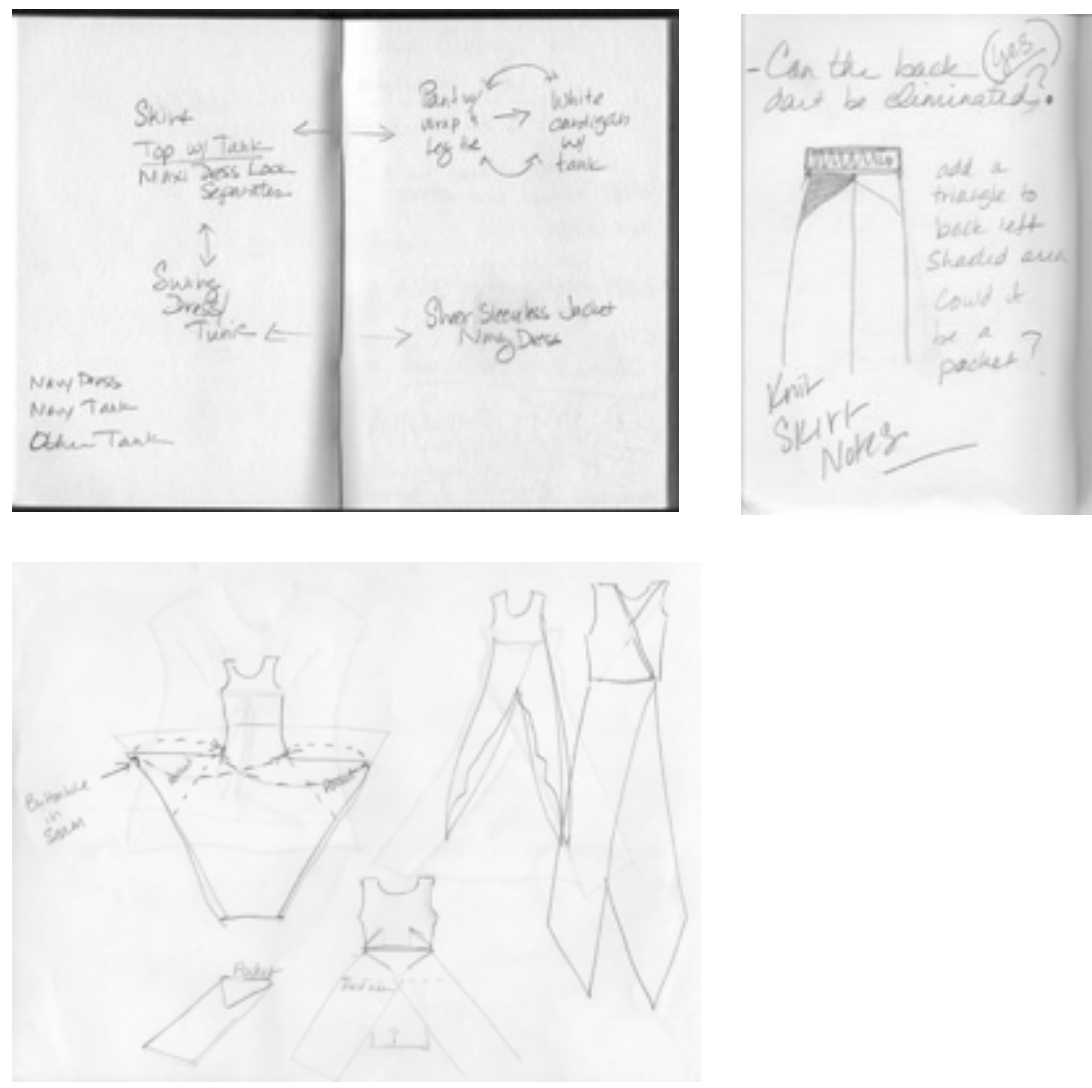

Figure 5-3. Three examples of entries in the design process journal: a mapping activity used in the early stages of planning garment types and their possible relationships to one another (top left); notes and questions put on paper during the prototype development stage of the maxi-skirt (top right); a quick and unperfected apparel design sketch that rapidly recorded several spontaneous ideas before they were lost (bottom). The researcher constantly worked through the design process on paper as a form of brainstorming and as a way to solve design problems.

Digital images. Digital images were used to visually record crucial aspects or unique steps of the design process, particularly in the initial stages of ideation and garment development. Images were used to record draping and patternmaking exercises, record phases of garment construction, and document final outcomes for all of the garments. In addition, a digital image file enabled the designer to later review the process 
to gain a fresh perspective and determine the exact direction in which garment development was headed. Notes in the process journal often corresponded to the digital images, though images were also used without accompanying notes as a form of reference and inspiration.

Digital images were also essential for garments with unique components, or whose design did not follow traditional steps for design development, one example of which was Maxi Skirt \#6, in Outfit C (Figure 5-4). Since the steps for draping the skirt were unique to this garment, a total of forty-one images were taken during the draping process so that the draping steps could be repeated for future prototypes. Because the final garment would be constructed in a knit fabric, a printed knit fabric served as the muslin, Figure 5-4. Draping with a printed knit muslin helped the designer evaluate how both the right and wrong sides of the fabric would appear on the final garment. Because both sides of the fabric would be visible on the outside of the completed skirt, it was decided that a knit fabric that appeared the same on both the front and back would be needed for the final garment.
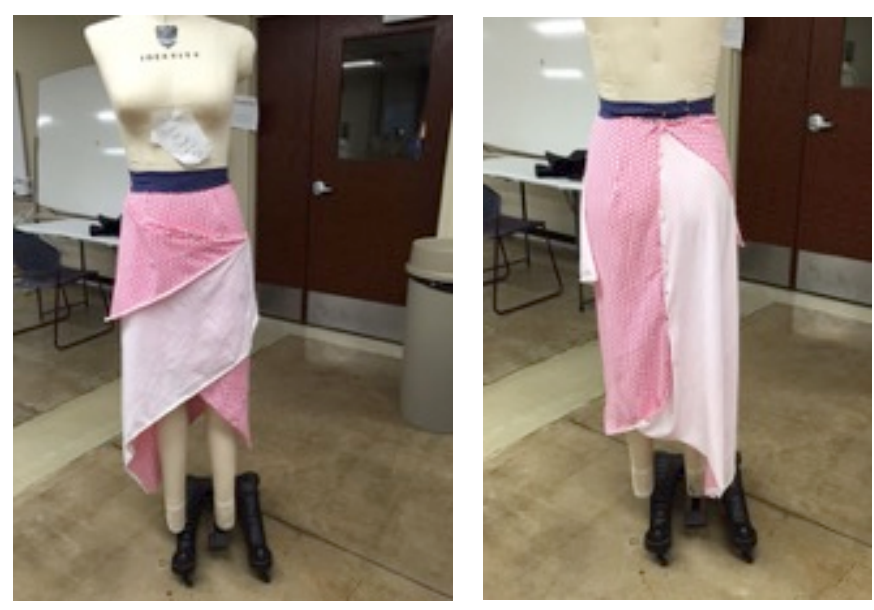

Figure 5-4. The images of the final draped outcome of Maxi Skirt \#6 on the dressmaker form that was stored in a digital file. A total of forty-one images of the maxi skirt were taken during the draping process. 
Garment inspiration. An important step in the design process was to explore and gather information that could provide inspiration for the design of the mini-collection. It is commonly understood that fashion is continually evolving (Keiser \& Garner, 2013), and to maintain a sense of newness, this evolution is often achieved through the addition, modification, or alteration of existing garment silhouettes, styles, and features (Ellinwood, 2011). Exploring ways to incorporate new design features was a suitable approach because it had already been established that women in this age group are interested in stylish and fashionable clothing, in particular creating their own personal styles (Holmlund, Hagman, \& Polsa, 2011; Lee et al., 2012; Thomas \& Peters, 2008). An interest in personal style through the use of clothing was important to the bloggers, and further studies also supported the idea that older women value individuality regardless of their age (Thomas \& Peters, 2009). Inspiration and information gathering was a valuable step because even non-traditional markets like the aging and disabled are interested in products that are aesthetically appealing (Bichard, Coleman, \& Langdon, 2007; Howe 2011). The aesthetic value of the garments was a key concern during the design process. In addition, it was important to maintain an awareness of trends so that the minicollection was perceived as being up to date in terms of current fashion. It was not an intention for the mini-collection to represent cutting-edge or avant garde fashion, nor was it intended to include only basic pieces. The goal was for the mini-collection to represent a range of styles and pieces representing both basic and fashion items.

The information described in the blog texts as well as the images in the posts provided the foundation for design development; this made sense because the purpose was to develop garments that could specifically suit women in this particular age range. If 
a particular blogger repeatedly listed specific brands and/or styles, then a point was made to investigate the brand mentioned, along with their merchandise offerings. For example, since Une Femme and several other bloggers repeatedly listed the Eileen Fisher brand, the Eileen Fisher website and styles were reviewed to provide inspiration during design development. Some of the bloggers also listed brands that specifically catered to an aging market, including Covered Perfectly, Eshakti, and Karina Dresses, and these websites were also reviewed for information.

Additional garment information was derived from current fashion images represented in magazines, catalogs, and on the internet. Several examples included maxilength skirts and tunic dresses, and sheer fabrics layered over opaque fabrics. A file folder was assigned to store hard copy images pulled from magazines and catalogs, and sketches were developed partly based on the photos.

A digital file was also created to store photos and design details found on the internet. These images included garment silhouettes and styles of interest (crop tops, sarongs, ankle-length pants, etc.) that were not geared toward an exclusively older market but that could potentially be adapted to be worn by baby boomer women. As a member of the cohort, the researcher was qualified to identify ideas that could inspire new garment designs for boomer women, and she filtered inspiration ideas that she deemed appropriate based on her knowledge of fashion and apparel design.

Experimentation and exploration. Experimentation was a key part of the initial design development process so that garment components and/or style variations that focused more on aesthetics than function could be incorporated into the mini-collection. 
Sometimes experimentation began with a general idea about a type of garment and then different silhouettes were explored by draping muslin on the dressmaker form. Design decision-making was a continual process that evolved as the muslin was pinned and the fabric was moved around the three-dimensional form. This was the case for the Knit Cardigan \#2, Outfit A (Figure 5-1). Fabric was draped around the form and special consideration was given to the shape and fullness of the sleeve. Fabric was pinned around a foam arm that was attached to the dressmaker form. The arm was raised, lowered and moved about to get an idea about how the garment looked and performed in different positions.

Exploration did not always result in usable ideas for the collection. One example that was not adopted for the mini-collection was the development of a traditional churidar pant pattern that featured fullness at the waistline, a lowered crotch, and a fitted ankle. Though Valerie and Jean posted several images of dropped crotch (harem) pants that provided the initial inspiration for the churidar pant pattern, it was eventually decided that this specific pant style, despite its novel silhouette, would most likely fail to garner acceptance by the majority of women in the study, and it was not developed further for use in the collection. This design decision was made after a consultation with another baby boom cohort member.

Experimentation with fabrics, trims and ornamentation was necessary to develop ideas for interesting or novel design details. One example included pairing different fabrics to create interesting edge finishes: for example, a silk organza printed fabric was cut on the bias and used as an edge finish on the linen Knit Cardigan \#2 (Figure 5-5, left), and a similar cotton print was used to finish the edge on Tunic Dress \#4 Figure 5-5, 
right). A removable magnetic embellishment (right) also resulted through experimentation with jewelry components designed to add interest to a back closure. These elements were then included in garments designed for the mini-collection.
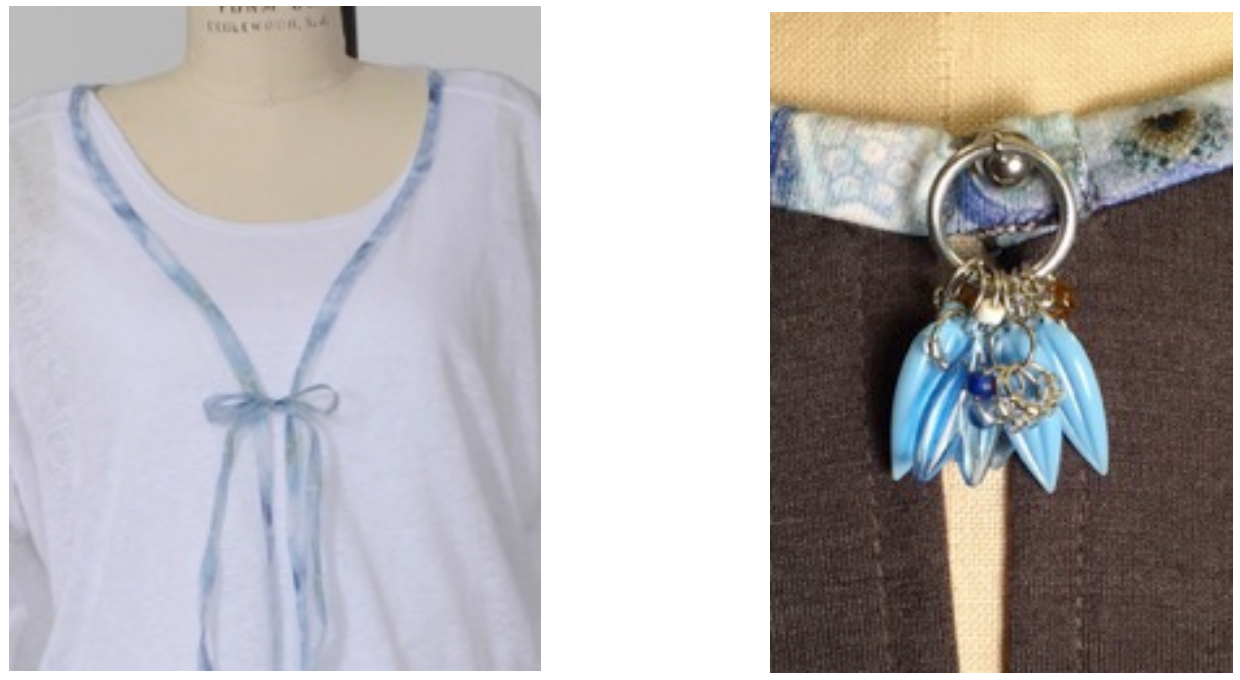

Figure 5-5. Silk organza print edge finish and tie (left) and cotton print edge finish with jewelry embellishment attached to the magnetic closure (right).

Digitally printed fabrics. The literature suggested that print held a strong influence on garment detail, particularly for tops (Howarton \& Lee, 2010), while also exhibiting a desirable aesthetic quality (Eckman, Damhorst, \& Kadolph, 1990). The blog data also supported the bloggers' preference for prints, and since many of the bloggers used printed garments to add interest to their outfits, it was determined that printed pieces would make a fitting addition to the mini-collection. As a side note, while many colors were presented in the blogs, blue was specifically mentioned as a favorite by Stephanae and Susan A, and because blue garments were often included in the blog posts (see Figure 4-13), a blue color scheme was chosen for the prints.

To create unique prints that could not be found elsewhere on the market, one-of-a kind digital printing was chosen for print development. The designs for the prints were 
developed by manipulating an image photographed by the researcher of an architectural detail in the Missouri State Capitol building in Jefferson City. The architectural detail was manipulated in Photoshop and used to create a digitally printed design on silk organza. The print shown in the bottom right of Figure 5-6 was engineered to work within the size constraints of the silk organza yardage so that no fabric would be wasted during the construction of the garment, and was engineered specifically for Sleeveless Jacket \#7 shown in the top left. In addition, another print was created using the lighter colored vertical strip portion of the original print, and this new design was featured in Print Top \#5 (top right).
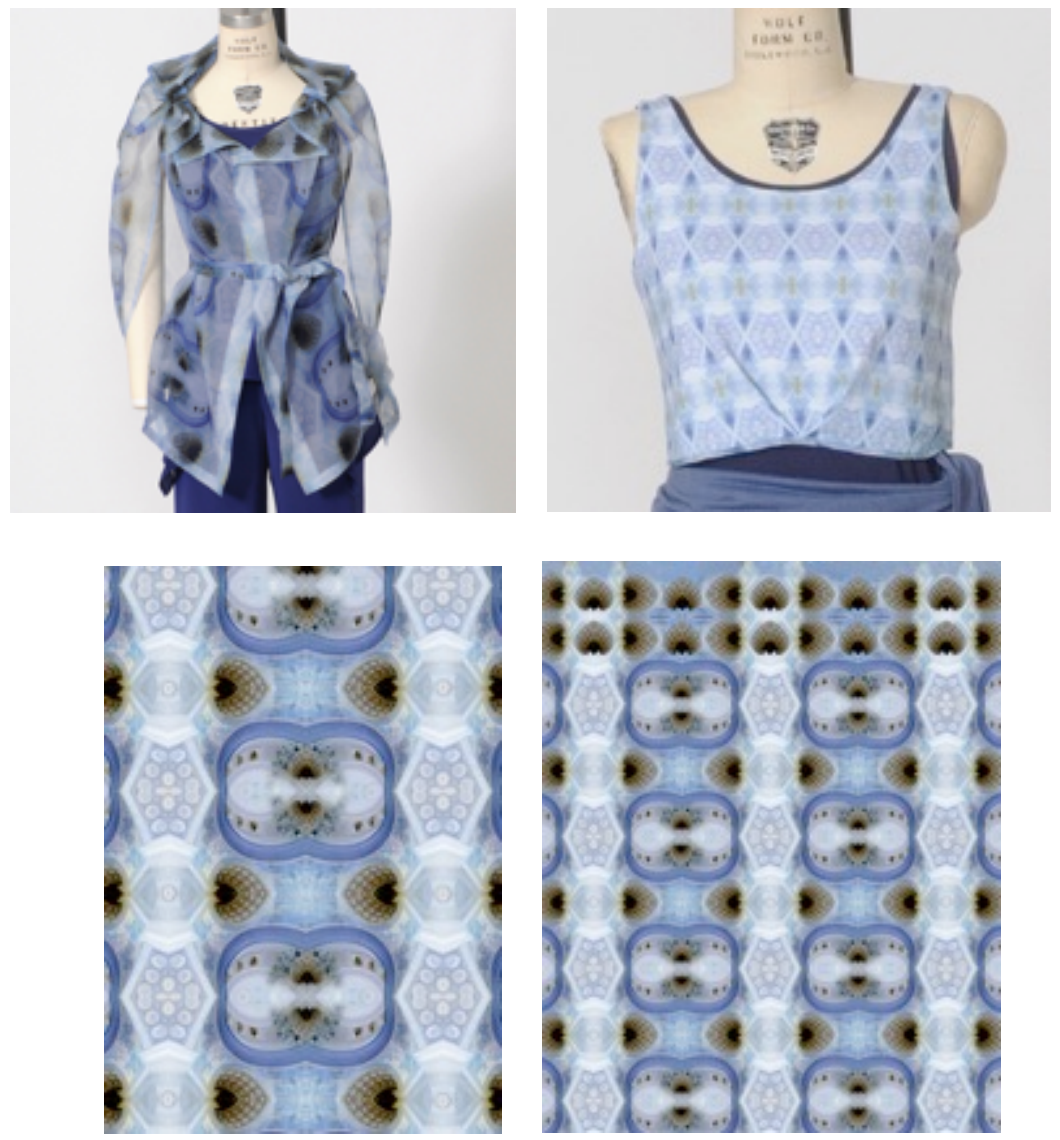

Figure 5-6. Sleeveless Jacket \#7 (top left) features a unique digital print, shown in detail (bottom left) and expanded view (bottom right). A motif in this print also served as a model for Reversible Print Top \#5. The lighter colored vertical strips were used to create an additional print for the reversible Sleeveless Top \#1 (top right). 


\section{Design Objectives}

The general design objectives for the mini-collection are summarized according to the following categories and are based on the review criteria that was developed in chapter four:

1. Garment Types: Information in the blog data was used to guide the actual types of garments included in the collection

2. Style: Unique feature(s) that may appeal to the wearer's sense of style were added and, if necessary, related to a modification of current trends

3. Color and Pattern: Adopted a blue color palette with navy, gray, and white accented with printed fabrics in the same color scheme

4. Fit and Adjustability: Fit ranged from body conforming to body-skimming with options for adjustability in key areas for several garments to aid comfort

5. Comfort: Garments were created from soft fabrics that often incorporated stretch or added ease to avoid restriction

6. Fabric: Incorporated primarily natural fibers that included cotton, cotton polyester blend, and silk

7. Versatility: Identified and developed wearing options to extend garment use

8. Ease of Wear: Garments were designed to be easy to put on and take off, magnets, buttons, and snaps were used as closures

The following section provides examples and images of apparel design solutions related to each of the objectives listed above. 
Garment types. Information in the blog data was used to guide the actual types of garments included. Because fashion is constantly evolving and about change (Keiser \& Garner, 2013), the introduction of new styles and/or garment features is necessary to keep a collection current and this was also a priority when designing the mini-collection. Sleeveless Jacket \#7, a one-of-a-kind design with a unique digital print, was included in the collection to add newness. Maxi Skirt \#6 was based on a current trend, with the draped front designed to be adjusted in multiple ways that changed the appearance of the front hem, an added feature not currently on the market. The rest of the collection incorporated multiple features to add newness to established styles and silhouettes in more subtle ways.
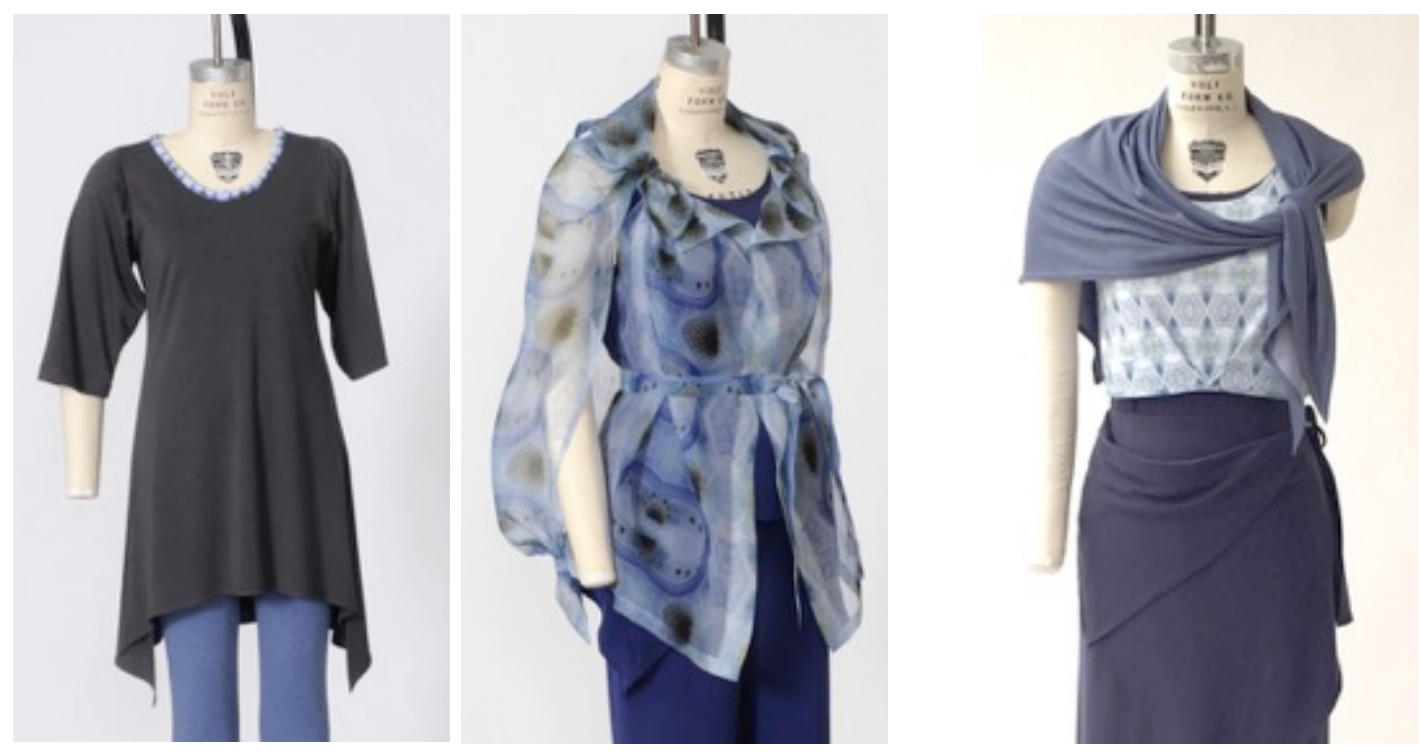

Figure 5-7. Bloggers were interested in apparel options that offered coverage to the arms. Three-quarter length sleeves, sheer coverage and a wrap were three options offered in the mini-collection: Tunic Dress \#4 (left), Sleeveless Jacket \#7 (center), sarong used as wrap with Outfit C (right).

The mini-collection consisted of a variety of garment types and styles that were mentioned by the bloggers in their posts and images. For the most part, blogs were reviewed beginning in the spring; therefore the collection was geared towards spring- and 
summer-wear, with the season also dictating the types of garments designed. Some of the bloggers mentioned that they preferred options for layering or to conceal their arms, so this was taken into account by designing a three-quarter-length sleeve for Tunic Dress \#4. Sleeveless Jacket \#7 was designed to cover the shoulders and arms, and the accompanying sarong could also be used as a wrap to cover accompanying sarong could also be used as a wrap to cover the top part of the arms, as shown in Figure 5-7.

Style. The personal style theme informed garment designs intended to help boomer women project a unique personal style and each of the four outfits included at least one garment that could be altered by the wearer in some way to allow for more versatility and a heightened sense of personal style. For example, Sleeveless Jacket \#7 features a one-of-a-kind print as well as an unusual garment silhouette (Figure 5-6), and Tunic Dress \#4 includes a magnetic jewelry-type embellishment created specifically for the garment (Figure 5-5). Knit Pant \#3 has a detachable sarong and removable ankle ties that allow for a customizable appearance depending on coordinating pieces (Figure 5-8). Unique feature(s) that may appeal to the wearer's sense of style had a dual purpose for several of the garments in order to accommodate the special requirements of some of the bloggers. For example, the magnetic jewelry-type embellishment in Tunic Dress \#4 also served as a magnetic closure that could be easily fastened and unfastened by someone with dexterity issues.

Some garment features were designed to be manipulated based on the wearer's preferences to change the garment's overall look: the hemlines on Tunic Dress \#4, (Figure 5-8, left) and Knit Cardigan \#2 (center) allow them to be tied to change the shape and symmetry of both garments. In addition, the slits and side openings in both pieces 
were designed to accommodate both standing and seated positions. Since longer garments have a tendency to bunch up while the wearer is sitting, creating slits and openings allowed for adjustment and while these options could be useful to someone in a wheelchair, they also create the potential for different styles within the same garment for all users.
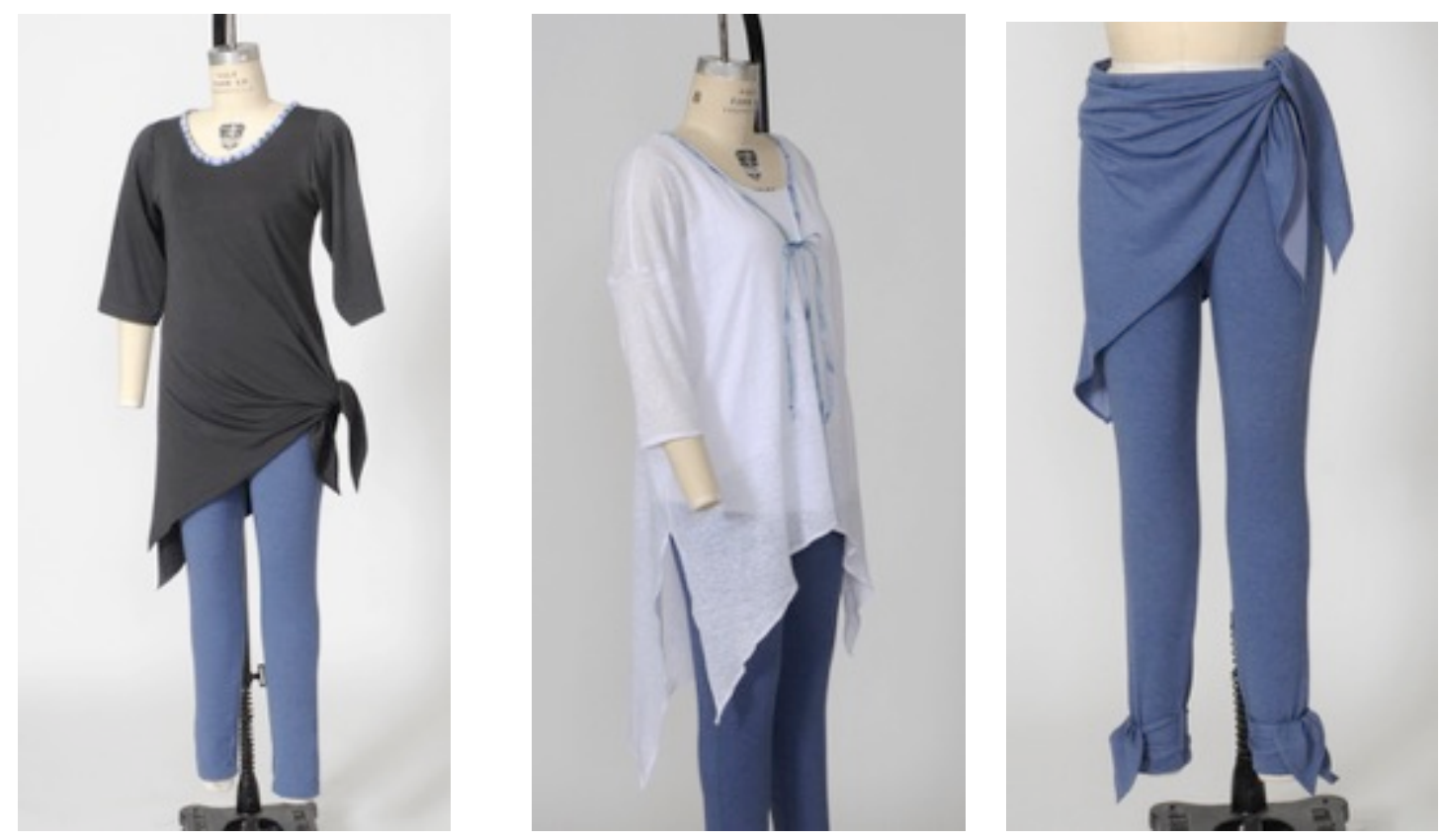

Figure 5-8. Three examples of garments whose appearance modified by tying: Tunic Dress \#4 (left), Knit Cardigan \#2 (center), and Knit Pant \#3 (right).

Careful consideration was given to proportion and scale, specifically related to two trends that were part of the inspiration-gathering portion of the design process. Reversible Top \#5 (Figure 5-6) was designed to be fitted at the bust and slightly looser in the upper torso with the bottom of the top hitting at the top of the waistline. The crop top trend was discovered during exploration and included to add newness to the collection. The look was modified because it was paired over a fitted navy tank for additional coverage and the top was fitted at the bust and designed to be slightly fuller at the waistline. The top was paired with the long, navy Maxi Skirt \#6 in Outfit C 
(see Figure 5-1) that played off of the maxi dress trend, a carryover from prior seasons that was also presented in the blogs. The front draped portion was designed to conceal the abdomen, and the longer skirt silhouette was intended to create the illusion of a longer leg line. These two pieces were specifically added to the mini-collection because bloggers had indicated that they were interested in current trends with modifications to accommodate an aging market.

Disabled bloggers and specifically bloggers in wheelchairs were interested in modified trends to suit their needs, one example of which was Alicia's desire for a top shortened in the front to more easily accommodate a seated position. Sleeveless Swing Top \#9 was designed specifically to be shorter in the front and longer on the sides to accommodate both a standing and a seated position, as well as potentially camouflaging the hip area when standing (Figure 5-9), while Reversible Print Top \#5 was designed to fit a seated wearer by hitting at the waist when in a seated position so as to not add bulk.

Color and print. As stated earlier, many of the bloggers listed blue as a preferred color, which led to the mini-collection revolving predominantly around a blue color scheme that featured navy, gray, light blue, and white along with different shades of blue ranging in hue and intensity. Developing the collection around a blue color scheme to tie it together as a whole made sense because many bloggers preferred the more subdued nature of the color blue (despite many of the bloggers' discussions of color, they often dressed in black and white and neutrals, as is evident in many of the images in chapter four). Digital prints were developed to add interest to the collection, as seen in the prints for Reversible Print Top \#5 and Sleeveless Jacket \#7 described earlier in this chapter. 


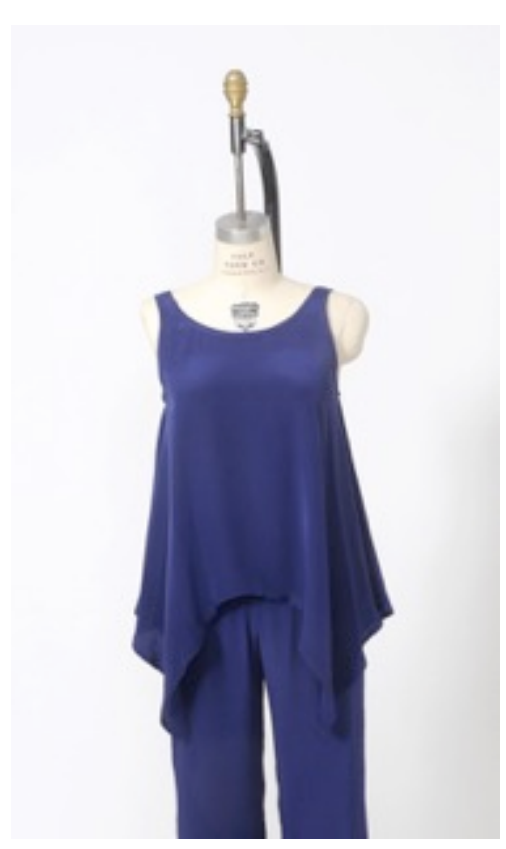

Figure 5-9. The length in the front of Sleeveless Swing Top \#9 was modified/shortened to be appealing to both wheelchair users and non-wheelchair users. A shorter length was described as desirable by blogger Alicia for a more streamlined appearance in the front while sitting in a wheelchair.

Fit and adjustability. Most garments in the collections were intended to be body skimming - fitted, but not overly tight. Two exceptions were Knit Cardigan \#2 and Sleeveless Jacket \#7, which were deliberately designed to be oversized and accommodate a range of sizes. Oversized pieces were combined with fitted pieces since such pairings were repeatedly present in the blog images. Finding garments that fit well was also a challenge for many of the bloggers, which suggested adjustability as a desirable garment quality to allow for a somewhat customized fit. In addition, adjustable features have the potential to impact comfort as well as fit: Knit Cardigan \#2 had tying options (discussed earlier) that allowed the wearer to not only change the look but also adjust the fit. This garment was oversized and one size fits most. Sleeveless Top \#1 also featured a shoulder strap that could be loosened and untied to adjust fit or aid in putting on or removing the 
garment if loosened and extended fully (Figure 5-10). The adjustable waistband in Knit Pant \#3 also allows for some size variation.
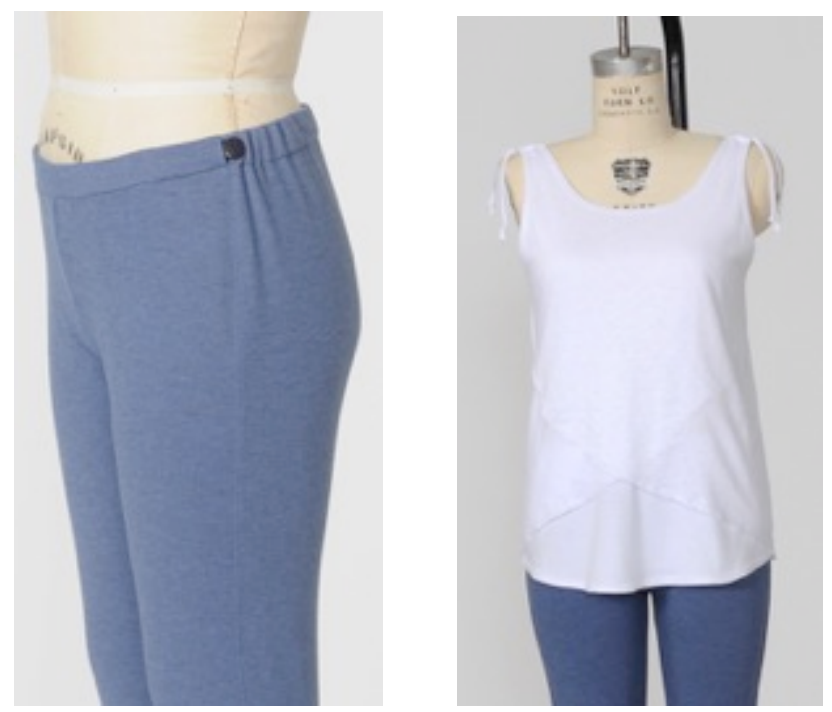

Figure 5-10. Garments that include features that allow adjustment in fits. Knit Pant \#3 (left) includes an adjustable waistband, while Sleeveless Top \#1 (right) has an adjustable shoulder tie.

Comfort, fabric, and ease of wear. An ongoing interest in comfort was addressed by paying special attention to the fiber content of the garments designed for this collection, which led to the use of a linen knit, cotton knit, cotton/rayon/spandex knit, cotton/polyester/rayon knit, and silk charmeuse. The fabrics were soft to the touch and three of the outfits included fabrics that stretched. Both pairs of pants in the collection feature elastic waistbands for comfort, with Knit Pant \#3 also including an adjustable waistband to accommodate variations in size.

The garments in the collection were designed to be inherently comfortable, making simplicity in the design a necessity — a guiding principle outlined in inclusive design. Several of the bloggers had dexterity limitations and mentioned the need for oversized buttons, hidden side zippers, and magnetic clasps. Not only were these needs taken into consideration, the principle to simplify was also a key factor, with garments 
predominantly designed to be pulled on. The garments designed for the mini-collection did not require zippers or buttons, with the exception of the adjustable waistband on the knit pant that did not need additional fastening once adjusted. As discussed earlier the tunic dress also had a magnetic closure.

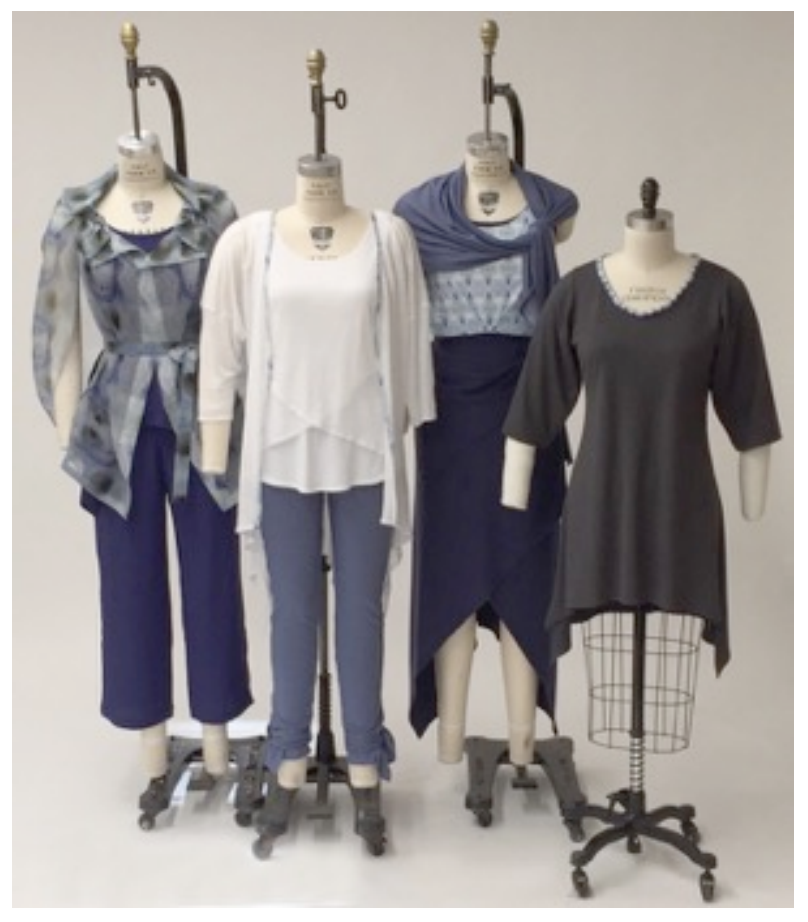

Figure 5-11. Coordinating pieces in the mini-collection creates what one blogger identifies as a capsule wardrobe.

Versatility. Versatility was important to many of the bloggers and specifically for Stephanae, a vision-impaired woman. Stephanae suggested a capsule wardrobe to make dressing more manageable because garments in the capsule wardrobe could work well with one another and be modified or layered to alter the wearer's overall look. The minicollection was thus comprised of versatile and interchangeable pieces that color coordinated to simplify dressing and potentially solve problems related to color matching.

Several bloggers mentioned pockets as a desirable way to make garments more versatile, and while the inclusion of pockets within at least one outfit was a priority, 
careful consideration was given to pocket placement on corresponding garments to avoid bulk. Pockets were added to Sleeveless Top \#1 and omitted from the accompanying Knit Pant \#3 so as not to add additional bulk where the two garments were worn together. This was important because bloggers such as Alicia and Charlotte mentioned excess bulk as undesirable.

\section{Apparel Design Process Using the Inclusive Design Framework}

As noted in the methods section, an inclusive design framework was used to guide the study. In order to clearly identify the inclusive design steps, they are presented here as a separate section and each of the ID phases will be reviewed as they pertain to different parts of the study.

The EDC inclusive design toolkit outlined a general design process and provided tools and resources to assist with inclusive apparel designs for this study. The ID process is a concept driven approach that included four phases, identified as Explore, Create, Evaluate, and Manage. Each of the phases will be outlined here, including principles to consider and an overview of the activities included in each phase. The principles are key points to consider within each phase and at times some of the principles were not applicable to apparel design. Stakeholders are often mentioned in ID: aside from the end users, stakeholders include regulators, shareholders, manufacturers, retailers, purchasers, installers, supporters, and maintainers. Since it was not the researcher's intention to manufacturer the prototypes at this stage, end users were the only stakeholders included in the activities performed for this study, and they include baby boomer women. 
Before reviewing the four phases, it is important to reemphasize that user diversity - that is, the "full range of ability variation" within the group of users - is the foundation for ID (University of Cambridge, 2013). The EDC website explains that typically, people are viewed as being either able-bodied or disabled, with products being designed for one category or the other. In fact capability varies continuously, and reducing the capability demands of a product results in more people being able to use the product and improves the user experience. (University of Cambridge, 2013)

This study used the blog data to better understand user diversity among women who fall within the baby boomer age range and who exhibit a range of abilities and needs. However, it is important to again note that inclusive design does not include specialized design solutions catered to specific disabilities, making simplicity a key focus of the design process rather than implementing customized disability solutions for each garment. To better cater to the diverse abilities and needs of baby boomer women, the goal was to design only those features that were necessary or that fit the needs of most.

Manage stage. The manage phase in ID encompasses all phases of product design and is used to keep projects moving forward and on budget. The guiding question for the manage stage was, What should we do next? It is important to note that all of the stages reviewed here were interrelated to some extent, and some stages were revisited multiple times during the design process. This is particularly true of the manage stage. The guiding principles for this stage emphasized flexibility in exploring the previous phases to refine the product and meet the maximum number of user needs. Activities 
listed in the manage stage are review progress \& plan next steps, refine product goals, build business case, and ensure common understanding.

Review progress and plan next steps. Reviewing and planning took place throughout the entire project, and while planning specific garment designs was valuable, it was secondary to the design of the outfits as a whole. It was also necessary to consider how the outfits related to one another to create a unified mini-collection. Because this chapter has outlined the apparel planning and development process in detail for the project, additional discussion will not be included here.

Refining product goals. A goal of this study was to identify ways to design more inclusively for an aging baby boomer market. Suggestions and recommendations are included in the final chapter and lay the foundation for refining product goals.

Build a business case. This activity is not applicable to this study because the garments designed were not intended to be produced on a larger scale, meaning that profitability was not a concern at this point. It would be of concern when and if the prototypes were developed for production.

Ensure common understanding. Vital to the success of most projects is clear communication and a mutual understanding of the project goals. Because this project was not a team project in the traditional sense, this was not applicable to this study.

Explore stage. The guiding question of the explore stage was, What are the needs? During this initial stage, five activities were presented as possible tools to aid in identifying user needs: creating a stakeholder map, observing users, generating personas, describing user journeys, and listing needs. The principles to keep in mind for this phase were: It's normal to be different, and detail matters. 
Create a stakeholder map. This consisted of making a list of the people potentially involved with the product, which for this study included women who fell approximately within the boomer range, who were interested in fashion and style, and who may exhibit a range of abilities. Information provided in Table 4-1 summarizes the demographic information for the bloggers and provides a detailed list of stakeholders in this portion of the study. Baby boomer women who evaluated the garments were also considered stakeholders and their demographic information is included in chapter six. As stated previously, other stakeholders besides end users were not included in this research.

Observe users. The blog posts and images provided an appropriate avenue to observe the bloggers. Both images and written texts were equally important, and together they helped to provide a more detailed account that included what the individual was saying within the text and showing within the images.

Generate personas. The purpose of this activity was to summarize the key users for the apparel. The EDC provided examples on their website in which personas were differentiated by age groups and this initially served as a guide for the process. Four personas were created for this study; each one features a blog writer(s) and is identified here by age cohort: pre-boomers, age 40-50 (Nicole); late boomers, ages 51-60 (Stephanae); leading-edge boomers, ages 61-69 (Valerie and Jean); and post-boomers, ages $70+$ (Judith). A profile picture and brief description were included in the persona chart summarizing each persona's general approach to aging and fashion. These summaries were written about the bloggers by the researcher as a way to compress and recapitulate their needs. It was a goal to represent a range of fashion approaches as well 
as a range of abilities in the personas, and the Personae Chart of bloggers can be found in Appendix 2.

Describe user journeys. This activity was provided to aid in identifying how the product would be used over a span of time that included purchasing, using, and disposing of the item. While this activity was not particularly applicable to this study, it provided the opportunity to reflect on the study's purpose, which was to develop ways of designing apparel to be more inclusive to a range of needs and specifically for an aging market. Identifying the needs and providing solutions could potentially create more positive user journeys in the future.

Capture needs list. This activity was designed to help designers better understand user needs and the reasons behind those needs. An extensive summary of the blogger preferences was described in chapter 4 and was a part of the data analysis process that helped to identify the bloggers' needs. Considering and developing a list of why the bloggers may have certain needs was a separate part of this activity.

Review criteria. An essential part of this phase was the development of the review criteria that aided in the evaluation of inclusive products and was outlined in chapter four. The review criteria was a direct outcome of the needs identified during this phase and specifically from the blog data analysis. The review criteria was based on the needs and the general apparel product qualities that were considered the most important from the blog data were garment types, style, color/pattern, fit, comfort, fabric, versatility, ease of wear and appearance with consideration to closures and modifying trends to suit the needs of an aging population. The review criteria guided the apparel design process earlier in this chapter and was used in the Evaluate phase of the study. The review criteria 
evaluated the concepts and then later the prototypes to make sure that the designs were meeting the needs for inclusive apparel designs.

Create stage. The guiding question for the create stage was, How can the needs be met? The create stage utilized the information compiled during the explore stage to develop solutions to meet the needs. This stage was broken down into three activities, identified as stimulate ideas, develop concepts, and make prototypes. Key principles to consider were to strive for simplicity, challenge assumptions, and let ideas breathe (University of Cambridge, 2013).

Stimulate ideas. A goal for this activity was to stimulate as many ideas as possible while avoiding decision-making too early in the process. Unusual ideas or solutions were encouraged, and ideas were documented as they surfaced. The inspiration files and sketches listed earlier in this chapter were instrumental to this activity and aided in the brainstorming process. Because EDC recommended developing creative environments to encourage new ways of thinking, design solutions were pondered while walking, biking, or people-watching, with the idea log noted earlier serving as a place to jot down spontaneous ideas.

Concept development. Concept development occurred when ideas were combined to find solutions. Specifically for this study, design concepts informed the development of initial prototypes that offered possible solutions to different combinations of needs identified by the bloggers, and it was determined that the most successful solutions would address a combination of needs that were not exclusive to ability issues. As discussed in chapter two, aesthetic qualities can both set a product apart and add to a product's 
acceptance, making the consideration of aesthetics a vital part of apparel design development during this stage.

Concepts were developed from the four themes discussed in chapter four and were personal style, self-concept, health \& ability, and apparel preferences \& garment characteristics. The themes were clearly connected and overlapped, which guided concept development and problem-solving for inclusive design. It was crucial that garment designs should enhance personal style, which would in turn aid in creating a positive selfconcept for baby boomer women. Health and ability concerns were noted and seriously considered as they related to the apparel preferences and garment characteristics mentioned as desirable by the bloggers.

Make prototypes. The final activity in the create stage was to make the prototypes to aid in demonstrating the inclusive design solutions. A prototype, according to the EDC, refers to visual communication of a basic idea, and could take the form of a rough sketch, model, or computer presentation. For this study, images of garments presented in the blogs provided a starting point to help generate new garment ideas. Next, patterns were developed and fabric muslins were sewn to work out design problems before the actual garments were constructed. The following list illustrates the process that led up to and includes prototype development using the basic Knit Pant \#3 as an example:

1. Observed the fitted pants that bloggers wore and wrote about in the blogs

2. Gathered information about current pant trends from the internet, magazines, and catalogs

3. Explored different pant silhouettes to include a pajama pant and haram pants

4. Experimented with waistband width and adjustment options 
5. Decision making resulted in the selection of a fitted pant silhouette that was chosen to stay true to the bloggers' preferred style

6. Developed a basic fitted knit pant muslin that allows for fit adjustment at the waist

7. Evaluated muslin using the review criteria to assess strengths and weaknesses

8. Tried the pants on to evaluate fit and comfort and to experience firsthand how they felt on the body in a variety of positions, including sitting, standing, and walking

9. Listed, sketched, and discussed options with advising faculty to develop additional features to make pant more versatile (deemed important by bloggers), including modifications to the current waistband to allow for easier adjustment

10. Fabric selection for final pant included an extra-soft cotton blend pant with stretch properties

11. Experimented with additional fabric to explore different options and combinations for new features at the ankle and waist, repeat steps five through eight

12. Developed actual pant prototype to include new design solutions such as removable ankle ties and a removable waist wrap/sarong

It was necessary to allow time between steps for ideas to fully formulate. Simplicity was a priority in the design of the pant, and during the process it was important to consider alternatives to a basic pant design that would not compromise simplicity in design or wear. As stated earlier, different silhouettes such as harem pant styles were explored, but the basic fitted style was chosen because it was overwhelmingly the bloggers' favorite 
and would be the most versatile. The decision to include additional removable features added a unique component to the pant without dramatically changing the basic silhouette.

Once the prototypes were developed, it was necessary to evaluate the designs and the next phase of ID directly informed the evaluation process. A review of the Evaluate phase and the activities within the phase will provide the needed background information to better understand the next part of the study. A review of the Evaluate phase follows.

Evaluate. The guiding question for the evaluate phase was, How well are the needs met? Activities included review criteria, tests with experts, tests with users, estimate exclusion, and presenting of evidence. Principles to keep in mind during this phase were to test the prototypes often, with experts and users, to make the necessary changes when needed. The apparel designs are based on evidence of the needs and are included in the review criteria. Finally, it was essential to be creative during the process.

Review criteria. ID places importance on setting and reviewing the criteria for determining whether a product was successful. Chapter four outlined how the review criteria was developed based on the bloggers' needs and chapter five demonstrated how the review criteria related to the objectives that guided the apparel design process. The review criteria also aided in the evaluation of the garments for the study. A discussion of the role of review criteria within question development is included in chapter six.

Test with experts. The evaluate stage was an important step in the ID process at two different points in the study. During the make prototypes activity, it was important to get feedback to further refine ideas before boomer women evaluated the outfits later in the study. Both the designer and a boomer-age model tried on the garments to evaluate them during and after garment construction. The advising faculty member also provided 
feedback during different stages of construction, including after the garments were completed.

Test with users. Because it is beneficial to obtain feedback from actual product users in order to better meet the needs, the last part of the study was designed to provide baby boomer women the opportunity to interact with and evaluate the apparel designs.

Estimate exclusion. An additional activity recommended in this stage was the estimation of user exclusion. The ID toolkit provided an exclusion calculator that enabled the product designer to estimate user exclusion related to the physical demands products may place on vision, hearing, thinking, dexterity, reach, stretch, and locomotion. This tool has potential value for apparel designers, though some adaptations to the calculator are needed to better determine the amount of exclusion related specifically to clothing. In general, the calculator enabled the researcher to estimate the degree to which someone may be excluded by answering questions about the degree of difficulty experienced in wearing a garment. The calculator transferred this information into usable data in the form of a percentage of exclusion with regard to both the overall physical demands on the user and population percentages of user exclusion. An example of the information generated about Sleeveless Top \#1 in this study can be found in Appendix 3. The chart shows the percentage of the population excluded from wearing this garment, with the result that no one within the age range (51-69) and sex (female) studied was excluded because the top was intended to be pulled on and did not require a closure. Garments like the knit pant that required an initial size adjustment using a button may potentially exclude some individuals with limited dexterity. 
Present the Evidence. This activity draws from the other activities and specifically the review criteria. Because the review criteria is based on the baby boomer women's needs, the review criteria is a helpful tool to systematically evaluate whether the needs had been met. This activity included recommendations for the next course of action related to the product design, and will be described fully in the last chapter.

The purpose of this chapter was to clearly describe the apparel design process for this study and to identify how the inclusive design framework informed the development of apparel solutions intended for baby boomer women. In the case of inclusive design, the steps that lead to the apparel designs were as important as the outcomes. This was because it was necessary to understand the increasing needs of an older market and then to develop solutions based on those needs in such a way that they were aesthetically pleasing. Additionally, the inclusive design framework challenges the apparel designer to include features that will satisfy a broad range of needs that also includes individuals with limitations. The next step in the study was to evaluate how well the apparel designs actually met the needs of baby boomer women that could potentially wear the garments. This was a part of the Evaluate phase of inclusive design and is described in detail in the next chapter. 


\section{Chapter 6 Garment Evaluation}

Evaluation is a critical stage in apparel product development as well as in the development of inclusively designed products using the inclusive design framework. The Evaluate phase of the study was necessary to assess how successfully the inclusive garment prototypes satisfied baby boomer women's needs. In addition, evaluating the garment prototypes to obtain feedback from baby boomer women regarding functionality, desirability, and inclusivity with a range of needs was a primary objective of this study.

To evaluate how successfully the garments met these needs it was vital to have actual baby boomer women provide their feedback about the completed apparel designs. This allowed the researcher to triangulate the data about clothing preference from the blogs in the Explore phase to obtain a richer understanding of the wearers' needs. The Evaluate phase is an ongoing process and does not end with this evaluation of the garments because the feedback gained from evaluation will aid in developing improvements to the prototypes. Prototype development is a critical stage in apparel design, and it is not uncommon for adjustments and improvements to occur multiple times before a design is perfected and approved for final production (Keiser and Garner, 2013). It is a necessary step in the apparel design process that will aid in developing solutions to meet the needs of an aging population.

\section{Review of the Sample}

Participants in this study were women who were interested in fashion and fell within the baby boomer age range. Upon confirmation of IRB approval, the women were recruited at the University of Missouri and from the Columbia, Missouri community. Fliers were distributed by hand on campus as well as throughout the community, and 
additional contacts were made through emails that included the study flier shown in Appendix 4. Women were recruited by word-of-mouth recommendations from women who intended to participate in the study, and women with a range of abilities were encouraged to participate to provide additional perspectives.

\section{Demographics}

Ten women participated in the study, ranging in age from 51 to 65 . One woman was in the leading-edge boomer cohort and was born between 1946 and 1954 and nine of the women were in the late boomer cohort and born between 1955 and 1964. Nine of the women identified as Caucasian and one woman listed her ethnicity as Caucasian/Hispanic. Eight participants recorded their highest level of education as college; one listed technical, trade, or two-year school; and one indicated high school. Five of the participants were married, one indicated her marital status as single, and four specified that they were divorced or widowed. Six participants were employed, one was unemployed, two listed that they were retired, and one added an additional category and indicated that she was not able to work because she was disabled. When asked about limited or declining ability, five participants did not check anything on a list provided that included vision, hearing, thinking, communication, reach and stretch, dexterity, and mobility. Four participants recorded a range of declining abilities that are included in Table 6-1. 


\begin{tabular}{|l|l|l|l|l|l|l|}
\hline Participant \# & Age & $\begin{array}{l}\text { Race/ } \\
\text { Ethnicity }\end{array}$ & $\begin{array}{l}\text { Level of } \\
\text { Education }\end{array}$ & $\begin{array}{l}\text { Marital } \\
\text { Status }\end{array}$ & $\begin{array}{l}\text { Employed } \\
\text { (Yes, No, or } \\
\text { Retired) }\end{array}$ & $\begin{array}{l}\text { Limited } \\
\text { or declining } \\
\text { Ability }\end{array}$ \\
\hline One & 60 & Caucasian & College & Married & Yes & None listed \\
\hline Two & 59 & Caucasian & College & Divorced & Retired & $\begin{array}{l}\text { Vision, hearing, } \\
\text { thinking, mobility }\end{array}$ \\
\hline Three & 57 & Caucasian & $\begin{array}{l}\text { High } \\
\text { School }\end{array}$ & Divorced & Retired & None listed \\
\hline Four & 57 & Caucasian & College & Divorced & Yes & None listed \\
\hline Five & 55 & $\begin{array}{l}\text { Caucasian/ } \\
\text { Hispanic }\end{array}$ & Technical & Single & $\begin{array}{l}\text { Disabled } \\
\text { (not } \\
\text { employed) }\end{array}$ & $\begin{array}{l}\text { Communication } \\
\text { Dexterity } \\
\text { Mobility }\end{array}$ \\
\hline Six & 59 & Caucasian & College & Married & No & None listed \\
\hline Seven & 57 & Caucasian & College & Married & Yes & None listed \\
\hline Eight & 56 & Caucasian & College & Married & Yes & Hearing \\
\hline Nine & 51 & Caucasian & College & Divorced & Yes & $\begin{array}{l}\text { Hearing } \\
\text { Dexterity }\end{array}$ \\
\hline Ten & 65 & Caucasian & College & Married & Yes & None listed \\
\hline
\end{tabular}

Table 6-1. Demographic information for study participants in Phase Three.

\section{Procedures for Garment Viewing by Research Participants}

Study location and room setup. Gwynn Lounge in Gwynn Hall, located on the University of Missouri campus, served as the location for the Evaluate phase of the study. The lounge was situated so that participants entered through a single entrance that was videotaped to record initial responses. The lounge included an open space to display the outfits as well as multiple seating options if needed. Four outfits that included a total of nine garments were displayed on four dressmaker forms (Figure 5-11) and placed in such a way that allowed for movement and interaction with the garments. The arrangement of the individual garments on the forms to create outfits was a design decision made by the researcher and may have created a preconceived idea about what pieces were intended to be worn together. A poster set up near the outfits provided images of twenty clothing options (Figure 6-1, top), and in addition, information sheets were displayed on a board near the garments where participants could review additional information about garment 
characteristics and features (Figure 6-1, bottom). A large screen located in a prominent location played a continuous, looped video recording of the modeled garments in motion.

Static video images of the modeled garments are available in Appendix 5.
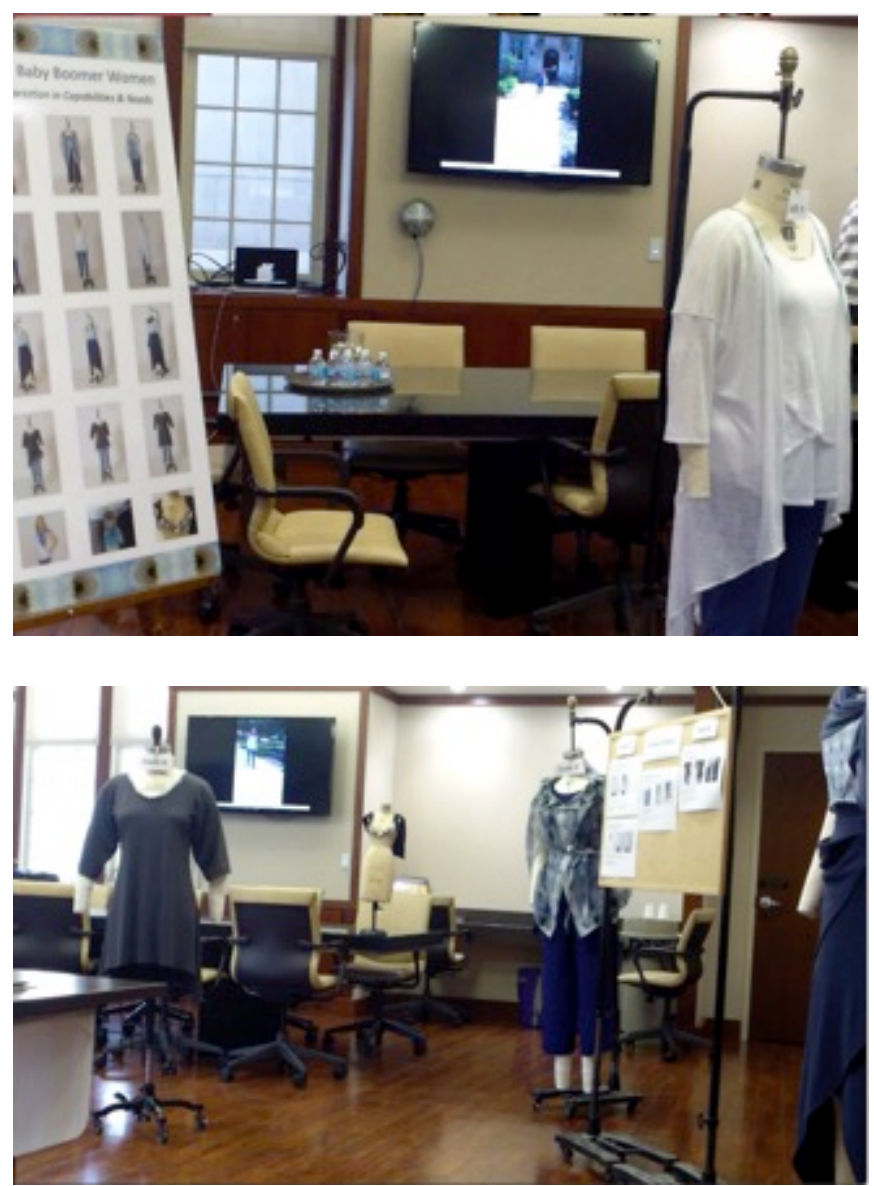

Figure 6-1. Two separate angles of the room setup facing away from the door. Note the poster showing different clothing options (top) and the board listing garment characteristics and features (bottom).

Two video cameras were set up to capture both audio and video documentation. A videographer initially set up both cameras and then periodically made adjustments to their locations and angles throughout the evaluation process to capture activity in the room. This was beneficial because the evaluation process was not static and participants moved freely about the room to gather information and make their evaluations. 
Participant consent. The researcher initially directed participants to a table located outside the lounge where prior to entering the room, participants were required to read and sign the IRB approved study consent form outlining the background, procedures, risks, compensation, confidentiality, and voluntary nature of the study. A copy of the consent form is available in Appendix 6.

Questionnaire distribution and evaluation process. Once consent was obtained, participants were escorted into the lounge by the researcher. The general room setup was explained to each participant with the four outfits, the clothing options poster, the information board, and the video identified. A questionnaire was distributed to each participant along with a clipboard and pen, and participants were encouraged to touch and interact with the garments during their evaluations. Participants were also urged to ask questions to clarify any part of the garment evaluation process at any time. Questionnaires were completed anonymously and contained no identifying marks that could connect a participant with a particular questionnaire. Upon completion, the questionnaires were put in an envelope and securely stored prior to data analysis.

In addition to the researcher, a University of Missouri graduate student was on hand as a backup to assist with general questions and to provide clipboards and questionnaires. Chocolates and bottled water were provided for participants as they navigated the room and participated in the study.

Participants worked on the questionnaires at their own pace, generally viewing the video first and then proceeding through the questionnaire while evaluating the individual outfits. This was a general observation made by the researcher that was also recorded in the video. Participants periodically stopped to examine both the information board that 
provided additional garment details and features as well as the poster of clothing wearing options. The evaluation process varied somewhat depending on what worked best for the particular participant.

After the evaluation session began the researcher divided her time between remaining outside the door to greet new participants and entering the room to see if there were any questions or concerns. At one point during the evaluation, several participants were discussing a garment amongst themselves and the researcher's appearance prompted a pause and a lapse of conversation. The researcher then decided to maintain a slightly more distanced presence in the event that she might affect the participants' comfort levels and the depth or sincerity of the needed responses. In general, however, the study participants worked independently with minimal amounts of conversation and limited interactions amongst themselves.

An exception to the overall evaluation process involved one of the participants (a wheelchair user) who also had significant limitations in both speech and dexterity. This necessitated additional help from the graduate assistant to read and clarify questions as well as to record the answers on the questionnaire for the participant. This created some initial distraction in the room, though it did not appear to visibly alter the other participants' actions in any way. By this time the majority of the participants had already entered the room and begun the evaluation process, so managing the atmosphere in the room was not a problem for the researcher.

The amount of time that the participants spent on the evaluations varied dramatically. Some participants stayed almost the entire two hours allotted for the evaluation, significantly longer than the estimated forty-five-minute completion time 
listed on the flier. Participants who arrived during the second hour of the scheduled time period generally spent less time on the evaluation, with one participant arriving within a half hour of the end time and moving through the evaluation process at a faster pace.

\section{Data Collection Methods and Research Instruments}

Semi-open questionnaire. The semi-open questionnaire was developed using Gillam's guidelines outlined in chapter 3, and was designed to collect opinions and preferences from boomer women specifically about the inclusive garments designed for the study. The questionnaire was divided into three sections. See Appendix 8 for an example of the entire questionnaire.

For review, question development was based on the review criteria developed from the four themes that emerged during the Explore phase of ID and created from the bloggers' needs identified in chapter four. The review criteria is a tool to aid in evaluating inclusively designed products, which for this study were the apparel designs. The first section of the questionnaire included boxes with prompts to guide feedback about the individual garments that were evaluated, and participants were instructed to record their reactions and opinions about the individual garments related to the prompts. Prompts were developed to elicit specific types of information about the garments (Gillam, 2005). Table 6-2 is an example of a single set of prompts for one specific garment, Sleeveless Top \#1 from Outfit A. 


\begin{tabular}{|l|l|}
\hline Outfit A: Garment \#1 Sleeveless Top & Your Opinions Below: Please Explain \\
\hline $\begin{array}{l}\text { Fashionable for this age group } \\
\text { (fashion refers to current clothing } \\
\text { trends) }\end{array}$ & \\
\hline $\begin{array}{l}\text { Personal style } \\
\text { (related to your personal style } \\
\text { preference) }\end{array}$ & \\
\hline Color, Pattern, Texture & \\
\hline $\begin{array}{l}\text { Appearance } \\
\text { (how it looks on the display/model) }\end{array}$ & \\
\hline $\begin{array}{l}\text { Evaluate Fit } \\
\text { (for this style of garment) }\end{array}$ & \\
\hline Comfort (as it appears on display) & \\
\hline $\begin{array}{l}\text { Quality } \\
\text { (fabric and construction) }\end{array}$ & \\
\hline $\begin{array}{l}\text { Versatility } \\
\text { (options for multiple use) }\end{array}$ & \\
\hline Ease of wear (uncomplicated) & \\
\hline $\begin{array}{l}\text { What does this garment need? } \\
\text { Comments }\end{array}$ & \\
\hline
\end{tabular}

Table 6-2. Example of the first section of the questionnaire, including prompts.

The second part of the questionnaire consisted of eight open-ended questions that were developed to elicit additional information about participant preferences regarding interests in fashion trends, personal style, clothing and fit challenges, special clothing needs, and recommendations. The questions were also designed using the review criteria and the questions are listed here:

1. What do you like most and least about the collection of clothing presented here? What garments would you consider wearing if they were offered in your size?

2. What is your level of interest in current trends in fashion? How has it changed over time?

3. How do you define your personal style? How difficult is it to find clothing that suits your style? Has your personal style changed over time?

4. What challenges do you have related to finding garments that fit? 
5. Do you have any special clothing needs related to physical changes as you age?

6. Do you have any special clothing needs related to lifestyle changes as you age?

7. What features would you like to see included in garments for women ages 51-69?

8. What advice do you have for clothing designers to help them better design clothing for this age group?

The third section of the questionnaire provided blanks to fill in or check off responses about six basic types of demographic information that included age, race/ethnicity, highest level of education, marital status, and employment. The last question provided a place to indicate a response to the following question: Do you have limited or declining ability in any of the following? The options were vision, hearing, thinking, communication, reach and stretch, dexterity, and mobility and each was listed with a brief definition. The questionnaire was tested with a boomer woman as well as piloted with two of the researcher's committee members and adjustments were made as a result of the feedback.

Video recording with audio. Two video cameras with audio were set up in Gwynn Lounge fifteen minutes prior to the start time and were positioned to record participant responses, first as they entered the room and again while they were in the process of evaluating the garments. Immediately following the evaluation session, the videographer gave the video cards to the researcher and she immediately placed them in a secure location for safekeeping. Verbal Ink, an internet transcription resource, transcribed the audio portions of the videos to prepare for analysis. Video images and the audio transcriptions were analyzed using the categorical approach outlined in the methods section to identify themes and patterned relationships. 


\section{Presentation of Findings: Semi-Open Questionnaire}

Overview. The purpose of the garment evaluation was to identify the specific clothing characteristics a group of baby boomer women identified as important, so it was critical to obtain information about individual garments as well as perceptions about outfits, styles, trends, and aging as a whole. As stated earlier, data analysis for this phase of the study used a categorical approach to identify themes and patterned relationships within the participants' responses; however, at times this became a challenge due to the small sample size and the range of opinions. Due to the small sample size and the lack of diversity among the group of participants, it is acknowledged that the following information cannot be generalizable to the female baby boomer population as a whole, though the data does provide detailed information about what this particular group of women deemed both desirable and undesirable, which was itself helpful to this study.

Participant responses were fairly brief for the first section of the questionnaire and more detailed for the second section. Occasionally, participants would fill in a section of the questionnaire with a one-word response that included yes, ok, fine, good, or excellent with no further explanation, though if a response was negative an explanation was generally included. Nine participants filled out the first part of the questionnaire by writing comments in the boxes provided. One participant developed her own Likert-type scale by rating outfits on a scale of one through five (five being the highest) and including several comments about individual garments. A detailed review of the evaluation of the individual garments is presented, and the eight questions in section two of the questionnaire will follow. Section three of the questionnaire included the demographic information that was presented earlier in the chapter, and will not appear 
here. Finally, a review of the video and audio recordings will follow with a summary of the research findings. The chapter will conclude with a summary of the questionnaires organized by theme and design criteria as a guide to design and evaluate the garments and outfits.

To obtain the information needed for the study it was vital to gather feedback from baby boomer women about their opinions on fashion, style, and clothing as well as their opinions about the outfits in the mini-collection. An overview is provided here that summarizes the participants' interest about fashion and style to gain a better understanding of this demographic's interest in clothing. It was essential to understand how the study participants viewed fashion and style related to clothing preferences because fashion, aesthetics, and personal style were found to be valued by boomer women in the literature (Holmlund, Hagman, \& Polsa, 2011; Lee et al., 2012) as well as by the bloggers described earlier in the study. This phase of the study required women in the age range of 51 to 69 years of age, and participants were not specifically required to have an interest in fashion or to have limited ability. Because this study followed the social model of disability that clearly separates the individual from the disability, individuals were not recruited specifically because they were disabled. The goal of inclusive design is to include individuals with a range of needs that are not necessarily limited to extreme disability. Although the sample was fairly small and the information is not generalizable to the baby boomer population as a whole, the women in the study provided some valuable information from a variety of different viewpoints related to their interest in fashion. The following is a summary of the participants' interest in fashion and 
personal style that was obtained from the questionnaires. This will be followed by a brief discussion about their abilities.

Interest in fashion varied considerably among the ten women who participated in the research. One of the participants, aged 59, indicated that she was extremely interested in fashion and asserted that she read about fashion, shopped for "funky, edgy, sophisticated [garments] with unique construction details," and sewed some of her own clothing. She noted that quality and workmanship were essential and noted an interest in younger styles intended for twenty- and thirty-year-old women but with slight modifications that might include additional coverage to certain areas of the body, specifically the "tummy and hips." She specifically mentioned that she was not interested in tailored clothing that she felt was offered everywhere.

The oldest study participant, aged 65, was also very interested in fashion and preferred tailored, professional, quality garments, even for casualwear. She indicated that women were increasingly staying in the workforce for longer and expressed the need for more clothing options for working women. She was very unhappy about her clothing options in Columbia, Missouri (a small midwestern college town) and stated that there was a need for garments for this age group made from long-lasting quality fabrics with good tailoring and reliable sizing.

Five additional participants ranging in age from 55 to 60 indicated they had a casual, comfortable style and were somewhat interested in fashion and/or trends. One woman specifically described her style as "casual elegance." Several women in this group were interested in fashionable clothing that was also comfortable and described their wardrobes as primarily comprised of basic pieces with an occasional trendy garment 
they added from time to time. The other two women were far more interested in comfort over fashion.

Two of the women in the study aged 56 and 57 described their styles as classic with an interest in simple pieces that were fashionable but not necessarily trendy. Examples of what they considered classic and fashionable were not provided, though one of the women expressed an interest in basic clothing and the other stated that she was neither a fashionista nor a trend follower and was primarily interested in comfort and quality.

One study participant, aged 51, indicated an increased interest in fashion but explained that her level of interest in fashion had increased over time due to weight loss, leading to her having more fashionable options available as a result of wearing a smaller size.

One of the objectives of the study was to include women with a range of abilities who could provide information that could aid in inclusive apparel design. Six of the study participants indicated that they did not have limited or declining ability in any of the categories listed in Table 6-1. The other four women listed one or more categories that included vision, hearing, thinking, mobility, communication, and dexterity, and none of the women listed reach and stretch as a limiting factor. With the exception of one participant, none of the women exhibited outward signs of limited ability or used any assistive devices such as a wheelchair or cane to move about during the study. One woman used a wheelchair and was able to maneuver around the room, though she needed help filling out the questionnaire due to limited dexterity. 


\section{Section One}

Outfit A: Garment \#1 Sleeveless Top. Study participants felt that the top was fashionable and commented that they liked the layered style and the pockets. Three participants specifically said they would wear the top and eight responded that it was related to their personal style preferences but did not indicate one way or another whether they would wear it. Several women mentioned that they did not like the sleeveless style and one person commented that she "doesn't care for sleeveless, and would wear something over it." One women questioned whether the top was age appropriate and remarked that it "may be a little young [for this age group] but appropriate for casualwear." Most women felt the garment was flattering but several qualified this by suggesting that it was flattering for particular sizes. One woman wrote that it was "not flattering for heavier stomachs" and another woman maintained that it was flattering for smaller women. The consensus was that the garment was comfortable, breathable, versatile, and easy to wear, with one woman commenting that the top was "lightweight and good for hot flashes." Three women were opposed to the color white, though several others thought that the color made it more versatile. Several women liked the shoulder ties as a design detail but no one considered it an option to make the garment easier to wear. When asked what the garment needed, the comments included magnetic buttons instead of shoulder ties, additional color choices, redesigning the top as a trapeze style/silhouette, and adding accessories.

Outfit A: Garment \#2 Knit Cardigan. When asked whether the cardigan was fashionable for this age group, seven participants responded specifically that it was fashionable, though one woman commented that it was "a little young." When asked 
whether it related to their personal style, five women responded favorably and two asserted that it wasn't really their style. One participant stated specifically that she didn't care for the dropped shoulder. Participants' opinions about the uneven hemline varied: they either strongly favored the hemline or didn't care for it at all. Overall, women liked the texture and weight of the fabric, and stated that they liked the white color, which they felt made the garment more versatile and "like[d] the tying options." The white color appeared to be more acceptable for the cardigan than for the sleeveless top it was paired with. Opinions about the blue trim varied, with one woman liking the trim, one woman suggesting to change the trim to white, and another recommending to make the cardigan a solid blue knit fabric. In response to the garment's overall appearance, opinions included "looks nice," "flattering," "too jagged," "too long," and "unimpressive." Most of the women found the fit to be flattering, with one woman remarking that it suited her because she doesn't like things "too loose"; however, in contrast another participant stated that it was sloppy and falling off the shoulders. Quality and fabric were evaluated as very good. Two women commented that they were concerned with the sheerness of the garment and one woman was concerned that the fabric could snag. Most respondents felt that the cardigan was versatile, with one woman saying that it could be worn with other outfits and another suggesting that it could work well as a light jacket. Two women stated that it was not versatile with the blue trim. All of the respondents agreed that it was easy and uncomplicated, and when asked what the garment needed, suggestions included a shorter length in the back, an elastic in the back, a straighter hem, and more color options.

Outfit A: Garment \#3 Knit Pant. Six women stated that the knit pant was fashionable for this age group, though only three said that they would actually wear the 
pants. Several women commented specifically about the fit when asked whether the garment related to their personal style. Several women expressed concern that the pants were too clingy or too tight, and one said that she preferred looser fitting pants. One woman asserted that she liked the slim leg but not the ties or loops, and another agreed that she would wear the pants but without the ankle ties and sarong. Overall, participants liked the feel of the fabric, the color, the texture, and the stretch, but one woman indicated that she felt the pants were "bland." One woman stated that they were a "great fabric in place of jeans," and several women specifically mentioned that they liked the adjustable waistband and that the pants would be easy to put on. When asked about the appearance of the pants in the display they remarked that the pants looked good to excellent, "even the ties," but they were "not sure who would wear the ties." Quality and fabric were favored, though responses about versatility ranged from not very versatile, somewhat versatile, and very versatile, especially for casual or work casual. While the majority of women were in favor of eliminating the ankle ties, one woman responded that she "like[d] the ties" but that the pants needed "a label in back" when asked what the garment needed.

Outfit A: Summary. Overall, Outfit A was positively accepted by the study participants. The data suggests that the inclusion of comfortable fabrics and features that affect comfort as well as allow for adjustability were favorably received by the study participants. Specifically, the fabrics chosen for the study worked well because they were natural fiber blends that incorporated stretch such as cotton, rayon and linen knits. The women preferred layering options like the cardigan to allow for arm coverage and liked the tying options that could adjust fit and change the appearance of the garment. The 
cardigan offered the right amount of coverage because it was slightly sheer without being too heavy. The tying options were successful because they provided versatility without being overly complicated. The adjustable waistband in the pant was a favorite feature that was well received and the study participants liked the button that could be adjusted and then concealed for a smooth fit. The removable ankle ties did not work well for the basic pant and it was apparent that added features do not necessarily increase the value of the pants even though they can be removed. In addition, fit was perceived differently among the women because some perceived the pants as tight fitting. The pant was not intended to be body conforming so therefore the fit was not successful. This suggests the importance of adding additional ease when designing for a baby boomer market.

Outfit B: Garment \#4 Tunic/Dress. Overall, respondents felt the tunic was fashionable for this age group and most would consider wearing the tunic/dress. One woman stated that she would "need to wear the tunic with pants" but that she "loved the style, sleeve length, back closure, and bling." In contrast, another woman wrote that "the back reminds me of a hospital gown," and that "the neck closure could be more fashionable," though she also indicated that it looked like something she already owned. When asked whether the garment related to their personal style preferences, six women stated yes, two indicated maybe, and one said no. One woman commented that it would accentuate her smaller waistline but another woman commented that it was "gray and shapeless." The group was split about the gray color, with some highly favorable of the color and others not liking the color at all but liking the printed trim at the neckline. Comments about the fit were positive except for one woman who suggested more room 
in the hip area. Collectively they liked the three-quarter sleeve length, though several commented that the sleeves were too wide and that they preferred a narrower sleeve. The comfort and quality were highly rated along with versatility, with one woman claiming that it "could be dressed up or down with jeans or slacks." The participants felt that the garment was uncomplicated and easy to wear, and when asked what the garment needed their responses included belt options, interchangeable magnetic jewelry options, and a shorter length.

Outfit B: Summary. The study participants favored the tunic dress and liked the special details that included the magnetic jewelry piece and the side slits with tying options. The comfortable knit fabric and the body skimming fit were also rated highly as well as ease of wear. This suggests that simple, easy silhouettes with special design details were important to the study participants and therefore the inclusion of these features aided in the success of the garment.

Outfit C: Garment \#5 Reversible Print Top over Navy Tank. Two participants felt that the top was fashionable for this age group and said that it related to their personal style; however, these responses were not in the majority. Other participants commented that the style was too youthful and that "probably not many in this age group would wear it," with one woman stating that the top was too short for this age group but that she personally would wear it. With the exception of one woman, participants indicated that they liked the print and the color. When asked about the top's appearance on the display, one woman stated that it looked very fashionable and another indicated that it looked "good on the model but [was] geared towards slender women." One woman thought the print top paired with the skirt didn't look streamlined, and another claimed that the top 
"needs to be a little longer to cover muffin top." Most felt that the garment appeared soft and comfortable, though one woman commented that it was too short for emotional comfort. Many women were in favor of the reversible style option, and when asked what the garment needed, their recommendations were to lengthen the top and widen the shoulder straps for better bra coverage.

Outfit C: Garment \#6 Maxi Skirt. The participants felt that the maxi skirt was fashionable for this age group but were split in terms of whether it reflected their personal styles. One woman commented that it was not her style but that she would wear it, while another woman commented that it was her favorite piece overall and that she was starting to wear more maxis. In contrast, several women specifically mentioned that they did not care for the shorter front and specifically that they were not fond of the hemline. All responses were favorable regarding the color, appearance, and versatility; one women commented that she "liked the tummy-covering feature," and another remarked that it was "easy to wrap and go with clever options" and indicated that she liked the option to tie the skirt in a variety of ways across the front. As a whole the women were not sure whether the skirt would be easy to wear, and when asked what the garment needed, their responses included additional colors, magnetic closures instead of ties, pockets, a label in the back, though one woman commented that the researcher "can't save it."

Outfit C: Summary. In general Outfit $\mathrm{C}$ had conflicting reviews from the study participants. The cropped style of the printed top was a modified trend that was not received well despite the fuller silhouette and pairing with the navy tank for coverage. It was perceived as too young and too trendy by many of the women so it is not considered a suitable silhouette for this age group. The maxi skirt appeared overly complicated to 
several women despite the elasticized, pull-on waistband and specifically, the tying options. Both the bloggers and the study participants indicated an interest in modified trends to suit an aging body but it was unclear what trends would be suitable for this age group.

Outfit D: Garment \#7 Sleeveless Jacket. This garment specifically generated a range of contrasting opinions; six women felt that it was fashionable for the age group but only three indicated that it related to their personal style. Others did not feel it related to their personal style for a number of reasons, such as its having too many ruffles and not being the participant's preferred neckline. One woman felt that the jacket looked older than was suited for the age group, though one woman specifically said that it "looks like something 50+ would wear." Eight women asserted that the color and print were highly favorable, and one woman noted its "beautiful fabric and unusual style features." Several commented that they loved the color and pattern, but one woman maintained that the print was too old for the age group. A majority, however, felt favorably about the jacket's overall appearance, and one stated specifically that the video "looks better on [a live model] than I thought it would." The jacket's quality was rated highly, though one woman noted that she preferred wash and wear. The group was also split on versatility and ease of wear: one woman claimed that she "loved the versatility built into the garment" and another stated that the jacket was "more limited than a basic [one]." When asked what the garment needed, responses included "other printed designs," magnetic closures, and the elimination of the ruffles. One woman commented that it was her favorite piece in the mini-collection, though in contrast, another stated that it needed imagination. 
Outfit D: Garment \#8 Sleeveless Swing Top. All of the participants felt that the top was fashionable for the age group and six stated that it reflected their personal styles. Several women commented that they liked the fabric and flow of the garment; however, one woman stated that she would prefer a longer hem in the front and back instead of having the longer length at the sides. Most of the women liked the top's overall appearance, with one woman commenting that she liked it paired with the jacket. Comfort and fit were rated highly, as was quality, though one participant said that the top needed too much care. The opinions were divided about versatility and ease of wear. When asked what the garment needed the participants suggested a straight hem with slits, an empire option, and accessories.

Outfit D: Garment \#9 Ankle Pant. All of the participants except one agreed that the pant was fashionable for the age group, though responses were divided as to how well it suited them personally: six specifically stated that the pant did not relate to their personal style, though three indicated that they liked it and/or would wear it. Half of the women also commented favorably about the slightly fuller leg and side slits, but the other half indicated specifically that they did not like those features. One woman commented that, "wide-leg pants make me look short and wide," but in contrast, another participant stated that she "like[d] the slightly fuller but not real full leg." All of the respondents liked the color blue and one commented that it was "nice for this time of year." Seven women also specifically commented on the nice appearance of the pant even though they didn't care for it personally. Several women commented that the pant looked comfortable as well as easy to wear, though one woman noted that the elastic might be too tight for arthritic joints. Others liked the ankle-length pant because it was short, but in contrast 
another asserted that the pant should be lengthened. When asked what the garment needed, the responses included narrower legs and ankles.

Outfit D: Summary. Overall, the study participants indicated that they liked the outfit and felt it was fashionable for the age group. This was a successful outcome of this ensemble. Several of the study participants were confused about the one of a kind jacket silhouette that included several belting options and this implies that new or unfamiliar design details may be confusing for boomers when the garments are intended to be easy to wear. The study participants favored the sleeveless swing top that was designed to be longer on the sides and shorter in the front to better accommodate both seated and standing wearers. This indicates that style silhouettes that provide solutions to include a range of abilities may be acceptable to boomer women based on the opinions of the study participants.

\section{Section Two}

The second part of the questionnaire included open-ended questions intended to gain information about participant preferences regarding interests in fashion trends, personal style, clothing and fit challenges, special clothing needs, and recommendations. The questions will be stated along with a summary of the corresponding responses. Variation existed in how the women answered the questions, some questions were left blank, and in a few instances the answers didn't pertain to the question or parts of the question were not answered fully. However, the answers were meaningful overall and provided valuable opinions from baby-boomer women. 
Question 1. What do you like most and least about the collection of clothing presented here? What garments would you consider wearing if they were offered in your size? Summary of responses: Four women responded that they would wear Outfit A, consisting of the sleeveless top, cardigan, and knit pant. Five participants stated that they would wear Outfit B, the tunic dress. No one indicated that they would wear the complete Outfit $\mathrm{C}$, the print top over the navy tank with the maxi skirt. Two women mentioned that they would wear the maxi skirt and another stated that she would wear the print top over the navy tank, though neither could imagine wearing the complete ensemble. Three women stated that they would wear Outfit D, the sleeveless jacket, swing top, and ankle pant; however, one person specifically commented that she would not wear the sleeveless jacket.

Overall, women commented favorably about the garment quality, color, fabric, comfort, versatility, and ease of wear, though one women claimed that a couple of pieces appeared to be a little young. In contrast, one woman wrote that, "Outfit A looks like a low price Eileen Fisher knock-off" and commented that "these do not say quality, chic or professional to me - they say matron." In general, the study participants commented on a range of individual pieces that they would wear depending on their personal style.

Question 2. What is your level of interest in current trends in fashion? How has it changed over time?

Summary of responses: The responses to the first part of this question related to fashion and style were discussed in detail in the demographics sections. Two of the study participants were very interested in fashion but mentioned dramatically different 
approaches to their personal style. One woman preferred edgier, trendier clothing and was interested in younger styles that could be modified for an older woman. Another woman was interested in tailored garments and pointed out that she was "very interested in fashion, but [the] scope of what feels appropriate has changed over time." Five of the study participants indicated that they had a casual style and were somewhat interested in fashion and trends; one of these woman commented that she was interested in fashion but that comfort was her priority. Another woman stated that, "I pay attention but don't follow trends," and another noted, "I don't keep up with fashion trends, I do a lot of basics with maybe a few trendy things here and there." Two additional women described themselves as classic: interested in fashion but not trends. One woman commented that fashionable options for clothing have increased since she had lost weight but was somewhat noncommittal about the extent of her interest in fashion. All of the women with the exception of two indicated that they had maintained a fairly consistent level of interest in fashion over time. One participant stated that her interest in fashion had increased as she aged, and as stated earlier, one woman's interest in fashion had to do with an increase in available choices.

Question 3. How do you define your personal style? How difficult is it to find clothing that suits your style?

Summary of responses: Over half of the responses included some mention of a casual approach to style, and some women listed jeans, t-shirts, loose fitting tops, and comfortable clothing in general. One of the participants mentioned that she had a comfortable sense of personal style and also said that her style had become more 
simplified over time. The two retired women in the study maintained a casual approach to dress that was consistent over time, though with an increased interest in comfort. In contrast, one woman mentioned that she had a "sharp, professional style even when dressed down," and another woman noted, "I like a funky, edgy, sophisticated style." Neither of them mentioned the importance of comfort anywhere in the questionnaire unless they were specifically evaluating a garment for comfort.

Question 4. What challenges do you have related to finding garments that fit? Summary of responses: The responses to this question varied, and one woman mentioned that she had a hard time finding cute clothing in a size extra large. Two of the women described problems related to being petite in size, with one woman saying, "I am petite, 5'3", $120 \mathrm{lb}$. and 59 years - too old for teen fashions that are what fits but too petite for boring misses styles. I am not interested in tailored styles that seem to be offered everywhere." In contrast, another petite study participant preferred tailored garments saying, "I am petite. I have few options in Columbia but I find some clothing at Talbots, I like Eileen Fisher and wear vintage." Several women referred to specific fit issues: one mentioned having a long torso and another mentioned having a short torso with a very long inseam. Two women specifically listed health-related obstacles that prevented them from finding garments that fit: one noted a drainage bag that she had to conceal and another stated that she had a hernia that was a nuisance.

Question 5. Do you have any special clothing needs related to physical changes as you age? 
Summary of responses: This question along with question six yielded the fewest responses. One woman observed that she needed a larger size and preferred stretchy comfortable clothing, and another commented on a desire for pants with elastic waistbands. One participant stated that she needed outfits that look good with flats due to a bad knee, but most of the participants indicated "no" or left the question blank. There was no mention of the health issues that women had listed in question \#4.

Question 6. Do you have any special clothing needs related to lifestyle changes as you age?

Most participants responded "no," but two woman mentioned shoes with minimal explanations. One woman preferred "comfortable stretchy, around the house clothes, that are presentable but not spandex work-out clothes."

Question 7. What features would you like to see included in garments for women ages 51 $-69 ?$

Summary of responses: Several of the comments pertained to comfort, fit, and garment features. Two participants stressed the importance of comfort, one listed adjustability in garments, and two suggested more magnets instead of buttons. Magnets were also suggested repeatedly for garments in the mini-collection with closures; this was an unusual response given the limited availability of magnetic closures in clothing on the market. It is possible that the women responded favorably to the tunic dress with a magnetic closure and suggested magnets based on that example. 
A trim fit was listed as preferable by most of the women in the study, specifically for garments that cover the abdomen. Pockets were on the list of must-haves for one woman, and one participant discussed an interest in fun prints like the ones featured in the Boden, Anthropologie, and H\&M catalogs. One woman simply stated "a bit more sexiness if possible." Two women stated their frustration with inconsistency in the current sizing system, and one woman in particular was unhappy with the lack of selection in larger sizes and claimed that "Not everyone is a size 2 and they [designers] need to make clothes for real people."

Question 8. What advice do you have for clothing designers to help them better design clothing for this age group?

Summary of responses: Several women specifically commented on the need for styles that were age appropriate. One participant commented "[I need] styles that are youthful without looking like I am trying to dress like a coed or a grandma," and several other women shared similar thoughts: "Keep in mind that our age group may be climbing over the hill but we still want to be considered attractive" and "[We] need designs that aren't boring but also that aren't too over the top like Chico's." It was also suggested that designers consider comfort, quality, versatility, and attractiveness for this age group, and that in addition, designers should modify younger styles for older consumers. Lastly, designers should consider designing for a body type that has changed as a result of aging: one participant noted specifically in relation to size that, "We are not all alike physically or in our tastes. Pay attention to our size challenges." 


\section{Video and Audio Recordings}

Video. After viewing the video recordings it was evident that all of the participants gave their full attention to the survey process, evaluating the garments from the moment they entered the room until the time they left. All of the women viewed the video of the modeled garments and took advantage of the resources available in the room, including the clothing options poster and information board. All of the participants interacted continuously with the garments during the evaluation process and from time to time stopped to reflect on what they were looking at. Their interactions included touching the garments and removing sections of an outer garment to view a layer underneath. One participant, a wheelchair user, interacted somewhat less than other participants, and certain sections of the garments were not as easy for her to touch: for example, the upper areas of some necklines that were out of reach. The graduate student assistant compensated for the lack of reach and was very helpful in bringing some of the garment pieces to her level as needed.

During the course of the evaluation there were only three occasions when notable interactions took place between participants. The first was an interaction with the closure on the back of the Tunic Dress \#4: one woman pointed out the magnetic closure to another woman who was in close proximity. She commented that the "bling" was removable and that the dress was easy to unfasten because of the magnet and encouraged the other woman to try it out. The other woman took the removable piece off of the dress and put it back on after unfastening the magnetic closure. They both appeared amused during the interaction. 
The second interaction took place between two other women as they were evaluating Sleeveless Jacket \#7. One woman watched another woman as she pulled back the hem of the jacket and pointed to Sleeveless Swing Top \#8 underneath. The woman who pulled the jacket back scowled and said, "I hate this," though the other woman just looked away.

Lastly, two women were looking at the half-scale dressmaker mannequin located on the table near the large screen; the small display form featured a necklace attached to a scarf. One woman pointed to the piece and asked whether it should be evaluated, and the other woman said, "No I don't think so." This was a display featuring a jewelry piece featured in the clothing options poster.

Because this was a study about fashion and style it seemed appropriate to document the clothing the study participants were wearing. These observations were made later during the video analysis; however, it was noted that they were one-time observations of clothing worn on a very hot summer day in Columbia, Missouri, when the temperatures were in the upper 90s. With the exception of one woman, all were wearing neutral-colored casual pants ranging in length from ankle length to slightly above the knee. The pants were generally fitted or straight-leg styling and paired with semi-fitted tops in shades of blue, green, burgundy, and gray, with one woman wearing a floral print top in purple and yellow. Three of the women also wore striped polo-type tops. Sleeve lengths included long sleeve, three-quarter length, short sleeve, cap sleeve, and sleeveless. The exception to the pant/shirt combination was a multi-strapped sundress that hit at knee length in a blue floral print with a layered statement necklace. Aside from this participant, the rest of the women wore either minimal jewelry or no jewelry at all. 
All of the participants wore garments that were either body skimming or slightly fitted with the exception of one woman who wore a loose gray t-shirt. With the exception of the woman in the sundress, the outfits were considered basic and casual or possibly work casual.

Audio. The audio portion of the videos was sent to the Verbal Ink company for transcription. The audio recordings were anonymous and could not be linked to any of the study participants. After reviewing the transcriptions several times, it was concluded that the audio did not reveal any additional information pertinent to the study. One conversation was transcribed between the graduate student assistant and the wheelchair user, and questions and answers that were recorded and transcribed were then compared to the participants' questionnaires for accuracy and all were verified as accurate.

\section{Synthesis of Findings}

The following discussion is organized according to the review criteria that was used as a guideline for question development for this phase of the study and directly related to the objectives for the apparel designs.

Garment types. Study participants stated a variety of different preferred styles and garment types when they were filling out the questionnaires. Preferred styles and garment types varied from individual to individual, and not all participants preferred everything included in the following lists. Study participants were not directly asked to specify their preferred types of clothing, so it is possible that some key items were not included here; however, the garments mentioned in this study overlap with the garments that were preferred in Howarton and Lee's study (2010), which indicated less interest in skirts and dresses than in pants and tops. The baby boomer women in this study favored 
looser tops, longer tops, tailored shirts, t-shirts, tops with sleeves, and sleeveless tops with layering options and capes for outerwear. Similar to the opinions expressed by the bloggers, many of the women in this study preferred tops with sleeves or layering options to provide coverage if needed. The inclusion of sleeves and layering options in the minicollection were sound design decisions for this study. Women liked the three-quarterlength sleeves for Tunic Dress \#4, and the cardigan was viewed as a good layering option over Sleeveless Top \#1; however, no one specifically mentioned either Sleeveless Jacket \#7 or the sarong/wrap worn with the sleeveless tops as either favorable or disagreeable options for arm coverage.

Jeans, straight-leg pants, fitted pants/leggings, ankle-length pants, capris, skimmers, and longer shorts were listed as preferred bottoms. Two women maintained maxi skirts as favorites, but other types of skirts were not mentioned and only one woman mentioned an interest in wearing casual dresses. There was no other indication that dresses or skirts were essential garments in the study participants' wardrobes.

In contrast to the study participants, the bloggers favored dresses and specifically maxi dresses; however, this could be related to the maxi dress trend and a general resurgence in the popularity of dresses at the time the blogs were reviewed. This could also explain why two of the study participants preferred maxi skirts. A preference for certain garments such as maxi dresses is often associated with current trends, and the popularity of these garments in the blogs may be directly linked to the level of current interest in the trend. In addition, some of the bloggers might adopt trends more readily because fashion and style (in addition to aging) were their main purposes for writing the blogs. 
Modifying trends to accommodate an aging market was a suggestion from both the blogs and from several of the study participants during garment evaluation. Because older individuals strive for continuity in their lives (Atchley, 1989), it is not uncommon for them to modify clothing to adapt to the aging process. Because it appeared that the baby boomer women were interested in fashion and trends when they were younger, it is understandable that they maintained an interest as they aged, though with modifications based on their current clothing preferences and needs.

Two garments in the mini-collection were designed to incorporate as well as modify current trends: Printed Top \#5 (the crop-top trend) and Maxi Skirt \#6 (the maxi trend). Many of the women were not interested in either Printed Top \#5 or Maxi Skirt \#6 even though modifications had been made to make the garments more suitable for an aging market. Though the printed top silhouette was modified to be slightly fuller than a version for a younger audience and was paired with a navy tank underneath for coverage, participants still did not like the silhouette and specifically disliked the shorter length. Even with modification, certain styles for baby boomer women may not be acceptable because of the comfort level associated with the amount of body coverage. One woman commented that Printed Top \#5 was "too short for emotional comfort" even though it was paired with a navy tank top that was worn underneath. Other aspects of the garment were highly rated such as print, comfort, and versatility, but the deciding factors for wearability were the silhouette, the length, and the perceived lack of coverage at the waistline.

Maxi Skirt \#6 was designed with an easy on-and-off elastic waistband with tying options to change the drape across the front of the skirt to camouflage the abdomen and 
alter the drape of the hemline. One woman commented that the skirt was too trendy and several didn't care for the uneven hemline. One study participant—aged 59 and described previously as being extremely interested in fashion - claimed that she would wear the printed top, but despite her having rated the maxi skirt highly in all categories, she felt that it still didn't fit her personal style and would not consider wearing it due to her preference for a shorter length.

One additional garment that was modified to be more inclusive to wheelchair users was Sleeveless Swing Top \#8. The style was modified to be shorter in the front and longer on the sides to eliminate bulk in the front. The participants stated that it was fashionable for the age group, and six participants including the wheelchair user indicated that they would wear the top. Several women suggested changes that might be less appealing to wheelchair users, though overall for this group of women the garment was successful in modifying a trend to increase the inclusiveness of the garment.

Several important points related to trends surfaced during the Evaluation phase. Regardless of the level of interest in fashion and trends, if garments are not perceived to be in accordance with personal style, then they will most likely not be adopted. With the exception of two women in the study, all were interested in classic or basic types of clothing with the addition of carefully chosen trendier pieces to add interest to their outfits. Ensembles such as Outfit C may not be adopted by some groups of boomer women because there may be minimal interest in the featured trend, or because too many trends were incorporated into one outfit. Additional feedback from baby boomer women is needed to identify the specific types of styles that could incorporate trends as well as which styles are preferred as basic clothing items (ones that do not incorporate trends), as 
well as the types of modifications to trends that would be considered acceptable for this age group.

Fashion and style. The semi-open questionnaires uncovered multiple interesting personal viewpoints about fashion for baby boomer women in the study, and it was evident in the comments recorded on the questionnaires that they clearly had a continued interest in fashion and indicated that they wished to maintain a stylish appearance as they aged. The interest in fashion and style in this study supports past research that acknowledged that older women value fashion, aesthetics, and individual style and view fashion as a part of their lifestyle (Holmlund, Hagman, \& Polsa, 2011; Lee et al., 2012; Thomas \& Peters, 2008). In addition, a continued interest in fashion and style supports the life course perspective that views life as a series of interrelated stages with each stage shaping the next (Moody \& Sasser, 2012). As a result of aging and moving from one stage in life to the next, it is understandable that baby boomer women might question the age appropriateness of their clothing choices.

On multiple occasions, the women specified that the garments on display were fashionable for the age group, though some did not feel that they were representative of their personal style or that they would wear them. It is possible that when designing for this age group, as with other age groups, the acceptance of fashion is highly variable depending on personal taste. In addition, there are different interpretations of what constitutes fashion. This was apparent in both the blogs and in the information provided from the study participants.

Study participants commented about the age appropriateness of certain styles. Several women felt that a few of the garments (Knit Cardigan \#2, Knit Pant \#3, Printed 
Top \#5) were too young for boomer women, and one woman felt that some of the garments (Tunic Dress \#4, Swing Top \#8) were too old for boomer women. Regarding the Knit Cardigan \#2 and Knit Pant \#3, one woman stated that they were "a little young, but okay for casual," indicating that younger styles might be acceptable for informal occasions. Styles like the cropped printed top were evaluated as too young by most of the study participants and so this garment was not successful in providing an age appropriate clothing option for boomer women.

The woman who had previously asserted that Tunic Dress \#4 was "old" for the age group also maintained that it was not professional; in this case, it is possible that she was evaluating the dress dressed based on her work clothing criteria. In contrast, another woman stated that Tunic Dress \#4 was "nice for office or everyday wear." The difference in opinions related to age-appropriate clothing is not surprising because the highly personal nature of age-appropriateness makes it difficult to define (Howarton \& Lee,2010).

Age appropriateness was also a topic in the blog posts; for example, Patti prefers occasion-appropriate clothing over age-appropriate clothing, which helps to explain why the study participant noted above might consider wearing a younger style for casualwear but not for a formal occasion. When designing for baby boomer women, it is unrealistic to view them as one homogenous group (Furlong, 2007); this was evident within the relatively small sample of women in this study.

A number of features were included in the garment designs to help baby boomer women project a unique personal style, and each of the four outfits included at least one garment that could be altered by the wearer in some way to change the look of the 
garment. The baby boomer women in the study liked having options for changing looks by belting or tying, and slits were specifically added to several garments to add design details that could be tied to change the look of the garment but that were also intended to allow for movement and adjustability in a seated position. Most of the women in the study responded favorably to Tunic Dress \#4 and indicated that they would most likely wear it with pants. This included the woman in the wheelchair, though it was unclear whether the slits were a beneficial feature other than for simply changing the garment's look.

Color, pattern and texture. Overall, the participants approved of the blue color scheme, with only two objecting to the more neutral pieces (the white Sleeveless Top \#1 and the gray Tunic Dress \#4). More important than the two objections was that on several occasions the participants wanted more color options; this makes sense because color is a highly personal preference and adding additional color options could increase product acceptance by appealing to a broader range of women. All but one participant favored both print designs, and it appeared from the feedback that the prints were a nice variation combined with the solid-colored garments. One exception worth noting was the blue print trim on the cardigan, which was perceived to limit the versatility of the garment for several participants, thus lessening the garment's overall appeal. This was not necessarily an objection to the actual print, but to its placement, thus suggesting that for at least some wearers, versatility may be more important than design features. This may apply to garments that are perceived as basic pieces that can coordinate with multiple other pieces in a wardrobe. 
Fit. Fit was important to the study participants as well as a priority for the bloggers. Several of the participants equated their personal styles with specific fit preferences and indicated that "too tight" garments like the knit pant were not their style. Good fit was also a perception that varied from individual to individual: two women viewed the fit of the same garment (Knit Cardigan \#2) in dramatically different ways, with one stating that it was a preferred fit and the other describing it as sloppy, even though it included features that allowed it to be tied in a variety of ways to adjust both coverage and fit. Because the foundation behind inclusive design advocates design solutions that do not appear adaptive, educating consumers about how to adjust fit will be necessary if special features are added to garments that are not obvious to the intended users.

Designing garments for this age group may be challenging based on varying fit ideals, specifically what constitutes good fit. Fit ideals may be influenced by a number of different factors such as fashion trends and styles, fabric, context, and intended use (Lee \& Steen, 2010). Aging, decline in ability, or disability may also influence fit ideals It is clear that baby boomer women value good fit (Holmlund, Hagman, \& Polsa, 2011; Lee et al., 2012) and research suggests that designers should focus on better fitting garments (Howarton and Lee, 2010). Incorporating features like the adjustable waistband in Knit Pant \#3 or the tying and belting options in the Knit Cardigan \#2 to adjust fit makes sense to accomodate size variations within a single garment. Several study participants suggested adjustability in garments as desirable for an older market.

Comfort. The importance of comfort was clearly indicated by all of the participants, with the exception of one woman who did not specifically mention comfort 
but evaluated garments in the mini-collection as comfortable. For most, comfort related primarily to the feel of the fabric and what participants perceived as comfortable by touching the garments. Because the addition of sensory qualities increases product desirability (Postrel, 2007), it was not surprising that soft knit fabrics in the collection were well received. Several of the study participants equated good fit with comfort and favored features such as elastic waistbands in garments such as Maxi Skirt \#6 and Ankle Pant \#9, but specifically the adjustable waistband in Knit Pant \#3 discussed earlier. The adjustable waistband could increase the amount of comfort in a garment by allowing adjustment even over the course of a day. This feature served a dual purpose because for many of the study participants, good fit added to their level of comfort. The interest in comfortable clothing with special features is not new (Jackson \& O’Neal, 1994), but one that can be explored further to develop inclusive solutions incorporating comfort.

Quality, fabric, and construction. Garments were perceived as high quality by all of the participants except for one participant who rated the quality of all of the garments except those in Outfit A as slightly above average.

Several women pointed out design features that they felt added to the quality of the mini-collection such as the bias trim on several garments or the removable magnetic jewelry embellishment; however, most of the comments regarding quality referred to the fabric or garment construction and were quite general. Regardless of the lack of specific information in both the responses here and in the blogs, it was clear that baby boomer women expected high-quality construction and fabrics.

Versatility. Garment versatility has the potential to add value to clothing, and bloggers as a whole felt more strongly about the importance of versatility and believed 
that it offered options to help them project their personal styles. When asked to give designers advice about designing for this age group, several study participants listed versatility as an important quality in their clothing but found it difficult to evaluate the level of importance of versatile garments. Likewise, Howarton and Lee indicated that only half of the baby boomer women in their study required versatility in garments (2010).

Regardless, participants highly rated the majority of garments in the minicollection as versatile but did not provide specific reasons for why versatility was lower for Knit Pant \#3, Print Top \#5, and Sleeveless Jacket \#7. Knit Pant \#3 was specifically designed to be versatile because it included removable features that could change its appearance depending on the wearer's preferences; however, the study participants' evaluation of versatility varied dramatically, and many did not find these additions (such as ankle ties and a sarong at the waist) desirable. Adding unwanted features like ankle ties may actually detract more from the desirability of a garment that may otherwise be acceptable as a basic style (though pockets, which were listed in the study as desirable) could be considered an added bonus.

Print Top \#5 was not accepted as a style that most of the study participants would wear, so it was not surprising that some women evaluated versatility as low, perhaps because they could not imagine wearing it under any circumstances. Some of the participants indicated that they were unsure about the versatility of Sleeveless Jacket \#7; the jacket was a one-of-a-kind garment and participants may have been unsure about how to style it beyond how it was presented on the form. The acceptance of unfamiliar styles may be enhanced by providing additional information about uses related to unusual 
features. In addition, clear and concise instructions will be necessary to encourage boomer women to explore new features and alternatives.

Ease of wear. Ease of wear is an essential garment quality for inclusive apparel design that advocates simplicity in design. All of the garments in the mini-collection were designed with ease of wear and simplicity in design as priorities. Participants assessed all of the garments as easy to wear with the exception of two garments: almost half of the participants questioned whether Maxi Skirt \#6 and Sleeveless Jacket \#7 would be easy to wear. Specific reasons were not offered; however, both garments were less traditional designs, which could be a possible explanation as to why they appeared more complicated. Maxi Skirt \#6 was a one-of-a kind draped design that offered unique tying options to change its appearance in the front, and it is possible that these unusual features on the garment's front overshadowed the simplicity of pulling it on and off with an elastic waistband. Sleeveless Jacket \#7 was also a one-of-a-kind garment that had an untraditional shape and several belted options that participants may not have been familiar with. Educating consumers about garment qualities that could make dressing easier may be necessary for untraditional designs. In addition, too much newness may be confusing for boomers when garments are intended to be easy to wear.

Because garments were designed with simplicity in mind, it was a goal to eliminate unnecessary and hard to manipulate closures. Elle, a wheelchair-bound blogger, suggested that designers consider magnets in place of buttons, so a magnetic closure was included in the design of Tunic Dress \#4 in the mini-collection. In addition, several study participants specifically mentioned magnets as favorable additions to garments in the mini-collection to make them easier to put on and take off. It is not clear whether these 
comments were a favorable reaction to the magnetic closure in the collection or if they had some other reference point for the use of magnets in clothing; in any event, exploring alternatives to current options for closures on the market could provide inclusive alternatives for individuals with dexterity issues.

Appearance. Clothing used as a tool to manage appearance has significant effects on the wearer (Jackson \& O'Neil, 1994), and it became apparent that women in this study were evaluating the outfits from varying points of view, some of which were more personal than others and may have something to do with acceptance of the garment and their own appearance management. In general, participants often switched from one point of view to another when they were evaluating different garments, or even different qualities within a single garment.

One point of view was that of a neutral observer, and these responses were more generic in nature and often in response to the Appearance prompt in section one that asked for opinions on the garment's appearance based on how it looked on the display form or in the video. Three examples, written by different women about Sleeveless Swing Top \# 8: "very useful and basic," "good fit and flattering," and "could be casual or dressy." When asked to explain how they perceived the garment appearances on the display forms and in the video, the evaluations were quite favorable, though not personalized in any way. Study participants consistently rated both the appearance on the display forms and in the video as excellent or very good, with an occasional mention of a specific design detail that they didn't necessarily care for but that generally did not adversely affect how they perceived the overall appearance of the outfits. 
The second point of view was written by the individual but as a group representative for baby boomer women: for example, a comment about Sleeveless Jacket \#7 was that it "looks like something 50+ would wear," and another comment about Maxi Skirt \#6 was that "it would look good on someone thin and tall but not for our age group."

A third more personal point of view was also presented when women commented specifically on how they perceived the garments to look on themselves. One such statement about Knit Pant \#3 was, "Not for me-too tight and too clingy," and one about Sleeveless Swing Top \#8 was, "Not sure about the uneven hem and too much at the waist and hip area for me," and one participant said that Tunic Dress \#4 "would accentuate my smaller waistline." Personal responses were an expectation in the questionnaire because personal opinions were encouraged — as well as needed — to gain a richer perspective about the apparel designs. It is unclear at this point why individual responses varied from neutral, to group representative, and then back to personal point of view; however, it is worth exploring the personalization of responses and the possible relationship to garment acceptance or lack of acceptance for personal use as one ages.

Similar to the earlier discussion about fashion and personal style, despite the overall appearance of the garments on the display form and in the video being rated favorably, this did not necessarily translate to personal acceptance for personal wear; this suggests that the women in this study may be evaluating the garments in such a way to determine what may be appropriate or look good for them personally. This evaluation suggests the importance of better understanding how baby boomer women manage their 
appearance through the selection process, their clothing choices, and the garments they actually wear.

\section{Additional Observations}

An unexpected outcome of the questionnaire was the lack of responses to questions \#5 and \#6 that asked participants to share information about special needs related to aging or lifestyle changes. Participants had little to say about these two questions in general, and mentioned nothing that could specifically aid designers in designing garments that could be more inclusive to a range of needs. Responses to other questions indirectly garnered more information on these topics, and it is possible that the small group of women who participated in this study had minimal needs related to aging or lifestyle changes or perhaps were not willing to acknowledge a need for special adaptations or features built in to the garments. Even the participant who was in a wheelchair did not list any special concerns or recommendations to these questions.

Phase three of the study provided another point of view about what baby boomer women are looking for in clothing. The baby boomer women in this study provided an additional, rich perspective to add to data obtained earlier in the study about the clothing preferences of bloggers in this age range; in addition, the feedback obtained about the individual garments and outfits designed for the study will be useful to aid in the development of future garment prototypes, and this provides a starting point for inclusive apparel design for this age group. The next chapter will extend this discussion to discuss and identify implications for future research. 


\section{Chapter 7 Conclusions and Recommendations}

The purpose of this study was to expand apparel design strategies using an inclusive design framework to evaluate baby boomer women's clothing preferences through their fashion blogs. In addition, it was important to design and construct a minicollection of clothing to provide physical garments that potential users interacted with to inform additional recommendations for future apparel prototypes designed for boomer women.

\section{Conclusions}

The conclusions from this study follows the three research questions and therefore will address three areas. The first area discusses the specific clothing characteristics that baby boomers, the bloggers, identified as important that in turn later informed the apparel design prototypes. This section will be organized by the ID review criteria created from the four themes that emerged through data analysis of the blogs. The second area discusses the inclusive design framework and will specifically evaluate the use of the framework for apparel design aimed at boomer women with a range of abilities. This section will be organized by the phases outlined in the inclusive design toolkit and are Manage, Explore, Create and Evaluate. In addition, this section will discuss the apparel design process and garment prototyping as a critical part of inclusive apparel design. The third section will discuss the use of social media and specifically the blogs that informed apparel design for baby boomer women.

The following is a summary of the major findings and conclusions drawn from this research after a restatement of the research questions. This discussion is followed by the researcher's recommendations and a final reflection. 
Research Questions. The following questions guided the research process:

1. What specific clothing characteristics do baby boomer women identify as important and how can their preferences be incorporated into inclusive apparel designs?

2. How can the inclusive design framework be adapted to apparel design strategies aimed at boomer women with a range of physical abilities?

3. How can blogs as a form of social media be used to inform apparel design for specific segments of the female boomer cohort?

Garment types. The specific types of garment that the bloggers identified as important overlapped with the preferred styles of the study participants. Both groups identified a range of preferred top styles with longer lengths that extended beyond the waistline and offered coverage to the mid-section and hip areas. Both groups of boomer women in the study were interested in tops with sleeves or clothing options to provide coverage to the arms such as cardigans and jackets. Garments in the mini-collection that successfully addressed the need for arm coverage were the knit cardigan and the tunic dress however it is unclear if the knit wrap/sarong and the sleeveless jacket offered suitable solutions in part because they were less traditional solutions. Bloggers as well as study participants were interested in a range of pant styles and lengths and favored fitted or slim fitting styles over fuller pants. Both the fitted pant and the ankle pant were acceptable styles for the study participants.

The styles in the mini-collection that were most successful for this study included the sleeveless top paired with the cardigan, knit pant, tunic dress, swing top, the 
sleeveless jacket and ankle pant. The maxi skirt was moderately successful however the (cropped) printed top was not acceptable to the study participants.

In general, the bloggers were far more interested in trends than most of the study participants with the exception of several of the bloggers that were primarily interested in creating a unique sense of style over adopting trends. Bloggers included dresses and specifically the maxi-dress trend as essential additions to their wardrobes. The study participants were interested in trends but less apt to incorporate multiple trends into a single outfit such as the printed top and maxi skirt. In addition, the study participants appeared to be more cautious about trends and were not inclined to consider trends that strayed too far from their preferred silhouettes and styles such as the cropped print top and maxi skirt mentioned here. Both groups of boomer women expressed an interest in modified trends to accommodate an aging market. Modifying garment styles to suit the needs of baby boomer women will require a clear understanding of their preferred styles and silhouettes that will include both adequate length and coverage. Modifications could include slight changes to the silhouette, changes in length or amount of ease, or additional features or qualities that make the garments easier to wear.

In addition when designing garments to meet a range of needs to include individuals with disability, it will be necessary to identify styles and silhouettes that will be appealing to both women with and without disabilities. One solution worth noting in the mini-collection was the sleeveless swing top because it was rated as fashionable and wearable by most of the women in the study. Lastly, if apparel trends conflict with a woman's sense of personal style then those styles most likely will not be considered for 
wear as was the case of the maxi skirt and the study participant that only wore shorter skirt lengths.

Fashion and style. Fashion is subjective and the baby boomer women in the study had a variety of opinions about fashion related to their own sense of personal style. Garments in the mini-collection that the study participants found fashionable were not necessarily clothing they would wear. Some women questioned the age appropriateness of some clothing styles in the mini-collection and this was also a topic that bloggers discussed in their posts. Both women in the study and the bloggers had a variety of different opinions about what was considered age appropriate clothing. Baby boomer women in the study varied in their approaches to fashion and style so providing style options is one solution that may help boomer women express their individuality in addition to potentially counteracting invisibility. Increased invisibility as a part of the aging process was a concern for some of the bloggers and they were interested in clothing options that could help them to maintain a more visible appearance.

Belts, ties and slits were all added features that provided options to change the look of several garments that were also inclusive to wheelchair users. Garments that can satisfy multiple needs for example, those that can both change the look of a garment while accommodating a disability may add additional value to inclusively designed garments and appeal to a larger group of women. The garments in the mini-collection that were successful at satisfying multiple needs were the cardigan, tunic dress and swing top. The cardigan and tunic dress offered tying options and the success of the swing top had to do with the silhouette of the garment. In addition the magnetic closure with 
embellishment also worked well and provided style combined with an easy to use fastener.

Color and pattern. The bloggers added color to their wardrobes to add visual interest in their outfits and study participants mentioned a desire for more color options when evaluating garments in the mini-collection. In addition, printed garments were favored as a way to liven up a neutral colored ensemble. It is not uncommon in the fashion industry to change color offerings and print designs to align with current trends and this is one way to add interest to garments designed for baby boomer women without dramatically changing a style or silhouette. Overall, the blue color scheme of the minicollection was successful. The study participants responded favorably to the blue color palette and the addition of the one-of-a-kind prints in the mini-collection. Several women expressed an interest in additional color options for the sleeveless top and tunic dress.

Fit. Good fit was a perception that varied among the study participants and specifically when evaluating the fit of the cardigan and the knit pant. The fit of these two garments was quite successful based on feedback from some of the study participants but not adequate by others depending on personal preferences about what was deemed too loose or too tight fit. The bloggers also had multiple opinions about what constituted good fit. In addition, personal fit ideals may change as a result of aging or disability and in turn influences apparel design preferences. Fit was closely linked with comfort by the study participants and will be discussed in the next section.

Comfort. Bloggers and study participants alike were interested in garments that were soft and appealing to the sense of touch so comfortable fabrics were essential for apparel designed for this age group. The study participants rated comfort highly for all of 
the outfits in the collection because they were soft to the touch and perceived as breathable and lightweight. Good fit was also associated with comfort by the study participants. Options for fit adjustments or features that allow for size variations could provide increased comfort to garments designed for baby boomer women. The elastic waistbands in the maxi-skirt and both pants as well as the adjustable waistband in the knit pant were successful design components that addressed comfort in the collection. Many of the bloggers as well as the study participants were vocal about preferences for comfortable garments that were also stylish and it was clear that they were not interested in giving up comfort for a fashionable appearance. This was particularly true for bloggers that were dealing with disabilities. Garments such as the cardigan, tunic dress, and the swing top in the mini-collection were evaluated as comfortable and attractive and may appeal to a broader range of women with and without disabilities.

Fabric, quality and construction. Bloggers and study participants indicated an interest in quality fabrics and in a high level of garment construction. The linen knit fabric of the cardigan and the silk fabric used in Outfit D were suitable high quality fabric choices for the mini-collection. Adding special features or trims also appealed to the women in the study and was another way to add value to apparel designs. The embellished magnetic closure on the tunic dress is a good example of this type of feature that was a successful addition to the dress in the collection. Fabrics trims added to the cardigan and tunic dress were well received by most of the study participants. Several participants felt that the trim on the cardigan affected the versatility of the garment so this suggests a need to consider what types of garments are best suited for trims that won't detract from versatility. 
Versatility. The bloggers indicated interest in versatility and this included interchangeable garment features and/or garments that have multi-uses or could be interchangeable to create different outfits. Special attention should be given to the specific types of features that may appeal to boomer women that may help them present their personal styles. The importance of versatility was harder to determine among the study participants even though they rated the mini-collection as very versatile.

Ease of wear. Simplicity in design is fundamental for designing inclusive prototypes that suit a range of needs and abilities. Educating consumers about garment qualities that may make dressing easier will be necessary and specifically for untraditional designs such as the sleeveless jacket and maxi skirt. These two garments were designed to be easy to wear but were perceived as complicated to put on and take off. It will be essential to assess the willingness on the part of older consumers to adopt new styles that may be easier to wear but less familiar. In addition, it will be valuable to explore additional options beyond magnets favored in the study, for garment closures that could accommodate a range of needs related to limitations with dexterity.

\section{Evaluation of the Inclusive Design Framework for Apparel Design}

Manage phase. Project management was a continual process and necessary to facilitate the design of the prototypes for the mini-collection. The manage phase connected all of the phases of concept development that began with exploration of the bloggers needs that informed the development of inclusive apparel prototypes. Because the mini-collection was comprised of multiple garments it was necessary to constantly review and refine the individual garments that made up four distinctly different outfits in 
order to create a cohesive mini-collection. It was essential to consider multiple options in order to make the garments more inclusive to a larger number of baby boomer women. Two activities presented in the Manage phase of inclusive design were particularly helpful. They were, review progress and refine the garment designs for evaluation in the last phase of the study. In addition the project goals were refined to prepare for the next phase of prototype development and this will be discussed in the recommendations section.

In general, the ID framework addressed the entire process of designing and manufacturing inclusive products. This study was focused on the prototype development stage for apparel so some of the activities were not applicable to this research in the Manage phase. Two activities that were not applicable were, build a business case and ensure that all project partners share a common understanding. Flexibility is built into the inclusive design process so it was necessary to utilize only those activities that were beneficial to the project.

Explore phase. The guiding question in the explore stage is, what are the needs? Five activities were provided to aid in determining the baby boomer's needs. The create a stakeholder map activity consisted of identifying the key individuals that were involved in the project and this included both the bloggers and study participants as end users. The observe users activity included the analysis of blog images and texts that resulted in a rich data source that directly informed the apparel designs. The generate personas activity was somewhat useful and resulted in a general summary of the product users, the bloggers. However, because the study included an extensive and detailed process for data analysis the generate personas activity was not necessary for this project. 
Generating personas may be useful for ID projects that don't include such a thorough process to identify the needs. The describe user journeys activity was not applicable to this study. Lastly, the capture needs list overlapped with data analysis because the needs were listed during data analysis.

Inclusive design advocates an individualized approach to evaluating the success of ID product outcomes. The review criteria was an exceptionally beneficial tool that was developed from the main themes during data analysis of the blogs. From the themes, review criteria was developed that both informed the apparel design objectives as well as guided evaluation of the garment outcomes. In addition, aesthetic criteria were incorporated into the review criteria to increase the likelihood of product (garment) acceptance.

Create phase. The guiding question for the create phase was, How can the needs be met? Several activities that were outlined as part of ID concept design are also inherently a part of the apparel design process and they were stimulate ideas and concept development. Concept development included incorporating a combination of ideas within a single garment design. The Create activities were focused on meeting the needs to provide inclusive apparel design solutions. The make prototypes activity was vital to the study to explore different ways to develop ID solutions that may interest baby boomer women. The garment prototypes were developed and refined in order to have physical garments for baby boomer women to interact with and evaluate. Attention was give to quality construction and finishing details. This is not always the case for inclusive design prototyping but it was necessary for this particular study so participants could have an authentic experience with the apparel prototypes during evaluation. 
The design process followed the basic guidelines for ID concept development however the apparel design process at times was creative and non-linear. It was both helpful and necessary to periodically revisit the design objectives to remain focused about inclusive design. Reflection and documentation were important activities for all stages of apparel design development but varied by garment because the design process was somewhat unique for the different styles. The researcher as designer carefully balanced both aesthetic and inclusive features within a single garment design to elicit feedback with the intention to eventually start the design process over again and make the needed improvements to the next set of prototypes. Prototype development is an ongoing process and does not stop with a single evaluation of the garments. As stated earlier, prototype development is a critical stage in apparel design that is ongoing and requires multiple evaluations and iterations before a final product is perfected and ready for production. This was the first attempt at getting closer to developing inclusive apparel designs for baby boomer women with a range of needs.

Evaluate phase. The guiding question for the evaluate phase was, how well are the needs met? The review criteria was an important part of the evaluation phase because as explained before, the garments were evaluated based on criteria developed from the needs determined from the baby boomer's blogs. Prior to garment evaluation with boomer women, the garments were tested with users that included a boomer woman, the researcher and her advisor as part of the test with users activity. This was helpful to identify potential concerns earlier in the design process.

The estimate exclusion activity was a tool provided on the EDC website. It has the potential to provide valuable information for apparel designers to better understand how 
design decisions impact the users ability to interact with the garments. The calculator was designed to estimate exclusion based on criteria that did not always translate to interactions with apparel products. This was understandable because it was not designed specifically to evaluate the unique qualities of clothing. The exclusion calculator was thought provoking and while it was not completely applicable to apparel design it created awareness about limitations that included vision, hearing, thinking, dexterity, reach, stretch and locomotion. The final activity in the Explore phase was present the evidence. Presenting the evidence included an evaluation of the strengths and weaknesses of the prototypes and is the foundation for future prototype development in the next cycle of concept design.

The inclusive design toolkit offered a well-defined and straight-forward process $f$ to follow for inclusive concept design for this study. The steps were easy to follow and the process was flexible and easily adapted to apparel design. Tools were provided to help move the design process along and/or to help document and evaluate the different phases of the project. A number of the activities were not applicable to inclusive apparel design and specifically for this research because of the limited scope of the project that was not concerned with the manufacturing phase of product development. This did not hinder the project in any way. The ID toolkit will be most helpful as an educational tool for new designers that are in the early stages of inclusive design. The ID toolkit provides an appropriate amount of information and tools to walk designers through the entire process efficiently, at no cost and is available to anyone with internet access. 


\section{The Use of Blogs in Research to inform Apparel Design for Baby Boomer Women}

The blogs were a vital source of information for this study and provided the fashion and style opinions from baby boomer women that were needed to design the initial apparel prototypes. The blogs were personal and candid and covered a variety of topics that enabled the researcher to better understand the motivations behind the bloggers' apparel choices at a particular point in time. This helped the researcher to better identify possible options for inclusive apparel design that may be better suited for baby boomer women. In addition the opinions presented by the style bloggers with health issues or disabilities added another layer of valuable information that directly aided in the design of apparel that could be more inclusive to a range of needs. The multiple viewpoints that were obtained from the bloggers about their clothing needs in addition to the feedback from the small group of study participants provided valuable information to inform the next stage of prototype development.

\section{Recommendations}

Inclusive apparel design for baby boomer women. The recommendations presented here will provide suggestions for the next stage of prototype development for apparel designed for baby boomer women and are intended for apparel designers, researchers and current and prospective students that are interested in inclusive apparel design and specifically for baby boomer women. In addition, this study documented and reflected on the apparel design process to capture design activity focused on problem solving that will add to the general body of design scholarship in the field of textiles and apparel design. 
The researcher recommends further studies to gain additional information from baby boomer women about their apparel needs. Both the blog data and study participants provided valuable information for this study however due to the relatively small sample size, additional information is needed from baby boomer women in order to refine the apparel designs as well as to better understand this group of women and what motivates their clothing selections.

Additional information is needed related to perceptions about age appropriate clothing, self-concept, personal style and invisibility. Specifically, the topic of invisibility is complex and warrants considerably more research. It will be beneficial to explore the relationship and power between wearer and spectator in appearance management and specifically as it relates to visibility and older women.

Both the bloggers and study participants identified many different garment styles that they preferred and the bloggers specifically identified versatility as an added value to their wardrobes. Based on the development of a versatile mini-collection and from information obtained from both the blog data as well as from the study participants, it will be beneficial to gain an even deeper understanding about the types of garment modifications that boomer women find desirable beyond the styles and the features that were mentioned as successful in the study and summarized in the conclusions section.

In-depth interviews will be the next logical step and are recommended to gather the additional information needed from a more diverse group of boomer women. It will be necessary to reach out to women with a range of health issues and disabilities to gain a better understanding of the personal challenges and obstacles they face when looking for clothing. This is key to a user centered inclusive design approach. In addition, current 
blog data will add another layer of information about current fashion and style preferences. It will also be beneficial to include a more diverse sample of baby boomer women that write blogs to include additional blogs written by women outside the United States.

Additional, information is needed to further identify and narrow down several key styles that boomer women prefer for the next stage of prototype development. It will be advantageous to design prototypes with multiple variations or modifications for a limited number of styles to focus specifically on the variations or modifications. These variations or modifications should incorporate current trends that boomers identify as desirable as well as inclusive features designed to meet a range of needs.

Inclusive design framework for apparel design. This study fully documented and evaluated the inclusive design framework, something that had been lacking in other studies. The inclusive design framework and specifically the EDC Inclusive Design Toolkit, is recommended as a useful tool to guide designers, researchers and students interested in concept development for inclusive apparel designs. The specific ID phases that include Manage, Explore, Create, and Evaluate, complement and overlap with other apparel design processes that include documentation, inspiration and information gathering, as well as experimentation exploration and prototyping.

The ID review criteria developed for this study is highly recommended as a useful tool to guide and evaluate inclusive apparel design that is focused on the specific clothing needs of boomer women that include both functional and aesthetic considerations.

Blogs in research to inform apparel design for baby boomer women. This study specifically adds to the limited body of research that uses blogs as data in 
qualitative research. Blogs provided valuable data and specifically for apparel designed for baby boomer women with a range of needs. The blogs provided information that was detailed and personal and not readily available elsewhere. Blogs in general should be considered a rich data source that could be equally helpful for similar qualitative research studies that require candid opinions about a range of personal topics that are available in the public domain, on the internet.

Researcher Reflection. Apparel designers and researchers have the potential to dramatically improve the quality of life for many individuals that find their apparel needs changing as a result of the aging process. It is my hope that this research will inspire and encourage future designers to consider a career path that will be committed to developing creative and inclusive design solutions for future generations. 


\section{References}

Administration on Aging. (2011). Retrieved 2013 from Administration on Aging: www.aoa.gov.

NC State University Center For Universal Design. (n.d.). Retrieved 2013 from NC State University: http:www.ncsu.edu/project/design-projects/udi/center-for-universaldesign/the-principles-of-universal-design/

The UCLA Internet Report- "Surveying the Digital Future Year Three (2003).Retrieved From UCLA Center for Communication Policy: http://images.forbes.com/fdc/mediaresourcecenter/UCLA03.pdf.

University of Cambridge. (2013). Retrieved 2015, from Inclusive design toolkit: www.inclusivedesigntoolkit.com/betterdesign2/whatis/whatis.html.

Atchley, R. (1989). A continuity theory of normal aging. The Gerontological Society of America, 29 (2), 183-190.

A Well Styled Life (2015a, March 29). The vanishing older women-part 2 [Web log post]. Retrieved from http://www.awellstyledlife.com/how-society-sees-older-women/

A Well Styled Life (2015b, March 29). The vanishing older woman-part 3 [Web log post]. Retrieved from http://www.awellstyledlife.com/how-older-women-can-remain-visible/\#more-2147

Bausch, P., Haughey, M., \& Hourihan, M. (2002). We blog: Publishing online with weblogs. Indianapolis: Wiley Pub.

Belk, R. (1988a). My possessions myself. Psychology Today, 22 (7-8), 50-51.

Belk, R. (1988b). Possessions and the extended self. Journal of Consumer Research , 15, $139-168$.

Bichard, J., Coleman, R., \& Langdon, P. (2007). Does my stigma look big in this? Considering acceptability and desirability in the inclusive design of technology products. In C. Stephanidis (Ed.), Universal Access in Human Computer Interaction. Coping with Diversity (pp. 622-631). Springer Berlin Heidelberg.

Bold, Blind, Beauty (2014a, Jan.19). Braille design [Web log post]. Retrieved from https://boldblindbeauty.com/2014/01/19/sparkling-sundays-braille-design/

Blind, Bold, Beauty (2014b, Oct. 25). Abstract musings [Web log post]. Retrieved from https://boldblindbeauty.com/2014/10/25/shoe-lovin-saturdaysabstract-musings/ 
Bold, Blind, Beauty (2015a, Jan. 27). How can I be fashionable in the new year if I am a Blind or visually impaired woman [Web log post]. Retrieved from https://boldblindbeauty.com/2015/01/27/trending-tuesdays-how-can-i-be-fashionablein-the-new-year-if-i-am-a-blind-or-visually-impaired-woman/

Bold, Blind, Beauty (2015b, March 3). Dare to be daring [Web log post]. Retrieved from https://boldblindbeauty.com/2015/03/03/trending-tuesdays-dare-to-be-daring/

Bold, Blind, Beauty (2015c, March 21) How to make a skirt in 3 minutes [Web log post]. Retrieved from https://boldblindbeauty.com/2015/03/21/how-to-make-a-skirtin-3-minutes/

Bold, Blind, Beauty (2015d, April 1). Graphic tee, killer jeans \& heels [Web log post]. Retrieved from https://boldblindbeauty.com/2015/04/01/graphic-tee-killer-jeans-

Borland, H. \& Akram S., Age no barrier to wanting to look good: Women on body image, age and advertising. Qualitative Market Research ,10 (3), 310-333.

Brault, M. W. (2012). Americans with disabilities: 2010 household economic studies. Current Populations Report, U.S. Census Bureau, U.S. Department of Commerce, Washington D.C.

Brisenden, S. (1986). Independent living and the medical model of disability. Disability, Handicap \& Society , 1 (2), 173-178.

Candy, F., \& Williams, A. (2011). Cinderella, you can go the the ball: inclusive footwear design at the intersection of medicine and fashion. Include 11 (pp. 1-10). London: Helen Hamlyn Centre, Royal College of Art.

Carroll, K., \& Kincade, D. (2007). Inclusive design in apparel product development for working women with physical disabilities. Family and Consumer Science Research Journal , 35 (4), 289-315.

Centers for Disease Control and Prevention. (2013). The state of aging and health in America 2013. Retrieved from http://www.cdc.gov/aging/pdf/stateaging-health-in-america-2013.pdf

Chang, H. J., Yurchisin, J., Hodges, N., Watchravesringkan, K., \& Ackerman, T. (2013). An investigation of self-concept, clothing selection motivation, and life satisfaction among disabled consumers. Family and Consumer Sciences Research Journal , 42 (2), 162-176.

Chenail, R. (2011). Qualitative researchers in the blogosphere: Using blogs as diaries and data. The Qualitative Report , 16 (1), 249-254. 
Choi, N., Dinitto, D., Eysenbach, G. (2013). The digital divide among low-income homebound older adults: Internet use patterns, ehealth literacy, and attitudes toward computer/internet use. Journal of Medical Internet Research, 15 (5), 1-21.

Clandinin, D. (Ed.). (2006). Handbook of narrative inquiry: Mapping a methodology. Thousand Oaks, CA: Sage.

Clandinin, D. J., \& Connelly, F. M. (2000). Narrative inquiry: Experience and story in qualitative research. CA: Jossey-Bass.

Clandinin, D., Pushor, D., \& Orr, A. (2007). Navigating sites for narrative inquiry. Journal of Teacher Education, 58 (21).

Clarke J.; Van Amerom, G. (2008). A comparison of blogs by depressed men and women. Issues in mental health nursing, 29 (3), 243-264.

Clarkson, J. (2007). Designing for a more inclusive world. Retrieved 2015, from The Centre for Excellence in Universal Design: http://universaldesign.ie/What-isUniversal-Design/Conference-Proceedings/universal-design-for-the-21st-centuryirish-internationalperspective/designing-a-more-inclusive-world.html.

Collier, M. (2004). Approaches to analysis in visual anthropology. In T. Van Leeuwen, \& C. Jewitt, The handbook of visual analysis. Sage.

Coleman, R., \& Myerson, J. (2001). Improving life quality by countering design exclusion. Gerontechnology , 1 (2), 88-102.

Consumer Expenditure Survey. (2013). Retrieved 2015, from U.S. Department of Labor: www.bls.gov/cex/csxgeography.htm

Costa, P. T., \& McCrae, R. R. (1980). Still stable after all of these years: Personality as a key to some issues in aging. In P. B. Baltes, \& O. G. Brim (Eds.), Life-Span Development and Behavior (Vol. 3, pp. 65-102). New York: Academic Press.

Crotty, M. (1998). The foundations of social research. London: Sage.

Cross, N. (1982). Designerly ways of knowing. Design Studies, 3(4), 221-227.

Cross, N. (2001). Designerly ways of knowing: Design discipline versus design science. Design Issues, 17 (3), 49-55.

Csikszentmihalyi, M., \& Rochberg-Halton, E. (1981). The meaning of things: Domestic symbols and the self. UK: Cambridge University Press.

Czaja, S. (2005). The impact of gaining on access to technology. Accessibiity and 
Computing, The Newsletter of ACM SIGACCESS, 83. Retrievedfrom https://www.researchgate.net/ profile/David_Rose21/publication/234806294_Cognition_and learning_meeting the _ challenge_of individual_difference/link/5554a20308ae6943a871039a.pdf\#page $=9$.

Czaja, S., Charness, N., Fisk, A., Hertzog, C., Nair, S., Rogers, W. \& Sharit, J. (2006). Factors predicting the use of technology: Findings from the center for research and education on aging and technology enhancement (CREATE). Psychology of Aging, 2, 333-352.

Dankl, K. (2013). Style, strategy and temporality: How to write an inclusive design brief. The Design Journal , 16 (2), 159-174.

De Klerk, H. M., \& Ampousah, L. (2003). Th physically disabled woman's experience of self. Disability and Rehabilitation , 25 (19), 1132-1139.

Denzin, N., \& Lincoln, Y. (2003). Collection and interpreting qualitative materials. Sage.

Eckman, M., Damhorst, M., \& Kadolph, S. (1990). Toward a model of the in-store purchase decision process: Consumer use of criteria for evaluating women's apparel. Clothing and Textiles Research Journal , 8 (2), 13-22.

Elegantly Dressed and Stylish (2015) About [Web log post]. Retrieved from http://www.elegantlydressedandstylish.com/about-me/

Ellinwood, J.G. (2011). Fashion by design. NY: Fairchild Books.

Emmison, M., Smith, P., \& Mayall, M. (2013). Researching the visual (Vol. 2). Sage.

Etchell, L., \& Yelding, D. (2004). Inclusive design: Products for all consumers. Consumer Policy Review , 14 (6), 186-193.

Fifty Not Frumpy (2015a, April 11). Warm weather jackets [Web log post]. Retrieved from https://fiftynotfrumpy.blogspot.com/2015/04/warm-weather-jackets.html

Fifty Not Frumpy (2015b, May 6). Maxi dresses [Web log post]. Retrieved from https://fiftynotfrumpy.blogspot.com/2015/05/maxi-dresses.html

File, T. \& Ryan, C. (2013). Computer and internet use in the United States: 2013. America in community survey reports ACS-28. U.S. Census Bureau,Washington DC.

Fiore, A. M. (2008). The digital consumer. Clothing \& Textiles Research Journal , 26 (2), 177-190.

Fiore, A., Kimle, P., \& Moreno, J. (1996a). Aesthetics: A comparison of the state of the 
art outside and inside the field of textiles and clothing, Part one: Creator and creative process. Clothing and Textiles Research Journal , 14 (1), 30-40.

Fiore, A., Kimle, P., \& Moreno, J. (1996b). Aesthetics: A comparison of the state of the art outside and inside the field of textiles and clothing, Part two: Object. Clothing and TextilesResearch Journal , 14 (2), 97-107.

Fiore, A., Moreno, J., \& Kimle, P. (1996c). Aesthetics: A comparison of the state of the art outside and inside the field of textiles and clothing, Part three: Appreciation process, appreciator and summary comparisions. Clothing and Textiles Research Journal, 14, 169-184.

Flattering 50 (2013, March 17). Casual dressing over 50: 6 easy pieces. [Web log post]. Retrieved from www. Flattering50.com/2013/03/casual-dressing-over-50-6-easypieces-50.html

Flattering 50 (2014). Style over 50: Repurposing the sleeveless LBD [Web log post]. Retrieved from http://www.flattering50.com/search?updated-min=2014-0101T00:00:00-08:00\&updated-max $=2015-01-01$ T00:00:00-08:00\&max-results $=50$

Flattering 50 (2015a). About Me (Weblog post). Retrieved from http://www.flattering50.com/p/since-turning-50-i-find-dressing-well.html

Flattering 50 (2015b). Buying a dress: 10 tips for women over 50. [Web log post]. Retrieved from www. Flattering50.com/2015/02/buying-dress-10-tips-for-womenover-50.html

Follette, Story, Mueller, \& Mace (1998). The Universal Design File: Designing for People of All Ages and Abilities. NC, USA: NC State University.

Fort Smith Stylista (2014a, June 2) Trending now: My old dress [Web log post]. Retrieved from http:/fortsmithstylista.blogspot.com/search?updated-min=2013-12-31T22:00:0008:00\&updated-max $=2014-07-28 \mathrm{~T} 18: 55: 00-05: 00 \&$ max-results $=50 \&$ start $=22 \&$ by date $=$ false

Fort Smith Stylista (2014b, June 16). Liked it so much I did it again [Web log post]. Retrieved from http://fortsmithstylista.blogspot.com/search?updated$\min =2013-12-31 \mathrm{~T} 22: 00: 00-08: 00 \& u p d a t e d-\max =2014-07-28 \mathrm{~T} 18: 55: 00$ 05:00\&max-results $=50 \&$ start $=22 \&$ by-date $=$ false

Frayling, C. (1993). Research in art and design. Royal College of Art Research Paper. 1 (1), London.

Freund, A., \& Baltes, P. (1998). Section, optimization, and compensation as strategies of life management: Correlations with subjective indicators of successful aging. 
Psychology and Aging , 13 (4), 531-543.

Friedman, K. (2008). Research into, by and for design. Journal of Visual Arts Practice, 7 (2), 153-160.

Furlong, M. (2012). Overview of the boomer market. In H. Moody, \& J. Sasser, Aging: Concepts and controversies. CA: Sage.

Furlong, M. (2007). Turning silver into gold: How to profit in the new boomer marketplace. FT Press.

Gillham, B. (2005). Research Interviewing: The range of techniques.

Goffman, E. (1971). Relations in public: Microstudies of the public Order. NY: Doubleday.

Goldman, A. (1990). Aesthetic qualities and aesthetic value. The Journal of Philosophy, 23-37.

Gray, C., \& Burnett, G. (2008). Making sense: An exploration of ways of knowing generated through practice and reflection in craft. Proceedings of the Crafticulation \& Education Conference, (pp. 24-26). Helsinki: NordFo.

Gray, C., \& Malins, J. (2004). Visualizing Research: A guide to the Research Process in Art and Design. Aldershot, Hants, England: Ashgate.

Hale, T. (2011). Newswire. Retrieved 2015, from Nielsen: www.nielsen.com/us/en/insights/news/2011/in-u-s-men-are-shopping-more-thanever-while- women-are-watching-more-tv.html.

Halliwell, E., \& Dittmar, H. (2003). A qualitative investigation of women's and men's body image concerns and their attitudes toward aging. Sex Roles, 49 (11/12), 675684 .

Harper, D. (1998). An argument for visual sociology. In J. Prosser (Ed.), Image based research: A sourcebook for qualitative researchers. London: Routledge.

Harper, D. (2002). Talking about pictures: A case for photo elicitation. Visual Studies, 17 (1).

Harrison, B. (2002). Photographic visions and narrative inquiry. Narrative Inquiry, 12 (1), 87-111.

Hekkert, P. (2006). Design aesthetics: Principles of pleasure in design. Psychology Science , 48 (2), 157-172. 
Herriott. (2013). Are inclusive designers designing inclusively? An analysis of 66 design cases. The Design Journal , 16 (2), 138-158.

Holmlund, M., Hagman, A., \& Polsa, P. (2011). An exploration of how mature women buy clothing; Empirical insights and a model. Journal of Fashion Marketing , 15 (1), 108-122.

Hookway, N. (2008). 'Entering the blogosphere': Some strategies for using blogs in social research. Qualitative Research , 8 (1), 91-113.

Howe, I. (2011). Fashioning identity: Inclusive clothing design and spinal cord injuries. Include 2011. London: The Helen Hamlyn Centre For Design.

Howarton, R., \& Lee, B. (2010). Market analysis of fit preferences of female boomers. Journal of Fashion Marketing and Management , 14 (2), 219-229.

Hunt, P. (1998). A critical condition. In T. Shakespeare (Ed.), Disabilities Reader: Social Science Perspectives (pp. 7-19). Continuum International Publishing Group.

Idiosyncratic Fashionistas (2009, August). About me (Web log post). Retrieved from http://idiosyncraticfashionistas.blogspot.com

Internet User Demographics. (2014). Retrieved 2015, from Pew Research Center: Internet, Science \& Tech, www.pewinternet.org/data-trend/internet-use/latest-stats/.

Isaksen, S. G., \& Treffinger, D. J. (2004). Celebrating 50 years of reflective practice: Versions of creative problem solving. Journal of Creative Behavior , 65-92.

Issyvoo, C. (2013, February 27). About sublime mercies (Web log post). Retrieved from http://www.sublimemercies.com/p/about.html

Jackson, H., \& O'Neal, G. (1994). Dress and appearance responses to perceptions of aging.Clothing and Textiles Research Journal , 12 (4), 8-15.

Jacobson, Dorrie (2014, May). About (Web log post). Retrieved from http://www.seniorstylebible.com/2014/05/

Johnson, K. P., Schofield, N. A., \& Yurchisin, J. (2002). Dress as a source of information: A qualitative approach to data collection. Clothing and Textiles Research Journal , 20 (3), 125-137.

Josselson, R. (2011). Narrative research. In F. Wertz, K. Charmaz, L. McMullen, R. Josselson, R. Anderson, \& E. McSpadden, Five Ways of Doing Qualitative Analysis: Phenomenological Psychology, Grounded Theory, Discourse Analysis, Narrative Research and Intuitive Inquiry. NY: The Guilford Press. 
Kaiser, S. B. (1997). The social psychology of clothing: Symbolic appearance in context. NY:Fairchild Pub.

Keiser, S. \& Garner, M. (2013). Beyond design: The synergy of apparel product development. NY: Fairchild Books.

LaBat, K., \& DeLong, M. (1990). Body cathexis and satisfaction with fit of apparel. Clothing and Textiles Research Journal , 8 (2), 43-48.

Lamb, J. M. (2001). Disablitlity and the Social Imortance of Appearance. Clothing and Textiles Research Journal, 19 (3), 134-143.

Lee, D., Im, S., \& Taylor, C. R. (2008). Voluntary self-disclosure of information on the Internet: A multimethod study . Psychology \& Marketing , 25 (7), 692-710.

Lee, Y. (2011). Clothing as an environment for older adults' successful ageing. International Journal of Consumer Studies , 35, 702-710.

Lee, Y., Damhorst, M., Lee, M., Kozar, J., \& Martin, P. (2011). Older women's clothing fit and style concerns and their attitudes toward the use of 3D body scanning. (Sage, Ed.) Clothing and Textiles Research Journal , 30, 102-118.

Lee, Y., \& Sontag, M. (2010). An assessment of the proximity of clothing to self scale for older persons. International Journal of Consumer Studies , 34, 443-448.

Lee, J., \& Steen, C. (2010). Technical Sourcebook for Designers. NewYork: Fairchild, Publications.

Lenhart, A., \& Fox, S. (2006). Bloggers Part 3. Motivation and Content. Retrieved 2015, from Pew Research Center: Internet, Science \& Tech, www.pewinternet.ort/2006/07/19/part-3-motivation-and-content/.

Lewis, C., Medvedev, K., \& Seponski, D. (2011). Awakening to the desires of older women: Deconstructing ageism within fashion magazines. Journal of Aging Studies ,25, 101-109.

Lockwood, L. (2014, 8/25). The neglected market: Boomers. Women's Wear Daily, pp. 4-8.

Macdonald, A. (2004, May). An aesthetics framework for discussing inclusive issues in design. International Design Conference-Design 2004. Dubrovnik.

Macdonald, A. (2013). The inner resource: Enabling the designer within us all-a case study. The Design Journal , 16 (2), 175-196.

Makela, M. \& Nimkulrat, N. (2011). Reflection and documentation in practice-led design 
Research. Paper presented at the Nordic Design Research Conference, Helsinki. Abstract received from http://www.nordes.org/opj/index.php/n13/article/view/98/82.

Manning, M. (2014, 9 9). Huffington Post Healthy Living. Retrieved 12 22, 2014, from Huffington Post: http://www.huffingtonpost.com/margaret-manning/fashion-forolder-women_b_5756636.html.

Martins, S., \& Martins, L. (2012). Ergonomics, design universal and fashion. Work: A Journal of Prevention, Assessment and Rehabilitation, 41 (1), 4733-4738.

McKee, A. (2003). What's interpretation got to do with it? In A. McKee, Textual Analysis. London: Sage.

Measuring America: Computer \& Internet Trends in America. (2014, Feb.). Retrieved 2015, from United States Census Bureau:

www.census.gov/library/infographics/computer_2014.html.

Moody, H. R., \& Sasser, J. R. (2012). Aging concepts and controversies. USA: Sage Publications Inc.

Murthy, D. (2008). Digital ethnography: An examination of the use of new technologies for social research. Sociology, 42 (5), 837-855.

Nam, J., Hamlin, R., Gam, H. J., Kim, J., Kumphai, P., Starr, C., et al. (2007). The fashion conscious-behaviours of mature female consumers. International Journal of Consumer Studies , 31, 102-108.

Newell, A. (2006). "Older peopls as a focus for inclusive design". Gerontechnology , 4 (4), 190-199.

Newell, A. (2000). "User sensitive inclusive design"-in search of a new paradigm. Universal Access in the Information Society, 39-44.

Newell, A. (2003). Inclusive Design or Assistive Technology. In J. Clarkson, S. Keates, $\&$ C. Lebbon (Eds.), Inclusive Design-Design for the whole population (pp. 172181).

Nimkulrat, N. (2007). The role of documentation in practice-led research. Journal of Research Practice, 3 (1), 6.

Nimkulrat, N. (2009). Creation of artifacts as a vehicle for design research. Proceedings of Engaging Artifacts, Norway. Abstract retrieved from http://www.nordes.org/opj/index.php/n13/article/viewFile/33/25.

Not Dead Yet Style (2015a, February 3). Two easy steps to finding your style [Web log 
post]. Retrieved from http://notdeadyetstyle.com/two-easy-steps-to-finding-yourstyle

Not Dead Yet Style (2015b, February 27). Sister act project: Style is ageless [Web log post]. Retrieved from http://notdeadyetstyle.com/sister-act-project-style-is-ageless

Not Dead Yet Style (2015c, March 5). How not to feel your age [Web log post]. Retrieved from http://notdeadyetstyle.com/how-not-to-feel-your-age

Not Dead Yet Style (2015d, April 8). A simple skirt as the core of my summer wardrobe [Web log post]. Retrieved from http://notdeadyetstyle.com/a-simple-skirt-as-coreof-my-summer

Not Dead Yet Style (2015e, April 14). What I wore: Preppy woman [Web log post]. Retrieved from http://notdeadyetstyle.com/what-i-wore-preppy-woman

Oliver, M. (1990). The individual and social models of disability. Joint Wordshop of the Living Options Group and the Research Unit of the Royal College of Physicians on People with Established Locomotor Disabilities in Hospitals, 23 July. http://www.leeds.ac.uk/disability-studies/arciveuk/Oliver/in\%20dis.pdf.

O'Rourke, P. (2015). AARP Magazine. Retrieved 2015, from AARP: www.aarp.org/politics-society/history/info-2014/youngest-baby-boomers-turn50.2.html.

Otiena, R., \& Shweta, L. R. (2007). Influences on clothing perception and preferences among women 18-55 years: A conceptual framework. World Journal of Business Management, 1(2), 47-58.

Pan, B., MacLaurin, T., \& Crotts, J. (2007). Travel blogs and the implications for destination marketing. Journal of Travel Research, 46 (1), 35-45.

Park, J., Morris, K., Stannard, C., \& Hamilton, W. (2014). Design for many, design for me: Universal design for apparel products. The Design Journal, 17 (2), 267-290.

Patton, M. (1990). Qualitative Evaluation and Research Methods (Vol. 2). Sage.

Pedgley, O. (2007). Capturing and analyzing own design activity. Design Studies, 28 (5), 463-483.

Pedgley, O., Wormald, P. (2007). Integration of design projects within a Ph.D. Design Issues, 23 (3), 70-85.

Perrin, A. (2015). Social media usage: 2005-2015. Retrieved 2015, from Pew Research Center: Internet, Science \& Tech: http://www.pewinternet.org/2015/10/08/socialnetworking-usage- 2005-2015/. 
Peters, C., Shelton, J., \& Thomas, J. B. (2011). Self-concept and the fashion behavior of women over 50. Journal of Fashion and Marketing Management , 15 (3), 291-305.

Plus Black Blog (2013a, Februrary 19). Be inspired by style for changing lives at plus black [Web log post]. Retrieved from https://blog.plusblack.co.uk/2013/02/19/beinspired-by-style-for-changing-lives-at-plus-black-2/

Plus Black Blog (2013b, February 22). In retail hell, wanting plus-size retail nirvana? Me too [Web log post]. Retrieved from https://blog.plusblack.co.uk/2013/02/22/in-retailhell-wanting-plus-size-retail-nirvana-me-too/

Plus Black Blog (2013c, November 7). The old ladies rebellion [Web log post]. Retrieved from https://blog.plusblack.co.uk/category/accessible-style/page/3/

Plus Black Blog (2014, October 23). Plus size shopping reality: Wall London [Web log post]. Retrieved from https://blog.plusblack.co.uk/2013/10/23/plus-sizeshopping-reality-wall-london/

Population Projections. (2014). Retrieved 2015, from United States Census Bureau: www.census.gov/population/projections/data/national/2014/summarytables.html.

Postrel, V. (2007). The Substance of Style: How The Rise of Aesthetic Value is Remaking Commerce, Culture and Consciousness. Harper Collins e-books.

Putnam, M. (2002). Linking aging theory and disability models: Increasing the potential to explore aging with physical impairment. The Gerontologist , 42 (6), 799-806.

Radvan, C. (2013). Inclusively Designed Womenswear through Industrial Seamless Knitting Technology. Fashion Practice: The Journal of Design, Creative Process \& Fashion Industry ,5 (1), 33-58.

Rainie, L. (2012). Baby boomers and technology. Retrieved 2015, from Pew Research Center: Internet, Science \& Tech: www, internet.org/2012/03/28/baby-boomers-andtechnology/.

Rainie, L., Madden, M., Boyce, A., Lenhar, A., Horrigan, J., \& Allen, K. (2003, April). The ever-shifting internet population; A new look at internet access and the digital divide. Retrieved 2015, from Pew Research Center Internet, Science \& Tech: www.pewinternet.org/2003/04/16/the-ever-shifting-internet-population-a-new-lookat-internet-access-and-the-digital-divide/.

Saldana, J. (2009). The coding manual for qualitative researchers. Thousand Oaks, CA: Sage.

Salemen, J. P. (2012). "One Size Does Not Fit All" . From Universal Design: 
www.universal design.com/2012-11-16-51-43/lettersandopinions/610-one-size-doesnot=fit-all-html

Salusso, C., Reich, J. J., \& Goldsberry, E. (2006). An alternative approach to sizing apparel for women 55 and older. Clothing and Textiles Research Journal, 24 (2).

Saucier, M. G. (2004). Midlife and beyond: Issues for aging women. Journal of Counseling and Development , 82 (4), 420-425.

Schwandt, T. (1994). Constructivist, Interpretivist Approaches to Human Inquiry . In N. Denzin, \& L. Y., Handbook of Qualitative Research (pp. 118-137). Sage.

Selwyn, N., Gorard, S., Furlong, J., \& Madden, L. (2003). Older adults' use of information and communications technology in everyday life. Ageing and Society, 23(5), 561-582.

Senior Style Bible (2014) Senior style bible [Web log post]. Retrieved from http://www.seniorstylebible.com/2014/05/

Senior Style Bible (2015). About [Web log post]. Retrieved from http://www.seniorstylebible.com/about/

Settersten, R., \& Mayer, K. (1997). The measurement of age, age structuring, and the life course. Annual Review of Sociology, 23, 233-261.

Silvergirl (2015, March 31). April fools [Web log post]. Retrieved from http://silverpooloflightgirl.blogspot.com/2015_03_01_archive.html

Sontag, S. (1972). The double standard of aging. Saturday Review of the Society, 2938.

Stalp, M. C., Williams, R., Lynch, A., \& Radina, M. E. (2009). Conspicuously consuming: The Red hat society and midlife women's identity. Journal of Contemporary Ethnography ,38 (2), 225-253.

Story, M., Mueller, J., \& Mace, R. (1998). The universal design file: Designing for people of all ages and abilities. Retrieved 2013, from NC State University: www.ncsu.edu/ncsu/design/cud/pubs_p/pudfiletoc.htm.

Sublime Mercies (2013, February 27). About sublime mercies (Weblog post). Retrieved from http://www.sublimemercies.com/p/about.html

Sublime Mercies (2014, July 10). Frida Kahlo's back: What you can learn from others' pain [Web log post]. Retrieved fromhttp://www.sublimemercies.com/search?updated$\max =2014-07-20 \mathrm{~T} 20: 07: 00-07: 00 \& \max -\mathrm{results}=3 \&$ reversepaginate $=$ true \&start $=20 \&$ by-date $=$ false 
Szmigin, I., \& Carrigan, M. (2001). Learning to love the older consumer. Journal of Consumer Behavior , 1 (1), 22-34.

The Center for Universal Design NCSU-Home. (2015). Retrieved 2015, from NC State University: www.ncsu.edu/ncsu/design/cud/.

The Red Hat Revolution. (2015). Retrieved 2015, from Red Hat Society: www.redhatsociety.com/about/red-hat-revolution.

Thomas, J. B., \& Peters, C. L. (2009). Silver seniors exploring the self-concept lifestyles and apparel consumption of women over age 65. International Journal of Retail \& Distribution Management, 37 (12), 1018-1040.

Twigg, J. (2007). Clothing, age and body: A critical review. Ageing \& Society, 27, 285305.

(2010). U.S. Census Bureau Data Statistics. United States Department of Commerce, www.census.gov.

Une Femme (2014, June 2). Grown-up dressing redux [Web log post]. Retrieved from http://unefemme.net/2014/06/grown-up-dressing-redux.html

U.S. Census Bureau Data Statistics. (2010). United States Department of Commerce, www.census.gov

Van de Logt, S. (2014). How to look stylish in a wheelchair [Web log post]. Retrieved from http://40plusstyle.com/how-to-look-stylish-in-a-wheelchair/

Van de Logt, S. (2015). Fabulous style has no size or age limit! A style interview with Delilah [Web log post]. Retrieved from http://40plusstyle.com/fabulous-style-has-nosize-or-age-limit-a-style-interview-with-delilah/

Vanderheiden, G., \& Vanderheiden, K. (1992). Guidelines for the design of consumer product to increase their accessibility to persons with disabilities or who are aging. Retrieved 2013, from trace.wisc.edu: www.trace.wisc.edu/docs/consumer_product_guidelines/toc.htm

Wallendorf, M., \& Arnould, E. (1988). "My favorite things": A Cross-cultural inquiry into object attachment, possessiveness, and social linkage . Journal of Consumer Research, 14, 531-547.

Wiles, R., Crow, G., \& Pain, H. (2011). Innovation qualitative research methods: A narrative review. Qualitative Research , 11 (5), 587-604.

Wingate, S. B., Kaiser, S., \& Freeman, C. (1983). Salience of disability cues in functional 
clothing: A multidimensional approach. Clothing \& Textiles Researce Journal , 4, $37-47$.

Woolf, H. B. (Ed.). (1979). Webster's New Collegiate Dictionary. MA: G. \& C. Merriam Company.

Yarnal, C., Son, J., \& Liechty, T. (2011). "She was buried in her purple dress and her red hat and all of our members wore full 'red hat regalia' to celebrate her life": Dress embodiment and older women's leisure: Reconfiguring the ageing process. Journal of Aging Studies , 25, 52-61. 
Appendix 1: Inclusive Design for Baby Boomer Women Poster

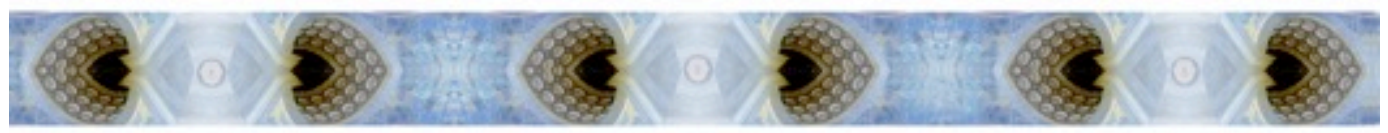

Inclusive Apparel Design for Baby Boomer Women

Clothing Options to Accommodate Variation in Capabilities \& Needs
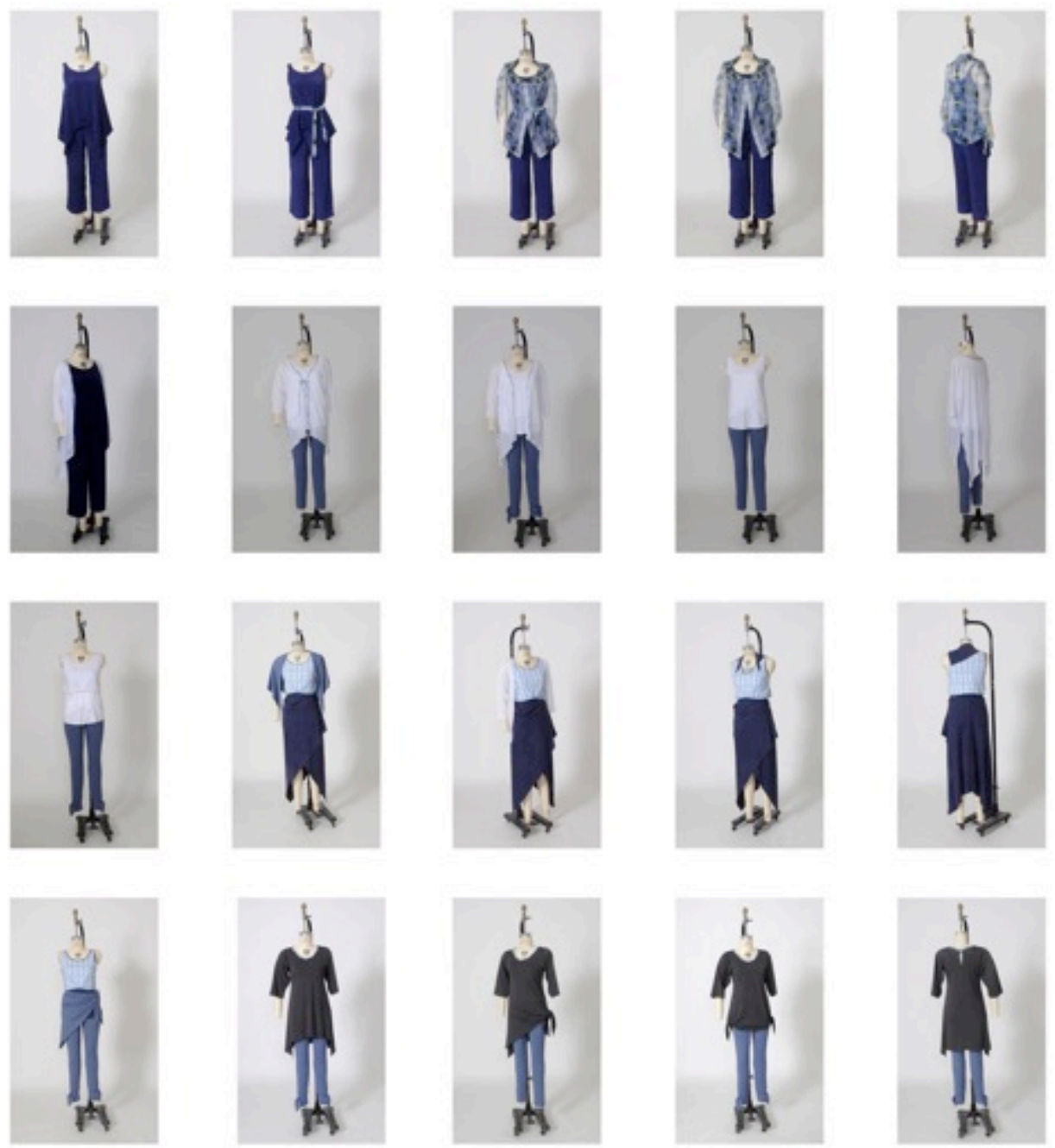

Sandra Starkey, PhD Candidate Dissertation Garment Evaluation Phase 3 Textile \& Apparel Mgmt University of Missouri July 15,2015
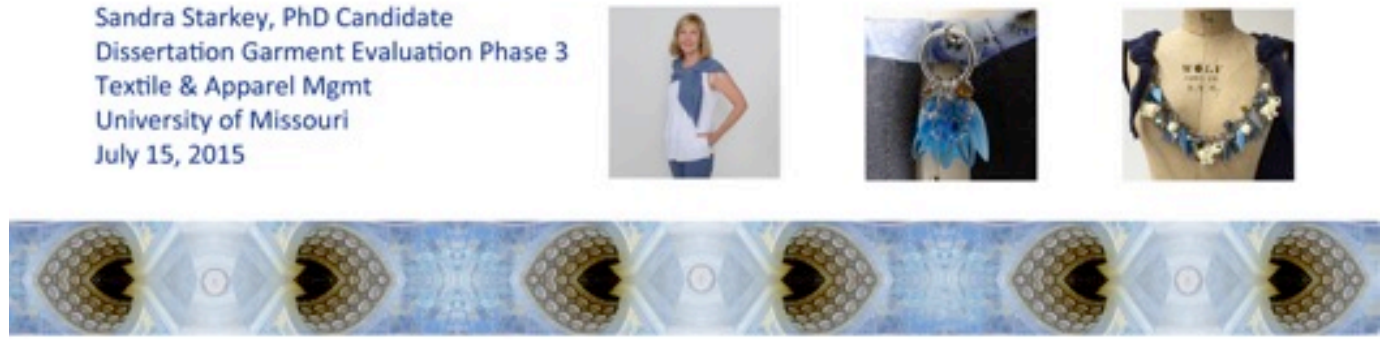


\section{Appendix 2: Blogger Personae Chart}

\begin{tabular}{|c|c|c|c|c|}
\hline $\begin{array}{l}\text { Blog Name } \\
\text { Website }\end{array}$ & $\begin{array}{l}\text { High Latitude Style } \\
\text { http://highlatitudestyle.com }\end{array}$ & $\begin{array}{l}\text { Bold Blind Beautiful } \\
\text { http://boldblindbeauty.com }\end{array}$ & $\begin{array}{l}\text { Idiosyncratic Fashionistas } \\
\text { http://idiosyncraticfashionistas.blogspot.com }\end{array}$ & $\begin{array}{l}\text { Style Crone } \\
\text { http://stylecrone.com }\end{array}$ \\
\hline $\begin{array}{l}\text { Blogger } \\
\text { Name }\end{array}$ & Nicole & Stephanae & Valerie and Jean & Judith \\
\hline $\begin{array}{l}\text { Blogger } \\
\text { Image }\end{array}$ & & & & \\
\hline $\begin{array}{l}\text { Age } \\
\text { Category } \\
\text { Other } \\
\text { Boomers in } \\
\text { this Cohort }\end{array}$ & $\begin{array}{l}\text { Pre-Boomer } \\
\text { Late 40's } \\
\text { Jess, Delilah, } \\
\text { Charlotte }\end{array}$ & $\begin{array}{l}\text { Late Boomer } \\
\text { Ages } 51-60 \\
\text { Jan, Brett, Eugenia, } \\
\text { Patti, Susan A, } \\
\text { Susan B, Alicia, Jodi }\end{array}$ & $\begin{array}{l}\text { Leading Edge } \\
\text { Age } 61-69 \\
\text { Jennifer, Jan }\end{array}$ & $\begin{array}{l}\text { Post Boomer } \\
70+ \\
\text { Dorrie }\end{array}$ \\
\hline $\begin{array}{l}\text { Personae } \\
\text { Description }\end{array}$ & $\begin{array}{l}\text { Nicole is a pre- } \\
\text { boomer but identifies } \\
\text { with women that are } \\
\text { aging and interested } \\
\text { in style. She lives in } \\
\text { Alaska and likes to } \\
\text { provide fashion tips } \\
\text { and advice for aging } \\
\text { women. }\end{array}$ & $\begin{array}{l}\text { Stephanae is a } \\
\text { younger boomer that } \\
\text { manages fashion, } \\
\text { style and aging within } \\
\text { the context of vision } \\
\text { loss. She lives in } \\
\text { Pennsylvania and is a } \\
\text { positive role model } \\
\text { for aging women. }\end{array}$ & $\begin{array}{l}\text { Valerie and Jean are older boomers } \\
\text { that buck the trends while } \\
\text { maintaining a unique sense of style. } \\
\text { They set a great example for women } \\
\text { of all ages (and men) and want older } \\
\text { women to feel comfortable with their } \\
\text { own unique style regardless of what } \\
\text { is currently in fashion. }\end{array}$ & $\begin{array}{l}\text { Judith is a } \\
\text { borderline boomer } \\
\text { and has a youthful } \\
\text { outlook on aging. } \\
\text { She lives in } \\
\text { Colorado and } \\
\text { combines vintage } \\
\text { pieces with new } \\
\text { fashion. }\end{array}$ \\
\hline
\end{tabular}


Appendix 3: ID Exclusion Calculator with Data Generated About Sleeveless Top \#1

\section{Exclusion Calculator}

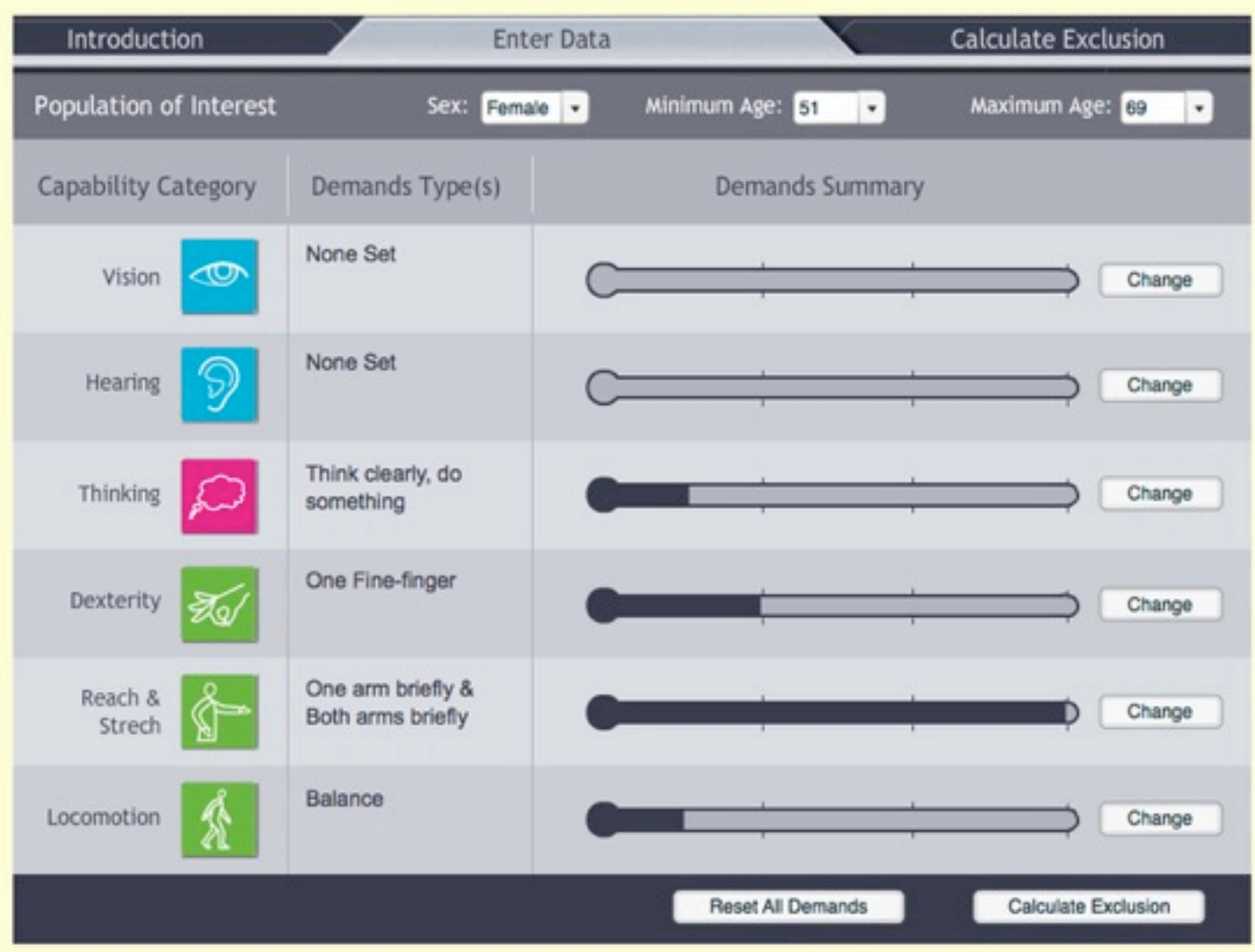




\author{
Appendix 4: Flyer Advertisement for Study Participants
}

\title{
Women Ages to 51 to 69 Your Opinion is needed!
}

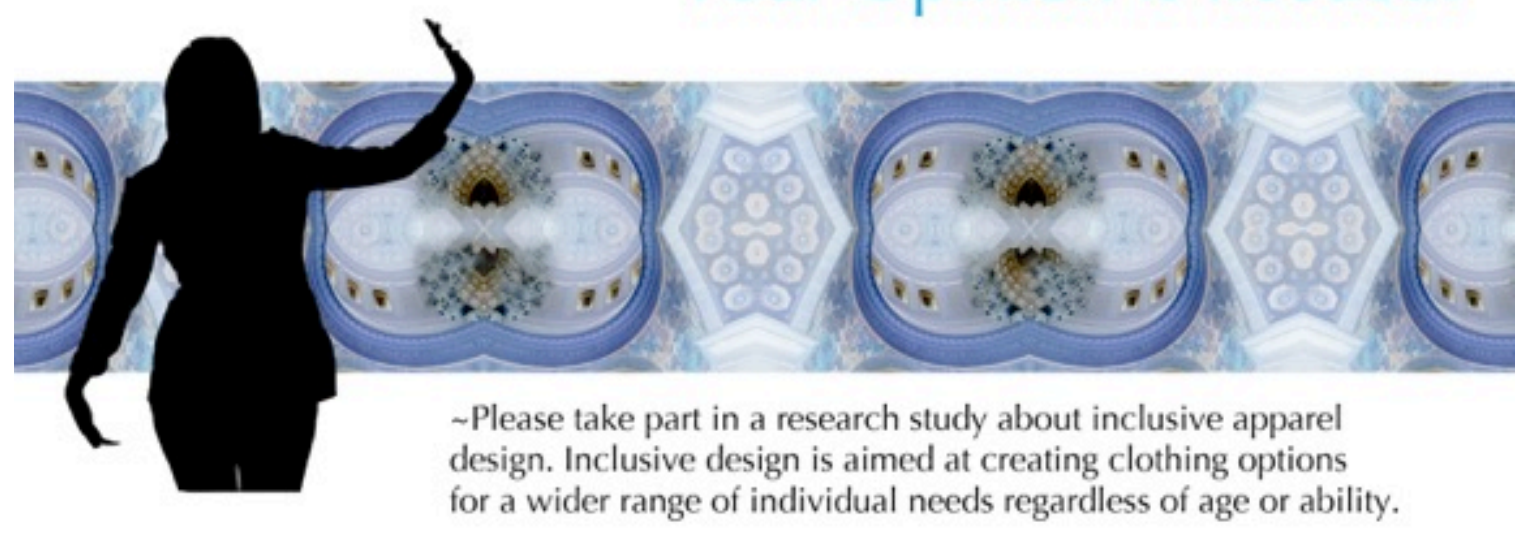

What: View a mini-collection of clothing designed for baby boomer women \& fill out a questionnaire.

When: Wed. July 15th, 2015

Where: Gwynn Hall, Gwynn Lounge Rm 117

Time: ${ }_{4} \mathcal{P M}$ to $6 \mathcal{P M}$, Plan 45 minutes to complete

RSVP: Sandraslsy69@mail.missouri.edu

You will receive a \$10- gift card to Target

$\begin{array}{lll}\text { Contacts: } & \text { Sandra Starkey, PhD Candidate } & \text { Jean Parsons, PhD } \\ & 137 \text { Stanley Hall } & 129 \text { Stanley Hall } \\ & \text { University of Missouri } & \text { University of Missouri } \\ \text { Columbia, MO 65203 } & \text { Columbi, MO, 65203 } \\ & \text { slsyb9email.missouri.edu } & \text { parsonsjlemissouri.edu }\end{array}$


Appendix 5: Static Images from Garment Modeling Video
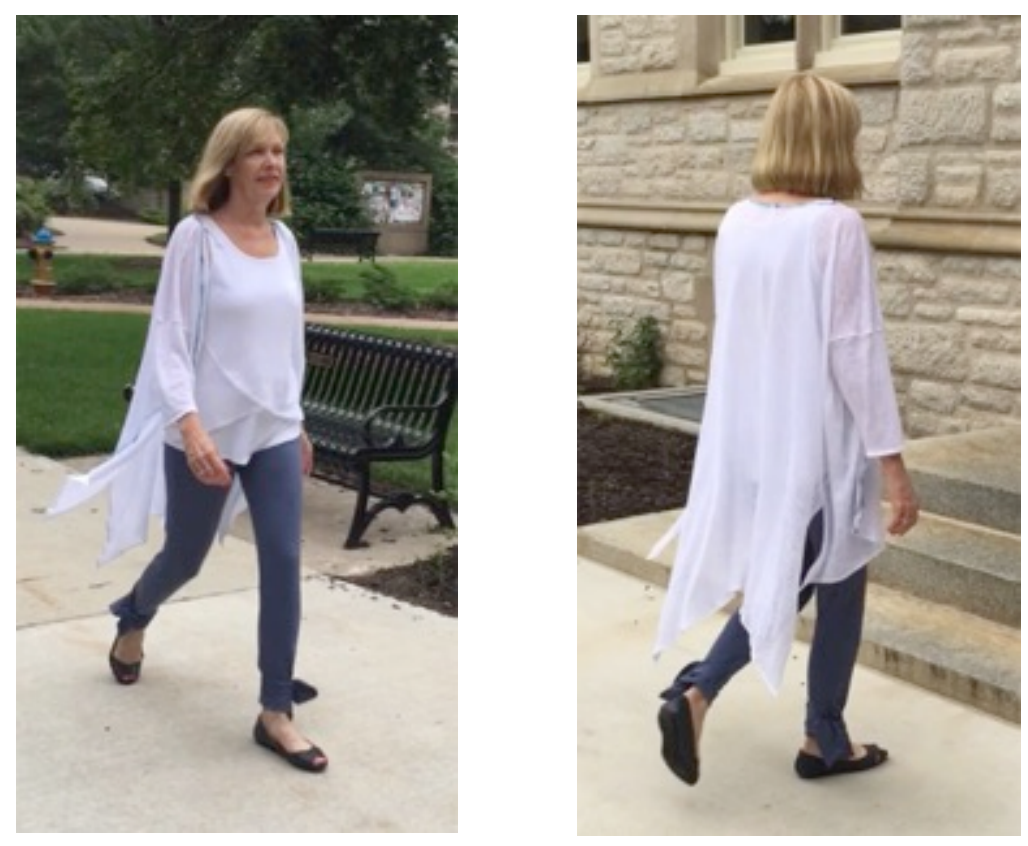

\section{Outfit A}
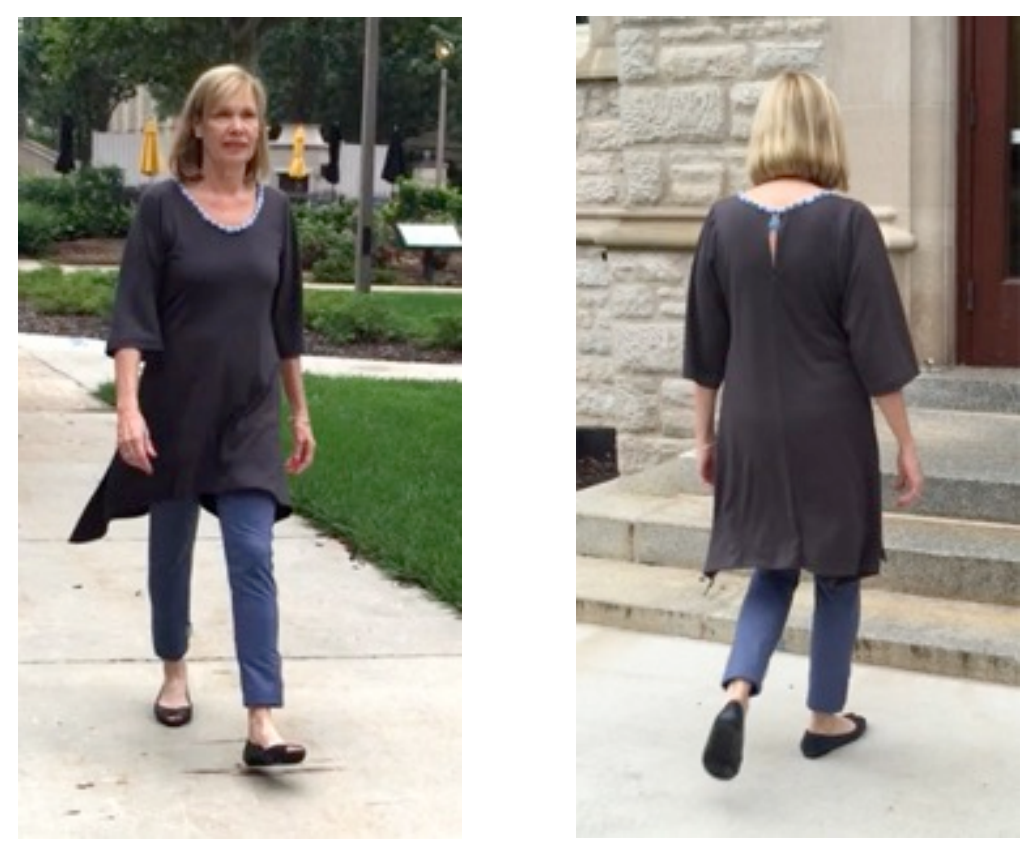

Outfit B 

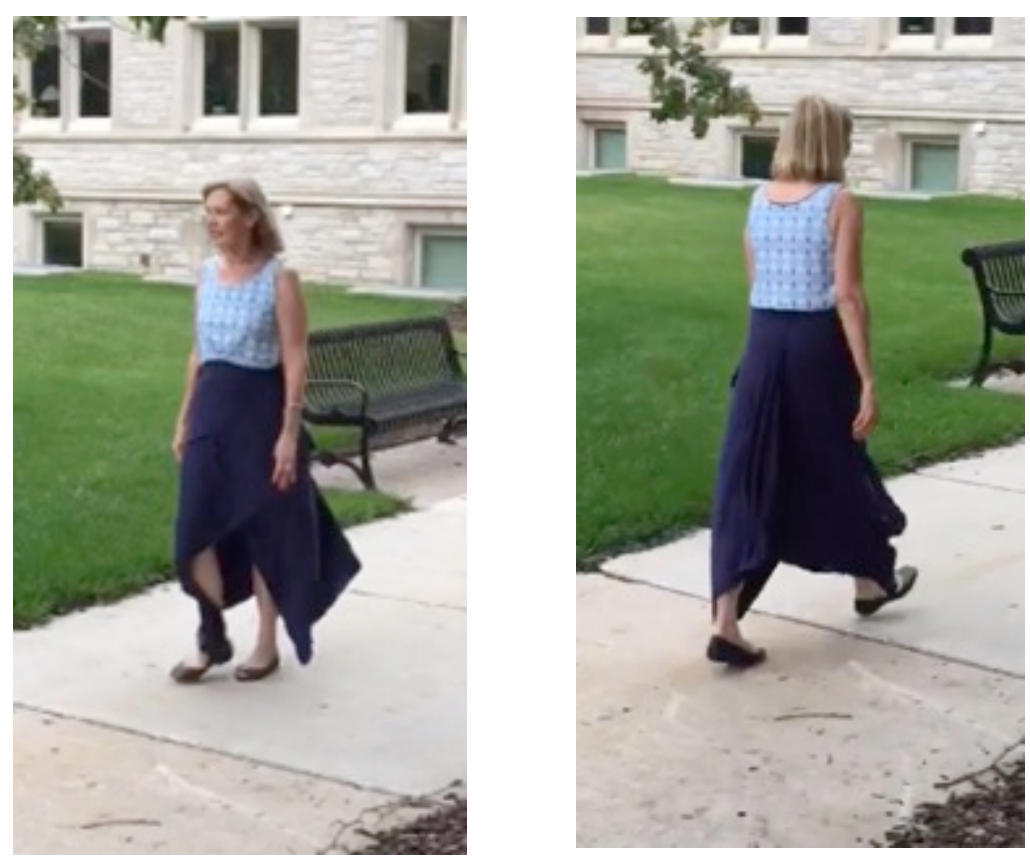

Outfit C
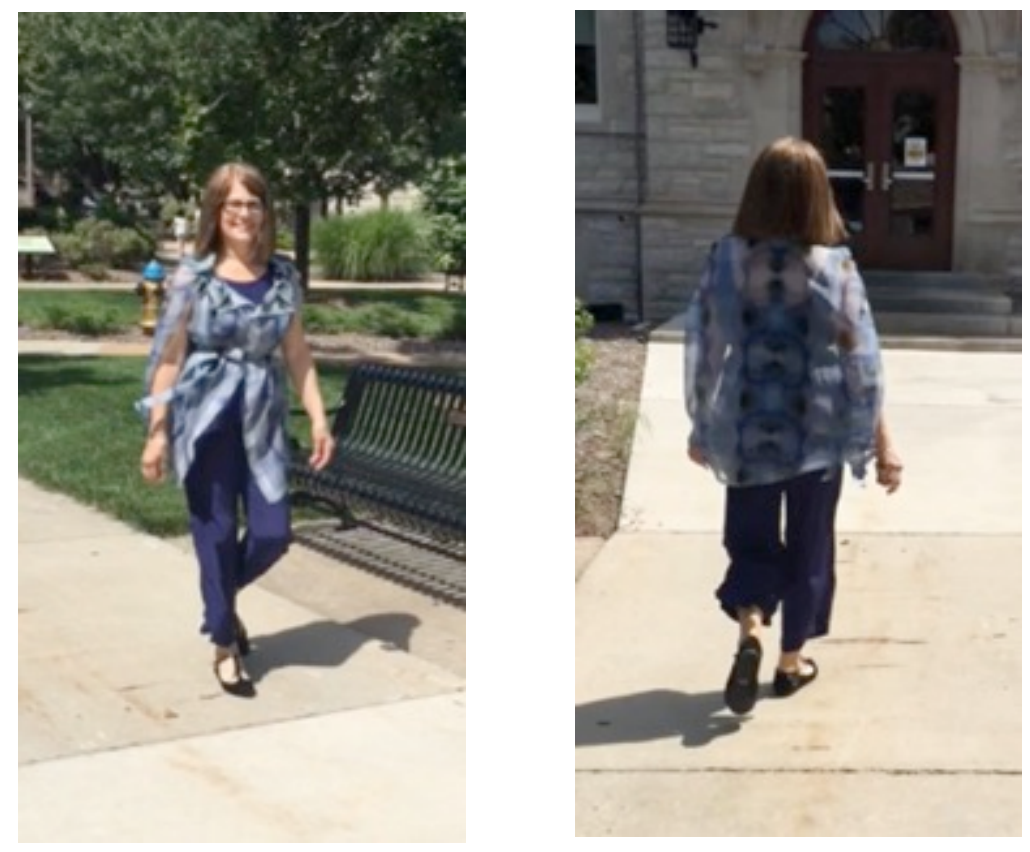

Outfit D 


\section{Appendix 6: Consent Form}

\section{Consent Form \\ Inclusive Apparel Design for Baby Boomer Women}

You are invited to be a part of a study and were selected as a possible participant because you are a woman that falls into the age ranges of 51 to 69 years and are interested in clothing, style and fashion. Carefully read this form and ask any questions you may have before agreeing to participate in this research.

\section{The study is conducted by:}

Sandra Starkey, Ph.D. Candidate (Principal Investigator)

Jean Parsons, Ph.D. (Advisor)

Department of Textile \& Apparel Management

University of Missouri

\section{Background Information:}

The focus of this project is to expand apparel design strategies to accommodate broader markets, especially aging women that fall into the baby boomer age range. This is a segment of the market that is often overlooked by designers and the apparel industry and additional clothing solutions are needed to include aging women with a range of abilities.

\section{Procedures:}

If you agree to take part in the study to evaluate clothing, we ask you to sign this form and do the following:

1. View the garments and review the accompanying information displayed alongside each piece of clothing.

2. View the video that is playing on the large screen that shows the garments worn by a live model.

3. Fill out the questionnaire provided that will document your reactions, opinions and general information about the garments in addition to any information you feel would be helpful to aid in future apparel design for baby boomer women.

4. Allow the researcher to digitally record the meeting in video and audio format.

5. Allow the researcher to review and securely store both the questionnaire and the video/audio tapes for use in the study.

\section{Risks and Benefits of Participation:}

Participation in this study does have minimal risk in which your opinions would be shared. No physical or emotional harm will be involved. Should there be any loss of confidentiality of the project information, the personal data collected for the study including your demographic information, email address and the video and audio recording of the study could identify you as a participant. However, the questionnaire will be secured in a locked cabinet, the audio/video will 
be stored in a password protected file and future publication will not disclose you as a participant. This study may benefit you by helping you understand your own personal clothing preferences.

\section{Compensation:}

You will receive a $\$ 10.00$ Target gift card for taking part in the study.

\section{Confidentiality:}

The records of this study will be kept private. Published reports will not include any information that will make it possible to identify the subject. Research records including your video/audio recordings will be stored digitally in a code-protected file. The questionnaire will be stored as a hard copy that will be locked in a cabinet. Data is only available to the designated researchers. During research analysis the video/audio data may be transcribed into text however there will be no personal information linking your voice to your identity.

\section{Voluntary Nature of the Study:}

Participation in this study is voluntary. Your decision to participate or not to participate will not affect your current or future relations with the University of Missouri. If you decide to participate you are free to not answer any question or withdraw at any time without affecting those relationships.

\section{Contacts:}

Sandra Starkey, Ph.D.

Jean Parsons, Ph.D.

129 Stanley Hall

University of Missouri

137 Stanley Hall

University of Missouri

Columbia, MO 65203

Slsyb9@mail.missouri.edu
Columbia, MO 65203

parsonsj1@missouri.edu
Campus Institutional

Review Board

483 McReynolds Hall

University of Missouri

Columbia, MO 65211

(573) 882-9585

\section{Statement of Consent:}

I have read the above information. I have asked questions and received answers. I consent to participate in the study.

Signature:

Date:

Signature of

Investigator:

Date: 
Appendix 7: Garment Description Sheets

\section{Outfit A Features: (Sleeveless Top, Cardigan, Knit Pant)}

\section{Garment \#1 Sleeveless Top}
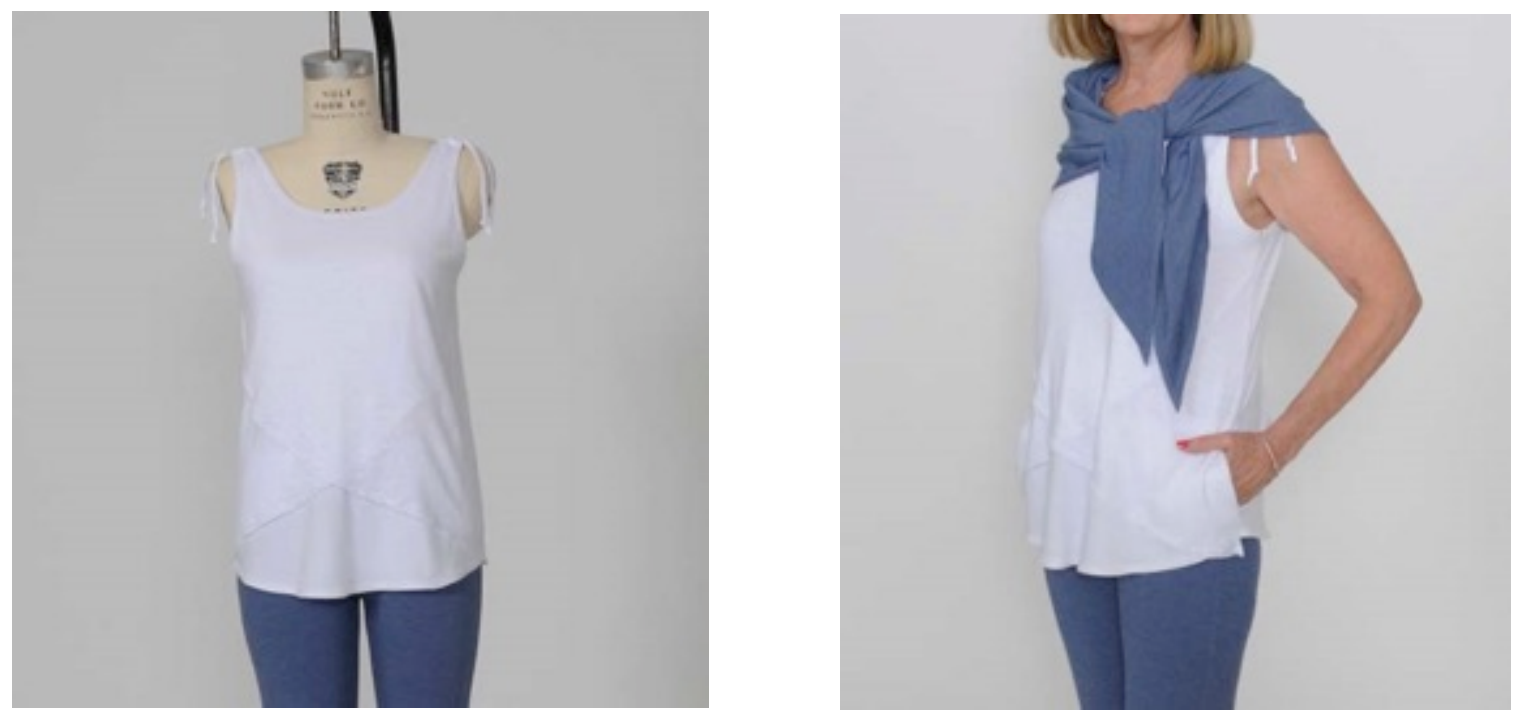

- Two concealed pockets at sides

- Unties at shoulder straps to open up garment when putting on

Fiber \& Fabric: Under layer cotton polyester knit, over layer linen knit Fit: Body-skimming at bust and slightly fuller through waist \& hip

Size: Misses 8 


\section{Outfit A Features: (Sleeveless Top, Cardigan, Knit Pant)}

\section{Garment \#2 Knit Cardigan}

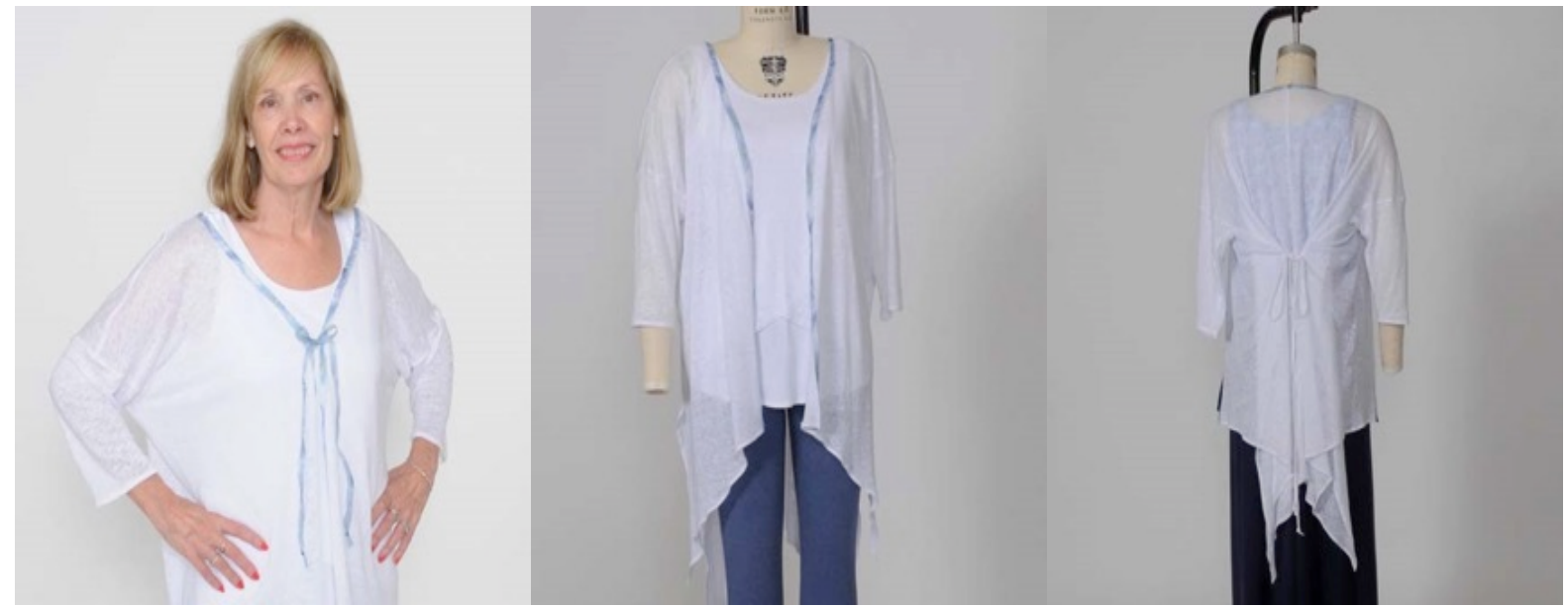

- Multiple tying options, removable ties front and back

- Hem/cardigan tails can be tied at the sides to change the look, side slit

Fiber \& Fabric: Linen, Knit

Fit: Dropped shoulder, loose and flowing

Size: One size fits most 


\section{Outfit A Features: (Sleeveless Top, Cardigan, Knit Pant)}

\section{Garment \#3 Knit Pant}
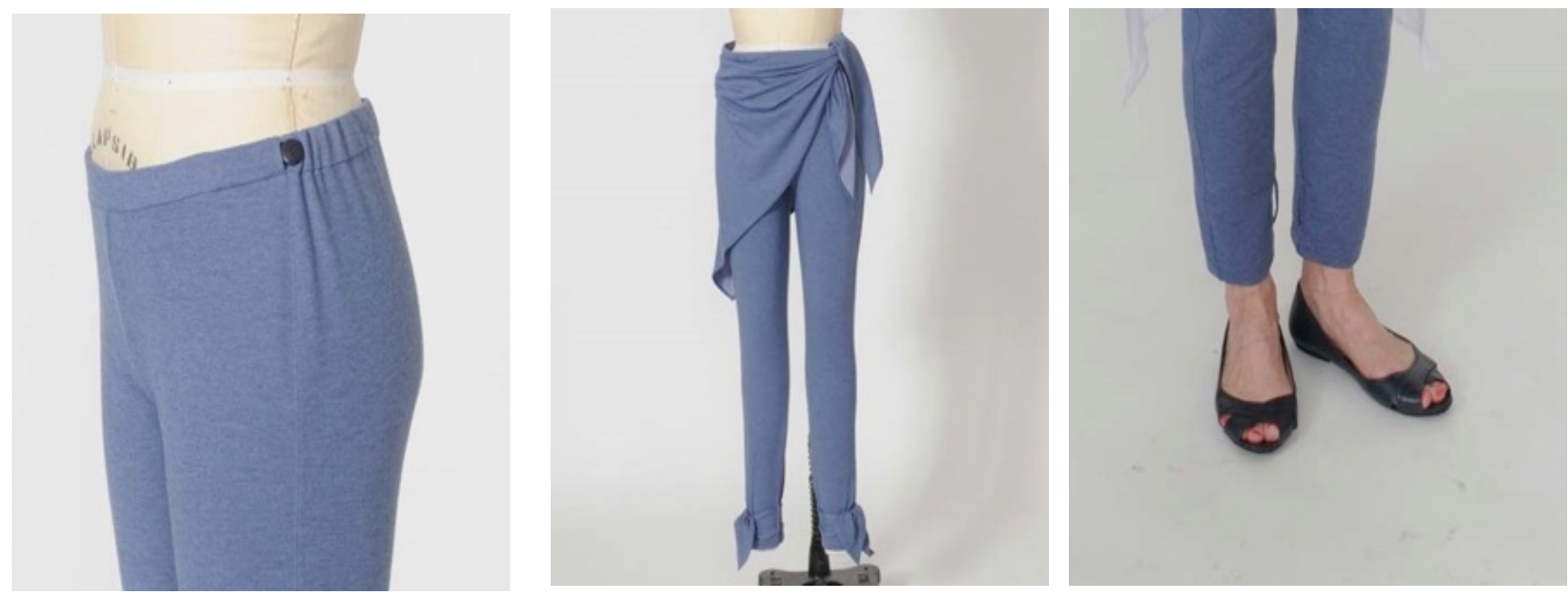

- Adjustable elastic waistband

- Detachable sarong waist-wrap

- Removable ankle ties

Fiber \& Fabric: Polyester, rayon, spandex, knit

Fit: Body-skimming/not tight

Size: Misses 8 


\section{Outfit B Features: (Tunic/Dress)}

\section{Garment \#4 Tunic/Dress}
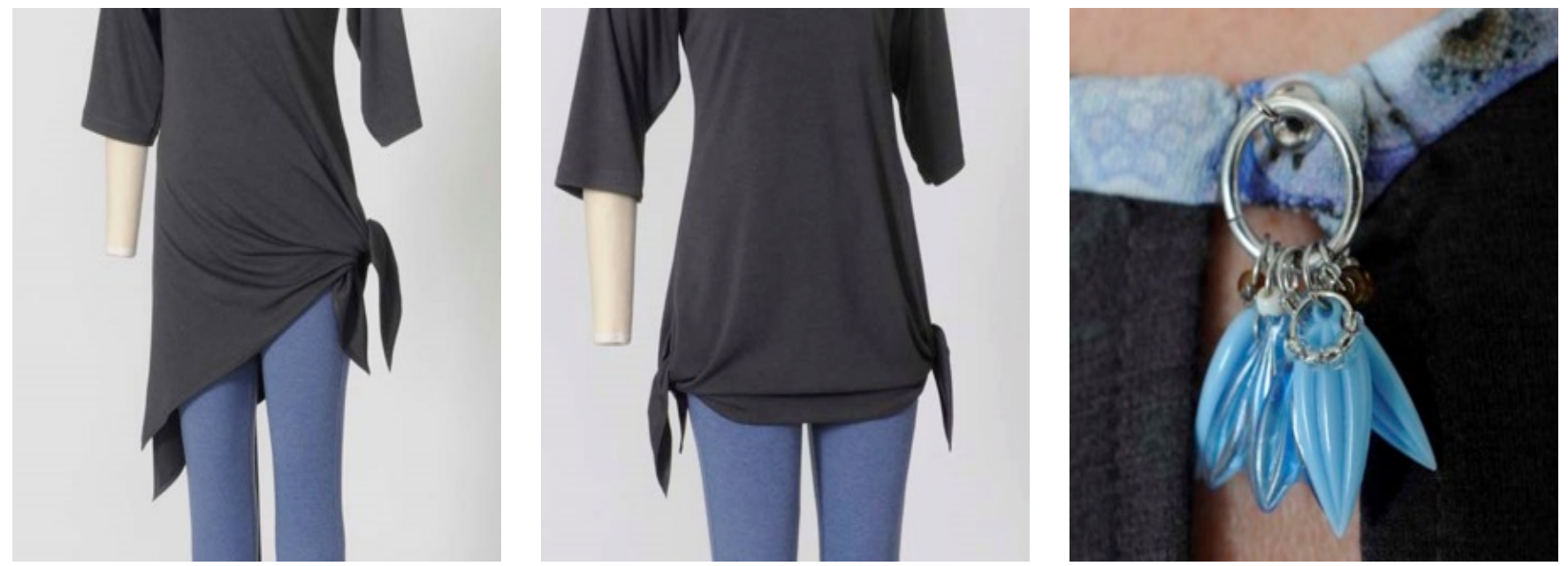

- Side slits with multiple tying options

- Magnetic closure at back neckline

- Detachable magnetic jewelry piece at back closure

Fiber \& Fabric: Polyester, rayon, knit

Fit: Fitted at bust and flared at waist and hip

Size: Misses 8 


\section{Outfit C Features: (Print Top Over Navy Tank with Maxi}

Skirt)

\section{Garment \#5 Print Top over Navy Tank}
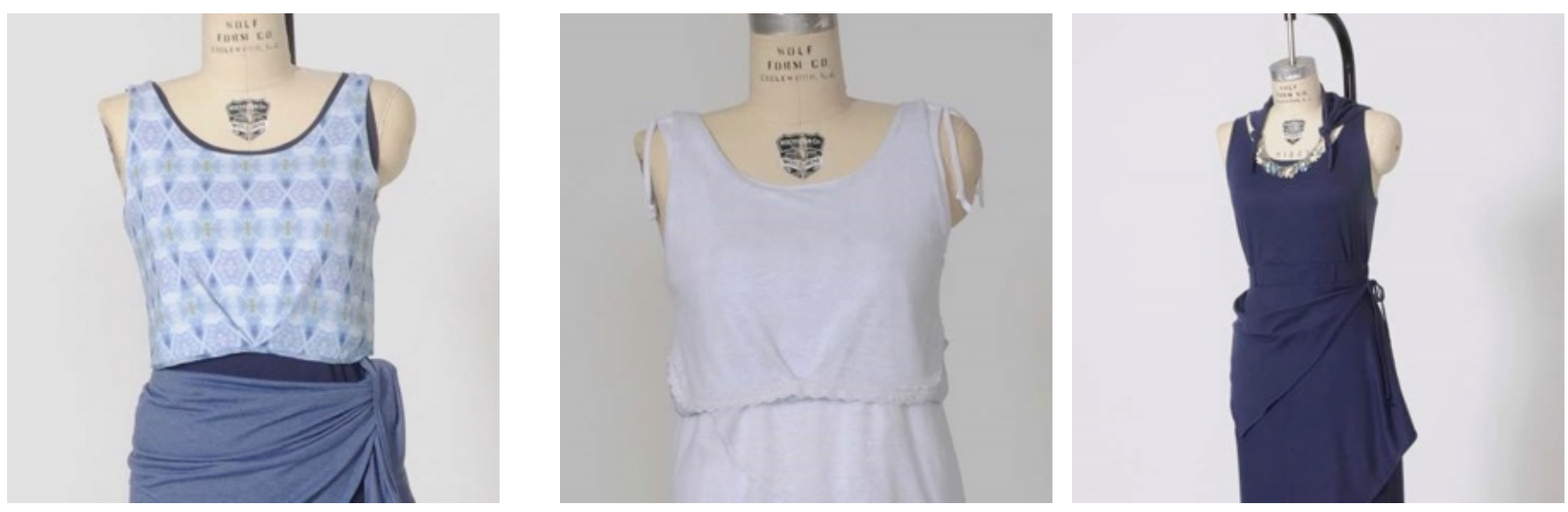

- Reversible print top can be worn as the white top in middle photo

- Layers over longer navy knit (right photo) or white sleeveless top (see poster)

- Original digitally printed textile design

Fiber \& Fabric: Cotton knit (left), linen knit (right)

Fit: Fitted at bust, hangs away from body at the bottom

Size: Misses 8 


\section{Outfit C Features: (Print Top Over Navy Tank with Maxi}

\section{Skirt)}

\section{Garment \#6 Maxi Skirt}

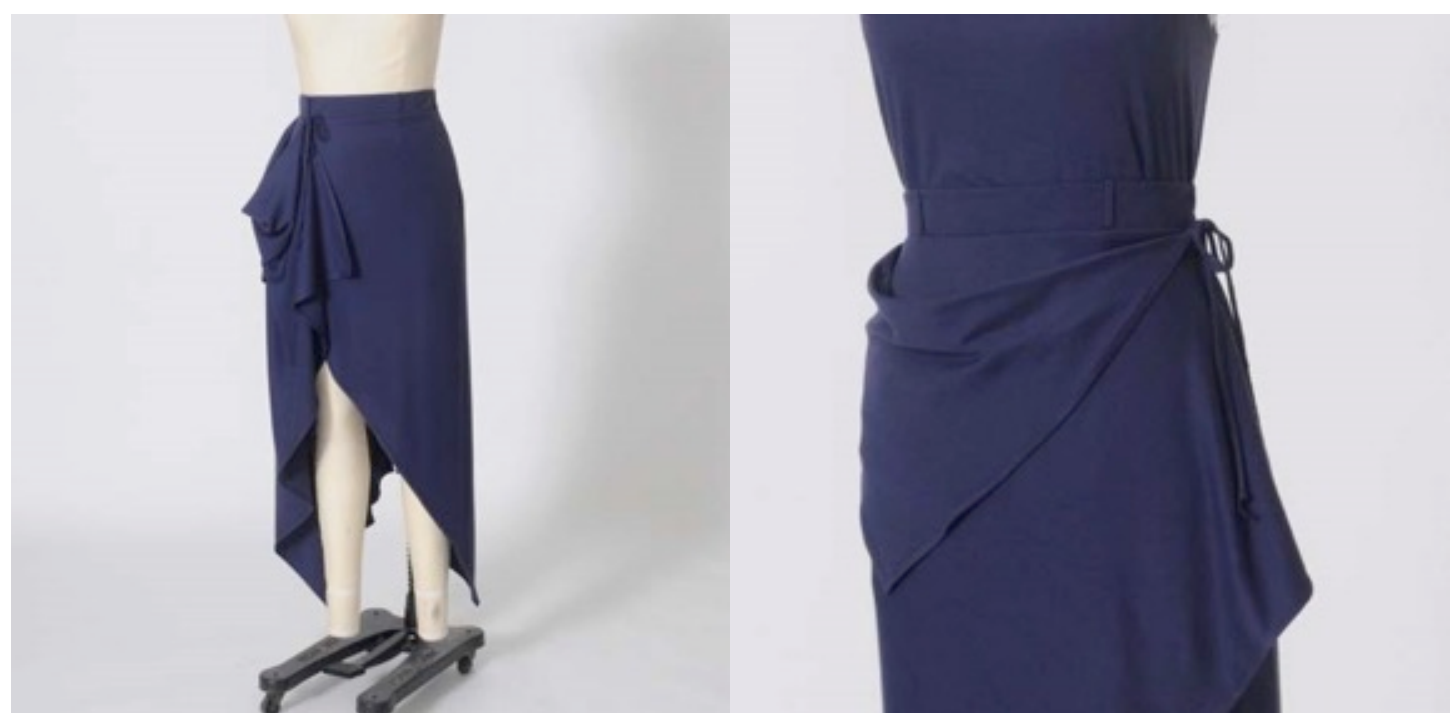

- Front wrap/drape can be tied at any belt loop to change the look

- Elastic waistband

- Tummy camouflaging front wrap

Fiber \& Fabric: Polyester, cotton, knit

Fit: Fitted waistline, body-skimming draped skirt

Size: Misses 8 


\section{Outfit D Features: (Sleeveless Jacket, Sleeveless Top, Ankle}

\section{Pants)}

\section{Garment \#7 Sleeveless Jacket}
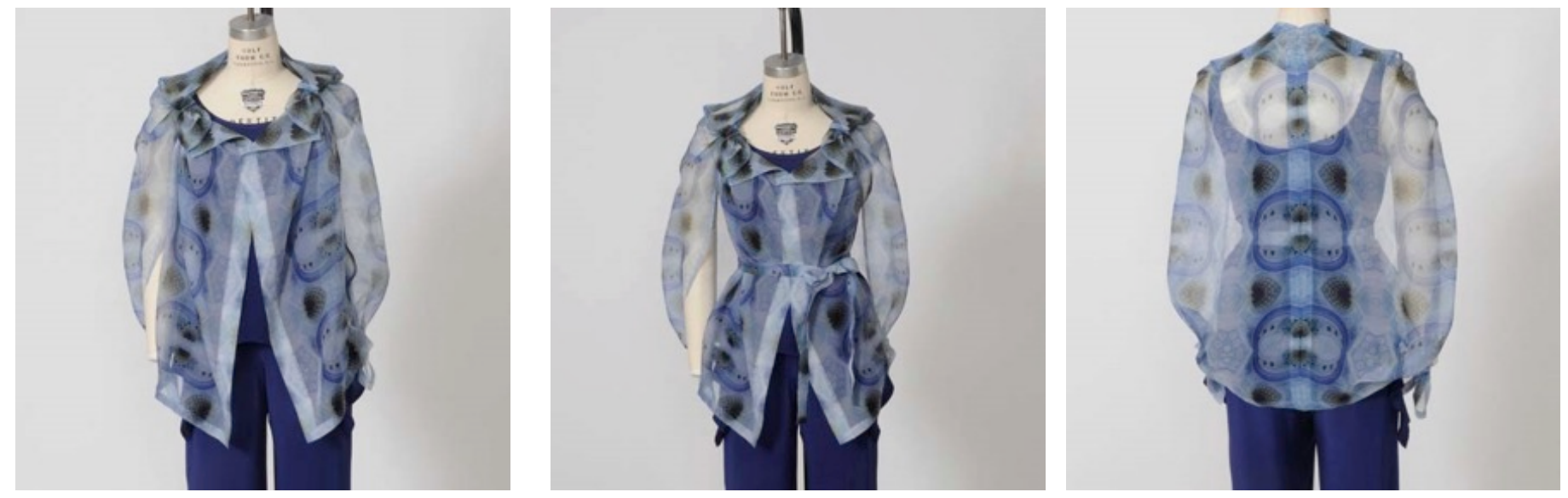

- Jacket front separates from the back into three pieces if needed for ease in putting on and taking off

- Generous open side slit for arms with sheer coverage

- Original digitally printed textile design

- Multiple Belt options to adjust fit. Front can be belted while back left loose (middle \& right photos).

Fiber \& Fabric: Silk organza

Fit: Loose with optional fitted waist

Size: Misses 8 


\section{Outfit D Features: (Sleeveless Jacket, Sleeveless Top, Ankle}

\section{Pants)}

\section{Garment \#8 Sleeveless Swing Top}
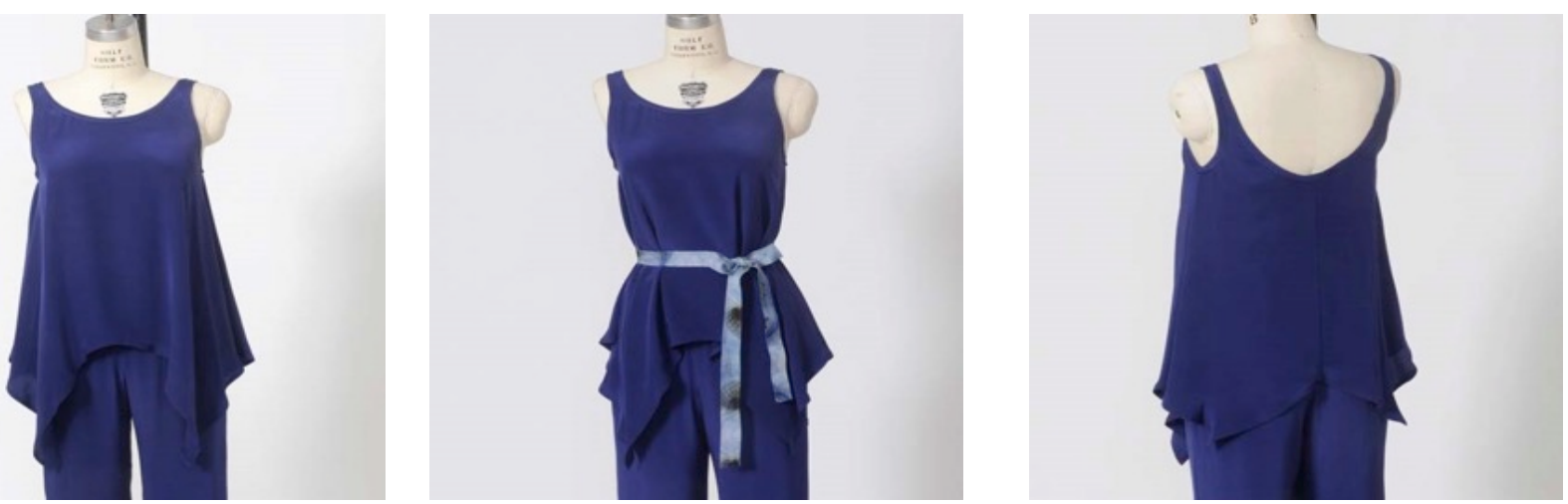

- Fuller drape at the sides

- Shorter front and back hemline in comparison to sides

- Higher neckline in front and lower in back

Fiber and Fabric: Silk charmeuse

Fit: Fitted at bust and fuller through the waist and hip

Size: Misses 8 


\section{Outfit D Features: (Sleeveless Jacket, Sleeveless Top, Ankle}

\section{Pants)}

\section{Garment \#9 Ankle Pant}
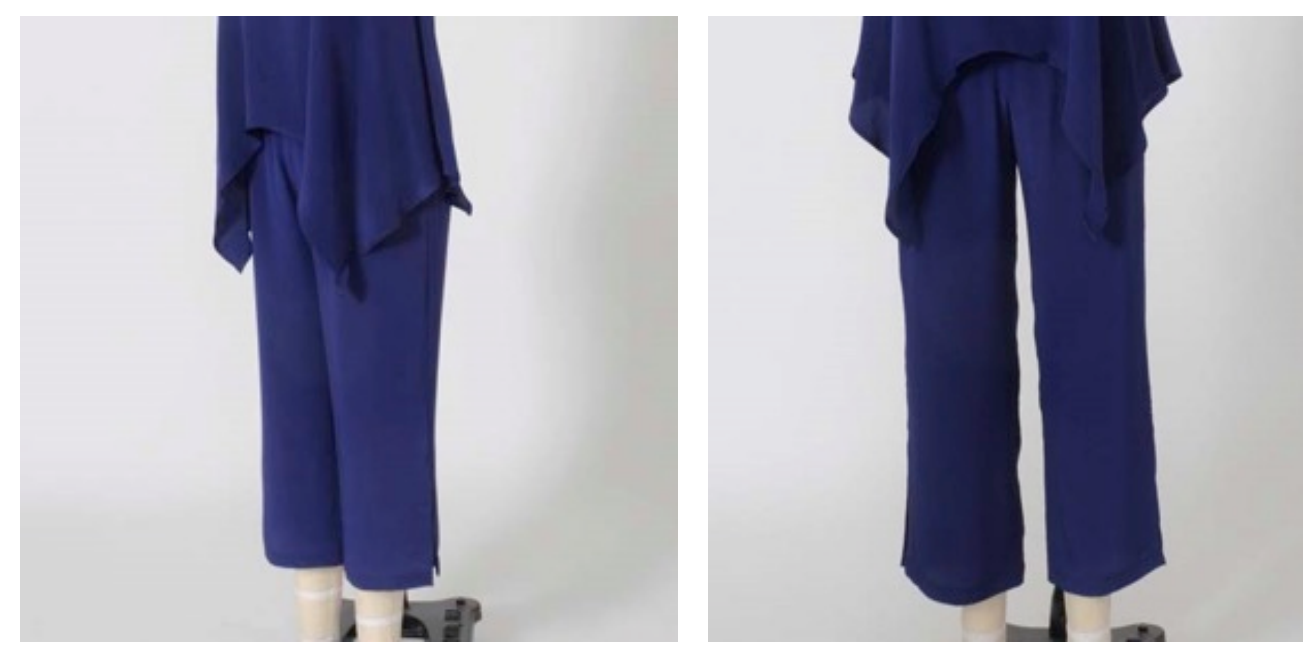

- Elastic waist with 2-inch waistband that hits at natural waistline

- Ankle length with side slits

Fiber \& Fabric: Silk charmeuse

Fit: Fitted waist, body skimming at hip with a straight leg

Size: Misses 8 


\section{Appendix 8: Study Questionnaire}

\section{Questionnaire: Inclusive Apparel Design for Baby Boomer Women Ages 51-69}

Please review the information provided alongside the garments on display \& provide your opinions about the following. You will evaluate the garments and then answer general questions for this study. There are no right or wrong answers. Thanks for helping with this research!

\begin{tabular}{|l|l|}
\hline Garment \#1 & Your Opinions Below: Please Explain \\
\hline $\begin{array}{l}\text { Fashionable for this age group } \\
\text { (fashion refers to current clothing trends) }\end{array}$ & \\
\hline $\begin{array}{l}\text { Personal style } \\
\text { (related to your personal style preference) }\end{array}$ & \\
\hline Color, Pattern, Texture & \\
\hline $\begin{array}{l}\text { Appearance } \\
\text { (how it looks on the display/model) }\end{array}$ & \\
\hline $\begin{array}{l}\text { Evaluate Fit } \\
\text { (for this style of garment) }\end{array}$ & \\
\hline Comfort (as it appears on display) & \\
\hline $\begin{array}{l}\text { Quality } \\
\text { (fabric and construction) }\end{array}$ & \\
\hline $\begin{array}{l}\text { Versatility } \\
\text { (options for multiple use) }\end{array}$ & \\
\hline Ease of wear (uncomplicated) & \\
\hline What does this garment need? Comments & \\
\hline
\end{tabular}

\begin{tabular}{|l|l|}
\hline Garment \#2 & Your Opinions Below: Please Explain \\
\hline $\begin{array}{l}\text { Fashionable for this age group } \\
\text { (fashion refers to current clothing trends) }\end{array}$ & \\
\hline $\begin{array}{l}\text { Personal style } \\
\text { (related to your personal style preference) }\end{array}$ & \\
\hline Color, Pattern, Texture & \\
\hline $\begin{array}{l}\text { Appearance } \\
\text { (how it looks on the display/model) }\end{array}$ & \\
\hline $\begin{array}{l}\text { Evaluate Fit } \\
\text { (for this style of garment) }\end{array}$ & \\
\hline Comfort (as it appears on display) & \\
\hline $\begin{array}{l}\text { Quality } \\
\text { (fabric and construction) }\end{array}$ & \\
\hline $\begin{array}{l}\text { Versatility } \\
\text { (options for multiple use) }\end{array}$ & \\
\hline Ease of wear (uncomplicated) & \\
\hline What does this garment need? Comments & \\
\hline
\end{tabular}




\begin{tabular}{|l|l|}
\hline Garment \#3 & Your Opinions Below: Please Explain \\
\hline $\begin{array}{l}\text { Fashionable for this age group } \\
\text { (fashion refers to current clothing trends) }\end{array}$ & \\
\hline $\begin{array}{l}\text { Personal style } \\
\text { (related to your personal style preference) }\end{array}$ & \\
\hline Color, Pattern, Texture & \\
\hline $\begin{array}{l}\text { Appearance } \\
\text { (how it looks on the display/model) }\end{array}$ & \\
\hline $\begin{array}{l}\text { Evaluate Fit } \\
\text { (for this style of garment) }\end{array}$ & \\
\hline Comfort (as it appears on display) & \\
\hline $\begin{array}{l}\text { Quality } \\
\text { (fabric and construction) }\end{array}$ & \\
\hline $\begin{array}{l}\text { Versatility } \\
\text { (options for multiple use) }\end{array}$ & \\
\hline Ease of wear (uncomplicated) & \\
\hline What does this garment need? Comments & \\
\hline
\end{tabular}

\begin{tabular}{|l|l|}
\hline Garment \#4 & Your Opinions Below: Please Explain \\
\hline $\begin{array}{l}\text { Fashionable for this age group } \\
\text { (fashion refers to current clothing trends) }\end{array}$ & \\
\hline $\begin{array}{l}\text { Personal style } \\
\text { (related to your personal style preference) }\end{array}$ & \\
\hline Color, Pattern, Texture & \\
\hline $\begin{array}{l}\text { Appearance } \\
\text { (how it looks on the display/model) }\end{array}$ & \\
\hline $\begin{array}{l}\text { Evaluate Fit } \\
\text { (for this style of garment) }\end{array}$ & \\
\hline Comfort (as it appears on display) & \\
\hline $\begin{array}{l}\text { Quality } \\
\text { (fabric and construction) }\end{array}$ & \\
\hline $\begin{array}{l}\text { Versatility } \\
\text { (options for multiple use) }\end{array}$ & \\
\hline Ease of wear (uncomplicated) & \\
\hline What does this garment need? Comments & \\
\hline
\end{tabular}




\begin{tabular}{|l|l|}
\hline Garment \#5 & Your Opinions Below: Please Explain \\
\hline $\begin{array}{l}\text { Fashionable for this age group } \\
\text { (fashion refers to current clothing trends) }\end{array}$ & \\
\hline $\begin{array}{l}\text { Personal style } \\
\text { (related to your personal style preference) }\end{array}$ & \\
\hline Color, Pattern, Texture & \\
\hline $\begin{array}{l}\text { Appearance } \\
\text { (how it looks on the display/model) }\end{array}$ & \\
\hline $\begin{array}{l}\text { Evaluate Fit } \\
\text { (for this style of garment) }\end{array}$ & \\
\hline Comfort (as it appears on display) & \\
\hline $\begin{array}{l}\text { Quality } \\
\text { (fabric and construction) }\end{array}$ & \\
\hline $\begin{array}{l}\text { Versatility } \\
\text { (options for multiple use) }\end{array}$ & \\
\hline Ease of wear (uncomplicated) & \\
\hline What does this garment need? Comments & \\
\hline
\end{tabular}

\begin{tabular}{|l|l|}
\hline Garment \#6 & Your Opinions Below: Please Explain \\
\hline $\begin{array}{l}\text { Fashionable for this age group } \\
\text { (fashion refers to current clothing trends) }\end{array}$ & \\
\hline $\begin{array}{l}\text { Personal style } \\
\text { (related to your personal style preference) }\end{array}$ & \\
\hline Color, Pattern, Texture & \\
\hline $\begin{array}{l}\text { Appearance } \\
\text { (how it looks on the display/model) }\end{array}$ & \\
\hline $\begin{array}{l}\text { Evaluate Fit } \\
\text { (for this style of garment) }\end{array}$ & \\
\hline Comfort (as it appears on display) & \\
\hline $\begin{array}{l}\text { Quality } \\
\text { (fabric and construction) }\end{array}$ & \\
\hline $\begin{array}{l}\text { Versatility } \\
\text { (options for multiple use) }\end{array}$ & \\
\hline Ease of wear (uncomplicated) & \\
\hline What does this garment need? Comments & \\
\hline
\end{tabular}




\begin{tabular}{|l|l|}
\hline Garment \#7 & Your Opinions Below: Please Explain \\
\hline $\begin{array}{l}\text { Fashionable for this age group } \\
\text { (fashion refers to current clothing trends) }\end{array}$ & \\
\hline $\begin{array}{l}\text { Personal style } \\
\text { (related to your personal style preference) }\end{array}$ & \\
\hline Color, Pattern, Texture & \\
\hline $\begin{array}{l}\text { Appearance } \\
\text { (how it looks on the display/model) }\end{array}$ & \\
\hline $\begin{array}{l}\text { Evaluate Fit } \\
\text { (for this style of garment) }\end{array}$ & \\
\hline Comfort (as it appears on display) & \\
\hline $\begin{array}{l}\text { Quality } \\
\text { (fabric and construction) }\end{array}$ & \\
\hline $\begin{array}{l}\text { Versatility } \\
\text { (options for multiple use) }\end{array}$ & \\
\hline Ease of wear (uncomplicated) & \\
\hline What does this garment need? Comments & \\
\hline
\end{tabular}

Please share the following information to help the study:

1. What do you like most and least about the collection of clothing presented here? What garments would you consider wearing if they were offered in your size?

2. What is your level of interest in current trends in fashion? How has it changed over time?

3. How do you define your personal style? How difficult is it to find clothing that suits your style? Has your personal style changed over time?

4. What challenges do you have related to finding garments that fit?

5. Do you have any special clothing needs related to physical changes as you age?

6. Do you have any special clothing needs related to lifestyle changes as you age? 
7. What features would you like to see included in garments for women ages $51-69$ ?

8. What advice do you have for clothing designers to help them better design clothing for this age group?

Information about you:

9. What is your age? years

10. What is your race/ethnicity? Caucasian, non-Hispanic African-American Hispanic Asian Other

11. What is the highest level of education you have completed? less than high school high school technical, trade or two year school college graduate school

12. What is your marital status? married partnership, not married single, never married divorced or widowed

13. Are you employed? yes retired

14. Do you have limited or declining ability in any of the following?

vision: perceive the world in images, motion and color hearing: sound detection thinking: understanding \& memory communication: talking and writing reach \& stretch: reaching up and out to the sides dexterity: gripping \& pinching mobility: walking, getting out of chairs 


\section{VITA}

Sandra Starkey was born in Lincoln, NE and obtained her Bachelor of Science degree in 1991 in Textiles, Clothing and Design from the University of Nebraska in Lincoln, Nebraska. After multiple years working in the fashion and apparel industry as a visual merchandising manager and small business owner and consultant, she returned to the University of Nebraska to teach and to continue her education in apparel and accessory design. She obtained her Master of Arts degree in Textiles, Clothing and Design with an entrepreneurship minor in 2011. Her thesis research and creative work explored the handbag as both a functional item and as an art form and investigated the multiple meanings the handbag represents for the owner. Her Master's program was under the advisement of Dr. Barbara Trout and her thesis exhibition was entitled Personal Fences and included a collection of handbags that were exhibited in the Robert Hillestad Textiles Gallery in Lincoln, Nebraska, in 2011. In 2012, she began her doctoral program in the Department of Textile and Apparel Management at the University of Missouri with a focus on inclusive apparel design solutions for an aging population. Recent research has been expanded to include user-centered design approaches and body scanning technology to aid in apparel design problem solving for diverse needs. 